Portland State University

PDXScholar

\title{
"It Puts a Face to All the Knowledge We've Gotten" : a Program of Research on Intimate Partner Violence Surrogate Impact Panels
}

Kate Louise Sackett Kerrigan

Portland State University

Follow this and additional works at: https://pdxscholar.library.pdx.edu/open_access_etds

Part of the Psychology Commons

Let us know how access to this document benefits you.

\section{Recommended Citation}

Kerrigan, Kate Louise Sackett, "'It Puts a Face to All the Knowledge We've Gotten" : a Program of Research on Intimate Partner Violence Surrogate Impact Panels" (2020). Dissertations and Theses. Paper 5455. https://doi.org/10.15760/etd.7328

This Dissertation is brought to you for free and open access. It has been accepted for inclusion in Dissertations and Theses by an authorized administrator of PDXScholar. Please contact us if we can make this document more accessible: pdxscholar@pdx.edu. 
"It Puts a Face to All the Knowledge We've Gotten": A Program of Research on Intimate Partner Violence Surrogate Impact Panels

by

Kate Louise Sackett Kerrigan

A dissertation submitted in partial fulfillment of the requirements for the degree of

\author{
Doctor of Philosophy \\ in \\ Applied Psychology
}

\author{
Dissertation Committee: \\ Eric Mankowski, Chair \\ Rachel Cunliffe \\ Greg Townley \\ Keith Kaufman
}

Portland State University

2020 
(C) 2020 Kate Louise Sackett Kerrigan 


\begin{abstract}
Intimate partner violence (IPV) is one of the most pressing and consequential social problems facing the United States. The current response to IPV in the U.S. is most often a form of tertiary prevention (Caplan, 1964), targeted at individuals directly responsible for (referred to here as "justice involved individuals" or JIIs) and harmed by IPV (referred to here as "survivors"). U.S. institutional responses to IPV are implemented through the criminal justice system. The inherent contradiction in grounding IPV intervention approaches such as BIPs within a social system that itself uses coercion, threat of punishment, and retribution to maintain order and control over others requires attention and the consideration of other approaches to IPV intervention that may facilitate desired behavioral changes in JII participants. This dissertation therefore examines an alternative approach to IPV intervention in the use of surrogate impact panels as a restorative justice practice for IPV intervention in coordination with local BIPs. Although the program of research on these panels includes a qualitative study of the perceived impacts of the panels on survivor speakers (Sackett Kerrigan \& Mankowski, 2020), this dissertation only focuses on the panel process and potential impacts of panels on JII participants. Three manuscripts are presented from a program of research spanning five years on the process and impact of IPV surrogate impact panels. The first manuscript (Chapter II) describes how surrogate impact panels function in the context of IPV. The second manuscript (Chapter III) gathers qualitative and quantitative data from multiple stakeholder perspectives to explore the perceived impacts of the panel on JII participants and identify salient domains of JII change for future measurement of panels. The third
\end{abstract}


manuscript (Chapter IV) builds directly on these previous studies to measure immediate changes in JIIs after panels using pre- and post-test surveys and observational coding of panel processes. In sum, this program of research clarifies the conceptualization of IPV surrogate impact panels and how JIIs' short-term changes after panels may relate to their long-term desistance from IPV. 


\section{Dedication}

To my family, all those working to heal themselves and those around them, and everyone imagining ways to address and prevent harm in our communities 


\section{Acknowledgments}

This dissertation would not have been possible to complete without the support of many groups and individuals. I am immensely grateful for having the opportunity to explore this area of research in partnership with the facilitators, survivors, and program participants connected with the local surrogate impact panel described in these pages. Thank you for your trust and willingness to partner in many aspects of this research, especially Matt Johnston, Melanie Stewart, Rachelle Scheele, Carrie Banks, those who attended panels over the past five years, and all of the participants in these studies. I hope this research continues to support your ongoing work.

These manuscripts benefited greatly from the perspectives and expertise of my committee members, Drs. Rachel Cunliffe, Greg Townley, and Keith Kaufman, who deepened my understanding of restorative justice theory, program evaluation, and community psychology throughout this program of research. Thank you all so much for your time and support in this endeavor. I would especially like to thank my advisor and committee chair, Dr. Eric Mankowski. I am so appreciative of your deep commitment to the integrity of the research process and grateful for your mentorship over the past five and a half years.

Many thanks to my labmates, cohort, friends, and family for the many ways in which you all cared for me throughout this process. Special thanks to Erin Ramey, Jason Kyler-Yano, Emma O’Connor, and Nick Glover for your direct contributions to these studies through data collection, data entry, and debriefing. I am so grateful to be connected to such an incredible group of people, professionally and personally. 
Finally, thank you to my husband, Brad. Meeting you was the best unexpected gift of moving to Portland for graduate school. Thank you for your patience and endless faith in me through this process. I could not have asked for anyone better to walk beside me in this work. I love you so much.

Note: This material is based upon work supported by the National Science Foundation Graduate Research Fellowship Program. Grant No. DGE-1057604. This work was also supported by a Society for Community Research and Action Thesis Research Grant. 
Table of Contents

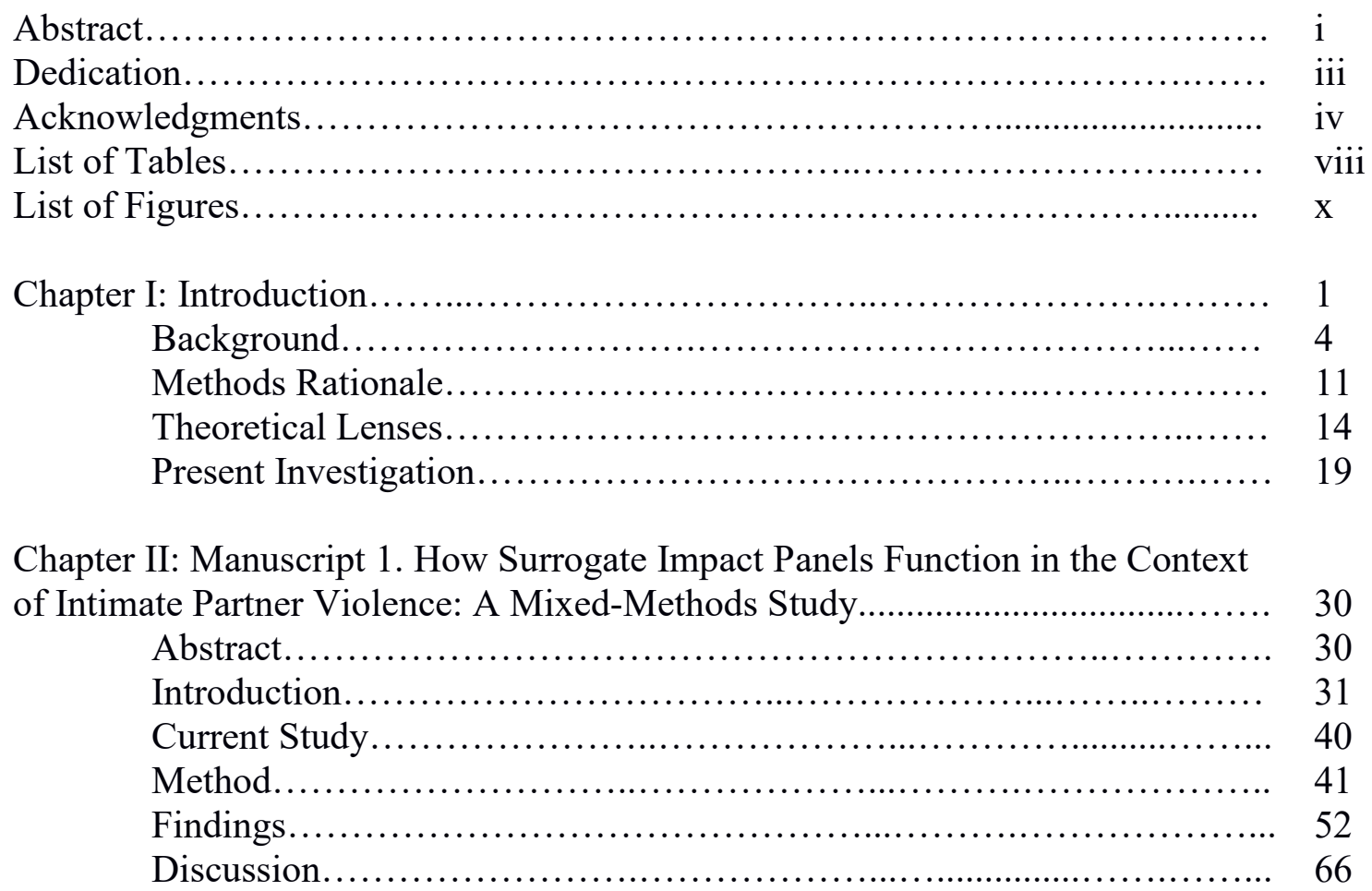

CHAPTER III: Manuscript 2. Planting Seeds for Change: Multiple Perspectives on How Intimate Partner Violence Surrogate Impact Panels Affect Abusive Partners................................................................. 85

Abstract.................................................................... 85

Background......................................................... 87

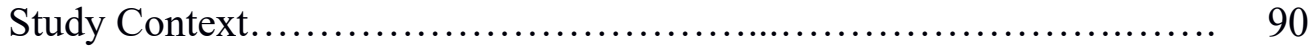

Method............................................................ 91

Findings........................................................ 97

Discussion...................................................... 108

CHAPTER IV: Manuscript 3. Facing the Reality of Intimate Partner Violence: A Pre-/Post-Test Study of Surrogate Impact Panels............................ 127

Abstract.......................................................... 127

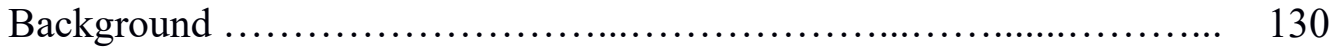

Study Design..................................................... 140

Method........................................................... 145

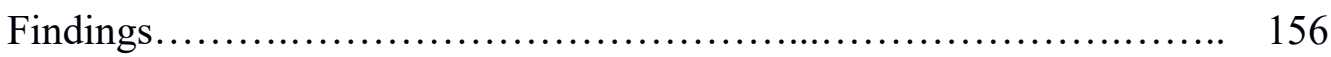

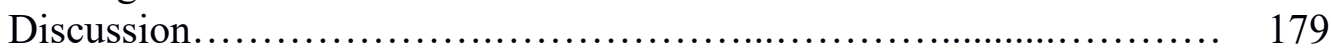

CHAPTER V: Summative Review.......................................... 233

Contributions and Implications................................ 234 
"IT PUTS A FACE TO ALL THE KNOWLEDGE” vii

Limitations..................................................... 243

Future Directions in Research and Action........................... 246

Appendix A: Reflexive Stance............................................ 254

Appendix B: Informed Consent Form ......................................... 263

Appendix C: Survey Measures.......................................... 265

Appendix D: Panel Observational Codebook........................................ 269

Appendix E: Additional Results..................................... 271 


\author{
List of Tables
}

\title{
Chapter II Tables
}

Table 2.1 Demographic Characteristics of Survivor Focus Group Participants..... 75

Table 2.2 Qualitative Analysis Source Materials Summary....................... 76

Table 2.3 Speakers' and JIIs' Perceptions of the Panel............................. 77

Table 2.4 Panel Interactional Processes Consistent with Restorative Justice

Principles.

Chapter III Tables

Table 3.1 Demographic Characteristics of Survivor Focus Group Participants..... 118

Table 3.2 Key Panel Impacts on JIIs.

Table 3.3 Survey Items and Descriptive Statistics of Feedback Form Versions A and $\mathrm{B}$

Table 3.4 Inter-Item Correlations of Feedback Form Versions A and B.

\section{Chapter IV Tables}

Table 4.1 Measures in Pre- and Post-Test Surveys of JIIs....................... 202

Table 4.2 JII Participant Demographics

Table 4.3 Pre- and Post-Panel JII Self-Report Facilitating and Hindering State Scores.

Table 4.4 Facilitating JII State Correlations Pre-/Post-Panel: Empathy, Reintegrative Shame, Retrospective Understanding of Abuse.

Table 4.5 Facilitating JII State Correlations Pre-/Post-Panel: Motivations, Empathy, Retrospective Understanding of Abuse....

Table 4.6 Facilitating JII State Correlations Pre-Panel: Motivations for Behavior Change

Table 4.7 Hindering JII State Correlations Pre-/Post-Panel: Stigmatizing Shame, Minimization, Lack of Violence Recognition, Victim Blaming, Resistance........ Table 4.8 Facilitating/Hindering JII State Correlations Pre-/Post-Panel:

Empathy, Reintegrative Shame, Understanding of Abuse, Stigmatizing Shame, Minimization, Resistance.

Table 4.9 Facilitating/Hindering JII State Correlations Pre-/Post-Panel:

Motivations for Behavior Change, Minimization, Resistance

Table 4.10 Multiple Linear Regression of Control Variables on Post-Panel JII Empathic Distress.

Table 4.11 Multiple Linear Regression of Control Variables on Post-Panel JII 
Table 4.12 Multiple Linear Regression of Control Variables on Post-Panel JII Minimization.

Table 4.13 Multiple Linear Regression of Control Variables on Post-Panel JII

Victim Blaming.

Table 4.14 Observed Group-Level Restorative Justice Process Frequencies...... 216

Table 4.15 Observed Group-Level Restorative Justice Process Correlations...... 217

Table 4.16 Observed Group-Level Restorative Justice Process and

Facilitating/Hindering Post-Panel JII State Correlations: Empathy, Reintegrative

Shame, Understanding of Abuse, Resistance

Table 4.17 Observed Group-Level Restorative Justice Process and Facilitating JII State Correlations: Motivations for Behavior Change 


\section{List of Figures}

Figure 4.1 Diagram of the panel setting......................................... 220

Figure 5.1 Empirically-grounded model of surrogate impact panel program

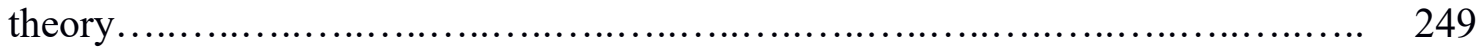




\section{Chapter I: Introduction}

"It's [a] very secret and shameful and private thing that, um, even your friends... they have no idea, they don't understand...It's not that they don't care, they justnobody wants to talk about it...and so for years I never told anybody. So the feeling of [having] a place, a safe place, to be able to share these things that I kept secret for years and years and years and years...[is] very freeing." - Female speaker new to impact panels, describing her experience in a focus group (Sackett, 2017)

"It's special to me to be heard. I feel like I've lived so much of my life, and I've not been heard. So this - I'm heard. Those guys are gonna sit there and listen to me. That is a wonderful feeling to have! It's empowering to know that they can get up and walk out, I'm not saying they can't, but they're there by their choice and so am I." - Female speaker with years of experience in impact panels, in a focus group (Sackett, 2017)

"I honestly never saw before or thought before that it could have such a big impact and such a long impact. I have never seen this before. I just never thought it could, and now I'm thinking about my victim, our incident happened three years ago...And I never realized that this is going to probably affect her for a long time, I never thought about how it could keep affecting her." - Male audience member, documented in field notes from a panel observation (Sackett, 2017)

Intimate partner violence (IPV) is one of the most pressing and consequential

social problems facing the United States. The current response to IPV in the U.S. is most often a form of tertiary prevention (Caplan, 1964), targeted at individuals primarily responsible for and harmed by IPV. U.S. institutional responses to IPV are implemented through the criminal justice system and include police arrest, protection orders, civil and criminal court cases, and community-based batterer intervention programs (BIPs). Separate services are typically offered in these institutional responses to those who are harmed by IPV (referred to here as "survivors") and those who are responsible for this harm (referred to here as "justice involved individuals," or JIIs, as these responses are 
often only made when these individuals are recognized by and involved in the criminal justice system).

This dissertation examines an alternative approach to IPV intervention relative to the typical institutional response of the criminal justice system. Specifically, the three studies in this dissertation evaluate the use of a specific type of restorative justice practice, a surrogate impact panel, as a component of IPV intervention, in coordination with local BIPs. This practice is be referred to here as a "surrogate impact panel," rather than the more commonly used term of victim impact panel, to invoke the nature of the relationships between panel participants in this setting (i.e., surrogates), as the survivors and JIIs who interact with one another in the IPV surrogate impact panels are not from the same relationship.

The manuscripts presented here are the culmination of a program of research spanning five years on the process and potential impact of IPV surrogate impact panels. Although this program of research includes a qualitative study of the perceived impacts of panels on survivor speakers (Sackett Kerrigan \& Mankowski, 2020), this dissertation focuses only on the process of the panel and its potential impacts on JII participants in order to explore how the panel may contribute to desired behavior changes in JIIs as a component of BIPs. The focus of the dissertation is not intended to imply, however, that the panels should be evaluated only in terms of their potential benefit to JII audience members, as it is fundamentally a survivor-driven and survivor-centered process. Like all restorative justice programs, the merit of the panel must be grounded in the values and priorities of those who are harmed in abusive relationships first and foremost. There is an 
inherent challenge in evaluating a program that is intended to meet different people's needs, which at times may even be in conflict with one another, and this dissertation attempts to describe only some of the value of different components of a program in serving some members' needs.

Therefore, this dissertation is not intended to be a comprehensive evaluation of all the possible merits of IPV surrogate impact panels, but rather a step towards filling several gaps in the literature regarding the specific processes involved in panels and proximal impacts on JII participants. The first manuscript (Chapter II) describes how these panels function in the context of IPV. This paper presents findings on the interactional processes of surrogate impact panels from a naturalistic mixed-methods study using ethnographic observation, archival survey analysis, and focus groups and interviews. The second manuscript (Chapter III) explores the perceived impacts of IPV surrogate impact panels on JII participants from multiple perspectives (survivor speaker, JII participant, and BIP provider sources). This paper presents additional qualitative and quantitative findings from the naturalistic study and identifies perceived panels impacts of JIIs connecting with survivor speakers, reaching new understandings of IPV, and expressing emotional impact and the intention to change. Finally, the third manuscript (Chapter IV) presents a pre- and post-test study of immediate changes that JII participants experience before and after IPV surrogate impact panels and a multi-rater assessment of restorative justice processes that are observed during panels. Analyses examine how preand post-panel JII participant feelings and beliefs are associated with one another and change after the panel, how restorative justice processes are associated with one another 
in panels, and how these processes are associated with post-panel JII participant states. Together, these manuscripts greatly increase the depth of knowledge gathered to date on how IPV surrogate impact panels function, how JII participants experience and change after panels, and how panels may relate to long-term impacts that support JII behavior change.

\section{Background}

Intimate partner violence. Abusive relationships can include a range of violent behaviors and are characterized by controlling tactics such as coercion, intimidation, isolation, denial and blaming, using children, using male privilege, and using economic abuse to maintain power over an intimate partner (Pence \& McMahon, 2008). The impact of IPV is far-reaching and can include harm to survivors' physical and mental health, employment issues, and harm to their children and extended family. The consequences of IPV can be severe and even lethal, as approximately half of all female homicides in the U.S. are committed by current or former intimate partners (Petrosky et al., 2017). As violence severity increases, survivors tend to experience proportional increases in health problems (Campbell, 2002). Decreased physical health and well-being can negatively impact functioning in other aspects of life, such as parenting, work, and other relationships (Browne, Salomon, \& Bassuk, 1999). IPV can also result in long-lasting psychological and emotional harm (Dutton \& Goodman, 2005), social isolation (Riger, Raja, \& Camacho, 2002; Sackett \& Saunders, 1999), and PTSD (Clark \& Foy, 2000). Survivors also may not have access to vital resources such as money, health care, child care, transportation, or housing, except through their abusive partner (Epstein, Bell, \& 
Goodman, 2003), and family members may be threatened with or experience violence from the abusive partner (Riger et al., 2002). All of these factors may limit the potential for survivors to exit abusive relationships, even when they desire to do so. Survivors' needs also vary based on other factors that interact with the harm they experience in abusive relationships and their capacity to leave these relationships, including their family structure, cultural background, immigration status, sexual orientation, personal characteristics (e.g., race, gender), social networks, and socioeconomic status (Bograd, 1999; Russo \& Vaz, 2001; Sokoloff \& Dupont, 2005).

Systemic response to IPV. The current systemic response to IPV is limited in its capacity to reduce IPV. The majority of people who experience IPV do not seek formal support. Even in cases of physical violence, $75 \%$ of physical assaults against women are estimated as not being reported to the police (Tjaden \& Thoennes, 2000). In some cases, accessing formal support systems can exacerbate the negative impacts of IPV (e.g., isolation), as in cases where seeking shelter requires a survivor to remain hidden in locations outside of their own home neighborhood and limits or cuts off their connections to other support from friends, religious groups, jobs, and school communities (Haaken \& Yragui, 2003). Others can face long-term removal from their communities, as in cases where a survivor's immigration status is threatened, removed, or leads to deportation when seeking services or having their current or former abusive partner prosecuted (Rap \& Silverman, 2002). Individuals marginalized in American society in multiple ways, such as black women by race- and gender-related oppression, are also particularly under- 
served by the criminal justice system and are less likely to seek help through police, health systems, or shelters (Hampton, LaTaillade, Dacey, \& Marghi, 2008).

Although advocacy services can increase social support for survivors, they do not appear to increase their ability to live violence-free (Sullivan, Campbell, Angelique, Eby, \& Davidson, 1994). A review of shelter and police outreach interventions for survivors did not find program effects sustained over time in reducing violence in survivors' lives (Stover, Meadows, \& Kaufman, 2009). Evaluations of BIPs suggest a similarly limited reach of their ability to reduce rates of IPV. BIPs typically use cognitive behavioral, group process, gender-based curricula to frame IPV as a choice to exert power and control over an intimate partner and problemmatize social norms about masculinity and the acceptability of violence (Gondolf, 2004). Meta-analyses of BIP evaluations have found patterns of small to moderate effect sizes in programs; abilities to reduce criminal recidivism (Babcock, Green, \& Robie, 2004; Cheng, Davis, Jonson-Reid, \& Yaeger, 2019; Karakurt, Koc, Cetinsaya, Ayluctarhan, \& Bolen, 2019). In addition, a review of mandatory arrest policies and various group-based intervention programs for offenders found only small or no effects on reducing criminal recidivism rates (Stover et al., 2009). While the lack of clear evidence regarding how to reduce IPV can be partly explained by issues in the way these programs are evaluated (e.g., aggregating results from highly varied intervention program approaches in a single comparison group for a meta-analysis of program effects; Miller, Drake, \& Nafzinger, 2013), best practices for IPV intervention remain debatable. 
Restorative justice. Restorative justice practices may be a useful addition to IPV interventions, but research to date has not identified a single model for doing so. Definitions of restorative justice have evolved over time (Roche, 2001), beginning with process-focused definitions (e.g., Marshall, 1996) and shifting to a multi-dimensional values- or principles-focused conceptualization (e.g., Bazemore, 2000). Restorative justice is a holistic response to harm that involves not only those responsible for causing it but also those who were harmed and members of the broader community, with an explicit focus on healing conflict (Zehr, 2002). Two models are particularly useful to understand in the context of the IPV intervention of interest in this dissertation: the Maximalist model (Bazemore, 2000) and the Interaction Ritual Model (Collins, 2004; Rossner, 2013).

The Maximalist model of restorative justice defines the boundaries of restorative justice based on the principles involved in the approach, allowing restorative justice practices to evolve in response to stakeholder needs (Bazemore, 2000). According to this model, restorative justice is not only limited to practices that involve face-to-face encounters between victims/survivors and JIIs from the same direct crime or harm. This model promotes creative approaches to repair harm and promote relational healing and identifies the following core principles of restorative justice practice: 1 . A focus on repairing harm and healing victims/survivors, JIIs, and communities injured by crime, 2 . Opportunity for active involvement and exchange of stakeholders (e.g., survivors and JIIs) in the justice process, as early and as fully as possible, and 3. Re-envisioning the roles 
and responsibilities of the community and government to promote justice (Bazemore, Elis, \& Green, 2007).

The Interaction Ritual Model suggests that restorative justice processes consist of interaction ritual process components that generate emotional states and lead to shifts in participant attributes and short-term outcomes (Rossner, 2013). Specifically, a build-up of emotional intensity, balanced exchange between participants, and rhythm leads to a turning point from an initial state of defiance and stigmatization into short-term outcomes of reintegration, group solidarity, emotional energy and motivation to change, and symbolic relationship. Repeated chains of ritual interactions (Collins, 2004) are theorized to build upon one another and increase motivation toward social goals, commitment to group symbols or shared morality, and social bonding (Rossner, 2013). Similar to the Transtheoretical Model (Prochaska \& DiClemente, 1983) applied to batterer intervention (e.g., Levesque, Gelles, \& Velicer, 2000), the Interaction Ritual Model conceptualizes change not as a linear process, but based on a threshold that must be met for interaction elements to feed back upon one another (Rossner, 2013). This creates a rhythmic coordination in the group and synchronization of conversation, bodily movements, and emotions that can transform individual participants.

The interaction ritual is conceptualized as a potential change mechanism that may motivate JII participants to seek out additional positive interactions and engage in prosocial behavior to sustain the positive emotional energy created through the restorative justice process. The impacts of the restorative justice interaction may be extended through the creation of symbolic reparations and shared agreements, as these helps 
remind participants of their group membership and solidarity after engaging in a single restorative justice process (Rossner, 2013). Although an evaluation of the long-term outcomes of IPV impact panels is outside the scope of the program of research presented in this dissertation, Rossner suggests that short-term emotional energy produced in a restorative justice encounter can increase and build through additional interaction ritual chains (Collins, 2004) and lead to long-term emotional energy. This could be a key explanatory factor in how restorative justice practices can prevent re-offense and promote long-term behavioral change.

Restorative justice in the context of IPV. Researchers and practitioners have expressed concern that restorative justice programs may be inappropriate or harmful in cases of IPV (e.g., Busch, 2002; Cameron, 2006; Condon, 2010). For example, some suggest that using restorative justice in this context could undermine the perceived seriousness of IPV and its consequences in the eyes of abusive partners and the general public. According to some critics, implementing restorative justice practices could lose ground in the decades-long fight to recognize IPV as a criminal act by mainstream institutions, particularly if restorative justice practices are offered as a diversionary program (Cameron, 2006). Others caution that a restorative justice approach could compromise survivors' safety by falsely suggesting to a survivor that their partner has changed and then opening lines of communication between them (Stubbs, 2007).

On the other hand, leaders in the restorative justice field suggest that those who have committed and been harmed by the most serious crimes may actually receive the greatest benefit from restorative justice processes (e.g., victim offender dialogue), as they 
may involve especially high levels of participant emotional engagement and be more likely to produce emotional empathy and remorse (Sherman \& Strang, 2003). With these considerations in mind, this dissertation examines the processes and processes and impacts of IPV surrogate impact panels, paying close attention to the experiences of panel participants and gathering information from multiple perspectives and methods, in order to understand how this type of restorative justice practices functions in the context of IPV.

Surrogate impact panels for IPV. Three published studies to date have examined the use of surrogate impact panels specifically for IPV intervention and their effects on panel participants (Burkemper \& Balsam, 2007; Fulkerson, 2001; Zosky, 2018). This small body of research suggests that panels may have promising impacts on participants, although the type and quality of supporting evidence varies across the three studies. Anecdotal evidence from the program director of one IPV impact panel suggests that the panel increased survivor healing and JII participant understanding of the impact of abuse on victims (Burkemper \& Balsam, 2007). A more rigorous evaluation found that a majority of panel participants endorsed panels as a worthwhile procedure, although the panel did not appear to reduce JII recidivism (Fulkerson, 2001). The most recent study found that a majority of JII panel participants agreed that the panel increased their awareness of the impact of IPV on direct victims and children and that they perceived panel attendance as beneficial (Zosky, 2018). The panel also evoked emotional responses and remorse in JIIs, empathy for speakers, commitment to learn and be accountable, and 
commitment to change and hope, based on participant open-ended comments (Zosky, 2018).

However, the specific processes that occurred during the panels evaluated in each of these studies were either unknown or differed in important ways from those used in the panels studied in this dissertation. Characteristics of previously evaluated panels that meaningfully differ from those of the local panel include being more closely integrated into court systems (Fulkerson, 2001), being similar to family conferences, a different type of restorative justice practice, and having a wide variety of panel participants (Burkemper \& Balsam, 2007), and lacking direct interaction between panel speakers and audience members (Zosky, 2018). These limitations undermine the confidence and relevance of the previous findings to questions about how the local panel of focus in this dissertation operates and how it impacts participants.

\section{Methods Rationale}

This dissertation uses a mixed-methods approach throughout the three manuscripts, including qualitative (interviews, focus groups, and open-ended survey responses), observational (ethnography, observational checklists/coding), and quantitative (self-report survey) methods. Evaluation approaches driven by the values of the intervention itself and use qualitative and other approaches capable of capturing nonlinear dynamics and processes of change are recommended for restorative justice programs (Presser \& Van Voorhis, 2002). These recommendations are all the more relevant to a restorative justice practice connected to BIPs, given the expected non-linear trajectories of change for panel participants from BIPs, informed by the Transtheoretical 
Model (e.g., Levesque, et al., 2000) and the Interaction Ritual Model of restorative justice (Collins, 2004; Rossner, 2013).

In addition, close attention to the process and dynamics of restorative justice practice are called for to better understand how IPV surrogate impact panels function, similar to the calls for close attention in the evaluation of restorative justice conferences (e.g., Braithwaite, 2002; Braithwaite, Ahmed, \& Braithwaite, 2006; Hayes \& Daly, 2006) answered by studies applying theoretical models and observational and outcome analysis (e.g., of ritual and emotions; Rossner, 2013). While previous studies of IPV impact panels provided anecdotal reports of impact on participants (Burkemper \& Balsam, 2007) or ratings of participant satisfaction, perceptions of procedural fairness, and recidivism (Fulkerson, 2001), only one has attempted to examine the experiences and perceived impacts of panel participation on offenders (Zosky, 2018). However, the most recent panel evaluation did not examine impact from multiple perspectives and did not include any measures of the panel processes themselves. Without unpacking the specific dynamics of IPV impact panels, participant experiences, and interactive processes that take place during panels, researchers' capacity to recognize what is achieved within the panel setting and meaningfully link panel processes to participant outcomes or impacts is greatly compromised. Thus, the studies in this dissertation evaluate program processes regarding the nature and frequency of program activities, the perceived impacts of the program on target populations, and immediate changes in program participants that may relate to conditions that the program targets or expects to change (Rossi, Lipsey, \& Freeman, 2004). Ultimately, this dissertation is intended to clarify and develop program 
theory articulating the sequence of hypothesized links between program activities, shortterm changes, and long-term impacts.

Evaluations of programs like IPV surrogate impact panels must be particularly attentive to the values and principles of restorative justice as a field, particularly understanding restorative justice as an intentional approach to being in relationship. A defining principle of restorative justice practice is its underlying nature of respect, inclusivity, and the development of trust within "an equitable, and inclusive, power relationship" (p. 194), wherein individuals responsible for harm can make amends (Drewery, 2016). Researchers must not ignore the foundations of restorative justice itself when evaluating whether it "works" by defining success based on common criminal justice standards (e.g., recidivism, supervision compliance). Instead, restorative justice research must be understood in relational terms (i.e., "the way in which people relate to one another" and to their communities; pp. 284, Llewellyn, Archibald, Clairmont, \& Crocker, 2014). A relational understanding of restorative justice is centered on the interconnectedness of people, defining wrongdoing as harm to the intersecting relationships of people involved and to those around them, their larger communities, and society more broadly. The goal of restorative justice therefore is to restore equality or “justness" of relationships, reflecting mutual respect, care, concern, and dignity stemming from mutual interconnectedness (Llewellyn et al., 2014). Measurement approaches must go beyond individual-level variables and data and be capable of describing the connections and relationships involved in restorative justice practices, which more holistically reflect the interconnectedness of outcomes. Therefore, this program of 
research pays particular attention to the dynamic processes of panels to map how connection and relationship are developed, even only temporarily, over the course of the IPV surrogate impact panels.

A better understanding of the close linkages between panel processes and impacts on participants can help explain what JII domains may be sensitive to change or impact from panel processes, which ultimately may inform what mechanisms have the potential to change individuals' behavior, attitudes, and perceptions necessary to support long-term desistance from IPV itself. For example, previous research of a different restorative justice practice, victim offender mediation (VOM), found that the VOM process allowed offenders to develop empathy for victims, see victims in a new way, and be seen themselves in a new way (Abrams, Umbreit, \& Gordon, 2006). The authors suggest that together, these impacts provide a long-term path to behavioral change.

\section{Theoretical Lenses}

Social ecological model. This dissertation is grounded in a dynamic, systemslevel perspective of social ecologies to consider the structural and dynamic process components of IPV surrogate impact panels (Kelly, Ryan, Altman, \& Stelzner, 2000) and how they are linked to participant experiences and immediate post-panel changes. Initially conceptualized as a structural map of different levels of an environment, the ecological model includes the microsystem, mesosystem, exosystem, and macrosystem (Bronfenbrenner, 1979). This model was later updated to include dynamic components of ecologies, particularly proximal processes and the chronosystem as an additional ecological level (Bronfenbrenner \& Morris, 2006). The chronosystem is the level in 
which change unfolds over time through regular discrete episodes (microtime), over days, weeks, or years (mesotime), and in larger cultural shifts over a lifetime or historical periods (macrotime). More complete ecological perspectives consider not only the multiple structural levels of a social system (e.g., microsystem, mesosystem, macrosystem), but also the dynamic qualities and characteristics of these systems. The interdependence principle of social ecological thinking is especially relevant when considering the IPV impact panel (Kelly et al., 2000). Interdependence refers to the interconnections that exist across the system, including direct and indirect relationships, such that impacting one part of the community potentially has effects or ramifications elsewhere in the community. This model has been previously applied to evaluate the effectiveness of indigenous interventions created by local practitioners, such as a sexual assault forensic exam and care program (Campbell, Patterson, \& Fehler-Cabral, 2010).

Individual-level factors for changing abusive behavior. Given the limitations of the current response to IPV, it is important to understand how change could be further optimized at the individual level. A review of the literature on specific processes by which abusive men change identified several primary groups of factors that may drive abusive behavior (Scott, 2004). First, social norms that explicitly and tacitly encourage male dominance and control over others are theorized to contribute to the perpetration of IPV within the social and political context of a patriarchal society (e.g., Carden, 1994). Second, individual characteristics (e.g., skills, personality, emotional development) may further differentiate abusive and non-abusive men. BIP participants' motivation and resistance to treatment may be especially critical factors to target, as they are predictive 
of treatment dropout and subsequently of the likelihood of reoffense (e.g., Gordon \& Moriarty, 2003; Taylor, Davis, \& Maxwell, 2001). Interventions that increase individuals' motivation or decrease their resistance could therefore be critical additions to existing BIPs.

The Transtheoretical Model of behavior change (Prochaska \& DiClemente, 1984; DiClemente \& Prochaska, 1985) suggests that individual-level motivation and behavior change are likely a long-term, nonlinear process in the context of IPV. The model proposes that two dimensions influence behavior modification: a person's stage of change (i.e., precontemplation, contemplation, preparation, action, maintenance) and their processes of change, or the specific activities that promote behavior modification (Prochaska, DiClemente, \& Norcross, 1992). Progression through the stages of change is conceptualized as cyclical movement, which includes relapse and recycling of behaviors (Prochaska \& DiClemente, 1984). Although a linear progression of change is possible in this model, the authors emphasize that it is relatively rare and is particularly so for behaviors that are addictive or difficult to change (Prochaska, DiClemente, \& Norcross, 1992). In the context of IPV, individuals attempting to change their abusive behavior would likely face challenges at every level in their social ecology (e.g., a social environment with norms of male dominance) and behavior change would be a long-term, even lifelong, process of moving forward and backward in their stages of change.

Group-level factors for changing abusive behavior. Previous research suggests that group dynamics and individual behavior within BIP groups are also critical features to attend to when attempting to understand the way in which participants change their 
abusive behavior. For example, BIP group dynamics were identified as one of the key factors for successful participant behavior change, according to interviews with BIP facilitators (Silvergleid \& Mankowski, 2006). Specifically, the blend of support and confrontation from other group members, sense of commonality through mutual sharing, and learning through modeling of other group members were identified as key group processes that positively influenced participants' individual process of change. A more recent study found that "protherapeutic behaviors" (p. 129), such as acknowledging responsibility for their behavior and interpersonal behavior indicating a change-oriented mindset, were positively associated with participants' self-reported motivation to change, facilitator-reported change behaviors, and lower partner-reported levels of violence (Semiatin, Murphy, \& Elliott, 2013).

Group-level dynamics must also be evaluated as indicators of the broader contextual assumptions underlying how a program functions, not only to be able to model these factors in relation to individual-level program outcomes but to consider them on their own as manifestations of the program's paradigmatic assumptions. The underlying assumptions of creating an institutional response to IPV within the criminal justice system frames criminal IPV acts as a violation of laws punishable by the state, rather than as a violation of individuals, relationships and communities (Zehr, 2002). The threat of punishment in this system is meant to deter individuals from committing such crimes, with adversarial processes unfolding in a non-participatory manner led by an external authority imposing outcomes according to law. There is an inherent contradiction in grounding IPV intervention approaches such as BIPs, intended to produce long-term 
behavioral changes in decreasing abusive treatment and associated beliefs about intimate partners, within a social system that itself uses coercion, threat of punishment, and retribution to maintain order and control over others. It is therefore necessary to consider how other approaches to IPV intervention may facilitate desired behavioral changes in JII participants through processes that center on and empower survivors and create noncoercive interactions between program participants in a restorative justice practice.

Social regularities and alternative settings. Finally, restorative justice practices such as IPV surrogate impact panels could also be understood as a mediating alternative institution between the criminal justice system and individuals. An alternative social setting (Cherniss \& Deegan, 2000; Sarason, 1972) facilitates thinking beyond the status quo and the logic of mainstream systems (e.g., the criminal justice system). Therefore, understanding the interactional processes of panels could illuminate the social regularity of the setting and its capacity to act as an alternative setting. A social regularity is created through patterns of norms, interactional processes, routines and sequential activities, and social networks within a setting (Seidman, 2012). These processes all mutually influence one another over time and therefore cannot be captured by one-time, static measures (Seidman, 1988). Rather than measuring static characteristics of individuals within settings, this program of research adopts temporal and dynamic perspectives to detect patterns of interactional processes over time from multiple standpoints, using behavioral observations of setting practices and sequential activities. Focusing on setting characteristics (e.g., social interactions) rather than on individuals alone can lead to a more complete understanding of the setting and its inhabitants in context, orienting 
interventions and evaluations toward setting processes instead of solely individual change (Seidman, 2012).

Given that social regularities occur in patterns across time, they are not able to be captured by one-time, static measures (Seidman, 1990). Instead, an action science approach to the study of social settings has the goals of understanding how a social setting works, how the relevant status quo functions, and how the strategies involved in the social regularities and setting operate (Seidman, 2012). Social regularities can be measured through a variety of methods, including behavioral observations of practices and interactions (Seidman, 2012). Both mean levels and the variance of aggregate ratings are important to consider, as within-setting variability can be used as a setting-level measure derived from individual level reports to account for variance in setting outcomes beyond that of individual mean ratings.

\section{Present Investigation}

The present investigation is the culmination of five years of research examining a local restorative justice practice operating in conjunction with BIPs. The first manuscript (Chapter II) begins with close attention to the steps and interactive processes of the surrogate impact panel, using mixed-methods to understand how interactions in the panel setting align with restorative justice principles (Bazemore et al., 2007). The second manuscript (Chapter III) gathers qualitative and quantitative data from multiple stakeholder perspectives to explore the perceived impacts of the panel on JII participants and identify salient domains for future measurement of participant change. The third manuscript (Chapter IV) builds directly on these previous studies to measure immediate 
changes in JII participants, using pre- and post-test surveys and observational coding of panel processes. In sum, this program of research provides a more complete conceptualization of IPV surrogate impact panels and expands what is known about short-term changes in panel participants that may lead to long-term desistance from IPV. 


\section{References}

Abrams, L. S., Umbreit, M., \& Gordon, A. (2006). Young offenders speak about meeting their victims: Implications for future programs. Contemporary Justice Review, $9(3), 243-256$.

Babcock, J. C., Green, C. E., \& Robie, C. (2004). Does batterers' treatment work? A meta-analytic review of domestic violence treatment. Clinical Psychology Review, 23, 1023-1053.

Bazemore, G. (2000). Rock and roll, restorative justice, and the continuum of the real world: A response to "Purism" in operationalizing restorative justice.

Contemporary Justice Review, 3(4), 459-477. Contemporary Justice Review, 3(4), $459-477$.

Bazemore, G., Elis, L., \& Green, D. L. (2007). The "independent variable” in restorative justice: Theory-based standards for evaluating the impact and integrity of victim sensitive process (part II). Victims \& Offenders, 2(4), 351-373.

Bograd, M. (1999). Strengthening domestic violence theories: Intersections of race, class, sexual orientation, and gender. Journal of Marital and Family Therapy, 25, 275289.

Braithwaite, J. (2002). Restorative justice and responsive regulation. Oxford, UK: Oxford University Press.

Braithwaite, J., Ahmed, A., \& Braithwaite, V. (2006). Shame, restorative justice, and crime. In F. Cullen, J. Wright, \& K. Blevins (Eds.), Taking Stock: The Status of Criminological Theory (pp. 397-417). Piscataway, NJ: Transaction Publishers. 
Bronfenbrenner, U. (1979). The ecology of human development. Cambridge, MA: Harvard University Press.

Bronfenbrenner, U., \& Morris, P. A. (2006). The bioecological model of human development. In R. M. Lerner \& W. Damon (Eds.), Handbook of Child Psychology: Theoretical Models of Human Development (pp. 793-828). Hoboken, NJ: John Wiley.

Browne, A., Salomon, A., \& Bassuk, S. S. (1999). The impact of recent partner violence on poor women's capacity to maintain work. Violence Against Women, 5, 393426.

Burkemper, B. \& Balsam, N. (2007). Examining the use of restorative justice practices in domestic violence cases. Saint Louis University Public Law Review, 27, 121-133.

Busch, R. (2002). Domestic violence and restorative justice initiatives: Who pays if we get it wrong? In H. Strang \& J. Braithwaite (Eds.), Restorative Justice and Family Violence (pp. 223-248). Cambridge, UK: Cambridge University Press.

Cameron, A. (2006). Stopping violence: Canadian feminist debates on restorative justice and Intimate violence. Theoretical Criminology, 10(1), 49-66.

Campbell, J. C. (2002). Health consequences of intimate partner violence. The Lancet, $359,1331-1336$.

Campbell, R., Patterson, D., \& Fehler-Cabral, G. (2010). Using ecological theory to evaluate the effectiveness of an indigenous community intervention: A study of Sexual Assault Nurse Examiner (SANE) programs. American Journal of Community Psychology, 46, 263-276. 
Caplan, G. (1964) Principles of prevention psychiatry. Oxford, UK: Basic Books.

Carden, A. D. (1994). Wife abuse and the wife abuser: Review and recommendations. The Counselling Psychologist, 22(4), 539-582.

Cheng, S. Y., Davis, M., Jonson-Reid, M., \& Yaeger, L. (2019). Compared to what? A meta-analysis of batterer intervention studies using nontreated controls or comparisons. Trauma, Violence, \& Abuse. Advanced online publication. https://doi.org/10.1177/1524838019865927

Cherniss, C. \& Deegan, G. (2000). The creation of alternative settings. In J. Rappaport and E. Seidman (Eds.), Handbook of Community Psychology (pp. 359-377). New York, NY: Kluwer.

Clark, A. H., \& Foy, D. W. (2000). Trauma exposure and alcohol use in battered women. Violence Against Women, 6, 37-48.

Collins, R. (2004). Interaction ritual chains. Princeton, NJ: Princeton University Press. Condon, M. (2010). Bruise of a different color: The possibilities of restorative justice for minority victims of domestic violence. Georgetown Journal On Poverty Law \& Policy, 17(3), 487-506.

DiClemente, C. C. \& Prochaska, J. O. (1985). Processes and stages of change: Coping and competence in smoking behavior change. In S. Shiffman \& T. A. Wills (Eds.), Coping and substance abuse (pp. 319-343). San Diego, CA: Academic Press.

Drewery, W. (2016). Restorative practice in New Zealand schools: Social development through relational justice. Educational Philosophy and Theory, 48(2), 191-203.

Dutton, M. A., \& Goodman, L. A. (2005). Coercion in intimate partner violence: Toward 
a new conceptualization. Sex Roles, 52(11/12), 743-756.

Epstein, D., Bell, M. E., \& Goodman, L. A. (2003). Transforming aggressive prosecution policies: Prioritizing victims' long-term safety in the prosecution of domestic violence cases. Journal of Gender, Social Policy \& the Law, 11, 465-498.

Fulkerson, A. (2001). The use of victim impact panels in domestic violence cases: A restorative justice approach. Contemporary Justice Review, 4(34), 355-368.

Gondolf, E. W. (2004). Evaluating batterer counseling programs: A difficult task showing some effects and implications. Aggression and Violence Behavior, 9, 605-631.

Gordon, J. A. \& Moriarty, L. J. (2003). The effects of domestic batterer treatment on domestic violence recidivism: The Chesterfield County experience. Criminal Justice and Behavior, 30, 118-134.

Haaken, J., \& Yragui, N. (2003). Going underground: Conflicting perspectives on domestic violence shelter practices. Feminism \& Psychology, 13, 49-71.

Hampton, R. L., LaTaillade, J. J., Dacey, A., \& Marghi, J. R. (2008). Evaluating domestic violence interventions for black women. Journal of Aggression, Maltreatment \& Trauma, 16(3), 330-353.

Hayes, H. \& Daly, K. (2004). Conferencing and re-offending in Queensland. Australian and New Zealand Journal of Criminology, 37(2), 167-191.

Karakurt, G., Koc, E., Cetinsaya, E. E., Ayluctarhan, Z., \& Bolen, S. (2019). Metaanalysis and systematic review for the treatment of perpetrators of intimate partner violence. Neuroscience Biobehavioral Reviews, 105, 220-230. 
Kelly, J.G., Ryan, M. Altman, E.B., \& Stelzner, S.P. (2000). Understanding and changing social systems: An ecological view. In J. Rappaport and E. Seidman (Eds.), Handbook of Community Psychology (pp. 133-159). New York, NY: Kluwer.

Levesque, D. A., Gelles, R. J., \& Velicer, W. F. (2000). Development and validation of a stages of change measure for men in batterer treatment. Cognitive Therapy and Research, 24(2), 175-199.

Llewellyn, J., Archibald, B. P., Clairmont, D., \& Crocker, D. (2014). Imagining success for a restorative approach to justice: Implications for measurement and evaluation. Dalhousie Law Journal, 36(2), 281-316.

Marshall, T. F. (1996). The evolution of restorative justice in Britain. European Journal on Criminal Policy and Research, 4, 21-43.

Miller, M., Drake, E., \& Nafziger, M. (2013). What works to reduce recidivism by domestic violence offenders? (Document No. 13-01-1201). Olympia: Washington State Institute for Public Policy.

Pence, E. \& McMahon, M. (2008). Power and control wheel. In C. M. Renzetti \& J. L. Edleson (Eds.), Encyclopedia of interpersonal violence. Thousand Oaks, CA: Sage Publications.

Petrosky, E., Blair, J. M., Betz, C.J., Fowler, K.A., Jack, S.P., Lyons, B.H. (2017). Racial and ethnic differences in homicides of adult women and the role of intimate partner violence - United States, 2003-2014. Morbidity and Mortality Weekly Report, 66(28), 741-746.

Presser, L. \& Van Voorhis, P. (2002). Values and evaluation: Assessing processes and 
outcomes of restorative justice programs. Crime \& Delinquency, 48(1), 162-188.

Prochaska, J. O., \& DiClemente, C. C. (1983). Stages and processes of self-change of smoking: Toward an integrative model of change. Journal of Consulting and Clinical Psychology, 51, 390-395.

Prochaska, J. O. \& DiClemente, C. C. (1984). The transtheoretical approach: Crossing traditional boundaries of change. Homewood, IL: Dorsey Press.

Prochaska, J. O., DiClemente, C. C., \& Norcross, J. C. (1992). In search of how people change: Applications to addictive behaviors. American Psychologist, 47(9), 11021114.

Rap, A. \& Silverman, J. (2002). Violence against immigrant women: The roles of culture, context, and legal immigrant status on intimate partner violence. Violence Against Women, 8, 367-398.

Riger, S., Raja, S., \& Camacho, J. (2002). The radiating impact of intimate partner violence. Journal of Interpersonal Violence, 17, 184-205.

Roche, D. (2001). The evolving definition of restorative justice. Contemporary Justice Review, 4(3-4), 341-353.

Rossi, P. H., Lipsey, M. W., \& Freeman, H. E. (2004). Evaluation: A systematic approach (7th ed.). Thousand Oaks, CA: Sage Publications.

Rossner, M. (2013). Just emotions: Rituals of restorative justice. Oxford, UK: Oxford University Press.

Russo, N. F. \& Vaz, K. (2001). Addressing diversity in the Decade of Behavior: Focus on women of color. Psychology of Women Quarterly, 25, 280-294. 
Sackett, K. L. (2017). Intimate partner violence impact panels for batterer intervention: A mixed-methods evaluation of a restorative justice process (Master's thesis). Retrieved from ProQuest. (doi:10.15760/etd.5964)

Sackett, L. A., \& Saunders, D. G. (1999). The impact of different forms of psychological abuse on battered women. Violence and Victims, 14, 105-117.

Sackett Kerrigan, K. \& Mankowski, E. S. (2020). Two sides of the same coin: How surrogate impact panels affect intimate partner violence survivors. Manuscript in preparation.

Sarason, S. B. (1972). The creation of settings and the future societies. San Francisco, CA: Jossey-Bass.

Scott, K. L. (2004). Predictors of change among male batterers: Application of theories and review of empirical findings. Trauma, Violence, \& Abuse, 5(3), 260-284.

Seidman, E. (1988). Back to the future, community psychology: Unfolding a theory of social intervention. American Journal of Community Psychology, 16, 3-24.

Seidman, E. (1990). Pursuing the meaning and utility of social regularities for community psychology. In P. Tolan, C. Keys, F. Chertok, \& L. Jason (Eds.), Researching Community Psychology: Issues of Theories and Methods (pp. 91-100).

Washington, DC: American Psychological Association.

Seidman, E. (2012). An emerging action science of social settings. American Journal of Community Psychology, 50(1-2), 1-16.

Semiatin, J. N., Murphy, C. M., \& Elliott, J. D. (2013). Observed behavior during group treatment for partner-violent men: Acceptance of responsibility and promotion of 
change. Psychology of Violence, 3(2), 126-139.

Sherman, L. W. \& Strang, H. (2003). Repairing the harm: Victims and restorative Justice. Utah Law Review, 1, 15-42.

Silvergleid, C. S. \& Mankowski, E. S. (2006). How batterer intervention programs work: Participant and facilitator accounts of processes of change. Journal of Interpersonal Violence, 21(1), 139-159.

Sokoloff, N. \& Dupont, I. (2005). Domestic violence at the intersections of race, class, and gender: Challenges and contributions to understanding violence against marginalized women in diverse communities. Violence Against Women, 11, 38-64.

Stover, C. S., Meadows, A. L., \& Kaufman, J. (2009). Interventions for intimate partner violence: Review and implications for evidence-based practice. Professional Psychology: Research and Practice, 40, 223-233.

Stubbs, J. (2007). Beyond apology? Domestic violence and critical questions for restorative justice. Criminology \& Criminal Justice, 7(2), 169-187.

Sullivan, C. M., Campbell, R., Angelique, H., Eby, K. K., \& Davidson II, W. S. (1994). An advocacy intervention program for women with abusive partners: Six-month followup. American Journal of Community Psychology, 22, 101-122.

Taylor, B.G., Davis, R.C., \& Maxwell, C.D. (2001). The effects of a group batterer treatment program in Brooklyn. Justice Quarterly, 18, 170-201.

Tjaden, P. \& Thoennes, N. (2000). Extent, nature, and consequences of intimate partner violence: Findings from the National Violence Against Women Survey. Washington, DC: U.S. Department of Justice, Office of Justice Programs, 
National Institute of Justice.

Zehr, H. (2002). The little book of restorative justice. Intercourse, PA: Good Books.

Zosky, D. (2018). "Walking in her shoes": The impact of victim impact panels on perpetrators of domestic violence. Victims \& Offenders, 13(6), 739-756. 


\title{
Chapter II: Manuscript 1. \\ How Surrogate Impact Panels Function in the Context of Intimate Partner Violence: A Mixed-Methods Study
}

Note: This manuscript is currently under review for publication. Current citation: Sackett Kerrigan, K. \& Mankowski, E. S. (2020). How surrogate impact panels function in the context of intimate partner violence: A mixed-methods study. Manuscript under review at Victims \& Offenders.

\begin{abstract}
Intimate partner violence (IPV) continues to be a prominent and urgent social problem, despite decades of intervention and prevention efforts. Restorative justice programs (e.g., victim impact panels) may be a useful addition to IPV intervention, but it is unclear how these panels operate and to what extent they are consistent with restorative justice models. This naturalistic study of IPV surrogate impact panels used ethnographic observation of panels $(n=18)$, archival analysis of audience responses to the panel $(N=287)$, and focus groups and interviews $(k=4)$ with IPV survivors, an audience member, and batterer intervention providers to investigate these gaps. Findings suggest the panels manifest interactional processes consistent with restorative justice principles (Bazemore, Elis, \& Green, 2007). Implications, limitations, and future aims of research on these panels are discussed.
\end{abstract}

Keywords: victim impact panel, intimate partner violence, restorative justice, batterer intervention, naturalistic inquiry 


\section{How Surrogate Impact Panels Function in the Context of Intimate Partner Violence:}

\section{A Mixed-Methods Study}

Intimate partner violence (IPV) is one of the most pressing and consequential social problems facing the United States. IPV is defined by the World Health Organization as behaviors that can include physical, sexual, and emotional abuse and controlling behaviors by a current or former romantic or sexual partner (2010). Controlling tactics that characterize abusive relationships include coercion and threats, intimidation, isolation, denial and blaming, using children, using male privilege, and using economic abuse (Pence \& McMahon, 2008). IPV negatively impacts millions of people in the U.S. each year, through immediate and long-term damage to the physical and mental health, employment and financial wellbeing, social supports and relationships of direct victims and those around them (Breiding et al., 2014). The response to IPV in the U.S. is most often a form of tertiary prevention (Caplan, 1964), targeted at individuals directly responsible for and impacted by IPV. U.S. institutional responses to IPV are implemented through the criminal justice system and include police arrest, protection orders, civil and criminal court cases, and batterer intervention programs (BIPs). Separate services are typically offered to those harmed in abusive relationships (referred to here as "survivors") and those recognized by the criminal justice system as perpetrating abuse in relationships (referred to here as "justice-involved individuals") through advocacy organizations and BIPs.

\section{Introduction}

IPV intervention through the criminal justice system. Criminalizing IPV led to 
some positive impacts, such as altering social norms related to IPV and victim-blaming attitudes (Salazar, Baker, Price, \& Carlin, 2003). In addition, increased system involvement by justice-involved individuals (JIIs) is linked to reduced criminal recidivism rates (Murphy, Musser, \& Maton, 1998). Despite these positive impacts, research shows some important limitations of the criminal justice system's response to IPV (Goodmark, 2017; Mankowski, Haaken, \& Silvergleid, 2002). Although advocacy services can increase survivors' social support, quality of life, and sense of personal power, they are more limited in their impact on reducing survivors' levels of physical abuse (Sullivan, Campbell, Angelique, Eby, \& Davidson, 1994). A comprehensive review of shelter and police outreach interventions for survivors found that program effects were not sustained over time in reducing violence in survivors' lives (Stover, Meadows, \& Kaufman, 2009). In addition, survivors who are dissatisfied with their experience in the criminal justice system subsequently indicate a reluctance to use the system in the future (Hotaling \& Buzawa, 2003). Furthermore, the criminal justice system particularly does not serve the needs of individuals marginalized in American society in multiple ways, such as black women by race- and gender-related oppression, who are less likely to seek help through police, health systems, or shelters (Hampton, LaTaillade, Dacey, \& Marghi, 2008).

Evaluations of intervention programs with JIIs indicate a similarly limited reach of their ability to largely reduce rates of IPV. Batterer intervention programs (BIPs) began in the 1970's and initially focused substantially on anger management, and then, based on the limited effectiveness of this individual approach, became more involved in 
the coordinated community response to IPV using a gender-focused curricula that framed IPV as a choice to exert power and control over someone else (Gondolf, 2004). Programs also linked IPV to social norms about masculinity and the acceptability of male violence. The most comprehensive quasi-experimental evaluation studies (Gondolf, 2002) and meta-analyses of BIP evaluations find a pattern of small to moderate effect sizes in programs' abilities to reduce criminal recidivism (Babcock, Green, \& Robie, 2004; Cheng, Davis, Jonson-Reid, \& Yaeger, 2019; Karakurt, Koc, Cetinsaya, Ayluctarhan, \& Bolen, 2019). A review of mandatory arrest policies and various group-based intervention programs for JIIs found only small or no effects on reducing criminal recidivism rates (Stover et al., 2009). Taken together with the limitations of survivor advocacy service programs, the current response to IPV is limited in its effectiveness to reduce IPV over the long term.

Restorative justice. The evidence reviewed above regarding the criminal justice response to IPV through BIPs demonstrates that the system is at least partially failing to meet the needs of all IPV survivors and JIIs. Given that a clear model for IPV intervention and prevention has yet to be conclusively identified, it is necessary to consider what possibilities for this effort lie outside the traditional criminal justice system response alone. One possible response is implementing restorative justice programs to meet unfulfilled needs of IPV survivors and JIIs, with program practices based on a different set of underlying principles than those of the criminal justice system. In the remainder of this literature review, we describe restorative justice theoretical models and outcomes and review what is known about restorative justice programs for IPV, including 
the small body of literature that exists on the use of surrogate impact panels specifically for IPV cases.

Definitions and theoretical models. Restorative justice refers to a holistic response to crime that involves not only JIIs but also victims of crimes and members of the community to collectively resolve offenses and their aftermath (Marshall, 1996; Zehr, 1990). This process is driven by stakeholder commitment and the desire to create a healing process that is responsive to participant needs (Bazemore \& Green, 2007). Restorative justice processes were first used for property crimes and minor conflicts, but over time have been applied to more severe harms such as drunk driving homicide, assault, and murder. Definitions of restorative justice have evolved over time (Roche, 2001), beginning with process-focused definitions (e.g., Marshall, 1996) and shifting to a multi-dimensional values- or principles-focused conceptualization (e.g., Bazemore, 2000). In the Maximalist model of restorative justice, Bazemore (2000) asserted that the boundaries of restorative justice must be flexible and open so that practices can evolve in response to future stakeholders and their needs. In this model, restorative justice encompasses but is not limited to programs that involve face-to-face encounters between victims and JIIs directly involved in a crime (Bazemore, 2000). This model allows for creative ways to repair harm and promote relational healing as long as processes are attuned to the following core principles: a focus on repairing harm and healing victims, JIIs, and communities injured by crime, opportunity for active involvement and exchange of stakeholders (e.g., survivors and JIIs) in the justice process as early and as fully as possible, and re-envisioning the roles and responsibilities of the community and 
government to promote justice (Bazemore, Elis, \& Green, 2007).

Considerations for IPV. Some researchers and practitioners are concerned that restorative justice programs may de-legitimize the perceived harms of IPV, sexual assault, or other gender-based crimes or undermine how seriously both JIIs and the general public view them (e.g., Busch, 2002). For example, Stubbs (2007) expressed concern that this type of process could compromise survivors' safety, either by opening lines of communication between survivors and JIIs without proper security guards in place or by leading survivors to believe that JIIs have changed when they have not genuinely accounted for their responsibility and worked through their patterns of abuse to truly change. Another major concern is that restorative justice, while claiming to be victimcentered, could shift attention to JIIs' situations too easily and lead to coddling or excusing JIIs in an effort to understand their behavior and what contributed to the situation (e.g., JII's personal trauma), further disempowering victims.

Given the considerations described above regarding the use of restorative justice programs for IPV cases, it is not clear whether findings from evaluations of restorative justice programs for other types of cases would replicate in this context. The majority of research on restorative justice programs has been conducted on programs that were not available for IPV cases. For example, an evaluation of the Reintegrative Shaming Experiments (RISE; Sherman, Strang, Barnes, Braithwaite \& Inkpen, 1998) in Australia specifically excluded cases of IPV. Although these experiments in the mid-1990's found that individuals who had been randomly assigned to restorative conferences had a net reduction in recidivism of $38 \%$ compared to those who went through normal court 
processing in Canberra, it is unknown whether this same effect could be expected for IPV cases.

The few programs in which IPV cases have been included have demonstrated positive effects such as reduced child maltreatment and increased social support (Pennell $\&$ Burford, 2002), with no additional or unintended consequences (e.g., additional incidents of abuse) than treatment as usual in BIPs (e.g., Mills, Barocas, \& Ariel, 2013). In addition, an empirical investigation of the concerns of survivor advocates about restorative justice yielded promising results regarding their perceptions of its potential to address IPV, as some survivor advocates perceived restorative justice interventions as potentially providing survivors an opportunity to speak more about their experience and have more influence over decision-making processes (Curtis-Fawley \& Daly, 2005).

Surrogate impact panels for IPV. Surrogate impact panels, also referred to as victim impact panels, are a specific type of restorative justice process in which survivors of crimes speak to individuals who have perpetrated similar crimes (Van Ness \& Strong, 1997). There is usually no direct connection between participants in a panel. Survivors speak about their experiences and the impact of a crime on their life and JIIs listen to increase their understanding of the effects of their crime empathy for their victims. Panels are often part of a larger intervention or treatment designed to change attitudes and behaviors and/or prevent future recidivism.

Little is known about the use of surrogate impact panels as a component of IPV intervention. Burkemper and Balsam (2007) reviewed the use of restorative justice for IPV cases and described efforts to develop IPV impact panels in one judicial circuit in 
Missouri. The panel model used there more closely resembles a family group conferencing model (e.g., Pennell \& Burford, 2002) than a surrogate impact panel, with a wide range of participants speaking on the panel including family members, a rehabilitated former abusive partner, and members of the broader community such as elected officials and faith leaders. The panels were still under development at the time of publication and longitudinal measures and analyses of change were therefore not possible at that time. The authors instead described anecdotal evidence of positive program outcomes based on an interview with the program director. These outcomes included JIIs' increased understanding of the impact of IPV and survivors' increased healing and empowerment.

A more rigorous study of IPV impact panels used a random assignment mechanism to evaluate their use as a sentencing and treatment option for IPV cases (Fulkerson, 2001). A comparison of self-report surveys of participants' experiences in the criminal justice system and the IPV impact panel found that a majority of panel participants endorsed the panel as a worthwhile procedure that they would recommend for IPV cases, although no differences were found in JII recidivism between those who did and did not attend the panel. The author did not describe any specific processes that occurred during these panels or the timing of when panels took place relative to other intervention activities for participants, which limit the extent to which these findings inform the current study of IPV impact panels as a component of BIPs.

More recently, an outcome evaluation of an IPV impact panel developed and implemented by a probation department in a Midwest US county circuit (Zosky, 2018). 
The panel process took place in a court house room, facilitated by someone in the probation department, with volunteer speakers who were victims of domestic violence and shared how their experience impacted their own lives and those of their family members. No direct interaction or discussion took place between the speakers and audience members; instead, small group discussions were led by trained facilitators with the audience to discuss the panel content. Anonymous surveys completed by participants $(n=340)$ over a three-year period (2014-2016) indicated that a majority of the JIIs indicated that the panel increased their awareness of the impact of IPV on direct victims and children and viewed their panel attendance as beneficial (Zosky, 2018). Grounded theory analysis of open-ended comments from a majority of the participants $(n=301)$ suggested that the panel evoked expressions of emotional responses and remorse in JIIs, empathy for the panel speakers as IPV victims, and commitment to learn and be accountable as well as of change and hope.

In sum, evaluation research on the use of IPV impact panels, particularly in the context of BIPs and other IPV intervention programs, is still at an early stage. Given the little published work around surrogate impact panels in the context of BIPs, existing research has not reliably identified constructs that would be expected to change based on theory or prior empirical studies. Previous studies have evaluated panels that use a variety of program practices, from a family group conferencing approach (Burkemper \& Balsam, 2007) to a panel presentation with no discussion or audience interaction (Zosky, 2018). These program differences limit the extent to which findings from previous evaluations of IPV impact panels can be assumed to transfer to other panel settings. Research on the 
use of IPV impact panels has shown some preliminary support that they increase JIIs' understanding of the impact of IPV and increase healing and empowerment of survivors, but specific types of impact have not been further examined. Thus, the use and outcomes of IPV impact panels have yet to be thoroughly researched.

Given the significant gaps in current knowledge on IPV impact panels, particularly the lack of support in theory or previous studies to guide the selection of comprehensive and sensitive program outcome measures, it is necessary to conduct a process evaluation of IPV impact panels and evaluate the extent to which these panels manifest restorative justice processes. Although IPV impact panels do not meet the minimum requirements for restorative justice programs set by the Purist model (McCold, 2000), particularly that of having face-to-face encounters between individuals from the same direct relationship or situation in which the harm occurred, this condition is especially relevant in the context of IPV. In this type of harm, face-to-face encounters not only might not be healing for survivors but could actually exacerbate harms or retraumatize these individuals. In addition, relational repair might not be a desired goal or outcome of a restorative justice process in these cases. Instead, a principle-based approach to restorative justice that is more flexible, driven by stakeholder commitment and desire to participate in a healing process and responsive to participant needs could be more fitting, as outlined in the Maximalist model (Bazemore, 2000). This flexible process could include goals of reconciliation, reparation, and/or repair of various harms that resulted from the abuse, but goals should be set by participants and especially responsive to survivors' needs. 


\section{Current Study}

The current study is situated within a local program of IPV surrogate impact panels in the Pacific Northwest region of the U.S. At these panels, survivors of IPV speak about their experiences of abuse and its impact on them to a group of JIIs enrolled in BIPs and mandated by their programs to attend the panel. The survivors speak on a completely voluntary basis and many of them participate in multiple panels per year. JIIs who are court-mandated to complete a BIP are required to attend a panel after participating in a BIP group for at least 26 weeks and to pay $\$ 25$ to attend the panel. A facilitator coordinates the panel and a probation officer is present to assist with setup and maintain order at each panel. Panels are held from 6 to 8 P.M. one weeknight per month in alternating local counties in large meeting rooms such as county building auditoriums. After each panel concludes, the speakers, panel facilitator, and any community observers stay afterward to debrief the panel. The JIIs wait to debrief until their next BIP group session.

Multiple methods and sources were used in this study to investigate several gaps identified in the literature regarding the use of surrogate impact panels in the context of IPV and batterer intervention. Specifically, we describe and document the pattern of interactional processes and sequential activities that occur over time in these panels and evaluate the extent to which participant experiences and program processes fit within the Maximalist model principles of restorative justice (Bazemore et al., 2007). The methods prioritized close attention to the process and experiences of individuals through prolonged observation in the setting to generate ecologically valid outcomes for use in 
future measurement of IPV impact panels. The study addresses two research questions: RQ1. How do survivors and JIIs experience and evaluate IPV impact panels? RQ2. What interactions take place during IPV impact panels that are consistent with restorative justice principles?

\section{Method}

The study triangulated methods and sources to increases the credibility of findings (Denzin, 1978), as multiple methods and sources generate a richer, more comprehensive account of the setting, program activities and potential outcomes than a single source alone. Sources were checked for both consistencies and inconsistencies to yield a deeper insight into the studied phenomenon. Although the goal was not to replicate or verify information across sources, the appearance of findings across more than one source or method reduces the uncertainty of its interpretation (Lincoln \& Guba, 1985) and increases confidence in the study findings. Methods and sources consisted of: an ethnographic inquiry of the panel process and participant experiences, an archival data analysis of open-ended comments on panel feedback forms to determine how JIIs describe their panel experiences, and focus groups and interviews with stakeholders (survivors, JIIs, and BIP providers) to gather a range of information regarding panel processes and participant experiences. Study procedures were approved by the Institutional Review Board at the authors' university.

These methods were selected to complement one another, with each bringing strengths in areas where others had limitations. Ethnographic inquiry increased the likelihood of observing naturalistic behaviors results, which focus groups alone may not 
have captured due to the moderator's role and involvement in arranging the group and facilitating the discussion (Morgan, 1988). Focus groups increased the range of perspectives on the study topic as well as the possibility of observing interaction among participants in the group discussion, which naturalistic observation in ethnography alone may not have revealed. Finally, archival survey data analysis provided individual-level data on JIIs' thoughts and reactions to the panel, which naturalistic observation and focus groups did not capture. Survey data also balanced information obtained through direct interaction with participants, which might otherwise be over-valued or considered more meaningful due to its vividness compared to statistics or summaries of quantitative information (Stewart \& Shamdasani, 1990).

Procedure. Ethnography. An ethnography was conducted as a first step of entering and understanding the study context. Strengths of ethnography include its capacity to address a large range of behaviors and interactions among participants and to study a program, its setting and participants in-depth and over an extended period of time (Schensul \& LeCompte, 2013). The first author was first invited to attend a panel by the panel facilitators in 2014, who had previously reached out to the second author for evaluation assistance and were interested in forming a collaborative research partnership. The method of ethnographic inquiry emerged as a natural research tool to organize the first author's impressions of the panel process and her initial and evolving research ideas. The ethnography consisted of the first author's first-hand examination of and deep immersion in the everyday context of the impact panel through repeated, varied forms of data collection (Banister, Burman, Parker, Taylor, \& Tindall, 1994). Rather than use 
deductive, predictive theoretical models, ethnography uses in-depth, open-ended interviewing and observation to gather rich information that can orient researchers and others to the context and history of the setting and activities (Schensul \& LeCompte, 2013). Validity in the context of ethnography refers to convergent or similar information over time from multiple sources and of multiple types of data that increase confidence in the interpretation of the data. In an effort to accurately convey accounts of the community context and situations in a socially valid manner and build empathic relationships with setting participants to promote understanding of their lived experience (Schensul \& LeCompte, 2013), the first author was consistently transparent with participants and stakeholders about her goal to engage as a researcher in the setting and her role as a graduate student affiliated with a local university.

The primary methods of ethnographic data collection and interpretation included observation, conversation and interviewing, and the skills necessary for integrating into the setting (i.e., relating, listening, explaining, observing, questioning, communicating, recording, discussing, and revising). As researchers themselves are an instrument for data collection in ethnography, it is crucial that researchers recognize and describe their perspective for readers. The first author's personal characteristics, including her physical characteristics, age, language skills, and gender, may have facilitated or hindered the field experience and impacted her positionality as "outsider" or "insider" in the setting (Schensul \& LeCompte, 2013). Entry and acceptance into the setting was not only a single task at the beginning of a field experience but rather something that was negotiated and renegotiated continuously. Her shifting positionality in relation to community 
members and situations also influenced what information was or was not revealed to her in the setting (Schensul \& LeCompte, 2013). As researchers become more knowledgeable of different groups, opinions, and views within the setting, they are better able to overcome the distance and power differential between researchers and community members to access and produce more valid information. For example, as the first author's role in the setting, relationship with the convener of the impact panels, and relationships with regular panel speakers developed over time, she gained access to different information and observed different interactions than at she had at the start of her engagement in this setting. The positionality and reflexive stance of the first author is a key component of the ethnographic analysis and was documented a first-person narrative to increase the transparency of how questions and interpretations of the panel evolved over the course of the study. This narrative is presented in Appendix A to support the credibility of the study's findings.

The study was designed to increase the trustworthiness of this naturalistic inquiry using guidelines suggested by Lincoln and Guba (1985) regarding the credibility, transferability, dependability, and confirmability of the results. Long-term, continuing interaction with study participants through ethnographic inquiry protects against internal validity threats (e.g., maturation) and increases the ability of researchers to comprehensively and adequately represent the multiple constructions of reality made by stakeholder participant groups regarding the program processes and participant experiences. This prolonged engagement and persistent observation in the setting builds trust and rapport between researchers and study participants and increases researchers' 
ability to observe and account for consistencies and inconsistencies in participants experiences' and perceptions of the panel across time. In addition, engaging in the setting for an extended period of time increases the ability of researchers to observe contradictory cases, test and retest assumptions and interpretations of observations, and correct any initial misconceptions (Lincoln \& Guba, 1985).

Non-participant observation of $N=18$ impact panels was completed by the first author from October 2014 to January 2017 in two local counties, totaling over 45 hours. Detailed observation field notes were taken either immediately after observations and unstructured interviews $(n=10)$ or recorded directly in the field $(n=6)$, with assent obtained from panel attendees prior to these panels. Observations continued as feasible until the information collected reached the point of saturation, at which point little or no additional relevant information was observed (O’Reilly \& Parker, 2012). The first author also conducted spontaneous, on-site unstructured interviews with panel facilitators, speakers, and JIIs.

Focus groups and interviews. Focus groups and interviews were conducted in order to gather a variety of responses from stakeholders regarding their perceptions of panel processes and participant experiences. A major strength of this research method is its ability to gather a wide range of ideas regarding a topic from the perspectives of multiple participants who can respond to one another, ideally increasing the breadth of information found in a study (Morgan, 1988).

As the pool of survivor panelists was small $(N=12)$ at the time of data collection, the sampling frame included all survivors from the pool who consented to be contacted 
for panel participation $(n=10)$. These survivors were contacted by the panel facilitator to ask for their consent to share their contact information (phone numbers or emails, at their discretion) with the first author. From this pool, $n=9$ replied to recruitment emails and phone calls and $n=8$ could be scheduled to participate in focus groups. One participant arrived after the cut-off time, so $n=7$ speakers ultimately participated in recorded focus groups $(k=2)$.

The sampling frame for JII focus groups included all panel attendees between August 2016 and January 2017. From the three panels that were held in this time period, 50 attendees were invited to participate through study announcements and flyers. These recruitment methods failed for the majority of the panels. Only two panel attendees were scheduled for a dyadic interview from these efforts and ultimately only $n=1$ arrived and a recorded interview was conducted with this participant using the same questions from the focus group script.

The sampling frame of BIP providers included any BIP provider who attended ( $n$ =11) a monthly local batterer intervention provider network meeting between July and October 2016. An unknown number of additional BIP providers may have also seen announcements for study recruitment over the online listserv for this provider network and could also be considered to be in the sampling frame. Through in-person announcements at these meetings, only $n=2$ providers were recruited and participated in a recorded dyadic interview, as many of the meeting attendees were not eligible for participation (i.e., they were not working directly in batterer intervention and were not referring JIIs to the panels). Responses to email announcements for study recruitment 
indicated that scheduling focus group meetings would not be possible for most providers, so the first author followed up with other eligible participants through unrecorded phone interviews $(n=3)$ using the same questions from the focus group script.

Focus groups and recorded interviews were conducted with participants over a 90-minute period with members seated in chairs arranged in a circle. These were held in familiar settings for each participant when possible, as commonly recommended (Stewart \& Shamdasani, 1990). At the beginning of each focus group or interview, all participants were given $\$ 25$ gift cards, \$5 cash for transportation, and provided light refreshments in compensation for their participation. Focus groups were conducted in a funnel format (Stewart \& Shamdasani, 1990) that began with general questions and narrowed to specific topics regarding panel experiences as the discussion progressed. Afterward, participants were thanked for their input during the discussion, debriefed regarding the study goals, and given time to ask any clarifying questions. Following completion of all focus groups and interviews, audio recordings were transcribed for analysis.

Archival surveys. Archival survey data was collected from JII panel attendees by panel facilitators over a period of two years $(n=287)$. Feedback forms were administered to JII panel attendees immediately after the conclusion of the panel and were collected by panel facilitators. The forms were developed by panel facilitators and do not utilize any existing validated scales. Data consisted of participants' open-ended responses to two questions on the form: "Please describe how these presentations might influence your choices about how you behave toward others in relationships (partner, children, etc.)" and "How might these presentations be improved to further help audience members 
understand the effects of abuse, be accountable for their abuse, and choose to using abuse and control in relationships?”

Participants. Participants included female survivors of IPV, male JIIs in BIPs, and BIP providers. Demographics were collected for participants in survivor focus groups $(k=2, n=7)$, one dyadic interview with BIP providers $(n=2)$, and an individual interview with a JII. No demographic information was collected from the male JIIs $(n=287)$ who attended the 11 impact panels from which archival data was analyzed in their feedback form responses or recorded from the 18 panels that were observed during the ethnographic inquiry.

All participants in the survivor focus groups identified their gender as female. Five of the seven participants had children. All participants were currently in the pool of panel speakers actively participated on the panel at the time of recruitment and data collection. Statistics describing the complete demographic information for the survivor focus group participants are reported in Table 2.1 .

The JII who participated in the interview was 37 years old and identified as male and White/Caucasian. He was married, with a relationship length of 10 years, and had three children. His highest education level completed was some college/trade school and he was currently employed. He indicated he had three prior arrests, was currently enrolled in a BIP, and had been in the program for 11 months. The interview took place two weeks after he attended the impact panel.

One participant in the provider focus group identified as female and the other as male. Their mean age was $53.5(S D=0.71)$ and both identified as White/Caucasian. One participant's highest education level completed was their GED/high school diploma while the other's was a graduate degree. Both were currently employed as BIP providers and 
currently referred JIIs from their groups to the panel at the time of the focus group. Both wrote that they had been referring JIIs from their programs to the panel from the start of the panels.

Analysis. Ethnographic analysis. To address RQ1 and RQ2, we produced a narrative sequential description of the social-interactional processes and survivor and JII experiences in IPV impact panels. This temporally-oriented narrative delineates the activities and interactions that occur in the panel and observed ways in which survivors and JIIs experience the panel. Ethnographic observation notes were analyzed using an inductive, systematic and generative approach to generate "thick description" (Geertz, 1973) of the panels and the experiences of panel participants. In addition, regular discussion and consultation with the first author's advisor guided her processing and reflection on developing an account of the impact of IPV impact panels on survivors and JIIs. Two research assistants also informed the first author's account of the panel processes, as they made written reflections on their activities for the study and interpretations they made in their work. One of these assistants was particularly involved in data collection and interpretation, as she examined and cleaned study data, observed eight panels with the first author and discussed the observations with her in post-panel debriefing conversations, assisted in pilot testing study materials, and discussed data interpretations in research team meetings.

Stages of writing in ethnography included inscription and description. Inscription consisted of learning how to notice important elements of the setting according its members and accurately writing them down (Schensul \& LeCompte, 2013). The first 
author's previous experiences, personal characteristics, research questions, training in research paradigms, and worldview all influenced this process. Description consisted of writing down jottings, field notes including conversations and activities in the setting, producing thick descriptions (Geertz, 1973) and narratives (Mankowski \& Rappaport, 2000), along with interpretations and explanations. Over time, these descriptions became increasingly focused on key features of the setting (Schensul \& LeCompte, 2013) and a coherent account of the setting and its participants was developed to address the study's research questions.

Qualitative analysis. To further investigate RQ1 and RQ2, the first author conducted an inductive content analysis of the themes evident in the qualitative data regarding how survivors and JIIs experience and evaluate the IPV impact panels. Content analysis (Elo \& Kyngäs, 2008) is a systematic technique that describes and quantifies key words or phrases found in participants' responses in order to generate domains of concepts related to the phenomenon of interest. This analysis was conducted on the qualitative data obtained from JIIs' responses to open-ended questions on the feedback forms and the responses from survivors, JIIs, and BIP providers in the interviews and focus groups. All sources considered in the ethnographic inquiry, transcripts of recorded focus groups and interviews, and notes were reviewed and coded in the qualitative analysis. The ranges and average word counts and numbers of coded reference units across all sources is summarized by source type in Table 2.2.

The steps of inductive content analysis followed in this study include data preparation, organizing, and reporting. Data were organized through a process of open 
coding, category creation, and abstraction to generate a codebook. As the reliability and validity of this largely ethnographic study was not grounded in a positivist or postpositivist framework of replicability, the authors determined that it would be more useful to obtain feedback from as many members of the research team as possible to increase the perspectives and multiple interpretations of the codebook itself than to train a single second coder on the codebook and document whether someone could consistently apply the same codes as the first author to the data. Therefore, multiple raters were not trained on the codebook to independently apply codes to the data, as measuring inter-rater agreement with Cohen's kappa (1960) would not be as informative as a rich discussion of the researchers' interpretations of the codes. Rather, the codes, definitions, and sample references assigned to each code were shared with a research team including two undergraduate research assistants, three graduate students, and the second author (the faculty advisor of the first author). Team members reviewed and considered the content and structure of the codebook before gathering for an hour-long discussion of the content. The discussion helped the first author surface her blind spots and assumptions about her interpretations of the data and informed the final understanding of the data presented in the findings below.

Peer debriefing and member checks further increase the credibility of findings (Lincoln \& Guba, 1985) as an external check on the research process and interpretations. This study incorporated peer debriefing through regular research team meetings and supervision meetings with the team advisor, the second author. Peer debriefing allows researchers to test working hypotheses, make findings and interpretations of the study 
explicit, and reflect on their own positionality and on the research process that could otherwise remain unexamined.

Qualitative data was coded and analyzed using NVivo Version 11 software. A conditional analysis was performed of the interdependent co-occurrence of groupendorsed themes for restorative process codes and panel experiences of survivors and JIIs. Results were examined to find meaningful links between processes, perceptions, and experiences within sources that were linked in proximity by source (e.g., a provider describing a panel process followed immediately by a perceived experience of JIIs). These links were not examined if they were across sources (e.g., between feedback form responses from different participants) as the authors were interested in the logical links from the same perspective of how processes and experiences unfolded during the panel.

\section{Findings}

At each of the 18 surrogate impact panels observed, the sequential activities always took place in the same series of steps. No combative disruptions from audience members were observed at any of the panels in the observation period. Panels that were observed with notes taken directly in the field $(n=6)$ allowed lengths of speaking time to be recorded. In these panels, individual speakers spoke from 12 to 37 minutes to share each of their stories $(M=23.14$ minutes; $S D=6.93)$. After the final speaker finished telling her story, the floor always opened up to follow-up questions from the audience. During this question and answer (Q \& A) session, the majority of social interactions, or interactional processes, were witnessed. For panels in which notes were taken directly in the field, the length of Q \& A sessions ranged from 23 to 50 minutes $(M=37$ minutes; 
$S D=11.22)$. The majority of questions and comments were posed by JII audience members, ranging from 4 to 10 questions in each panel $(M=7$ questions/panel).

Questions were usually asked by multiple JIIs in attendance. In three panels, all questions were asked by different JIIs in the audience. In two panels, one JII asked two of the ten total questions and two JIIs each asked two of the seven total questions. In addition to questions from JIIs, the panel facilitator sometimes asked questions when no questions were forthcoming from the audience. The panel facilitator asked between one and five questions in these panels, usually asking one or none.

RQ1: Panel participant experiences. Although there was variation in how different speakers experience the panel, a shared group experience emerged during content analysis based on the many common, overlapping perceptions and interpretations of their experience from the data sources. The speakers' experience is therefore presented here as a single, coherent account. The JIIs' experiences were less consistent than the survivors' experience and are thus described as two accounts, as some JIIs were found to shift into a more open space than others during the panel and therefore engaged in different processes and had different impacts from the panel. A particular effort was made to identify and describe survivors' and JIIs' perceptions of their panel experiences, as perceptions not only influence how participants first enter and interact with the panel setting but also how they make meaning out of their panel experience, including evaluations and judgments of the panel, and integrate that into their personal understandings. Speakers' and JIIs' perceptions before, during, and after the panel are summarized in Table 2.3. 
Survivor experience. Speakers perceive the panel as a safe, welcome space where they can prioritize their own needs. As one speaker put it, survivors can prioritize themselves and their experience by speaking on the panel: "It's the one time we get to be selfish with our own stories, it's our journey." They are choosing to take up space and time by sitting on the panel as a speaker. Because the panel setting is explicitly designed to focus on their experiences and welcome their personal stories, the panel is perceived as removing the shame from speaking about abuse that is implicit or explicit in other settings. In a focus group, one speaker explained that abuse is difficult to talk about in other settings even with friends, so being able to talk about it publicly frees them from the shame of their experiences. She elaborated:

It's a very secret and shameful and private thing that, um, even your friends...they have no idea, they don't understand...it's not that they don't care, they just- nobody wants to talk about it. And so for years I never [pause] told anybody...So, the feeling of- have a place, a safe place, to be able to share these things that I kept secret for years and years and years and years [is] very freeing.

While there are some aspects of the panel experience that are not entirely comfortable for the speakers, this discomfort does not preclude other positive experiences or decrease the safety of the panel in the context of this setting. Some speakers express anxiety, discomfort, or nerves at times during the panel process. These feelings often stem from the prospect of speaking on the panel for various reasons, such as one speaker who has social anxiety and regularly discloses this during panels to the audience. The knowledge of an upcoming panel can also cause some anxiety or noticeable discomfort in the days leading up to speaking. One panelist told the audience one night on a panel that she was feeling anxious and irritable in the couple days leading up to it and did not sleep 
well, saying "So, it's hard to be here." When speakers felt any pressure to tell their story succinctly or in a specific way anxiety could also increase, as some on the panel indicated by that saying they were "running out of time" or that they "don't have time to tell the whole thing." Importantly, these moments of discomfort were discussed in isolation as rare examples of how the panel is challenging for speakers, and did not undermine their global perception of the panel being a safe space. The speaking experience is complex, containing both benefits and challenges, but the overall process is perceived as a beneficial one overall.

JII transformative experience. JIIs initially enter the panel with one or more preconceptions and expectations about what they will experience in this setting. JIIs and providers voiced that some JIIs expect the process to be confrontational or antagonistic towards them in some way, while others anticipate that the experience will be irrelevant to them. For these JIIs, the panel is initially perceived as no more than a requirement that they must complete by attending to satisfy their PO or BIP provider.

Early preconceptions can be associated with some anxiety about the panel for JIIs, who may begin the panel with some degree of resistance to the process. In an interview, a JII explained that his initial anxiety about attending the panel stemmed from his expectations about it, as he imagined that the men in the audience would be shamed or blamed or judged. He said, "I was really expecting that, I guess, attitude from the speakers, like, 'You guys are all bad people because you're here.'” Program logistics regarding finding the panel location and affording the attendance fee can also cause anxiety for JIIs, according to an informal interview with a BIP provider. 
Panel perceptions can change over the course of the panel for some JIIs, as they see that their initial expectations of being antagonized or the irrelevance of the panel content are not met. Some perceive the process as non-confrontational, and that they are not pre-judged by the speakers. They become more comfortable with the process as the panel unfolds and lower their defenses, decreasing any resistance to the process, and engage more openly with the speakers and the process. Some JIIs feel safe and supported by the panel and perceive the environment as friendlier than they expected after the panel begins. The JII who was interviewed said that the nature of the panel was a pleasant surprise: "This was more of, just, kind of an open conversation, so I actually appreciated that."

If JIIs are able to experience the shift in perception of the panel to take it seriously and connect, they may be able to get something out of the panel unique relative to other interventions. Some JIIs noted the unique benefits of attending the panel compared to other programs or experiences, such as a JII who wrote on a feedback form "I have never heard the victims of domestic violence speak about their experience before. I hear mostly the experiences of the abusers at [BIP name]."

JII static experience. In contrast to those who have a transformative experience at the panels, some JIIs do not shift out of their anxiety or resistance or lack of engagement in the process and instead have a static experience across the panel. Their resistance or lack of engagement remains throughout panel and does not change, possibly resulting in rejection or lack of integration of the panel experience.

Speakers, JIIs, and those who coordinate the panel (the panel facilitator and POs) 
were all observed engaging in patterns of social interaction consistent with restorative justice definitions and principles. The processes described here were identified as fitting closely with the Maximalist restorative justice principles of stakeholder involvement (particularly Survivor-JII exchange), repairing harm (particularly relationship building), and role transformation (Bazemore et al., 2007). The vast majority of observed interactional processes were consistent with the first two principles, stakeholder involvement in the survivor-JII exchange (12 observed processes) and repairing harm (10 observed processes), while relatively fewer were consistent with the final principle of reenvisioning roles to promote justice (5 processes). All observed interactional processes are categorized by their consistent principle in Table 2.4 , which indicates the type(s) of source in which the processes were endorsed, the number of sources in which the process was coded, and the number of specific units coded across all sources that endorsed the process. The interactional processes are described below in more detail.

1. Stakeholder involvement. The rhythm of each panel can shift in ways that suggest more or less engagement between the speakers and audience members. At times, a lot of energy moved back and forth between the audience with their questions and responses from speakers, with lots of nodding on both sides, "Mhmm" comments, and even laughter. Sometimes the speakers made jokes that would ease any tension in the room and lift its energy, seen in effects like a big laugh throughout the whole room. Speakers at these points appeared very comfortable, leaning back in their chairs, and the audience members and speakers clearly spoke directly to each other without waiting for the facilitator to prompt questioners from the audience. 
JII engagement in the panel was observed primarily through behavioral indicators such as raising their hands to ask a question or volunteer for an activity and moving their heads to make eye contact with different speakers. Every source type endorsed some form of JII engagement in the panel and this was one of the most frequently occurring codes in the qualitative analysis, both in the number of sources coded (30) and the number of coded references (91). JIIs asked questions about the speakers themselves, about children or youth, about a speaker's abuser, and on their own personal problems. One of the most frequently observed interactional processes between the audience and speakers that originated from JIIs was a JII asking questions focused on speakers. JIIs also made references to speakers' comments that demonstrated they had been listening to the stories, such as when one clarified, "Did I hear you say that your son lives with your abuser?" Their referencing of speaker's comments was demonstrated in multiple source types spanning panel observations, survivor focus group transcripts, and JII comments on feedback forms or the JII interview transcript. For example, one JII who volunteered for a perspective-taking activity prefaced his participation by saying to one of the speakers, "[The instructions] say to shout this in an angry voice, but I know you said that loud male voices bother you, [Speaker's Name]," so he completed the activity without raising his voice.

Speakers were engaged during the vast majority of each panel, supported by references across all source types and most clearly observed through their participation sharing their stories and in listening and responding to other speakers' stories and JIIs' comments and questions. Speakers' stories are not scripted and each speaker must be 
engaged to decide what they would like to focus on and how they share their story each night. Speakers told stories of mental and emotional abuse, verbal abuse, financial abuse, and physical abuse and described the impact of abuse on themselves, their children (including themselves when they were a child), and on their abusers as well. The vast majority of speaker statements coded were references to the impact of abuse on themselves or its impact on children, but statements about the impact of abuse on their abuser were also somewhat frequent. Their statements during the panel and responses to direct questions indicated that they were paying attention to other panel participants and considering how things that others shared compared to their own experience. They made eye contact with one another at times and with the audience, sometimes turning their body to face more toward one participant or another while they were speaking.

Silence could also be a sign of the level of engagement by JIIs in the audience. When one speaker was describing how her ex-partner was physically abusive, she said that she "used to tell him if you'd just hit me, it would be kinder than what you're doing to me. Because then at least" (long pause) "someone would care about me, someone would see that I needed help." She reached for tissues. She said "he never hit me...he never punched me or slapped me across the face. He did strangle me, throw me down the stairs, pulled me by my hair, pried the phone from my bruised hands, blocked me." She said that it is "hard to explain how physical abuse is not scary," but only "now remembering and looking back that it is scary to remember being strangled" or choked so that she couldn't breathe. It was only when she attended a training on strangulation after her abusive relationship that she learned her symptoms after being strangled (e.g., "hurt 
to swallow for a month and a half") makes her "still start to panic, still get emotional" about it. She realized in that training that she "actually could have really died at that moment." As she told this part of her story, it was completely quiet in the room. No one audibly shifted in their seats or coughed, creating a feeling that everyone was there with the speaker in that moment, waiting to hear the rest of her story. Everyone in the audience was facing her, looking at her, or looking down at the ground. Of those who stared at the ground, one or two sometimes looked up at her. She said that her ex-partner's actions had nothing to do with their love for one another, but nevertheless "if I had died, I know he would have been defensive...that he didn't mean to, it was an argument, he was just trying to get his phone." She believes that his excuses and defensiveness "would have been the same regardless of if she made it or not."

Lack of active engagement in the panel was observed only in the JIIs, not in the speakers, which was not surprising given that JIIs' participation in the panel is not completely voluntary. Their lack of engagement was endorsed by all source types except JII sources themselves, suggesting that JIIs may be unaware of their lack of engagement or that those who are not engaged did not contribute information to the study material (e.g., did not write anything in response to the open-ended questions on the feedback form). In one panel, a man appeared to be either sleeping or kept his eyes closed most of the time. Other examples of lack of engagement included appearing to be incapacitated (e.g., withdrawing from a substance) or otherwise not paying attention, having a lull or lack of questions from the audience, JIIs leaving the auditorium for a period of time (presumably to use the building facilities), or engaging in other activities while present at 
the panel (e.g., reading a book). Acts of more extreme disengagement were relatively rare, such as an audience member being seen leaving the auditorium once during a panel.

Distinct from lack of engagement, JII resistance was observed when JIIs actively resisted the panel before or during the process, verbalized in assumptions or preconceptions about the panel. Rather than simply not paying attention or passively waiting for the panel to conclude, resistance could be heard in some comments from JIIs during the Q \& A session. Examples included “Honestly, I didn't really want to come/be here tonight, I didn't know how it was going to go" and "to be honest I was pretty irritated that I had to come tonight, I feel like I like my group, I like the guys in my group, and yeah I didn't want to come to this." These comments were only heard as a preface to a JII's description of how their impression changed after the panel began. Since some audience members occasionally voiced these impressions, it is likely that others had similar thoughts but sat silently and potentially remained resistant to the process over the course of the panel. JII resistance to the panel process was endorsed across all source types.

2. Repairing harm. Interactional processes identified as consistent with the restorative justice principle of repairing harm were relational interactions between survivors and JIIs, such as speakers and JIIs finding common ground during the panel. Speakers audibly related to JIIs at the panel while they shared, sometimes explicitly tailoring their responses to what they thought JIIs needed to hear that night. This process was frequently endorsed both in panel observations and in the survivor focus group transcripts. Speakers commented on the similarities of their experiences and JIIs' 
experiences at the panel or in other aspects of their lives, such as one speaker mentioning that her husband went through the BIP that men in the audience were in that day. Speakers noted that the hard work of participating in the panel was shared across survivors and JIIs, such as one who reassured the men in the audience, saying, "If you're feeling a little stress, know you're not alone in being uncomfortable. It's not easy sitting on this side of the table, I'm sure it's not easy on that side either." Speakers also gained insights by relating to JIIs at the panel, such as one speaker who explained to the audience at a panel one night that "when I meet people like you, that was like, oh - you're doing your work, so that means I can do my work, and he [her ex] has to do his work - it was eye-opening."

Both survivor speakers and JIIs in the audience also showed encouragement and affirmation toward one another for their mutual participation in the panel process. Speakers encouraged and affirmed the JIIs in their efforts to change, positively recognizing and praising their choices and behaviors to work on themselves in their BIP groups and in the panel. Although this process was only occasionally endorsed in panel observations and in the survivor focus group transcripts, these moments stood out very clearly during panel observations. One speaker shared, "I'm always heartened to see men, especially young men, come here because there's such a change you can make." Another encouraged the audience, saying, “one good thing is that you're here, maybe you're pissed off but you're here, and that's more than a lot of others would do, you didn't have to come."

Speakers frequently expressed gratitude and appreciation to JIIs and this process 
was endorsed across all source types. One speaker told the audience that she was "so grateful to have you all here tonight. You didn't have to show up, you made a choice, other options were offered to you, but you're here." Speakers also sometimes expressed non-judgmental respect to JIIs in comments, such as one who said they were "not here to judge you or point fingers or anything." This process was endorsed in both panel observation notes and survivor focus group transcripts. Another speaker expressed a lack of judgment toward the audience by commenting on how the panel addresses IPV by "removing it from being a secret, something to be ashamed about it, on either side." JIIs similarly related to speakers, expressed gratitude and appreciation to the speakers after they shared their stories, and affirmed the speakers in various ways. These were the most commonly endorsed JII processes of repairing harm, supported with data from all source types. The most frequent JII process observed or described across sources was JIIs affirming speakers in various ways. Affirmation of speakers was typically observed in JIIs who nodded or said "Mhmm" in response to speakers' comments, or sometimes making longer comments that were explicitly affirming. In multiple panels, audience members spontaneously thanked the speakers by name and clapped after hearing each of the speakers' their stories. During one Q \& A session, a JII told the speakers “Thank you guys, what you do, it does help. Thank you." Another JII verbalized his recognition that the panel "took courage" for the speakers to share their stories, while a third JII told the speakers, "I commend you, [it] takes fortitude to speak." After every panel concluded, there were usually a few JIIs who lingered to shake hands with the speakers and have brief follow-up conversations with them. In one of these conversations, 
a JII told one of the speakers, "It's very special to me, what you said."

Speakers also affirmed one another as they participated on the panel together. This process was frequently seen in panel observations and referenced in survivor focus group transcripts. For example, speakers sometimes nodded as the others spoke, noted moments of resonance or common experiences, and emphasized the points that other speakers make during the panel. During one panel, a speaker affirmed and expanded on the points of the prior two speakers: "Well I agree with you both that the verbal lasts and is hard, in some ways the physical is hard because it's still lasting in some ways."

In contrast, some JIIs invalidated or dismissed speakers' experiences through their comments or questions. This process was observed less frequently but was endorsed by all source types. Occasionally, JIIs asked victim-blaming questions, such as "What was it in the man that made you stay for so long?" In these cases, the speakers responded by challenging their statement while still showing respect by not attacking the individual, such as one speaker who replied, "Why isn't the question 'Why did he keep abusing her?"”

3. Re-envisioning roles to promote justice. The following observed panel activities re-envisioned the roles of program participants by creating unique opportunities for survivors and JIIs to engage in the panel together. The typical role in IPV intervention for survivors was transformed from passive service recipient to active controller of a process focused on their experience and perspective. The typical role for intervention professionals was similarly transformed, from authoritative experts to supportive facilitators of the intervention process.

Speakers were observed as in control over the panel process with ownership and 
authority over the entire panel. This process was endorsed across all source types, except JII sources. Speakers set audible limits on what they shared about their experiences, sometimes sharing few personal details about her experience or responding to JIIs' questions with comments such as 'I'm not going any further, I don't want to talk about my relationships." This process was endorsed across all source types except provider sources. Another speaker re-directed the conversation during a Q \& A session, saying, "I want to go back to that question you asked," when she did not get a chance to respond before another JII jumped in with a new question. The ability to choose how and to what extent they share their stories and engage in panel processes allows speakers to participate in the ways they are most comfortable, fostering safety in the setting beyond any external provision of safety by professionals or security figures (e.g., POs). Survivors' perception of the panel as a safe place for them seems to be strengthened by these processes consistent with re-envisioning roles to promote justice, particularly those of the speaker's control of the panel process and choice in what to share of her experience. The safety also allows them to engage in restorative processes, including affirming other speakers and JIIs, relating to JIIs, and showing non-judgmental respect or appreciation to JIIs.

The roles for service professionals were also re-envisioned in some ways, from experts or authority figures to facilitators and promoters of the panel process. POs and panel facilitators affirmed speakers and showed great respect for them, such as a PO saying that "it's always a pleasure and honor" to support this work in a post-panel debriefing conversation. The process of POs and panel facilitators treating speakers with 
respect was endorsed across all source types, except JII sources. The panel facilitator similarly affirmed JIIs in actions that demonstrate their belief that the work JIIs are engaged in to change is possible, such as taking the time to explain the panel guidelines and share suggestions about how to get the most out of their panel experience. The community setting in which the panels were held also communicated respect for the JIIs that they could be trusted and were not perceived to be highly threatening or requiring setting characteristics such as armed or locked safeguards. However, some references observed across source types indicated adherence to more traditional roles for POs and panel facilitators, including PO active control over the audience and panel facilitator control over the panel process, suggesting that the process may not fully transform their roles in this setting.

\section{Discussion}

As a whole, the findings presented above provide a rich, in-depth narrative account of an IPV impact panel's sequential activities and identify specific interactional processes that occur in the panel setting that manifest key restorative justice principles (Bazemore et al., 2007). The ethnographic inquiry brings a new depth of understanding to this type of restorative justice process through a detailed account of specific panel processes, participant experiences, and program settings, filling a gap in the literature on restorative justice panels for IPV cases. To address RQ1 regarding how survivors and JIIs experience and evaluate the IPV impact panels, we created one experience narrative for survivors and two narratives for JIIs, describing the perceptions and evaluations of the panel for each of these participant groups. The perceptions of each group are summarized 
in Table 2.3. To address RQ2 regarding how the interactions that take place during the panel are consistent with restorative justice principles (Bazemore et al., 2007), we identified and described the panel interactional processes categorized by each restorative justice principle in Table 2.4 .

Contributions. Previous research on the use of impact panels for IPV cases suggested that these panels increase JIIs' understanding of the impact of IPV and increase survivors' healing and empowerment (Burkemper \& Balsam, 2007). However, most previously published studies on IPV impact panels did not describe the panel processes in sufficient detail for their findings to be expected to transfer to other contexts with any confidence. Findings from the current study therefore add considerable depth and breadth to what is known about IPV impact panels.

Restorative justice processes have historically been used less frequently for IPV than for crimes that are less severe and interpersonal in nature, so it was not clear whether or how theories based on restorative justice programs for other crimes would apply to the use of these programs for IPV cases. Multiple models of restorative justice also conflict in how they define restorative justice and in what processes are considered most effective for programs, so it was uncertain whether any of these models would be capable of predicting outcomes specific to IPV impact panels. Findings from these multiple sources and methods did relate in interpretable ways to existing theory and models of restorative justice processes to further illuminate consistencies and inconsistencies between restorative justice theoretical models and real-world program practices.

Perhaps one of the most striking aspects of the panel process is that the power 
imbalance between IPV survivors and JIIs is inverted in the interactional processes observed in the setting in a way that re-envisions the roles of survivors in a process to address IPV to have control over the panel process while simultaneously not shaming or attacking JIIs who participate. The panel manifests restorative justice principle-based interactional processes that are the complete opposite of the controlling tactics and abusive behaviors that characterize IPV (Pence \& McMahon, 2008). The panel process elevates the experiences of formerly abused partners and opens the possibility of repairing harm to those who have experienced IPV by challenging JIIs in the audience and having their reported experiences heard and affirmed by those around them. Rather than using that elevated stance and power to shame or blame the former abusers in the audience though, the speakers exert their influence to process and re-frame their own experiences and can end up connecting with the JIIs over the shared difficulty in doing work like attending the panel. The setting creates the potential for them to re-frame their experience of abuse and turn it into "something beautiful," as one speaker stated during a panel.

The IPV panel process and impacts were also found to be consistent with many components of restorative justice theories. Restorative justice frames crime as a violation of individuals, relationships and communities (Zehr, 1990), and the impact panel centers the process on the individuals who were violated (i.e., survivors who control the panel process) in order to repair the harms for both those violated and those who perpetrated the violations (i.e., JIIs). Many restorative justice programs have a common goal of facilitating some form of encounter, direct or indirect, between individuals affected by a 
crime (Zehr, 1990), which was also found in the IPV impact panel process, in which a direct encounter is facilitated between individuals affected by similar (though not directly identical) crimes. An important difference between the IPV surrogate impact panel and other restorative justice processes is that the panel is not a stand-alone process focused on addressing a specific crime or harm involving individuals from the same incident(s), as in a dialogue or conferencing process. Therefore, the panel is not intended to result in specific outcomes decided by participants, primarily victims and individuals involved in the situation (Zehr, 1990), although it is an inclusive process that encourages participation widely among survivors and JIIs from BIPs.

In addition, concerns about using restorative justice programs for IPV cases can be greatly informed by the current study's findings. Many of the papers published that critique or caution against the use of restorative justice processes for IPV cases make implicit assumptions about aspects of restorative justice in this context. Although concerns have been expressed that restorative justice processes for IPV may claim to be victim-centered but could actually further disempower victims by coddling or excusing JIIs in an effort to understand their behavior (Stubbs, 2007), our panel observations indicate that the process is able to hold both priorities simultaneously by centering survivors' experiences and having speakers control their own panel participation while respecting JIIs and promoting their potential to change and through the panel process. The elevation of survivors' experiences during the panel process stands in sharp contrast to what many survivors endured in abusive relationships (Curtis-Fawley \& Daly, 2005), in which abusive partners and others minimize both survivors' interpretations of their 
own experience (e.g., that the abuse was not harmful or not real) and abusers' responsibility for their behavior (e.g., that their actions were the survivors' fault).

The study findings suggest that IPV impact panels create unique patterns of social interaction between JIIs and survivors that are not possible in other settings within the coordinated community response, as intentional interactions between survivors and JIIs are either prohibited or extremely unlikely to occur through other programs or activities (e.g., BIPs, victim advocacy organizations). While BIPs tend to use cognitive behavioral, gender-based psychoeducational curricula to link IPV to social norms about masculinity and the acceptability of violence (Gondolf, 2004), the IPV impact panels focus on survivor accounts of the harms of IPV and produce interactional processes that are largely unique to the panel setting, such as JIIs affirming speakers and speakers showing non-judgmental respect to JIIs.

The study findings suggest that IPV impact panels create unique patterns of social interaction between JIIs and survivors that are not possible in other settings within the coordinated community response, as intentional interactions between survivors and JIIs are either prohibited or extremely unlikely to occur through other programs or activities (e.g., BIPs, victim advocacy organizations). While BIPs tend to use cognitive behavioral, gender-based psychoeducational curricula to link IPV to social norms about masculinity and the acceptability of violence (Gondolf, 2004), the IPV impact panels focus on survivor accounts of the harms of IPV and produce interactional processes that are largely unique to the panel setting, such as JIIs affirming speakers and speakers showing non-judgmental respect to JIIs. 
Of the three principles that Bazemore et al. (2007) suggest guide restorative justice processes, those focused on repairing harm and stakeholder involvement through survivor-JII exchange are particularly relevant to the IPV impact panel. The vast majority of interactional processes were consistent with these principles, though some additional processes were consistent with re-envisioning roles to promote justice. Given that the panel involves survivor participation by definition and some level of participation from some JIIs during the Q \& A session, it is not surprising that the largest number of processes and references were consistent with the first principle of stakeholder involvement. Although the panel does not explicitly state that repairing harm is a primary goal of the process, findings indicate that many interactions take place during the panel that are consistent with this principle. Both survivors and JIIs relate to, show respect for, and affirm or encourage one another in varying ways during the panel. The third principle of the model, re-envisioning the roles and responsibilities of the community and government to promote justice, is also not an explicit focus of the panel process, but the panel accomplishes a similar re-envisioning by creating unique roles and opportunities for survivors and JIIs to engage in restorative interactions together. The typical intervention role for survivors is transformed from one of passive service recipient to active controller of a process focused on her experience and perspective. The typical intervention role for JIIs is similarly transformed, from stigmatized criminal to a person who is affirmed for working to take responsibility for his behavior.

Limitations. These study findings and implications are limited by panel and participant selection effects. Given that typical rates of BIP drop out range between $40 \%$ 
and $60 \%$ of those mandated to attend (Eckhardt, Murphy, Black, \& Suhr, 2006), JIIs who were observed in this study included only those who both completed at least 26 weeks in their BIPs and arrived at the panel after being referred for attendance. Those who dropped out of programs or passively or actively avoided attending a panel might behave differently during panels (e.g., some may be more defensive or resistant to intervention activities and therefore less likely to interact during the panel process). In addition, speakers who were observed participating on the panel represent a subset of IPV survivors who knew about the existence of the IPV impact panel, sought out the opportunity to participate, and typically chose to speak repeatedly on panels. Other survivors may be generally less interested in speaking with JIIs themselves or may be closer in time to their own direct experience of abuse and need more time to heal before engaging in a panel process. Although the sequential activities of the panel are not dependent on the individual attendees who participate in a specific panel, the interactional processes recorded during observations only emerged out of interactions between specific survivors and JIIs.

A key theoretical limitation of findings based on this specific community intervention program is the condition under which JIIs participate in the IPV impact panels. Currently, JIIs are mandated to attend a panel by their POs as a condition of BIP completion. This directly opposes restorative justice theory, which emphasizes that restorative justice practice ideally takes place between individuals who all enter the process voluntarily and with genuine openness and willingness to engage in the process (Cheon \& Regehr, 2006). Although probation requires JIIs to attend the panels, there 
were no recorded instances of any consequences for failing to attend by the time a JII completed their other BIP attendance requirements. Therefore, meeting the requirement of panel attendance could be considered somewhat, though not completely, voluntary on the part of JIIs. Nevertheless, this partially voluntary or fully involuntary condition of JII participation limits the extent to which our findings may be transferable (Lincoln \& Guba, 1985) to other restorative justice program settings.

Future aims. The current study yielded data that inform theoretical understandings of restorative justice processes, with a combination of data collection methods and sources that generated rich information about how IPV impact panels function and how participants experience these panels. Findings from this study could be used to generate theory-driven hypotheses about the panel's impact on participants for further testing with quantitative methods. For example, the study findings could inform the creation or selection of survey measures for ongoing evaluations of the IPV impact panel. The deeper understanding of the process of IPV impact panels and the experiences of panel participants increases the likelihood of measuring ecologically valid domains in future studies of panel impact.

Future studies could also focus on uncovering more specific mechanisms through which panel processes, perceptions, and impacts are inter-related for survivor and JII participants (e.g., in a process and outcome model of the impact panel). Because a wider range of speaker behaviors was more possible to observe than that of JII behaviors, future research would be strengthened by more direct measures of JII engagement and processing during the panel (e.g., monitoring emotional responses or attention throughout 
the panel) as additional indicators of JII experiences. A follow-up longitudinal quasiexperimental study using random assignment or propensity score matching of JIIs who do and do not participate in an IPV impact panel would also be useful to determine how the proximal processes identified in the current study relate to longer-term, distal outcomes for survivors and JIIs, such as JII remorse and living free of violence.

This study focused on the panel processes and experiences of survivor and JII participants rather than on larger communities, so the findings stated here cannot speak to the roles or responsibilities of communities or governments. Future research could expand this analysis to evaluate proximal processes and outcomes for these other stakeholder levels. Promising results could illuminate not only the proximal and distal processes of change for survivors and JIIs but the way in which they are situated within the broader response to IPV. Expanding on the knowledge produced here with this continuing line of research could guide the development of more comprehensive, coordinated responses to IPV that include restorative justice programs for IPV prevention and intervention. 
Table 2.1

Demographic Characteristics of Survivor Focus Group Participants

\begin{tabular}{|c|c|}
\hline Variable & Sample $(n=7)$ \\
\hline Mean age $(S D)$ & $48.4(14.8)$ \\
\hline \multicolumn{2}{|l|}{ Ethnicity (\%) } \\
\hline African American & 0 \\
\hline Caucasian & 85.7 \\
\hline Hispanic/Latino & 14.3 \\
\hline Other & 0 \\
\hline \multicolumn{2}{|l|}{ Marital Status (\%) } \\
\hline Single & 28.6 \\
\hline Living together & 42.9 \\
\hline Married & 28.6 \\
\hline Separated & 0 \\
\hline Divorced & 0 \\
\hline Mean relationship (years) $(S D)$ & $4.3(2.9)$ \\
\hline \multicolumn{2}{|l|}{ Education (\% highest completed) } \\
\hline Some high school & 0 \\
\hline GED or high school diploma & 28.6 \\
\hline Some college/trade school & 28.6 \\
\hline College degree & 28.6 \\
\hline Some graduate school & 14.3 \\
\hline Graduate degree & 0 \\
\hline Currently employed $(\%)$ & 57.1 \\
\hline \multicolumn{2}{|l|}{ Length of time participating on panels (\%) } \\
\hline 1 year & 28.6 \\
\hline $2-3$ years & 42.9 \\
\hline $3-5$ years & 0 \\
\hline $5-10$ years & 0 \\
\hline $10-15$ years & 28.6 \\
\hline \multicolumn{2}{|l|}{ Number of panels participated as a speaker (\%) } \\
\hline $1-3$ & 28.6 \\
\hline $4-5$ & 28.6 \\
\hline 10 & 14.3 \\
\hline $40+$ & 28.6 \\
\hline \multicolumn{2}{|l|}{ Panel referral source $(\%)$} \\
\hline DVSD & 28.6 \\
\hline Advocate/advocacy organization & 0 \\
\hline Counselor/counseling organization & 28.6 \\
\hline Other & 42.9 \\
\hline
\end{tabular}

Note. Other panel referral sources were being "asked to speak," "asked to join by participant," and referred by the local county website. 
"IT PUTS A FACE TO ALL THE KNOWLEDGE"

Table 2.2

Qualitative Analysis Source Materials Summary

\begin{tabular}{|c|c|c|c|c|c|c|}
\hline \multirow{2}{*}{ Source Type } & \multicolumn{3}{|c|}{$\underline{\text { Word Count }}$} & \multicolumn{3}{|c|}{$\underline{\text { Coded Reference Units }}$} \\
\hline & Min. & Max. & $M$ & Min. & Max. & $M$ \\
\hline $\begin{array}{l}\text { Post-Field Panel } \\
\text { Observation Notes } \\
(n=10)\end{array}$ & 129 & 1801 & 735.3 & 7 & 40 & 19.5 \\
\hline $\begin{array}{l}\text { In-Field Panel } \\
\text { Observation Notes } \\
(n=6)\end{array}$ & 2539 & 4621 & 3468.3 & 79 & 127 & 105 \\
\hline $\begin{array}{l}\text { Focus Group and } \\
\text { Interview } \\
\text { Transcripts }(n=4)\end{array}$ & 14614 & 25392 & 18026 & 130 & 305 & 223.8 \\
\hline $\begin{array}{l}\text { Feedback Form } \\
\text { Comments }(n=12)\end{array}$ & 244 & 1459 & 696.1 & 11 & 81 & 37.2 \\
\hline $\begin{array}{l}\text { Informal Phone } \\
\text { Interviews with BIP } \\
\text { Providers }(n=3)\end{array}$ & 1134 & 3132 & 2199.3 & 9 & 46 & 32.3 \\
\hline $\begin{array}{l}\text { Panel Speakers } \\
\text { Workshop Notes ( } n \\
=8)\end{array}$ & 113 & 4938 & 1737.9 & 1 & 24 & 11.9 \\
\hline $\begin{array}{l}\text { BIP Provider } \\
\text { Meeting Notes }(n= \\
\text { 5) }\end{array}$ & 2937 & 5582 & 4264.2 & - & - & - \\
\hline $\begin{array}{l}\text { BIP Group } \\
\text { Observation Notes } \\
(n=2)\end{array}$ & 998 & 1889 & 1443.5 & - & - & - \\
\hline
\end{tabular}


Table 2.3

Speakers' and JIIs' Perceptions of the Panel

\begin{tabular}{llll}
\hline \multirow{2}{*}{ Perspective } & \multicolumn{1}{c}{ Pre-Panel } & \multicolumn{1}{c}{$\begin{array}{c}\text { Perceptions } \\
\text { During Panel }\end{array}$} & \multicolumn{1}{c}{ Post-Panel } \\
\hline Speaker & $\begin{array}{l}\text { Panel is a safe, welcome } \\
\text { space to share their } \\
\text { experiences }\end{array}$ & $\begin{array}{l}\text { Panel removes shame } \\
\text { from speaking about } \\
\text { abuse }\end{array}$ & $\begin{array}{l}\text { Panel removes barriers } \\
\text { between survivors and } \\
\text { JIIs and facilitate }\end{array}$ \\
$\begin{array}{l}\text { Justice } \\
\text { involved } \\
\text { individual } \\
\text { (JII) }\end{array}$ & $\begin{array}{l}\text { Panel expected to be } \\
\text { confrontational or } \\
\text { antagonistic }\end{array}$ & $\begin{array}{l}\text { Panel feels more open } \\
\text { and comfortable than } \\
\text { expected }\end{array}$ & $\begin{array}{l}\text { Panel content } \\
\text { perceived as more } \\
\text { realistic, serious, or } \\
\text { "real life" compared to } \\
\text { other intervention } \\
\text { settings (e.g., BIP } \\
\text { groups) }\end{array}$ \\
& $\begin{array}{l}\text { Panel expected to be not } \\
\text { relevant to them; attend } \\
\text { only to fulfill requirement }\end{array}$ & $\begin{array}{l}\text { Panelists can be } \\
\text { perceived as genuine or } \\
\text { as practiced, rehearsed, } \\
\text { or insincere }\end{array}$ & $\begin{array}{l}\text { Panel rejected; } \\
\text { "garbaged or "man } \\
\text { bashing" }\end{array}$ \\
\hline
\end{tabular}


Table 2.4

\begin{tabular}{|c|c|c|c|c|}
\hline $\begin{array}{l}\text { Restorative } \\
\text { Justice } \\
\text { Principle }\end{array}$ & Panel Interactional Process & $\begin{array}{l}\text { Coded } \\
\text { Source } \\
\text { Type }^{\text {a }}\end{array}$ & $\begin{array}{l}\text { Coded } \\
\text { Sources }\end{array}$ & $\begin{array}{l}\text { Coded } \\
\text { Reference } \\
\text { Units }\end{array}$ \\
\hline \multirow{12}{*}{$\begin{array}{l}\text { Stakeholder } \\
\text { Involvement }\end{array}$} & Speaker describes impact of abuse on herself & $\mathrm{O} / \mathrm{S} / \mathrm{J} / \mathrm{P}$ & 21 & 210 \\
\hline & JII engagement in panel process & $\mathrm{O} / \mathrm{S} / \mathrm{J} / \mathrm{P}$ & 30 & 91 \\
\hline & JII asks question focused on speaker & $\mathrm{O} / \mathrm{S} / \mathrm{J} / \mathrm{P}$ & 14 & 34 \\
\hline & Speaker engagement in panel process & $\mathrm{O} / \mathrm{S} / \mathrm{J} / \mathrm{P}$ & 11 & 24 \\
\hline & JII resistance to panel process $[\mathrm{R}]$ & $\mathrm{O} / \mathrm{S} / \mathrm{J} / \mathrm{P}$ & 8 & 15 \\
\hline & JII references speaker's comments & $\mathrm{O} / \mathrm{S} / \mathrm{O}$ & 10 & 19 \\
\hline & JII lack of engagement in panel process $[R]$ & $\mathrm{O} / \mathrm{S} / \mathrm{P}$ & 10 & 15 \\
\hline & Speaker describes impact of abuse on youth/children & $\mathrm{O} / \mathrm{S}$ & 11 & 50 \\
\hline & Speaker describes impact of abuse on her abuser & $\mathrm{O} / \mathrm{S}$ & 7 & 19 \\
\hline & $\begin{array}{l}\mathrm{JII} \text { asks question focused on their own personal problems } \\
{[\mathrm{R}]}\end{array}$ & $\mathrm{O} / \mathrm{P}$ & 5 & 7 \\
\hline & JII asks question focused on youth/children & $\mathrm{O} / \mathrm{P}$ & 6 & 6 \\
\hline & JII asks question focused on speaker's abuser & $\mathrm{O}$ & 7 & 9 \\
\hline \multirow{10}{*}{$\begin{array}{l}\text { Repairing } \\
\text { Harm }\end{array}$} & JII affirms speaker & $\mathrm{O} / \mathrm{S} / \mathrm{J} / \mathrm{P}$ & 22 & 94 \\
\hline & JIIs relate to speakers & $\mathrm{O} / \mathrm{S} / \mathrm{J} / \mathrm{P}$ & 20 & 58 \\
\hline & JII expresses gratitude or appreciation to speakers & $\mathrm{O} / \mathrm{S} / \mathrm{J} / \mathrm{P}$ & 22 & 43 \\
\hline & Speaker expresses gratitude or appreciation to JIIs & $\mathrm{O} / \mathrm{S} / \mathrm{J} / \mathrm{P}$ & 8 & 15 \\
\hline & $\mathrm{JII}$ invalidates or dismisses speaker $[\mathrm{R}]$ & $\mathrm{O} / \mathrm{S} / \mathrm{J} / \mathrm{P}$ & 11 & 11 \\
\hline & Speaker relates to JIIs at panel & $\mathrm{O} / \mathrm{S}$ & 11 & 59 \\
\hline & Speakers affirm one another & $\mathrm{O} / \mathrm{S}$ & 11 & 40 \\
\hline & JII does not relate to speaker $[R]$ & $\mathrm{J} / \mathrm{P}$ & 4 & 9 \\
\hline & Speaker shows non-judgmental respect to JIIs & $\mathrm{O} / \mathrm{S}$ & 5 & 8 \\
\hline & Speaker affirms JIIs' efforts to change & $\mathrm{O} / \mathrm{S}$ & 4 & 6 \\
\hline \multirow{5}{*}{$\begin{array}{l}\text { Re-envisioning } \\
\text { Roles }\end{array}$} & Speaker controls the panel process & $\mathrm{O} / \mathrm{S} / \mathrm{P}$ & 12 & 38 \\
\hline & Speaker chooses what to share of her experience & $\mathrm{O} / \mathrm{S} / \mathrm{J}$ & 10 & 24 \\
\hline & $\mathrm{PO}$ active audience control [R] & $\mathrm{O} / \mathrm{S} / \mathrm{P}$ & 4 & 11 \\
\hline & Panel facilitators control panel process $[\mathrm{R}]$ & $\mathrm{O} / \mathrm{S} / \mathrm{P}$ & 2 & 11 \\
\hline & Facilitator/PO treat speakers with respect & $\mathrm{O} / \mathrm{S} / \mathrm{P}$ & 4 & 8 \\
\hline
\end{tabular}

Note. ${ }^{\mathrm{a}}$ Abbreviations of sources that endorsed codes are $\mathrm{O}$ (observations of panels - notes taken immediately after observation or in the field), S (survivor focus group transcripts), J (JII feedback form comments or interview transcript), and $\mathrm{P}$ (BIP providers dyadic interview transcript or unrecorded interview notes). 


\section{References}

Babcock, J. C., Green, C. E., \& Robie, C. (2004). Does batterers' treatment work? A meta-analytic review of domestic violence treatment. Clinical Psychology Review, 23, 1023-1053.

Banister, P., Burman, E., Parker, I., Taylor, M., \& Tindall, C. (1994). Qualitative methods in psychology: A research guide. Buckingham, UK: Open University Press.

Bazemore, G. (2000). Rock and roll, restorative justice, and the continuum of the real world: A response to "Purism" in operationalizing restorative justice. Contemporary Justice Review, 3(4), 459-477.

Bazemore, G., Elis, L., \& Green, D. L. (2007). The "independent variable" in restorative justice: Theory-based standards for evaluating the impact and integrity of victim sensitive process (part II). Victims \& Offenders, 2(4), 351-373.

Bazemore, G. \& Green, D. L. (2007). "Yardsticks" for victim sensitive process:

Principle-based standards for gauging the integrity of restorative justice process. Victims and Offenders, 2(3), 289-301.

Breiding, M. J., Smith, S. G., Basile, K. C., Walters, M. L., Chen, J., \& Merrick, M. T. (2014). Prevalence and characteristics of sexual violence, stalking, and intimate partner violence victimization - National intimate partner and sexual violence survey, United States, 2011 (MMWR 63 Publication No. SS-08: 1-18).

Washington DC, U.S. Government Printing Office.

Burkemper, B. \& Balsam, N. (2007). Examining the use of restorative justice practices in 
domestic violence cases. Saint Louis University Public Law Review, 27, 121-133.

Busch, R. (2002). Domestic violence and restorative justice initiatives: Who pays if we get it wrong? In H. Strang \& J. Braithwaite (Eds.), Restorative Justice and Family Violence (pp. 223-248). Cambridge, UK: Cambridge University Press.

Caplan, G. (1964) Principles of prevention psychiatry. Oxford, UK: Basic Books.

Cheng, S. Y., Davis, M., Jonson-Reid, M., \& Yaeger, L. (2019). Compared to what? A meta-analysis of batterer intervention studies using nontreated controls or comparisons. Trauma, Violence, \& Abuse. Advanced online publication. https://doi.org/10.1177/1524838019865927

Cheon, A. \& Regehr, C. (2006). Restorative justice models in cases of intimate partner violence: Reviewing the evidence. Victims and Offenders, 1(4), 369-394.

Curtis-Fawley, S. \& Daly, K. (2005). Gendered violence and restorative justice: The views of victim advocates. Violence Against Women, 11(5), 603-638.

Denzin, N. K. (1978). Sociological methods. New York, NY: McGraw-Hill.

Eckhardt, C. I., Murphy, C., Black, D., \& Suhr, L. (2006). Intervention programs for perpetrators of intimate partner violence: Considerations from a clinical research perspective. Public Health Reports, 121(4), 369-381.

Fulkerson, A. (2001). The use of victim impact panels in domestic violence cases: A restorative justice approach. Contemporary Justice Review, 4(34), 355-368.

Geertz, C. (1973). The interpretation of cultures: Selected essays (Vol. 5019). Basic Books, Inc.

Gondolf, E. W. (2004). Evaluating batterer counseling programs: A difficult task 
"IT PUTS A FACE TO ALL THE KNOWLEDGE"

showing some effects and implications. Aggression and Violence Behavior, 9, $605-631$.

Goodmark, L. (2017). Innovative criminal justice responses to intimate partner violence. In C.M. Renzetti, J.L. Edleson, and R.K. Bergen (Eds.), Sourcebook on Violence Against Women (3rd edition) (pp. 253-270). Los Angeles, CA: Sage.

Hampton, R. L., LaTaillade, J. J., Dacey, A., \& Marghi, J. R. (2008). Evaluating domestic violence interventions for black women. Journal of Aggression, Maltreatment \& Trauma, 16(3), 330-353.

Hotaling, G. T., \& Buzawa, E. S. (2003). Victim satisfaction with criminal justice case processing in a model court setting. (NCJ 195668). Washington, DC: National Institute of Justice.

Karakurt, G., Koc, E., Cetinsaya, E. E., Ayluctarhan, Z., \& Bolen, S. (2019). Metaanalysis and systematic review for the treatment of perpetrators of intimate partner violence. Neuroscience Biobehavioral Reviews, 105, 220-230.

Lincoln, Y. S. \& Guba, E. G. (1985). Naturalistic inquiry. London, England: Sage Publications.

Mankowski, E.S., Haaken, J., \& Silvergleid, C.S. (2002). Collateral damage: An analysis of the achievements and unintended consequences of batterer's intervention programs and discourse. Journal of Family Violence, 17, 167-184.

Mankowski, E.S. \& Rappaport, J. (2000). Narrative concepts and analysis in spiritually based communities. Journal of Community Psychology, 28, 479-493.

Marshall, T. F. (1996). The evolution of restorative justice in Britain. European Journal 
"IT PUTS A FACE TO ALL THE KNOWLEDGE"

on Criminal Policy and Research, 4, 21-43.

McCold, P. (2000). Toward a holistic vision of restorative juvenile justice: A reply to the maximalist model. Contemporary Justice Review, 3(4), 357-414.

Mills, L. G., Barocas, B., \& Ariel, B. (2013). The next generation of court-mandated domestic violence treatment: A comprehensive study of batterer intervention and restorative justice programs. Journal of Experimental Criminology, 9, 65-90.

Morgan, D. L. (1988). Focus groups as qualitative research (Vol. 16). Thousand Oaks, CA: Sage Publications, Inc.

Murphy, C.M., Musser, P.H., \& Maton, K.I. (1998). Coordinated community intervention for domestic abusers: Intervention system involvement and criminal recidivism. Journal of Family Violence, 13, 263-284.

O’Reilly, M., \& Parker, N. (2012). 'Unsatisfactory saturation': A critical exploration of the notion of saturated sample sizes in qualitative research. Qualitative Research, 13(2), 190-197.

Pence, E. \& McMahon, M. (2008). Power and control wheel. In C. M. Renzetti \& J. L. Edleson (Eds.), Encyclopedia of interpersonal violence. Thousand Oaks, CA: Sage Publications.

Pennell, J. \& Burford, G. (2002). Feminist praxis: Making family group conferencing work. In H. Strang \& J. Braithwaite (Eds.), Restorative justice and family violence (pp. 108-127). Cambridge, UK: Cambridge University Press.

Roche, D. (2001). The evolving definition of restorative justice. Contemporary Justice Review, 4(3-4), 341-353. 
Salazar, L. F., Baker, C. K., Price, A. W., \& Carlin, K. (2003). Moving beyond the individual: Examining the effects of domestic violence policies on social norms. American Journal of Community Psychology, 32(3-4), 253-264.

Schensul, J. L. \& LeCompte, M. D. (2013). Essential ethnographic methods: A mixed methods approach. (2 $2^{\text {nd }}$ ed.). Lanham, MD: AltaMira Press.

Sherman, L., Strang, H., Barnes, G., Braithwaite, J., \& Inkpen, N. (1998). Experiments in restorative policing: A progress report to the national police research unit on the Canberra reintegrative shaming experiment (RISE). Australian Federal Police, Australian National University. Retrieved from http://www.aic.gov.au/rjustice/rise/index.html.

Stewart, D. W. \& Shamdasani, P. N. (1990). Focus groups: Theory and practice. Newbury Park, CA: Sage Publications.

Stover, C. S., Meadows, A. L., \& Kaufman, J. (2009). Interventions for intimate partner violence: Review and implications for evidence-based practice. Professional Psychology: Research and Practice, 40, 223-233.

Stubbs, J. (2007). Beyond apology? Domestic violence and critical questions for restorative justice. Criminology \& Criminal Justice, 7(2), 169-187.

Sullivan, C. M., Campbell, R., Angelique, H., Eby, K. K., \& Davidson II, W. S. (1994). An advocacy intervention program for women with abusive partners: Six-month follow-up. American Journal of Community Psychology, 22, 101-122.

Van Ness, D. \& Strong, K. (1997). Restoring justice. Cincinnati, OH: Anderson Publishing Co. 
Von Hirsch, A., Ashworth, A., \& Shearing, C. (2003). Specifying aims and limits for restorative justice: A 'making amends' model? In A. Von Hirsch, J. V. Roberts, A. E. Bottoms, K. Roach, \& M. Schiff (Eds.), Restorative justice and criminal justice: Competing or reconcilable paradigms (pp. 21-41). Oxford, UK: Hart Publishing.

Zehr, H. (1990). Changing lenses. Harrisonburg, VA: Herald Press.

Zosky, D. (2018). "Walking in her shoes": The impact of victim impact panels on perpetrators of domestic violence. Victims \& Offenders, 13(6), 739-756. 


\title{
Chapter III: Manuscript 2. \\ Planting Seeds for Change: Multiple Perspectives on How Intimate Partner Violence Surrogate Impact Panels Affect Abusive Partners
}

Note: This manuscript is currently under review for publication. Current citation: Sackett Kerrigan, K. \& Mankowski, E. S. (2020). Planting seeds for change: Multiple perspectives on how intimate partner violence surrogate impact panels affect abusive partners. Manuscript under review at Violence Against Women.

\begin{abstract}
Intimate partner violence (IPV) is a critical social issue, with limited current intervention strategies. Restorative justice programs including surrogate impact panels may be an important addition to IPV intervention, but research is limited on their effectiveness. This paper reports the perceived impacts of surrogate impact panels on offenders from batterer intervention programs using justice-involved individuals' (JIIs) surveys $(N=289)$ and focus groups/interviews $(k=7)$ with survivor speakers, JIIs, and BIP providers. JIIs experienced connection with survivor speakers, reached new understandings of IPV, and expressed emotional impact and intent to change. Implications, limitations, and future research directions are discussed.
\end{abstract}

Keywords: intimate partner violence, restorative justice, victim impact panel, batterer intervention, mixed-methods analysis 
Planting Seeds for Change: Multiple Perspectives on How Intimate Partner Violence Surrogate Impact Panels Affect Abusive Partners

Intimate partner violence (IPV) is one of the most prevalent violent crimes in the United States and more innovative intervention strategies are needed to effectively reduce and prevent its occurrence. IPV refers to a pattern of abusive behaviors that can include physical violence, sexual violence, stalking, and psychological aggression perpetrated by a current or former partner. In the US, over one in three women and one in four men experience IPV in their lifetime (Black et al., 2011). Consequences can include longlasting psychological and emotional harm (Dutton \& Goodman, 2005), social isolation (Riger, Raja, \& Camacho, 2002), PTSD (Clark \& Foy, 2000), and death (Petrosky et al., 2017).

The most widely implemented responses to IPV in the US are through the criminal justice system, including mandating individuals responsible for perpetrating IPV (referred to here as "justice-involved individuals") to attend batterer intervention programs (BIPs). Those harmed in abusive relationships are referred to here as "survivors." While the criminalization of IPV has led to positive outcomes (e.g., altered social norms regarding IPV; Salazar, Baker, Price, \& Carlin, 2003), some survivors report dissatisfaction with the criminal justice system and reluctance to use it in the future (Hotaling \& Buzawa, 2003). BIPs attempt to challenge social learning that reinforces men's use of violence by demonstrating nonviolent models for their behavior (Bandura, 1971; Sonkin \& Durphy, 1997), but justice-involved individuals' (JIIs) resistance creates barriers to program impact (e.g., Daniels \& Murphy, 1997) including not only skills 
deficits but lack of motivation to change their abusive behavior (Edleson \& Tolman, 1992;

Gondolf, 2002). Although evaluations of BIPs have demonstrated small to moderate effects in reducing JII recidivism (Babcock, Green, \& Robie, 2004; Cheng, Davis, Jonson-Reid, \& Yaeger, 2019; Karakurt, Koc, Cetinsaya, Ayluctarhan, \& Bolen, 2019), not all JIIs respond positively to BIPs. This evidence suggests that the current criminal justice system response to IPV is at least partially failing to ensure survivor safety and JII accountability. It is therefore necessary to consider what additional programs could augment this response.

\section{Background}

Restorative justice and intimate partner violence. Restorative justice programs are an innovative but largely untested strategy for reducing IPV, limited by the relatively small number of empirical evaluations of these programs in this context. Restorative justice broadly refers to a holistic response to crime that involves not only those who are responsible for a crime, but also those who are harmed by the crime and other community members (Zehr, 1990). Although IPV cases have been specifically excluded from many restorative justice programs (e.g., Sherman, Strang, Barnes, Braithwaite \& Inkpen, 1998), the few programs in which IPV cases have been included have demonstrated positive effects such as reduced child maltreatment and increased social support (Pennell \& Burford, 2002) at no additional safety risk than treatment as usual in BIPs (e.g., Mills, Barocas, \& Ariel, 2013). Due at least partly to the limited availability of restorative justice programs for IPV, studies evaluating the use of restorative justice in this context tend to focus on smaller samples or single case studies of individuals' experiences. For 
example, Miller and Iovanni (2013) conducted a case study of one couple who elected to go through a post-conviction restorative justice dialogue about their experience with severe IPV and its effects. They found that the dialogue led the survivor to feel empowered by having control over what was going to be discussed during the dialogue, strengthened by showing the JII how strong she was not in an inverted power balance produced by the dialogue, and validated by hearing the JII say none of the abuse was something that the she deserved or caused.

Restorative justice programs may de-legitimize the perceived harms of these crimes and undermine how seriously both JIIs and the general public view them. The interactions between survivors and JIIs in a panel could compromise survivors' safety or shift too much attention to JIIs' situations in a coddling or excusing manner in an effort to understand their behavior (Stubbs, 2007). Ultimately, the panel could be disempowering to survivors who participate in this environment (Stubbs).

On the other hand, restorative justice could be a potentially promising practice by addressing IPV in unique ways that address some perceived failings of the criminal justice system (Curtis-Fawley \& Daly, 2005). Some survivor advocates have more positive beliefs about the potential of restorative justice to help survivors of gendered violence. They perceive the criminal justice system as failing to validate survivors' accounts of their own experiences, effectively handle cases between two partners in a continuing relationship, and adapt to the needs of children involved in a case. Potential benefits of restorative justice for survivors described by some advocates include the ability to speak more about their experience, to be empowered by having more influence 
over the decision-making process, and to have an opportunity to confront the JII (CurtisFawley \& Daly). Some also see restorative justice as an opportunity to address the power imbalance between JIIs and survivors by prioritizing survivors' voices.

Surrogate impact panels. Surrogate impact panels are a specific type of restorative justice practice in which those who have been harmed by a crime speak to individuals who have perpetrated similar crimes (Van Ness \& Strong, 1997). Typically on a panel, there is not a direct personal relationship between the speakers and the audience members, which may both increase the safety of the speakers and reduce audience members' defensiveness when hearing about how others have been impacted by similar crimes.

Given these conflicting views, data are needed to evaluate the effects on survivors and JIIs of participating in an impact panel specifically for IPV. Anecdotal evidence from an interview with one program director found that the panel increased survivor healing and JII understanding of the impact of abuse on survivors (Burkemper \& Balsam, 2007). A more rigorous evaluation found that a majority of panel participants endorsed impact panels as a worthwhile procedure, although the panel did not appear to affect JII recidivism (Fulkerson, 2001). However, the specific processes that occurred during the panels evaluated in each of these studies were either not described or differed in important ways from those used in panels implemented as part of BIPs (Sackett Kerrigan \& Mankowski, 2020a). These limitations undermine confidence and relevance of the findings for how impact panels operate as a component of BIPs. 
Recently, a more rigorous outcome evaluation was completed of an impact panel that demonstrated positive impacts (Zosky, 2018). The panel process took place in a courthouse room, facilitated by someone in the probation department, with volunteer speakers who were survivors of domestic violence and shared how their experience impacted their own lives and those of their family members. No direct interaction (through questions and answers) took place between the speakers and audience members; instead, small group discussions were led by trained facilitators with the audience to discuss the panel content. Surveys completed by participants $(n=340)$ over a three-year period (2014-2016) indicated that a majority of the JIIs endorsed that the panel increased their awareness of the impact of IPV on direct survivors and children and viewed their panel attendance as beneficial (Zosky). Grounded theory analysis of open-ended comments from a majority of the participants $(n=301)$ indicated that the panel evoked expressions of emotional responses and remorse in JIIs, empathy for the panel speakers as IPV survivors, and commitment to learn and be accountable as well as of change and hope.

\section{Study Context}

This study is situated within a program of research intended to further understand the how an IPV surrogate impact panel functions in the Pacific Northwest and its impacts on both participating survivors and JIIs. Although this program of research includes a qualitative study of the perceived impacts of panels on survivors who speak on the panel (Sackett Kerrigan \& Mankowski, 2020b), this study focuses only on the perceived impacts of the panel on JII participants in order to explore how the panel may contribute 
to desired behavior changes in JIIs as a component of BIPs. The focus of the dissertation is not intended to imply, however, that the panels should be evaluated only in terms of their potential benefit to JII audience members, as it is fundamentally a survivor-driven and survivor-centered process. In the panels, survivors of IPV speak about their experiences of abuse and its impact on them to a group of IPV JIIs who are enrolled in BIPs. The survivor speakers participate in the panel on a completely voluntary basis. JIIs are required to attend the panels after participating in BIP groups for at least 26 weeks and pay $\$ 25$ to attend the panel. A facilitator coordinates the panel and a probation officer is present at each panel. Panels are held from 6 to 8 P.M. one weeknight per month in alternating local counties in large meeting rooms such as county building auditoriums. The panel is a public meeting open to guest observers and community members are welcome to attend by contacting the panel facilitator. Further details about the panel process are reported in an observational study (Sackett Kerrigan \& Mankowski, 2020a). In order to inform the debate about the value and possible risks of surrogate impact panels for IPV intervention, the current study aimed to uncover how the IPV impact panel was perceived to affect JIIs, based on the perspective of multiple stakeholder groups. One research question was posed: What are the perceived impacts of IPV impact panels on JIIs?

\section{Method}

This study utilized a multi-method, multi-source approach to investigate the perceived impacts of the surrogate impact panel on JIIs, including a survey of the participating JIIs at the conclusion of each of the 11 panels, two survivor focus groups, 
one provider dyadic interview, four phone interviews with providers, and an individual interview with a JII.

Participants. Participants included female survivors of IPV $(n=7)$, male JIIs in BIPs $(n=289)$, and BIP providers $(n=2)$. All survivors who serve as panel speakers $(N=$ 12) were contacted by the panel facilitator to ask for their consent to share their contact information (phone numbers or emails, at their discretion) with researchers. Of those who consented to be contacted $(n=10), n=7$ speakers ultimately participated in survivor focus groups $(k=2)$.

The sampling frame for JII focus groups included all panel attendees between August 2016 and January 2017. Of the three panels that were held in this time period, approximately 40-50 attendees were invited to participate. Recruitment activities included announcements and flyers shared at the end of each panel to schedule participants in person, but these efforts failed for the majority of the panels. Only two panel attendees shared their contact information to consent to participate in a focus group, and although both were scheduled for a dyadic interview, one attended and an individual interview was conducted $(n=1)$.

Program staff were recruited by making announcements to all BIP providers in attendance $(n=11)$ at local professional meetings between July and October 2016 . Scheduling availability for focus groups proved to be a large barrier to participation, so only one dyadic interview was scheduled with providers $(n=2)$ and other providers participated through informal phone interviews $(n=4)$.

Demographic information was collected from participants who completed formal 
interviews. This information is presented in Table 3.1 for survivors (focus groups: $k=2$, $n=7$ ) and described here for providers (dyadic interview, $n=2$ ) and a JII (individual interview). Demographic information was not collected from the male JIIs $(n=289)$ who attended one of 11 IPV impact panels or the providers $(n=4)$ who participated only through informal interviews instead of focus groups.

The JII who participated in the interview was 37 years old and identified as male and White/Caucasian. He was married, with a relationship length of 10 years, and had three children. His highest education level completed was some college/trade school and he was currently employed. He indicated he had three prior arrests, was currently enrolled in a BIP, and had been in the program for 11 months. The interview took place two weeks after he attended the impact panel.

One participant in the provider focus group identified as female and the other as male. Their mean age was $53.5(S D=0.71)$ and both identified as White/Caucasian. One participant's highest education level completed was their GED/high school diploma while the other's was a graduate degree. Both were currently employed as BIP providers and currently referred JIIs from their groups to the panel at the time of the focus group. Both wrote that they had been referring JIIs from their programs to the panel from the start of the panels.

Procedure. Archival survey data collection. Archival survey data was collected from JII panel attendees by panel facilitators over a period of two years (2009-2011). The survey (or "feedback form") was developed by staff who originally facilitated the panel, with a slight adjustment in the wording of one item across the two-year period of data 
collection that differentiate two versions of the forms (A and B) used during this time.

The form does not utilize any validated scales and the theoretical basis of the decision to include items for each version of the feedback form is not known; therefore, we utilized the version with the largest number of responses. Each form contained eight quantitative items (see Table 2) that participants rate their agreement with on a five-point Likert-type scale from "No" (1) to "Extremely" (5), and two qualitative open-ended questions regarding how the panel might influence their choices and behavior in relationships and how the panel might be further improved. The feedback forms were designed as postpanel evaluations to assess program outcomes for individual participants. Feedback forms were administered immediately after panels concluded and were collected by panel facilitators in return for a receipt for attending the panel. JIIs were instructed by panel staff to respond to the questions honestly to give their feedback on the panel and help panel facilitators improve the process for future panels.

Focus groups and interviews. Focus groups and interviews were conducted in order to gather a variety of responses from stakeholders regarding their perceptions and experiences of the panel and of the perceived impact of the IPV impact panel on JIIs. Participant observation and consultation with stakeholders identified the following groups as likely to hold varying important pieces of information about the panel process: panel speakers (survivors), panel attendees (JIIs), and BIP providers (referring sources for panel attendees). The focus group script included six questions in a funnel format (Stewart \& Shamdasani, 1990), narrowing from the first question "What is the panel like for JIIs?" to the most specific final question "What unique contribution (benefit or harm) 
do panels give JIIs?”

The scope of qualitative data included in the analysis was also widened to increase confidence in the study findings through additional sources of data saturation (O’Reilly \& Parker, 2012) and sources for triangulation (Denzin, 1978). Therefore the final qualitative analysis includes focus group transcripts (survivors), a dyadic interview transcript and notes from informal phone interviews (BIP providers), and an individual interview transcript and brief responses to open-ended questions on panel surveys (JIIs).

Formal interviews (focus groups, dyadic interviews, and the individual interview) were conducted with participants over a 90-minute period and in familiar settings for participants when possible, as commonly recommended (Morgan \& Krueger, 1993; Stewart \& Shamdasani, 1990). All formal interview participants were given $\$ 25$ gift cards and $\$ 5$ cash transportation compensation at the beginning of the interview and provided light refreshments as compensation for their participation.

Analysis. Quantitative analysis. Quantitative responses $(n=289)$ to feedback forms were analyzed regarding JIIs' self-reported perceptions of how the panel impacted them. Descriptive statistics were calculated for JIIs' responses to the feedback form items to examine which items were ranked higher than others on average, which items were responded to in greater variation than others, and which items were strongly correlated with one another. Slight variations in the wording of two items on the feedback forms by a single word ("The presentations helped me understand the long-term effects of [my] abuse of others"; presence or absence of the word indicated in brackets) were analyzed in terms of Cronbach's alpha (1951) to determine the scale reliabilities and whether findings 
could be reported in aggregate across all feedback forms.

Qualitative analysis. An inductive content analysis (Elo \& Kyngäs, 2008) was conducted to determine what themes were evident in the qualitative data regarding the perceived impacts of the panel on JIIs. Specifically, this analysis was conducted on the qualitative data obtained from JIIs' responses to open-ended questions on the feedback forms and the responses from survivors, JIIs, and BIP providers in the formal or informal interviews and focus groups.

The first author developed a codebook and coded the data based on her extensive experience in the panel setting (Sackett, 2017). Feedback on the codebook and codes was obtained from several members of the authors' research team to increase the perspectives and multiple interpretations of the codes and associated text. Codes, definitions, and sample references assigned to each code were shared with the authors' research team of two undergraduate research assistants, four graduate students, and the second author (the faculty advisor of the first author). Team members reviewed the content and structure of the codebook and discussed the codes in an hour-long meeting to surface the first author's blind spots and assumptions about her understanding of the data to inform the analysis and presentation of the findings below.

JII perceived impacts were identified by coding qualitative data sources (notes from informal interviews with BIP providers, JII feedback form open-ended responses, and interview/focus group transcripts with survivors, BIP providers, and a JII) using NVivo software. In order to better understand how panel impacts were meaningfully linked by participants across sources, a conditional analysis of the interdependent co- 
occurrence of group-endorsed themes was conducted for the perceived panel impacts on survivors and on JIIs. Two matrix queries searched for "near" content (within 50 words) in selected nodes for these categories of codes. Themes were compared for consistencies or convergence across groups and nested within the perspectives of each group (Hughes \& DuMont, 1993). Inconsistencies across themes were also examined to consider the interplay of individual- and group-level coding for a more comprehensive analysis (Morgan, 1988).

\section{Findings}

Positive panel impacts on JIIs identified across data sources were connection with speakers, reaching new understandings, and emotional impact and intent to change. The primary negative panel impact on JIIs identified was panel rejection. Codes within each of these categories of impact, with frequency counts of their coded text units and the participant perspective (survivor, JII, and/or BIP provider) that endorsed each code, are listed in Table 3.2.

Positive panel impacts. Connection with speakers. In order for any of the subsequent categories of impact to be possible, JIIs must first connect in some way with the speakers. This process includes lowering their defenses that many bring into the setting and relating to speakers.

For some JIIs, their conceptions of the panel change throughout the panel process, as they see that their expectations of antagonism and irrelevance are not met and that the process is instead not confrontational and they are not met with judgment from the speakers. They become more comfortable with the process as the panel unfolds and lower 
their defenses, decreasing any resistance to the process, and engage more openly with the speakers and the process. Some JIIs feel safe and supported by the panel and perceive the environment as friendlier than they expected after the panel begins. The JII who was interviewed said that this was a pleasant surprise. "This was more of, just, kind of an open conversation, so...I actually appreciated that."

Lowering defenses or decreasing resistance is facilitated by listening to speakers who are not their direct survivors or listening to other men in the BIP group discuss the panel. An informal interview with a JII who attended the panel months prior to this conversation explained that "to hear that from not the person I had abused was helpful." Speakers notice what happens when JIIs relax after their defenses lowered, as one explained during a focus group:

Once they figure out we're not there to make them responsible for our pain, and they can relax a little bit, they can allow themselves to be a little more sensitive and to talk about things that they're embarrassed about talking about, their secrets.

In an example of a connection recently made with two JIIs after a panel, another speaker alluded to the men's decision to allow themselves to connect and lower their defenses in that moment. Referring to a moment of connection made during the panel, she explained, "I think when people reach that moment...they have a decision to make. Am I gonna shut back down? Or am I gonna go ahead and just let these feelings happen and think about things a little differently next time.” Providers also see that JIIs lower their defenses during the panel in their BIP group debriefing when a JII returns from a panel. One provider described this process as relieving for JIIs, saying, “They talk about the relief that these women did not do any of those things... which is also...quite disarming, 
actually, of them... That's a common thing I hear afterwards, is one of the surprises, is how non-angry these women are.” Recognizing speakers' comfort with the panel process can also be disarming, as one JII expressed during an interview. Seeing that speakers are stable and comfortable participating on the panel and interacting with JIIs in that setting for the duration of the panel was extremely surprising to him. He said, "I felt like they were okay with us being there...I didn't really feel like they were scared, or intimidated, or like they held any kind of resentment against us...which, I kind of- I guess I almost expected that."

JIIs also expressed that they were bothered by their perception of audience resistance or disengagement, as they themselves were engaged and expected others to do so as well. The JII who was interviewed said that he felt frustrated and distracted by the behavior of another man in the audience when he attended the panel. He explained, "There was a guy in front of us that kept falling asleep, it was a little distracting...and frustrating...I thought it was kind of rude." This disapproval is expressed out of a sense of respect for the speakers and possibly the belief that other audience members should be striving to connect with the speakers.

The JII who was interviewed also explained that details from the speakers' experiences helps him find connections between his experience and their stories, and said that more details would be helpful to hear to facilitate those connections and "the relatability" of their experiences. Other JIIs state how they related to the speakers' stories in their written comments on the feedback forms, such as one who wrote "I really related to [Speaker's name]'s story tonight - I had done many things she said her husband did." 
This can create a sense of intimacy or relationship with speakers during the panel, as one provider described, as the panel creates opportunities for more intimate connection or relationship with the speakers in a way that is very personal, more than is possible in other settings or interactions. This provider explained, "The question and answer part is very important" during the panel because the interactive nature of the panel at that point “makes it more intimate...It's not just you detached, listening, where you can hide out." In other words, interacting with speakers during the question and answer session personalizes the process and makes it so that JIIs cannot "hide" their selves from the speakers in those moments.

Reaching new understandings. The panel appears to lead some JIIs to reach new or deeper understandings of the material covered in the panel, such as the impact of abuse. These realizations can come from considering the experience of abuse in the speakers' lives or in the lives of their own victims. Although new or deeper understandings of abuse are desired impacts on JIIs, some audience members might not make any new or further realizations or understandings as a result of attending the panel. One JII indicated that he had not reached any new insight, writing on a feedback form, "How I spe[a]k to people. I don't see a way to make it bett[e]r."

JIIs' responses to feedback forms can show how they reach some of these new insights or understandings. JIIs express how they are considering their victim's point of view in various ways during the panel, such as how their victim was affected by their actions. One JII wrote that the panel "made me think back to the way I treated my family." Another JII wrote in his feedback that the panel "really makes me think about the effects 
on my children." Feedback form responses also show that JIIs are wrestling with thoughts or questions during the panel and that they need time to cognitively process what they are experiencing during the panel. A JII expressed this need in his feedback, writing, "I need to think about this. I need time.” Another JII wrote notes on the back of his feedback form illustrating his thought process during the panel and consideration of whether a question would be appropriate to pose or not to the speakers. He wrote, "If I ask? Did the guy who committed suicide's parents blame you [Speaker's name] for the death is that wrong?"

Some JIIs also perceive the panel and the impacts of abuse described by speakers as more realistic, "real life," or serious than other settings for sharing this information, such as in BIP groups. Comments that indicated this perspective focused on the word "real" or the phrase "taking it seriously." Providers described how the panel is different than a BIP group or other intervention programs and surfaced this perception in the dyadic interview. One provider explained that contrary to a video of similar content, with the panel "you're in the room with that voice. It's not a piece of paper, it's not on the screen, it's a real person sharing this effect." A second provider endorsed this perception as well, saying the experience for JIIs is "something different than hearing it just from their facilitator." JIIs also endorsed this perception themselves, usually in written comments on the feedback forms. One JII wrote "Hearing from the victim brings empathy to reality." A second JII's feedback response emphasized the realness of the speakers in the panel's influence: "Listening to real life people in person could only have a very strong influence on anyone.” The impact was clarified in a third JII's written 
feedback, "The topics they have brought up were very impactful and help make things very real."

JIIs' new understandings can be reinforced by seeing their own experience of the panel reflected in others' experiences of the panel, such as similarities in how they experienced the panel and how men in their same BIP group experienced the panel. During the interview with a JII, he described the debriefing process in his BIP group as such an experience for him. Multiple men from his group had attended the same panel with him, and he said that when they discussed it back in group, "the way that I felt was pretty much what I heard from everybody. Um, I know that a lot of the guys really- it resonated, when [Speaker's name] said that, you know, like, her partner wanted help for them."

As can be seen in the BIP group debriefing, among many other processes, the panel's impact on JIIs mingles with the impact that their BIP group and other experiences have on them. The impact from the panel is connected to other previous or ongoing work the JIIs engage in, such as the BIP group, counseling, 12-step self help groups (e.g., Alcoholics Anonymous), or other experiences. A provider describes this mingling metaphorically, explaining that "Seeds that are planted for them in the group are watered and nurtured by the panel, the panel plants some additional seeds and then in the group those get watered." This provider explained that the panel is a vital enhancement to the group process. As a standalone experience it would be important, but together with the BIP group she said it is really vital, because either one alone is not enough to do the work from her point of view. This mingling could also be seen in JIIs' responses to the 
feedback forms, as one wrote: "This presentation reinforced what I have been learning." Another explained, "It puts a face to all the knowledge we've gotten." These comments imply that they have already been working on understanding the impact of abuse or other material covered by the panel, and that rather than introducing this material for the first time, the panel facilitates further understanding.

Dimensions of new understanding. The quantitative responses from JIIs on the feedback forms provide further insight and nuance into how JIIs reach new understandings about the impact of abuse from the panel (see Table 3.3). The highest ranked items with the least amount of variation that were that the panel helped them understand the long-term effects of abuse on others $(M=4.17, S D=0.95)$, understand what survivors of domestic violence experience $(M=4.16, S D=0.93)$, and understand how their verbal and emotional abuse harmed their victims $(M=4.10, S D=0.91)$, indicating that JIIs generally agree substantially (the scale anchor corresponding to a value of 4 is "quite a bit") with these statements. Understanding how physical abuse harmed their victims was less endorsed and with greater variation $(M=3.85, S D=1.00)$ than most of the other statements. An item referring more generally to the panel changing how JIIs think or feel about domestic violence had the lowest mean response and highest variation $(M=3.81, S D=1.12)$. This is not surprising, as the generality of this item implies that the panel has unique or overarching reach regarding this impact, when in reality this process is taking place in the context of other intervention programs that are also designed to influence JIIs' thinking on this subjects. All items were significantly correlated with one another, with seven of the eight items strongly correlated $(p<.001)$ 
with coefficients ranging from $r=0.54$ to $r=0.73$ (see Table 3.4). The largest correlation in magnitude was between the top two mean-ranked items: "The presentations helped me understand the long-term effects of (my) abuse of others" and "I feel more understanding about what survivors of Domestic Violence experience." All other correlations between items, excluding the item assessing a behavioral intention, were large, ranging from $r$ $=.48$ to $r=.65$, and highly statistically significant $(p<.001)$. The lowest correlations were still statistically significant, with all at an alpha level of $p<.001$ except for one at $p$ $<.01$, but were moderate in magnitude, ranging from $r=.22$ to $r=.27$. Scale reliability estimates of all eight items showed strong internal consistency of items $(\alpha=.88)$.

Emotional impact and intent to change. Positive panel impacts on JIIs also include emotional processing and impacts that relate to intention to change or actual changes they make following the panel. JIIs who lower their resistance can become emotional or uncomfortable at the panel, which could be a result of their listening and being troubled by what they hear and how it relates to their own behavior. JIIs feel uncomfortable during the panel, experiencing emotional or other discomfort sitting in the audience or participating in the panel, but this discomfort contributes to the panel impact of healing. For example, some JIIs wrote in their comments on feedback forms that "It was good but hard to see the feelings on [Speaker's name] and [Other speaker's name]'s face" and "Discussing the effects on children is very helpful, painful, but very effective." This discomfort is a beneficial impact of the panel on JIIs according to one of the providers in the dyadic interview, who explained, "Part of what my challenge is, without traumatizing the men or punishing them...can they sit with a little dis-ease. And, honestly, 
I think potentially the survivor panel is one of the most real ways you can do that."

Sitting with discomfort can lead JIIs to feel humbled or sobered, as JIIs show humility or solemnity or indicate that they feel bad, troubled, or sad about their behavior. A JII expressed humility in his written feedback form comments, saying, "Thank you for allow[ing] me to be present." Another described the panel's impact in the feedback forms as "It really gave me the chills. Made me feel bad about what I have done." In the interview, one JII connected the importance of feeling uncomfortable during the panels to sitting with this dis-ease, as he described the difficulty of realizing how long the speakers' experiences of abuse have continued to affect them and how likely it is that his abuse toward his wife will affect his daughter much longer than he anticipated. "And so that's, like, [pause, sighs] I mean, it makes me sad...for me at least, it's just, you know, knowing that I did those things, um...I would say it's- it's hard to hear, but I need to hear it."

Even as JIIs sit with their discomfort, they feel supported by the panel process, due to the panel environment, the attitude from the speakers, or by having other men in the audience with them to go through the panel together. One JII wrote on a feedback form that "It is very helpful to be in an intimate setting to discuss matters so close to home." In the interview, another JII explained that the overall attitude he got from the speakers made him feel supported during the panel, that it was "okay" and that the speakers almost seemed to appreciate the JIIs for being there. He also had other members of his BIP group attend the panel with him and he said that they all sat together during the panel and that was also supportive.

JIIs feel hopeful about themselves or the future after attending the panel. On 
feedback forms, JIIs wrote "I liked the message of hope at the end" and "I foresee positive self-growth for myself." A provider explained how she thinks JIIs get this hope, as they see that somebody can be hurt without wanting to hurt someone else back (in this case, the JIIs in the audience), which gives them hope for their own potential to change. JIIs also recognize and appreciate moments when speakers show compassion for their abuser. In the interview, a JII said that one of the aspects of the panel that he most appreciated was one speaker's story in "how she shared about the abuse that her husband did to her and, um, how that made her feel and her feelings of wanting help for her husband. Um, [LONG PAUSE] just, for my experience, that was helpful to hear.”

JIIs also express a willingness or intention to change after attending the panel. On a feedback form, one JII wrote simply "I need to change myself." JIIs also express plans or future intentions for how they will use this experience or how the panel will influence their behavior in the future. A JII wrote on his feedback form about the panels that "They are going to help me be not abusive.” Other JII feedback form responses listed more specific plans, such as "won't mistreat my children, will be part of their lives more now," "I feel like I will try to empathize more in my relationships," "Try to understand how others might feel," and "I will pay more attention to my choice of words and how they might impact others."

Some JIIs reach new levels of responsibility or accountability following their panel attendance. A provider in an informal interview gave an example of how the panel led to an increase in her group member's accountability, explaining that he admitted after the panel that he had done something to his partner that he had never admitted before to 
her as a provider or in the group to the other men. She said he disclosed committing a very violent, damaging form of physical abuse to his partner at a time when she was in a very vulnerable position, which paralleled the experience of one of the speaker's on the panel that he attended. She said that the panel was transformative for this man and that "this really was a turning point for him, he became more serious and it really changed him.” Another provider agreed that the panel can get JIIs to take things more seriously, adding that she saw changes once they became more serious like JIIs not tending to blame their victims as much after attending the panel.

Negative panel impact. Panel rejection. Rarely, a JII explicitly and actively rejects the panel after it concludes. This is most commonly seen in written comments on the feedback forms after the panel. Comments that indicated panel rejection included writing that the panel was "garbage" or "just a man bashing session" on feedback forms. Providers confirmed that some JIIs do not reach any new understandings and do not seem to relate to, connect with, or find things in common with any of the speakers, instead maintaining their panel resistance. A provider explained that not everyone gets to a point where they can relate to what the speakers are sharing, instead, "Some are like 'That could never be me, I would never do that." Another provider shared his concern in the dyadic interview that certain types of content that speakers share may prevent JIIs from relating to their experiences. The provider explained:

Sometimes when they have panelists who are like, it's all super severe, worst forms of domestic violence, um, or physical violence I should say, is- a lot of the men will then...they just shut them off, 'cause it's like 'I never did that. I'm not like that.'...And so it's easy for them, if the stories get extreme, for them to distance themselves. 'He sounds like a real asshole' and 'No wonder she, you know, but mine wasn't...' 
In some cases, JIIs perceive the panelists as practiced, overly rehearsed, or not sincere, which may also contribute to panel rejection. For example, in response to final open-ended question on the feedback form asking for ways to improve the panel, one JII's suggestion was to have speakers who are "not quite as practiced in telling their respective stories." A provider shared this perception when describing how JIIs that they have referred to the panel responded when they returned to the BIP group, "I've heard comments in the past about 'She seemed new, she seemed very polished', and I do think that if it feels too smooth, it feels like you're at a, you know, at a motivational speaker."

JIIs who remain resistant to the panel throughout the process are the hardest group to make inferences about, as they are not likely to volunteer to participate in follow-up interviews or stay after the panel concludes to engage the speakers or others in conversation. Provider accounts are the primary means of understanding this group, based on their understanding of the men when they return to their BIP groups and debrief with the providers.

\section{Discussion}

Findings from this multi-method study demonstrate a range of impacts on JIIs of surrogate impact panels for IPV from the perspectives and experiences of survivors, JIIs, and BIP providers. Impacts on JIIs were grouped into themes of connection with speakers, reaching new understandings, emotional impact and intent to change, and panel rejection.

\section{Contributions to the literature on IPV surrogate impact panels. Our findings} are consistent with the anecdotal evidence reported from an interview with the program director of another impact panel for IPV (Burkemper \& Balsam, 2007). Similar to the 
positive outcomes reported by that program director, JIIs' increased understanding of the impact of IPV was a common theme found in the current study. In addition, this study extends the known positive impacts of the panel on JIIs with evidence that the panel process also leads to healing for JIIs (e.g., feeling humbled or sobered and expressing intention to use the panel experience to further their process of change). We also found more specific ways that impacts consistent with those found in Burkemper and Balsam's (2007) study seem to occur for JIIs. For example, JIIs' increased understanding of the impact of abuse included perceiving the panel content as more serious or "real" in comparison to other settings that delivered similar messages (e.g., BIP groups).

Comparisons are more difficult to make between the current study and another published study of IPV impact panels (Fulkerson, 2001). In general, positive evaluations of the impact panels were found for some participants in both the current study and Fulkerson's study. Both studies also found that not all JIIs appreciated or seemed to benefit from the panel process, as seen in a follow-up interview with one JII who said that the panel did not change his attitude and was not beneficial (Fulkerson, 2001) and JII resistance to or lack of engagement with the panel process in the current study.

Finally, findings were also quite consistent with those of the most recent evaluation of impact panels for IPV (Zosky, 2018). Although the panel process itself differed in the current study compared to this evaluation, both studies found the panel to increase JIIs' awareness of the impact of IPV on survivors and children. The high number of references of appreciation for the panel found in JII feedback forms in the current study was paralleled in the majority of participants viewing the panel as beneficial in 
Zosky's study. The theme of emotional impact and intent to change identified in the current study were also consistent with the grounded theory findings of Zosky's study, particularly JIIs' statement of emotion, commitment to learn and be accountable, and commitment to change. In contrast to Fulkerson's (2001) and Zosky’s (2018) findings that awareness and empathy for the victim were commonly named by JIIs as positive outcomes of panel participation, increased empathy was not found to be a primary panel outcome for JIIs in the current study.

Differences between Fulkerson's (2001) findings and those of the current study could be due to differences in the time frame of data collection for the two studies. The impacts found in the current study thus focus more on proximal effects during, immediately after, or soon after the impact panel process, whereas the outcomes described in Fulkerson's study could be more distal outcomes (e.g., empathy) that participants believed the panel contributed to over time. Fulkerson also compared JII recidivism rates between those who did and did not participate in the panel and found no differences, which is a more distal outcome than was possible to measure or considered a meaningful indicator of the panel's impact on JIIs in the current study.

Potential differences in the panel process between these three studies could also explain the discrepancies in the studies' findings. One key difference between Fulkerson's (2001) study and the current study is that after volunteering and consenting to potentially participate in an impact panel, not only JIIs but also survivors were randomly assigned to engage or not engage in the panel process. It is not clear whether assignment to the impact panel condition for survivors meant that they themselves were 
then speaking on the panel or if they were listening to a panel (as JIIs likely were). In either case, the survivors' experiences in that study were likely very different than the experiences of survivors in the current study, and this in turn likely affects how JIIs experience the panel and the impacts of attendance on them. Notable differences between the panel process examined in the current study and the panel studied by Zosky (2018) that could account for some discrepancies in findings include the difference in timing of when JIIs participated in the panel (i.e., not all had completed at least 26 weeks of BIP attendance before the panel) and the lack of direct interaction through a question and answer session between the speakers and audience members.

Contributions to the literature on restorative justice for IPV. Findings from these multiple sources and methods related to existing theory and models of restorative justice processes in interpretable ways that further illuminate consistencies and inconsistencies between restorative justice theoretical models and real-world program practices. The current study's findings were largely consistent with those of a case study of a restorative justice dialogue for an IPV case between a survivor and JII from the same relationship (Miller \& Iovanni, 2013). The case study found some promising potential benefits of restorative justice processes for IPV, such as having temporal distance from the crime(s), which allowed the participants to process their experiences, begin to heal, and to accept responsibility (on the part of the JII) before engaging in the dialogue process. Temporal distance was also found to be beneficial in facilitating the IPV impact panel process of the current study. JIIs are required to complete at least 26 weeks of a BIP group before attending an IPV impact panel, in order for them to begin moving 
through their process of change and decreasing their resistance to the material covered in the panel. Providers and the JII who was interviewed indicated that it is helpful for JIIs to go to the panel after some time in the program so that they are less resistant to the panel process and more likely to be impacted by the panel. In the case study (Miller \& Iovanni), the JII expressed remorse during the dialogue, expressed a commitment to behavioral change, and said he felt transformed by participating in the dialogue and grateful for the opportunity to try to help his victim heal from the abuse. Although the IPV impact panels do not involve individuals from the same previously abusive relationship, similar themes to the dialogue's benefits were found in the current study. Similar to the JII's remorse expressed during the post-conviction dialogue, JIIs in the current study expressed disapproval of abusive behavior, a desire to change, an intention to use this experience in the future, felt uncomfortable and humbled/sobered, and saw the panel content as more serious and "real."

The current study's findings were more consistent with a study of survivor advocates' perceptions of the use of restorative justice as a response to gendered violence in Australia (Curtis-Fawley \& Daly, 2005). Some advocates believed that restorative justice could potentially address the power imbalance between JIIs and survivors by prioritizing survivors' voices and experiences while facilitating JIIs' acknowledgment of their violence and their responsibility for it, potentially aiding in survivor healing. The IPV impact panel seems to facilitate some JIIs' acknowledgment of the impact of abuse and their responsibility for their abusive behavior by having them listen to surrogate survivors, with whom they can lower their defenses, make connections with, reach deeper 
or new understandings, and promote healing and change.

Limitations. Although the findings and implications described above suggest that IPV impact panels have promising impacts including healing and reaching new understandings for JIIs, there are several ways in which these findings are limited. First, the exclusive focus on the perceived impacts on JIIs alone, rather than on survivor participants, presents an incomplete picture of the potential merits of this restorative justice program. Although this program of research includes a qualitative study of the perceived impacts of panels on survivor speakers (Sackett Kerrigan \& Mankowski, 2020b), the evidence presented in the current study regarding the possible benefits of the panel for JIIs is limited in describing the value of this survivor-centered process. In addition, selection effects of panel and study participation mean that the data obtained in the study, even from multiple sources with multiple methods, captures only certain perspectives of IPV survivors, JIIs, and BIP providers. Given that typical rates of BIP drop out tend to range between $40 \%$ and $60 \%$ of JIIs mandated to attend these programs (Eckhardt, Murphy, Black, \& Suhr, 2006), the screening period for JIIs of completing at least 26 weeks of BIP groups before attending the panel means that only those who have not dropped out by that point in the program are actually referred to attend the panel. The JIIs who were willing to participate in a focus group and the single one who arrived to be interviewed thus represent an even smaller group of JIIs who experienced the IPV impact panel. Selection effects similarly constrained the range of perspectives and data gathered from BIP provider and survivor participants. Providers' extremely limited availability prevented multiple focus groups or a larger single focus group from being conducted 
about their experiences. Although speakers had the highest response rate of the three types of participant samples in this study, limited availability prevented two speakers from participating and an additional two speakers in the pool of panel participants did not respond to any study recruitment messages. The perspectives of survivors in this study therefore differs from others who have either not heard about the opportunity to speak on a panel or have chosen not to do so.

One key theoretical limitation based on the current practices of this specific community intervention program is the conditions under which JIIs participate in the IPV impact panels. Currently, JIIs are required by participating BIPs to attend a panel in order to meet requirements set by their POs. However, restorative justice theory emphasizes that restorative justice practice ideally takes place between individuals who are all entering the process voluntarily and with genuine openness and willingness to engage in the process, and that the voluntary nature of participation in restorative justice processes is especially important for survivors (Cheon \& Regehr, 2006). Although JIIs are required to attend the impact panels, a mandate from POs that is enforced by BIP providers, there were no recorded instances of POs or BIP providers enforcing monetary or other consequences if JIIs failed to attend the panel by the time they completed the program. Therefore, meeting this requirement of panel attendance could be considered somewhat, though not completely, voluntary on the part of JIIs. Nevertheless, this partially voluntary or involuntary condition of JII participation limits the extent to which findings from the current study may be transferable (Lincoln \& Guba, 1985) to other restorative justice programs. 
The survey data utilized in the archival analysis of feedback forms are also limited in several ways. The single time point at which this data was collected (i.e., after panel participation only) means that average ratings of JIIs' impression of the panel and variance between their responses may not indicate differential influences of the panel alone, but rather other pre-existing differences between JIIs not measured in the survey. Therefore, JIIs' feedback form responses were carefully weighed against data gathered through other methods and sources in this study to make interpretation as comprehensive as possible. Although JIIs' responses to the feedback forms provided some insight into their experience of the panel, they may also have highly endorsed most of the quantitative items or written positive impressions of the panel and its impact in response to the openended questions because of a desire to appear favorable to the panelists or the panel facilitators. The conditional withholding of payment receipts that prove panel attendance for JIIs until they turn in a completed feedback form could also influence a conscious or sub-conscious decision to rate the panels more favorably, as JIIs need to receive this receipt as evidence of their panel attendance for their BIP providers. This could potentially impact the trustworthiness of responses gathered from these sources, although the triangulation of information that was possible through the research methods (Denzin, 1978) mitigates some of that concern.

Future aims. Findings from this study will be used to generate hypotheses about the panel's impact on participants for further testing with quantitative methods and contribute to the creation of survey items (Morgan, 1988) for ongoing evaluation of the IPV impact panel. Utilizing information gathered through this study's multiple sources 
and methods could reduce potential sources of error in future research, such as specification error through omitting relevant constructs or domains of experience that may or may not be predicted by existing restorative justice theoretical models. Increasing the amount of information known about the process of IPV impact panels and their perceived impact on survivors and JIIs through panel participants' voiced understandings of their own experiences (Morgan, 1988) could increase the likelihood of measuring relevant domains in future studies.

The study design yielded data that inform current theoretical understandings of restorative justice processes and highly ecologically valid results relevant to this specific context of IPV intervention. The combination of data collection methods, sources, and analyses generated rich information, the analysis of which that involved not only inductive processes via participant contact but also deductive processes of engaging with theory (Morgan, 1988). Turning to the direct source of a program's participants, in this case the survivors and JIIs who participate in the IPV impact panel, effectively specified salient activities, interactional processes, and perceived impacts of the panel on survivors and JIIs, can be used in future studies to measure and improve ongoing efforts to effectively deliver this community-based intervention (Morgan, 1988).

Follow-up studies could further evaluate the indicator outcomes specified by study participants. Such studies could focus on several additional research areas beyond the scope of the current study, such as antecedents like JII characteristics that may predict how JIIs differentially participate in and are impacted by the IPV impact panel. Studies could also focus on uncovering more specific mechanisms through which panel processes, 
perceptions, and impacts are inter-related for both survivor and JII participants (e.g., in a process and outcome model of the impact panel).

A follow-up longitudinal quasi-experimental study using random assignment or matching of JIIs who do and do not participate in an IPV impact panel would be useful to further to assess the processes and impacts of the panel identified in this study. Longitudinal follow-up studies would also help determine how the proximal processes and outcomes identified in the current study relate to longer-term, distal outcomes for survivors and JIIs, such as JII remorse and living free of violence. Promising results could illuminate the proximal and distal processes of change for survivors and JIIs and guide the development of more comprehensive, coordinated responses to IPV that include restorative justice programs for IPV prevention and intervention. 
Table 3.1

Demographic Characteristics of Survivor Focus Group Participants

\begin{tabular}{|c|c|}
\hline Variable & Sample $(n=7)$ \\
\hline Mean age $(S D)$ & $48.4(14.8)$ \\
\hline \multicolumn{2}{|l|}{ Ethnicity $(\%)$} \\
\hline African American & 0 \\
\hline Caucasian & 85.7 \\
\hline Hispanic/Latino & 14.3 \\
\hline Other & 0 \\
\hline \multicolumn{2}{|l|}{ Marital Status (\%) } \\
\hline Single & 28.6 \\
\hline Living together & 42.9 \\
\hline Married & 28.6 \\
\hline Separated & 0 \\
\hline Divorced & 0 \\
\hline Mean relationship (years) $(S D)$ & $4.3(2.9)$ \\
\hline \multicolumn{2}{|l|}{ Education (\% highest completed) } \\
\hline Some high school & 0 \\
\hline GED or high school diploma & 28.6 \\
\hline Some college/trade school & 28.6 \\
\hline College degree & 28.6 \\
\hline Some graduate school & 14.3 \\
\hline Graduate degree & 0 \\
\hline Currently employed $(\%)$ & 57.1 \\
\hline \multicolumn{2}{|l|}{ Length of time participating on panels (\%) } \\
\hline 1 year & 28.6 \\
\hline $2-3$ years & 42.9 \\
\hline $3-5$ years & 0 \\
\hline $5-10$ years & 0 \\
\hline $10-15$ years & 28.6 \\
\hline \multicolumn{2}{|l|}{ Number of panels participated as a speaker $(\%)$} \\
\hline $1-3$ & 28.6 \\
\hline $4-5$ & 28.6 \\
\hline 10 & 14.3 \\
\hline $40+$ & 28.6 \\
\hline \multicolumn{2}{|l|}{ Panel referral source $(\%)$} \\
\hline DVSD & 28.6 \\
\hline Advocate/advocacy organization & 0 \\
\hline Counselor/counseling organization & 28.6 \\
\hline Other & 42.9 \\
\hline
\end{tabular}

Note. Other panel referral sources were being "asked to speak," "asked to join by participant," and referred by the local county website. 
Table 3.2

Key Panel Impacts on JIIS

\begin{tabular}{|c|c|c|c|}
\hline Theme & Code & Sources $^{\mathrm{a}}$ & Frequency $^{\mathrm{b}}$ \\
\hline \multirow{5}{*}{$\begin{array}{l}\text { Connection } \\
\text { with speakers }\end{array}$} & JII relates to speaker & All (S/J/P) & 58 \\
\hline & JII lowers defenses & All (S/J/P) & 21 \\
\hline & JII does not relate to speaker & $\mathrm{J} / \mathrm{P}$ & 9 \\
\hline & JII recognizes speaker comfort with panel process & $\mathrm{J}$ & 4 \\
\hline & $\begin{array}{l}\text { JIIs feel sense of relationship or connection with } \\
\text { speakers }\end{array}$ & $\mathrm{J} / \mathrm{P}$ & 2 \\
\hline \multirow[t]{6}{*}{$\begin{array}{l}\text { Reaching new } \\
\text { understandings }\end{array}$} & $\begin{array}{l}\text { JII reaches new or deeper understanding about the } \\
\text { impact of abuse or how they can change }\end{array}$ & All (S/J/P) & 121 \\
\hline & $\begin{array}{l}\text { JII perceives the panel content as more serious or } \\
\text { "real life" }\end{array}$ & $\mathrm{J} / \mathrm{P}$ & 37 \\
\hline & Panel impact extends and contributes to BIP's impact & All $(\mathrm{S} / \mathrm{J} / \mathrm{P})$ & 34 \\
\hline & JII takes own victim's perspective & $\mathrm{J} / \mathrm{P}$ & 33 \\
\hline & JII references speaker's comments during the panel & $\mathrm{S} / \mathrm{J}$ & 19 \\
\hline & JII later recalls details about the panel & All (S/J/P) & 12 \\
\hline \multirow[t]{10}{*}{ Healing } & $\begin{array}{l}\text { JII expresses intention to use panel experience in the } \\
\text { future }\end{array}$ & $\mathrm{J}$ & 74 \\
\hline & JII appreciates the panel experience & $\mathrm{J} / \mathrm{P}$ & 38 \\
\hline & JII becomes emotional & All (S/J/P) & 21 \\
\hline & JII feels uncomfortable during the panel & All (S/J/P) & 20 \\
\hline & $\begin{array}{l}\text { JII expresses willingness or desire to change after the } \\
\text { panel }\end{array}$ & $\mathrm{J}$ & 19 \\
\hline & JII feels humbled or sobered & All (S/J/P) & 17 \\
\hline & $\begin{array}{l}\text { JII feels more comfortable with the panel as it } \\
\text { progresses }\end{array}$ & $\mathrm{S} / \mathrm{J}$ & 16 \\
\hline & $\begin{array}{l}\text { JII reaches new level of responsibility or } \\
\text { accountability after attending the panel }\end{array}$ & $\mathrm{J} / \mathrm{P}$ & 6 \\
\hline & JII feels supported by the panel process & $\mathrm{J}$ & 4 \\
\hline & JII feels hopeful about themselves or the future & & 3 \\
\hline \multirow[t]{2}{*}{ Panel rejection } & JII rejects the panel after attending & All (S/J/P) & 6 \\
\hline & $\begin{array}{l}\text { JII perceives panelists as overly rehearsed, not } \\
\text { genuine, or insincere }\end{array}$ & $\mathrm{J} / \mathrm{P}$ & 2 \\
\hline
\end{tabular}

Note. ${ }^{\mathrm{a}}$ Abbreviations of endorsing sources are $\mathrm{S}$ (survivor focus groups), $\mathrm{J}$ (JII feedback form comments or interview), and P (BIP provider dyadic interview or unrecorded interview notes). ${ }^{b}$ Frequency refers to total number of text reference units to which the code was assigned. 
Table 3.3

Survey Items and Descriptive Statistics of Feedback Form Versions A and B

\begin{tabular}{|c|c|c|c|c|c|c|c|}
\hline \multirow{2}{*}{ Item } & \multirow{2}{*}{$N$} & \multirow{2}{*}{ M } & \multirow{2}{*}{ SD } & \multicolumn{2}{|c|}{$\underline{\text { Kurtosis }}$} & \multicolumn{2}{|c|}{$\underline{\text { Skewness }}$} \\
\hline & & & & Estimate & SE & Estimate & $\mathrm{SE}$ \\
\hline $\begin{array}{l}\text { 1. The presentations helped me } \\
\text { understand the long-term } \\
\text { effects of (my) abuse of others. }\end{array}$ & 286 & 4.17 & 0.95 & -0.63 & 0.29 & -0.72 & 0.14 \\
\hline $\begin{array}{l}\text { 2. I feel more understanding } \\
\text { about what survivors of } \\
\text { Domestic Violence experience. }\end{array}$ & 283 & 4.16 & 0.93 & -0.30 & 0.29 & -0.76 & 0.15 \\
\hline $\begin{array}{l}\text { 3. I better understand how my } \\
\text { verbal and emotional abuse has } \\
\text { harmed my victim(s). }\end{array}$ & 287 & 4.10 & 0.91 & -0.96 & 0.29 & -0.45 & 0.14 \\
\hline $\begin{array}{l}\text { 4. I feel more convinced that I } \\
\text { should stop being violent and } \\
\text { controlling in my relationships. }\end{array}$ & 279 & 4.08 & 0.98 & -0.79 & 0.29 & -0.53 & 0.15 \\
\hline $\begin{array}{l}\text { 5. The presentations were } \\
\text { helpful to me. }\end{array}$ & 287 & 3.92 & 0.91 & -1.04 & 0.29 & -0.18 & 0.14 \\
\hline $\begin{array}{l}\text { 6. I better understand how my } \\
\text { physical abuse has harmed my } \\
\operatorname{victim(s).~}\end{array}$ & 277 & 3.85 & 1.00 & -0.49 & 0.29 & -0.40 & 0.15 \\
\hline $\begin{array}{l}\text { 7. The presentation has } \\
\text { changed how I think/feel about } \\
\text { Domestic Violence. }\end{array}$ & 284 & 3.81 & 1.12 & -0.42 & 0.29 & -0.60 & 0.15 \\
\hline $\begin{array}{l}\text { 8. I am interested in } \\
\text { participating in a } \\
\text { meeting/discussion with a } \\
\text { survivor of domestic violence } \\
\text { to talk about my offenses and } \\
\text { the impact of my domestic } \\
\text { violence and verbal abuse. }\end{array}$ & 257 & 1.69 & 1.28 & 1.69 & 0.30 & 1.75 & 0.15 \\
\hline
\end{tabular}

Note. Survey items rated on a five-point scale of 1 (No), 2 (A little), 3 (Yes), 4 (Quite a bit), 5

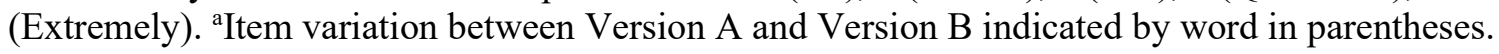




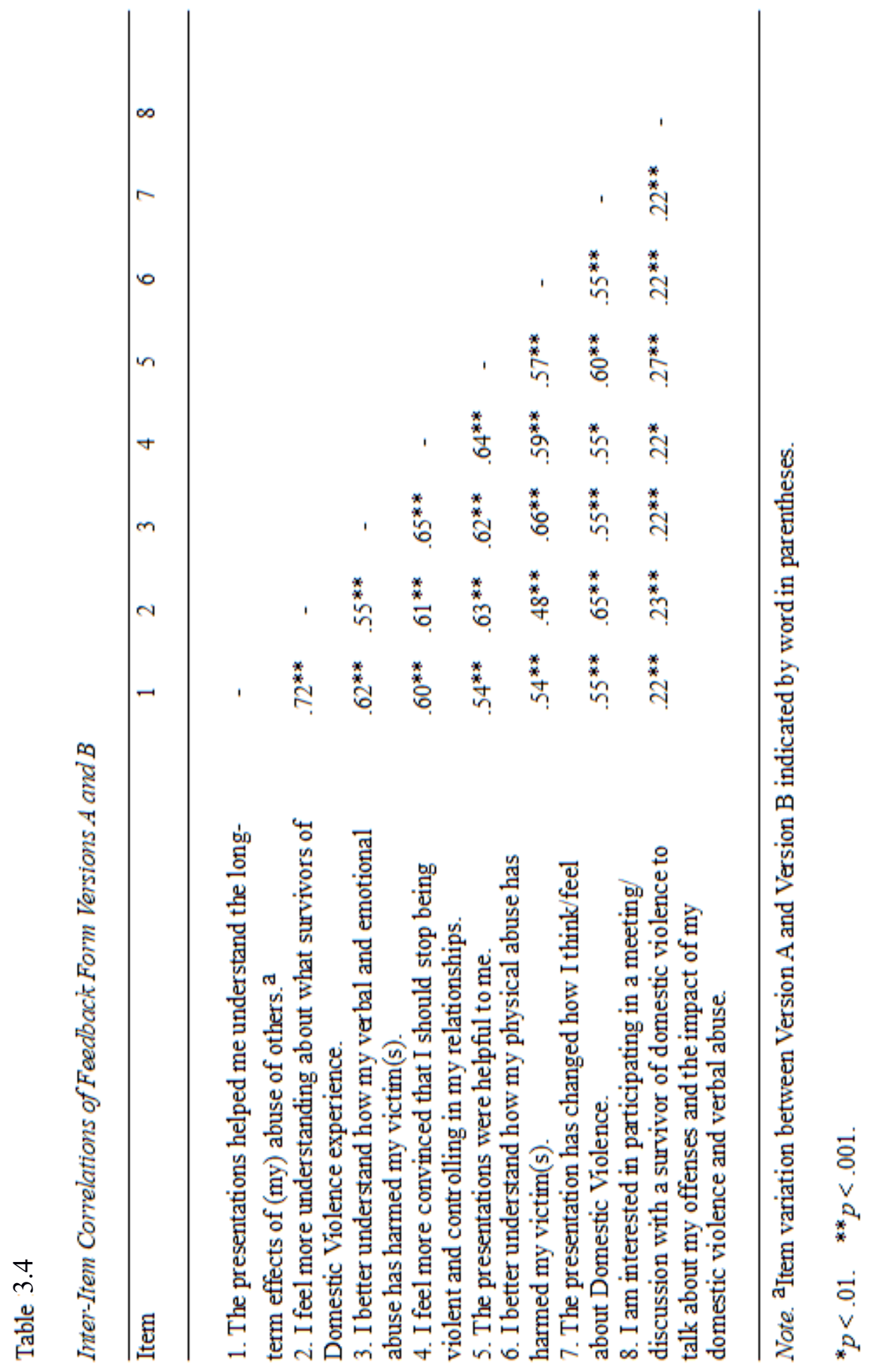




\section{References}

Babcock, J. C., Green, C. E., \& Robie, C. (2004). Does batterers' treatment work? A meta-analytic review of domestic violence treatment. Clinical Psychology Review, 23, 1023-1053.

Bandura, A. (1971). Social learning theory. New York: General Learning Press.

Black, M. C., Basile, K. C., Breiding, M. J., Smith, S. G., Walters, M. L., Merrick, M. T.,...Stevens, M. R. (2011). The national intimate partner and sexual violence survey (NISVS): 2010 summary report. Atlanta, GA: National Center for Injury Prevention and Control, Centers for Disease Control and Prevention.

Burkemper, B. \& Balsam, N. (2007). Examining the use of restorative justice practices in domestic violence cases. Saint Louis University Public Law Review, 27, 121-133.

Cheng, S. Y., Davis, M., Jonson-Reid, M., \& Yaeger, L. (2019). Compared to what? A meta-analysis of batterer intervention studies using nontreated controls or comparisons. Trauma, Violence, \& Abuse. Advanced online publication. https://doi.org/10.1177/1524838019865927

Cheon, A. \& Regehr, C. (2006). Restorative justice models in cases of intimate partner violence: Reviewing the evidence. Victims and Offenders, 1(4), 369-394.

Cohen, J. (1960). A coefficient of agreement for nominal scales. Educational and Psychological Measurement, 20(1), 37-46.

Clark, A. H., \& Foy, D. W. (2000). Trauma exposure and alcohol use in battered women. Violence Against Women, 6, 37-48. 
Curtis-Fawley, S. \& Daly, K. (2005). Gendered violence and restorative justice: The views of victim advocates. Violence Against Women, 11(5), 603-638.

Daniels, J. W., \& Murphy, C. M. (1997). Stages and processes of change in batterers' treatment. Cognitive and Behavioral Practice, 4, 123-145.

Denzin, N. K. (1978). Sociological methods. New York, NY: McGraw-Hill.

Dutton, M. A., \& Goodman, L. A. (2005). Coercion in intimate partner violence: Toward a new conceptualization. Sex Roles, 52(11/12), 743-756.

Eckhardt, C. I., Murphy, C., Black, D., \& Suhr, L. (2006). Intervention programs for perpetrators of intimate partner violence: Considerations from a clinical research perspective. Public Health Reports, 121(4), 369-381.

Edleson, J. L., \& Tolman, R. M. (1992). Intervention for men who batter: An ecological approach. London, England: Sage Publications.

Elo, S. \& Kyngäs, H. (2008). The qualitative content analysis process. Journal of Advanced Nursing, 62(1), 107-115.

Fulkerson, A. (2001). The use of victim impact panels in domestic violence cases: A restorative justice approach. Contemporary Justice Review, 4(34), 355-368.

Gondolf, E.W. (2002). Batterer intervention systems: Issues, outcomes and recommendations. London, England: Sage Publications.

Hotaling, G. T., \& Buzawa, E. S. (2003). Victim satisfaction with criminal justice case processing in a model court setting. (NCJ 195668). Washington, DC: National Institute of Justice. 
Hughes, D. L., \& DuMont, K. (2002). Using focus groups to facilitate culturally anchored research. American Journal of Community Psychology, 21(6), 775-806.

Karakurt, G., Koc, E., Cetinsaya, E. E., Ayluctarhan, Z., \& Bolen, S. (2019). Metaanalysis and systematic review for the treatment of perpetrators of intimate partner violence. Neuroscience Biobehavioral Reviews, 105, 220-230.

Lincoln, Y. S. \& Guba, E. G. (1985). Naturalistic inquiry. London, England: Sage Publications.

Miller, S. L. \& Iovanni, L. (2013). Using restorative justice for gendered violence: Success with a postconviction model. Feminist Criminology, 8(4), 247-268.

Mills, L. G., Barocas, B., \& Ariel, B. (2013). The next generation of court-mandated domestic violence treatment: A comprehensive study of batterer intervention and restorative justice programs. Journal of Experimental Criminology, 9, 65-90.

Morgan, D. L. (1988). Focus groups as qualitative research (Vol. 16). Thousand Oaks, CA: Sage Publications, Inc.

Morgan, D. L. \& Krueger, R. A. (1993). When to use focus groups and why. In D. L. Morgan (Ed.), Successful Focus groups: Advancing the State of the Art (pp. 3-19). London, England: Sage Publications, Inc.

O’Reilly, M. \& Parker, N. (2012). 'Unsatisfactory saturation': A critical exploration of the notion of saturated sample sizes in qualitative research. Qualitative Research, 13(2), 190-197.

Petrosky, E., Blair, J. M., Betz, C.J., Fowler, K.A., Jack, S.P., Lyons, B.H. (2017). Racial and ethnic differences in homicides of adult women and the role of intimate 
partner violence - United States, 2003-2014. Morbidity and Mortality Weekly Report, 66(28), 741-746.

Riger, S., Raja, S., \& Camacho, J. (2002). The radiating impact of intimate partner violence. Journal of Interpersonal Violence, 17, 184-205.

Sackett, K. L. (2017). Intimate partner violence impact panels for batterer intervention: A mixed-methods evaluation of a restorative justice process (Master's thesis). Retrieved from ProQuest. (doi:10.15760/etd.5964)

Sackett Kerrigan, K. \& Mankowski, E. S. (2020a). How surrogate impact panels function in the context of intimate partner violence: A mixed-methods study. Manuscript in preparation.

Sackett Kerrigan, K. \& Mankowski, E. S. (2020b). Two sides of the same coin: How surrogate impact panels affect intimate partner violence survivors. Manuscript in preparation.

Salazar, L. F., Baker, C. K., Price, A. W., \& Carlin, K. (2003). Moving beyond the individual: Examining the effects of domestic violence policies on social norms. American Journal of Community Psychology, 32(3-4), 253-264.

Sherman, L., Strang, H., Barnes, G., Braithwaite, J., \& Inkpen, N. (1998). Experiments in restorative policing: A progress report to the national police research unit on the Canberra reintegrative shaming experiment (RISE). Australian Federal Police, Australian National University. Retrieved from http://www.aic.gov.au/rjustice/rise/index.html 
Sonkin, D. J. \& Durphy, M. (1997). Learning to live without violence: A handbook for men. Volcano, CA: Volcano Press.

Stewart, D. W. \& Shamdasani, P. N. (1990). Focus groups: Theory and practice. Newbury Park, CA: Sage Publications.

Stubbs, J. (2007). Beyond apology? Domestic violence and critical questions for restorative justice. Criminology \& Criminal Justice, 7(2), 169-187.

Van Ness, D. \& Strong, K. (1997). Restoring justice. Cincinnati, OH: Anderson Publishing Co.

Zehr, H. (1990). Changing lenses: A new focus for crime and justice. Harrisonburg, VA: Herald Press.

Zosky, D. (2018). "Walking in her shoes": The impact of victim impact panels on perpetrators of domestic violence. Victims \& Offenders, 13(6), 739-756. 


\title{
Chapter IV: Manuscript 3. \\ Facing the Reality of Intimate Partner Violence: A Pre-/Post-Test Study of Surrogate Impact Panels
}

\begin{abstract}
Surrogate impact panels are a restorative justice process (Van Ness \& Strong, 1997) that have been incorporated into batterer intervention programs (BIPs) in some regions across the U.S., in which intimate partner violence (IPV) survivors typically speak about the impact of abuse to groups of justice-involved individuals (JIIs) who are required to attend the panel. However, this potentially innovative modification of court-mandated BIPs has not been evaluated rigorously. The proposed study addresses this gap by empirically measuring the process and immediate changes of participants in IPV impact panels in the Pacific Northwest. Pre- and post-panel surveys of empathy, guilt, motivations for behavior change, understanding of abuse, shame, minimization, resistance, and demographics were completed by JIIs $(N=93)$ who were mandated to attend a panel. Observer reports of restorative justice processes occurring in panels were collected as an other-report of panel processes. Analyses examined associations of and changes in JII states pre- and post-panel, frequencies of panel processes, associations of panel processes, and associations between panel processes and JII states after panels. JIIs experience moderate to large increases in state empathy, guilt, and a general motivation for behavior change after panels. They also experience small decreases in minimization, victim blaming, and a self-focused motivation for behavior change. In addition, theoretically derived sets of facilitating and hindering participant states and panel processes were found to occur during panels. IPV surrogate impact panels show promise as an addition to BIPs. Further evaluation is warranted regarding how IPV surrogate impact panels may contribute to comprehensive IPV
\end{abstract}


intervention.

Keywords: victim impact panel, domestic violence, restorative justice, batterer intervention 
Facing the Reality of Intimate Partner Violence: A Pre-/Post-Test Study of Surrogate

\section{Impact Panels}

Intimate partner violence (IPV) is one of the most prevalent violent crimes in the United States and more innovative intervention strategies are needed to effectively reduce and prevent its occurrence. IPV refers to a pattern of abusive behaviors that can include physical violence, sexual violence, threats, stalking, and psychological aggression perpetrated by a current or former partner. Abusive relationships are characterized by controlling tactics such as coercion, intimidation, isolation, denial, and blaming to maintain power over an intimate partner (Pence \& McMahon, 2008). In the US, more than one in three women and one in four men experience IPV in their lifetime (Black et al., 2011). Consequences can include long-lasting psychological and emotional harm (Dutton \& Goodman, 2005), social isolation (Riger, Raja, \& Camacho, 2002), PTSD (Clark \& Foy, 2000), and death (Petrosky et al., 2017).

The most widely implemented responses to IPV in the US are through the criminal justice system, including mandating justice-involved individuals (JIIs) for IPV to attend batterer intervention programs (BIPs). While the criminalization of IPV has led to positive outcomes (e.g., altered social norms regarding IPV; Salazar, Baker, Price, \& Carlin, 2003), some survivors report dissatisfaction with the criminal justice system and reluctance to use it in the future (Hotaling \& Buzawa, 2003). BIPs attempt to challenge social learning that reinforces men's use of violence by demonstrating nonviolent models for their behavior (Bandura, 1971; Sonkin \& Durphy, 1997), but JII resistance creates barriers to program impact (e.g., Daniels \& Murphy, 1997) including not only skills 
deficits but lack of motivation to change their abusive behavior (Edleson \& Tolman, 1992;

Gondolf, 2002). Although evaluations of BIPs have demonstrated small to moderate effects in reducing JII recidivism (Babcock, Green, \& Robie, 2004; Cheng, Davis, Jonson-Reid, \& Yaeger, 2019; Karakurt, Koc, Cetinsaya, Ayluctarhan, \& Bolen, 2019), not all JIIs respond positively to BIPs. Accessing formal support systems can sometimes exacerbate the negative impacts of IPV (e.g., isolation; Haaken \& Yragui, 2003) and individuals marginalized in American society in multiple ways are also particularly under-served by the criminal justice system and less likely to seek help through it (Hampton, LaTaillade, Dacey, \& Marghi, 2008). This evidence suggests that despite its positive impacts, the current criminal justice system response to IPV is at least partially failing to ensure survivor safety and JII accountability. It is therefore necessary to consider what additional programs could augment this response.

\section{Background}

Restorative justice approaches to IPV. Restorative justice approaches are a possible addition to the institutional response to IPV, but research is very limited on their use in this context. Restorative justice broadly refers to a holistic response to addressing harm with an explicit focus on healing those who have been harmed (Zehr, 1990). Restorative justice processes can involve the individual(s) responsible for causing harm, those who were harmed, and additional community members. A defining principle of restorative justice practice is its underlying nature of respect, inclusivity, and the development of trust within respectful relationship, wherein responsible individuals can 
make amends (Drewery, 2016). The goal of restorative justice is to restore equality or justness of relationships, grounding them in respect, care, concern, and dignity.

Current understandings of how restorative justice programs can address IPV are limited by the relatively small number of empirical evaluations of these programs in this context. Although IPV cases have been explicitly excluded from many restorative justice programs (e.g., Sherman, Strang, Barnes, Braithwaite \& Inkpen, 1998), the few programs in which IPV cases have been included have demonstrated positive effects such as reduced child maltreatment and increased social support (Pennell \& Burford, 2002) at no additional safety risk than treatment as usual in BIPs (e.g., Mills, Barocas, \& Ariel, 2013). These promising findings suggest that restorative justice programs may be beneficial in IPV cases.

Surrogate impact panels for IPV. Surrogate impact panels (also referred to as victim impact panels) are an innovative but largely untested strategy for reducing IPV. Surrogate impact panels are a specific type of restorative justice practice in which those who have been harmed by a crime speak to individuals who have perpetrated similar crimes (Van Ness \& Strong, 1997). There is typically no direct personal relationship between the participants in these panels in order to both increase safety during the process and reduce defensiveness regarding how panel speakers were impacted by crime.

Research is extremely limited on the use of surrogate impact panels for addressing IPV, but the small body of research on this restorative justice practice suggest that panels may benefit participants in multiple ways (Burkemper \& Balsam, 2007; Fulkerson, 2001; Zosky, 2018). Anecdotal evidence based on an interview with a program director of this 
practice suggested that their panel increased survivor healing and JII understanding of the impact of abuse on survivors (Burkemper \& Balsam, 2007). A more rigorous evaluation of an additional implementation of IPV surrogate impact panels found that a majority of participants endorsed the panels as a worthwhile procedure, although panel attendance was not associated with a reduction in JII recidivism (Fulkerson, 2001). However, the specific processes that occurred during the panels evaluated in each of these studies were either not described or differed in important ways from those used in panels implemented as part of BIPs. These limitations undermine confidence and relevance of the previous findings for understanding panels in the current study, which operate as a component of BIPs.

The most recent study of IPV surrogate impact panels found that a majority of JII panel participants agreed that the panel increased their awareness of the impact of IPV on direct survivors and children perceived panel attendance as beneficial (Zosky, 2018). Analysis of open-ended comments from participants indicated that the panel evoked emotional responses and remorse in JIIs, empathy for speakers, commitment to learn and be accountable, and commitment to change and hope. However, the panel process in this study (Zosky) differed again from other evaluated panels (Burkemper \& Balsam, 2007; Fulkerson, 2001) and the panel of focus in the current study in important ways, particularly in a lack of direct interaction between speakers and audience members through a question and answer session.

The current study is the next step in a program of longitudinal, multi-method research to evaluate a local IPV surrogate impact panel and builds upon previous research 
that generated ecologically-grounded indicators of panel outcomes for survivors and JIIs in this context (Sackett, 2017). A two-year inductive inquiry into the process and potential outcomes of the panel, using multiple methods and sources including ethnography, archival survey data from JIIs, and focus groups with survivors and BIP providers, found that the panel creates unique patterns of social interaction between JIIs and survivors relative to other settings within the coordinated community response, reenvisioning the roles of survivors, JIIs, and professionals in this process (Sackett Kerrigan \& Mankowski, 2020a). Findings from this study further indicated that program participants and stakeholders perceive the panel as increasing JIIs' empathy for survivors and understanding of the impact of abuse, which complement the programming goals of BIPs (Sackett Kerrigan \& Mankowski, 2020b). While JIIs seem to enter the panel process with some degree of resistance, some of them may become open to listening to the speakers, take the perspective of survivors, and reach a deeper understanding of the impact of abuse.

Defining the social ecology of IPV surrogate impact panels. If researchers and practitioners are truly interested in understanding whether IPV surrogate impact panels "work," the definition of success must be outlined in both theoretically and practically relevant terms. The social ecological model is one broad theory that can integrate previous research on restorative justice and IPV interventions to define these terms. Initially conceptualized as a structural map of different levels of an environment, the ecological model includes the microsystem, mesosystem, exosystem, macrosystem, and chronosystem (Bronfenbrenner, 1979; Bronfenbrenner \& Morris, 2006). Dynamic 
components of ecologies, particularly proximal processes and the chronosystem, are crucial to consider in a systems-level perspective of social ecologies to understand how structural and dynamic processes are linked to participant experiences and outcomes in the ecology (Kelly, Ryan, Altman, \& Stelzner, 2000). The interdependence principle (Kelly et al., 2000) is especially relevant when framing IPV surrogate impact panels as a social ecology, which refers to the interconnections that exist across the ecology (including direct and indirect relationships) such that impacting one part of the community potentially has effects or ramifications elsewhere in the community. This model has been previously applied to evaluate the effectiveness of indigenous interventions created by local practitioners, such as a sexual assault forensic exam and care program (Campbell, Patterson, \& Fehler-Cabral, 2010). A social ecological framing can organize potential indicators of panel success in terms of individual-level and grouplevel factors relevant to manifesting the principles of restorative justice and changing abusive behavior.

Individual-level factors in changing abusive behavior. Several primary groups of factors may drive abusive behavior (Scott, 2004) and could therefore be targeted by IPV surrogate impact panels as possible points of intervention for behavior change. First, social norms that explicitly and tacitly encourage male dominance and control over others are theorized to contribute to the perpetration of IPV within the social and political context of a patriarchal society (e.g., Carden, 1994). Second, individual characteristics (e.g., skills, personality, emotional development) may further differentiate abusive and non-abusive men. BIP participants' motivation and resistance to treatment may be 
especially critical factors to target, as both a lack of motivation and treatment resistance are predictive of treatment dropout and subsequently a higher likelihood of reoffense (e.g., Gordon \& Moriarty, 2003; Taylor, Davis, \& Maxwell, 2001). Increasing individuals’ motivation to change or decreasing their resistance are therefore be critical ways in which IPV surrogate impact panels could benefit BIP participants.

However, any possible individual-level changes need to be understood within the broader social ecological context within which individuals are situated. The Transtheoretical Model (Prochaska \& DiClemente, 1984; DiClemente \& Prochaska, 1985) is recommended for IPV program evaluations to delineate possible trajectories of individual behavior change and inform how interventions might promote successful change efforts (Begun, Shelley, Strodthoff, \& Short, 2001). This model conceptualizes individual-level motivation and behavior change as long-term, nonlinear processes. It also proposes that behavior modification is driven by two influences: a person's stage of change (i.e., precontemplation, contemplation, preparation, action, maintenance) and their processes of change, or the specific activities that promote behavior modification (Prochaska, DiClemente, \& Norcross, 1992). Progression through the stages of change is conceptualized as cyclical movement, including relapse and recycling of behaviors (Prochaska \& DiClemente, 1986). Although a linear progression of change is possible in this model, the authors emphasize that linear change is relatively uncommon and is particularly rare so for behaviors that are addictive or especially difficult to change (Prochaska et al., 1992). In the context of IPV, individuals attempting to change their abusive behavior likely face challenges to their behavior change at every level in their 
social ecology (e.g., a social environment with norms of male dominance) and true change is a long-term, even lifelong, process including both progress and failure in moving along in their stages of change. Researchers must therefore be aware of these temporal considerations when conceptualizing behavior change and realistic about the time required for real change in this model, as true change is believed to require "extensive synthesis and assimilation by the individual, especially for those in the earliest stage” (p. 122, Begun et al., 2001).

Several key restorative justice outcomes are also relevant to how IPV surrogate impact panels may influence individual-level efforts to change abusive behavior: empathy, reintegrative shame, and stigmatizing shame, which may result from different ways in which social disapproval is expressed. Reintegrative shame and stigmatizing shame are two types of social disapproval that are believed to elicit different responses from the targets of the shaming (Braithwaite, 1989), particularly in how they affect their sense of conscience and manage their shame-related emotions. Reintegrative shaming is conceptualized as the social disapproval of an act that is directed toward a person's problematic behavior in a way that maintains respect for the person and avoids labeling them and concludes the act of social disapproval with a ritual of reintegration to eventually bring the person back into the community. On the other hand, stigmatizing shaming is an expression of social disapproval that is communicated disrespectfully, directed toward an individual's entire personhood by labeling the target of disapproval with stigmatizing names (e.g., thief, cheat), with no concluding ritual to terminate disapproval. These types of shaming also subsequently predict different likelihoods of 
reoffense (Braithwaite \& Braithwaite, 2001). Reintegrative shaming is expected lead to lower reoffense rates because it encourages acknowledgment of guilt and any related emotions, and such acknowledgment is associated with increased victim empathy, decreased anger, and decreased externalization of responsibility or blame (Ahmed, 2001; Harris, 2003). Stigmatizing shame is expected to increase the likelihood of reoffense, as such shaming humiliates the individual, impedes acknowledgment of shame and remorse, and instead displaces shame (Ahmed, 2001) with increased externalization of blame and anger toward those expressing social disapproval. Deficits in components of empathy, such as perspective-taking, have also been shown to predict different types of abusive behavior (Covell, Huss, \& Langhinrichsen-Rohling, 2007). These individual-level feelings and beliefs are therefore important possible points of intervention for IPV surrogate impact panels.

Group-level factors. Previous research suggests that group dynamics and individual behavior within BIP groups may further illuminate the way in which participants change their abusive behavior through interventions. For example, interviews with participants who successfully completed a BIP group and with BIP facilitators identified BIP group dynamics as one of a few key factors for participant behavior change (Silvergleid \& Mankowski, 2006). A more recent study also found links between observable group behaviors, participant self-reported motivation to change, facilitatorreported change behaviors, and partner-reported levels of violence (Semiatin, Murphy, \& Elliott, 2013). Observable behaviors in BIP groups included 1. acknowledgment (versus denial) of behavior and responsibility, 2. interpersonal behavior indicating a change- 
oriented mindset, and 3. verbalizations of positive perceptions of the group's value in promoting change. These behaviors were positively associated with participant selfreported motivation to change prior to and during treatment, homework compliance, and group facilitator-reported therapeutic working alliance (Semiatin et al., 2013). The study also found that participants who demonstrated more protherapeutic behaviors during their final two BIP group sessions perpetrated less partner-reported psychological and physical violence six months after scheduled BIP completion than those who were less protherapeutic in their BIP. Group-level dynamics are therefore important windows into how a program functions and how it may affect program participants.

Although a model of IPV surrogate impact panels has not been widely shared or accepted in the field to date, other restorative justice models may apply in this context and potentially identify important group-level dynamics. The Interaction Ritual Model (Collins, 2004) has been used previously to evaluate restorative justice conferences between two individuals from the same crime (Rossner, 2013), and this deductive model closely aligns with the previous inductive findings of the program of research on IPV surrogate impact panels within which the current study is situated (Sackett Kerrigan \& Mankowski, 2020a; Sackett Kerrigan \& Mankowksi, 2020b). This model suggests that restorative justice processes consist of a build-up of emotional intensity, balanced exchange between participants, and rhythm, which together lead to a turning point in individual participants from an initial state of defiance and stigmatization into short-term outcomes of reintegration, group solidarity, emotional energy, motivation to change, and symbolic relationship. The observable externalizations of these processes and outcomes 
include the synchronization of body movements and sounds (e.g., group crying or laughing), touching (e.g., hugs, handshakes, pats), eye contact, a shift in the body posture or facial expressions of individuals conveying an increase or momentary burst in emotional energy (e.g., sitting upright and smiling at the end of a process when initially sitting hunched over, downcast, and disengaged), and conversational turn-taking or the lessening of conversational gaps (Collins, 2004). These can lead to distal outcomes of long-term emotional energy and reduced reoffending, as participants seek out additional positive interactions and engage in pro-social behavior to sustain the positive emotional energy created through the restorative justice process.

Group-level dynamics can also be evaluated as indicators of the broader contextual assumptions underlying how a program functions and are therefore important to model not only in relation to individual-level program outcomes, but to understand their intrinsic value as manifestations of the program paradigm. For example, housing the institutional response to IPV within the criminal justice system frames criminal IPV acts as a violation of laws punishable by the state, rather than as a violation of individuals, relationships and communities (Zehr, 1990). The threat of punishment in this system is meant to deter individuals from committing IPV crimes to avoid the adversarial processes of the criminal justice system, which unfold in a non-participatory manner and instead are led by an external authority that enacts punishment according to law. On the other hand, IPV surrogate impact panels may help BIPs promote long-term behavioral changes in abusive behavior, but intentionally creates a social system that does not use punishment or retribution to maintain order and control over others. Therefore, it is important to know 
whether IPV surrogate impact panels truly center on survivors and if they create noncoercive interactions between program participants in a restorative justice practice.

\section{Study Design}

Leaders in the field call for comprehensive evaluation of IPV intervention programs (Bowen \& Gilchrist, 2004; Gondolf, 2012) and suggest that more holistic evaluation of these programs would deepen our understanding of how they impact participants. They particularly encourage researchers to look beyond outcome measures of recidivism alone. Evaluation approaches driven by the values of the intervention itself, particularly those including qualitative and other approaches capable of capturing nonlinear dynamics and processes of change, are also recommended for restorative justice programs (Presser \& Van Voorhis, 2002), rather than defining success based on common standards of the criminal justice system (e.g., recidivism, supervision compliance; Llewellyn, Archibald, Clairmont, \& Crocker, 2014). Although the ultimate goal of BIPs and other IPV intervention programs is the cessation of violence, close attention to process and immediate outcomes could more thoroughly explain how program mechanisms impact JII behavior and inform efforts to improve programs and further reduce JII recidivism. In addition, IPV surrogate impact panels are a brief two-hour intervention and were therefore not anticipated to affect participants' general disposition to experience guilt, shame, and empathy, but rather their immediate emotional experiences in the panel setting.

The current study therefore focused on the proximal feelings and beliefs of JII panel participants before and after the panel and the group-level restorative justice 
processes that occurred during panels. Although this program of research includes a qualitative study of the perceived impacts of panels on survivors who speak on the panel (Sackett Kerrigan \& Mankowski, 2020c), the scope of the current study was limited only to panel processes and the feelings and beliefs of JII participants during panels to understand how the panel may contribute to desired behavior changes in JIIs as a component of BIPs. The focus of the study is not intended to imply, however, that the panels should be evaluated only in terms of their potential benefit to JII audience members, as it is fundamentally a survivor-driven and survivor-centered process. Salient JII state feelings and beliefs to measure in the current study were identified based on findings of the perceived panel impacts on JIIs in a previous study of this panel (Sackett Kerrigan \& Mankowski, 2020b) and the targeted individual-level domains of the Interaction Ritual Model of restorative justice (Rossner, 2013). Based on this previous research, the following states were expected to be conducive to the panel process or facilitate desired behavior changes after panels: empathy, guilt, motivations for behavior change, and understanding the impact of abuse. The following states were expected to hinder the panel process or not contribute to desired behavior changes after panels: shame, minimization, lack of violence recognition, victim blaming, and resistance. In addition, relevant group-level restorative justice processes to measure in the current study were identified based on Interaction Ritual Model restorative justice processes (Rossner, 2013) and field observations of panel processes in previous studies of this panel (Sackett Kerrigan \& Mankowski, 2020a; Sackett Kerrigan \& Mankowski, 2020b). The following group-level processes were expected to facilitate restorative justice encounters and 
desired individual-level behavior change after panels: facilitating speaker actions (showing positive support for JIIs, sharing story in a non-threatening way, showing vulnerability), facilitating JII actions (positive support for speakers, positive engagement, positive accountability), and facilitating exchanges between speakers and JIIs (positive speaker-JII exchange, attunement/syncing). The following group-level processes were expected to hinder restorative justice encounters and desired individual-level behavior change after panels: hindering speaker actions (negative support for JIIs, sharing story in a threatening way), hindering JII actions (negative support for speakers, negative engagement, negative accountability), and hindering exchanges between speakers and JIIs (negative speaker-JII exchange).

Study context. The IPV impact panel has been operating as a component of BIPs in Washington County, Oregon for more than fifteen years. Panels occur at regular intervals six to ten times per year and typically consist of three survivor speakers and 15 to 30 audience members from BIPs. Although intimate partner violence is known to occur within a variety of relationships regardless of the members' sexuality (e.g., Baker, Buick, Kim, Moniz, \& Nava, 2013), historically the panel has only included female speakers who were involved in heterosexual relationships, and primarily male audience members (although not exclusively). Survivor speakers participate voluntarily. JIIs are mandated by probation to attend one panel in addition to regular BIP groups. Before attending the panel, JIIs are screened by BIP facilitators and are only eligible to attend it after completing at least 26 weeks in the BIP group. Panel activities consist of a facilitated introduction, consecutive sharing of stories by the survivor speakers, a 
question and answer session between the JIIs and speakers, and panel wrap-up. A panel facilitator and probation officer are always present to ensure the respect and safety of all participants. No harmful physical contact has ever occurred during the history of this panel.

Research questions. The proposed study empirically evaluated the processes and outcomes of IPV impact panels in response to several research questions:

$\boldsymbol{R Q 1 . ~ W h a t ~ f e e l i n g s ~ a n d ~ b e l i e f s ~ d o ~ J I I ~ p a r t i c i p a n t s ~ e n d o r s e ~ p r e - ~ a n d ~ p o s t - p a n e l ~}$ and how are these states associated with one another at each time point?

Hypotheses: Facilitating individual-level states of JII empathy, reintegrative shame, motivations for change, and understanding the impact of abuse will be positively associated with one another $(H l a)$. Hindering individual-level states of JII stigmatizing shame, minimization of abuse, and resistance will be positively associated with one another $(H 1 b)$. These facilitating and hindering individual-level states will be negatively associated with one another $(H 1 c)$.

$\boldsymbol{R Q 2 . ~ H o w ~ d o ~ J I I ~ p a r t i c i p a n t s ~ c h a n g e ~ p r e - ~ t o ~ p o s t - p a n e l ~ i n ~ t h e ~ f a c i l i t a t i n g ~ a n d ~}$ hindering feelings and beliefs targeted by restorative justice processes?

Hypotheses: Facilitating individual-level states (JII empathy, reintegrative shame, and motivations for change) will increase after the panel $(H 2 a)$. Hindering individuallevel states (JII stigmatizing shame, minimization of abuse) will decrease after the panel $(H 2 b)$.

$\boldsymbol{R Q 3 .}$ What group-level restorative justice processes occur during IPV surrogate impact panels? 
$\boldsymbol{R} \mathbf{Q}$. How are group-level restorative justice processes associated with one another during IPV surrogate impact panels?

Hypotheses: Facilitating group-level processes in speaker actions (showing positive support for JIIs, sharing story in a non-threatening way, showing vulnerability) will be positively associated with facilitating group-level processes in JII actions (positive support for speakers, positive engagement, positive accountability) and with facilitating group-level processes in exchanges between speakers and JIIs (positive speaker-JII exchange, attunement/syncing) ( $H 4 a)$. Hindering group-level processes in speaker actions (negative support for JIIs, sharing story in a threatening way) will be positively associated with hindering group-level processes in JII actions (negative support for speakers, negative engagement, negative accountability), and hindering group-level processes in exchanges between speakers and JIIs (negative speaker-JII exchange) $(H 4 b)$.

Research question 5 (RQ5). How are group-level restorative justice processes associated with post-panel JII individual-level states?

Hypotheses: Facilitating group-level processes (positive support for JIIs, positive support for speakers, attunement/syncing) will be positively associated with facilitating individual-level states (empathy, reintegrative shame, motivations to change, understanding the impact of abuse) ( $\mathrm{H} 5 \mathrm{a}$ ). Hindering group-level processes (negative support for JIIs, negative accountability, negative speaker-JII exchange) will be positively associated with hindering individual-level states (stigmatizing shame, minimization of abuse, resistance) $(\mathrm{H} 5 \mathrm{~b})$. 


\section{Method}

Participants. Participants $(n=93)$ consisted of adult JIIs enrolled in BIPs for at least 26 weeks $(M=36.93, \mathrm{SD}=10.19)$ who self-selected into the sampling frame of the study $(N=165)$ by attending one of six IPV impact panels held between August 2018 and June 2019. Audience sizes ranged from 22 to 36 per panel, with approximately 28 members on average per panel. Panel attendees were invited to participate in the study as an optional activity before and after the panel and consent was done through a verbal explanation of study benefits and individual signed consent form. The consent process explained that all study activities were completely voluntary, with no compensation to participants, and that study researchers were completely independent from their probation officers and BIP providers. At the first panel, the consent process and first study activity of completing the pre-test was scheduled before the panel officially began, and had a very low response rate $(11.4 \%)$. After study activities were officially integrated into the panel activities, with the consent and first survey occurring after the facilitator welcomed the audience and described the panel steps with time set aside for audience members to participate if desired, response rates increased to $53.8 \%$ to $86.9 \%(M=74.9 \%)$. Attrition from pre- to post-test was relatively low across the six panels $(M=15.9 \%)$ and ranged from 0 to $30.0 \%$.

A priori power analyses indicated that for a power of .80 and an alpha of .05 , a sample size of 80 would be sufficient to detect effect sizes of .28 in paired $t$-tests of two dependent means to analyze changes in pre-/post-panel JII states (Erdfelder, Faul, \& Buchner, 1996). This sample size would also be sufficient to detect small to large effect 
sizes in multiple regressions to analyze how group-level restorative justice processes are associated with pre- and post-panel JII states. Small to medium effects were anticipated in this study, based on previous restorative justice research (e.g., $d=.227$, Armour, Windsor, Aguilar, \& Taub, 2008; $f^{2}=.132$ for motivation; Rossner, 2013), although large effects of restorative justice processes have been previously found (e.g., $f^{2}=.433$ to .656; Rossner, 2013).

Procedure. JIIs were asked to complete a self-report survey immediately before and after attending a panel. Domestic Violence Safe Dialogue (DVSD), the organization that coordinated the panels, agreed to include this as a component of panel attendance for all JIIs to support the research process and reduce attrition. The consent process to participate informed participants of the author's role as a doctoral student unaffiliated with BIPs or with DVSD. The consent form is included in Appendix B. During each panel, at least two trained researchers used an observational checklist to document and categorize restorative justice processes that occurred during panels in vivo.

Measures. Self-report survey. The pre- and post-test surveys contained measures of three sets of participant states: facilitating, hindering, and additional states. Facilitating states included empathy, reintegrative shame, motivations for behavior change, and understanding the impact of abuse. Hindering states included stigmatizing shame, minimization, lack of violence recognition, victim blaming, and resistance. Finally, two measures were included to describe additional participant states that were also expected to relate to panel processes and desired changes after panels based on prior research on this IPV surrogate impact panel (Sackett, 2017), but which were difficult to make 
hypotheses about based on restorative justice theory and intimate partner violence intervention research. The first measure rated their emotional involvement in the panel, identification with the content of the panel, and the perceived factuality of the panel. The second measure consisted of demographic items. Some measures were included only in the post-test to prevent participants from being sensitized to panel process or outcome domains prior to completing the panel. Table 4.1 lists all survey measures and indicates whether they are included in at pre-test only or both pre- and post-test.

Below, the internal validity of each scale is presented with a brief description of the scale. The construct validity, discriminant validity, and test-retest reliability of each scale is unknown, as scales were modified due to time constraints for the data collection and to tailor items more closely to the panel context. Appendix C lists all survey items.

Facilitating JII participant states: Empathy, reintegrative shame, motivations for behavior change, and understanding the impact of abuse. Empathy (empathic distress, concern, and perspective-taking) were measured using two scales. Eight items of emotion adjectives that load onto factors of empathy and personal distress $(\alpha=.89$ to .93 ; Batson, Fultz, \& Schoenrade, 1987) were used to measure changes in JIIs' state empathy in the sub-dimensions empathic concern and distress on a five-point scale. Sample empathic concern items included "moved" and "compassionate" and sample empathic distress items included "upset" and "distressed." Five items from the Defendant Empathy Scale $(\alpha=.85$; Haegerich $\&$ Bottoms, 2000) were used to further measure changes in JIIs' state empathy in the sub-dimension of perspective-taking on a seven-point scale, specifically of their own victims/survivors (e.g., "I can really feel what my victim(s) must have been 
feeling during my abusive incident(s)"). Reintegrative shame was measured using the five items described as measuring "guilt" from the five-point State Shame and Guilt Scale ( $\alpha=.82$ to .89; Marschall, Sanftner, \& Tangney, 1994), such as "I feel bad about something I have done." These items described an individual's negative attributions about their own behavior (e.g., "I cannot stop thinking about something bad I have done") and related negative feelings (e.g., "I feel remorse, regret"). Motivations for behavior change were measured using the nine-item Motivating Factor for Behavior Change Scale $(\alpha=.72$; Schmidt et al., 2007). Participants were asked to rate the importance of each motivation on a scale from one to nine, with motivations such as "Don't want to lose my job" and "Effect of abuse on my children." Finally, understanding the impact of abuse was measured using the seven-item Understanding of Abuse scale, developed by panel coordinators based on their observations and experiences facilitating the panel (WCCC, 2007). This six-point scale assessed JII participants' retrospective increase in understanding of abuse at the end of the panel. Items included "I better understand how my verbal and emotional abuse has harmed my victim(s)" and "The panel tonight helped me understand the long-term effects of abuse of others." Scale reliability tests showed strong internal consistency $(\alpha=.88)$ in the previous study of this IPV impact panel (Sackett, 2017).

\section{Hindering JII participant states: Stigmatizing shame, minimization, and} resistance. Stigmatizing shame was measured using five items described as measuring "shame" from the five-point State Shame and Guilt Scale $(\alpha=.82$ to .89; Marschall et al., 1994), such as "I want to sink into the floor and disappear." These items described an 
individual's negative attributions about their entire selves, rather than their behavior alone, (e.g., "I feel like I am a bad person") and related negative feelings (e.g., "I feel humiliated, disgraced"). Minimization, lack of violence recognition, and victim blaming were measured using 16 items from the five-point Intimate Violence Responsibility Scale $(\alpha=.75$ to .83 ; Yun $\&$ Vonk, 2011). Items corresponded to sub-scales of minimization (e.g., "What I did wasn't that big a deal"), lack of violence recognition (with reversecoding of items, e.g., "What I did was harmful to my partner"), and partner blaming (e.g., "It happened because my partner pushed my buttons").

Four dimensions of resistance (problem with alliance, hopelessness, psychological reactance, and passive reactance) were measured with sub-scales of the five-point Resistance Scale ( $\alpha=.71$ to .80 ; Levesque, Velicer, Castle, \& Greene, 2008). Twelve items described problems with alliance specifically with people on the panel (e.g., "How much did you feel that people on the panel were criticizing you?"), hopelessness (e.g., “How hopeless did you feel about making changes in your life?”), psychological reactance (e.g., "How angry did you get when someone told you what you should and should not do in your relationship?"), and passive reactance (e.g., "How bored or uninterested did you feel during the panel tonight?”).

Additional JII participant states. Emotional involvement, identification, and factuality were measured on a seven-point scale using 10 items describing aspects of narrative persuasion tailored to the context of the panel $(\alpha=.89$ to .95 ; Cho, Shen, $\&$ Wilson, 2014). Items corresponded to emotional involvement (e.g., "I could feel the emotions of the people on the panel tonight"), identification (e.g., "I could relate to the 
situation(s) described in the panel"), and factuality (e.g., "The panel described something that had really happened"). Finally, participants responded to demographic survey items including situational context factors (e.g., how long ago their arresting incident occurred, length of time in BIPs) and individual characteristics (e.g., age, gender, socioeconomic status, race, marital and familial status). Items were selected based on demographics from previous studies of this panel (Sackett Kerrigan \& Mankowski, 2020a; Sackett Kerrigan \& Mankowski, 2020b) and the only published evaluation that compared a restorative justice program to BIPs (Mills et al., 2013).

Restorative justice process observational coding. Although observational methods are a key data source for understanding a phenomenon and contribute different information than is possible to reach through self-report alone (Fiske, 1979), they are difficult to implement in community contexts and particularly rare in intimate partner violence research, with some notable exceptions (e.g., Gondolf, 2002). Naturalistic observation in particular can provide valuable information about community-based interventions, particularly when such observation can be done in a way that fits within the constraints of naturally occurring events, assesses processes believed to occur during target events, and preserves the context of the behaviors that occur in the setting (Roberts et al., 1991).

To assess whether and how Interaction Ritual Model processes are consistent with the group-level processes that occur in panels, an observational codebook was created by the first author based on previous field observations of these panels in this program of research (Sackett Kerrigan \& Mankowski, 2020a; Sackett Kerrigan \& Mankowski, 2020b) 
and key components of the deductive model (Rossner, 2013). The following facilitating group-level processes were measured: facilitating speaker actions (showing positive support for JIIs, sharing story in a non-threatening way, showing vulnerability), facilitating JII actions (positive support for speakers, positive engagement, positive accountability), and facilitating exchanges between speakers and JIIs (positive speakerJII exchange, attunement/syncing). The following hindering group-level processes were measured: hindering speaker actions (negative support for JIIs, sharing story in a threatening way), hindering JII actions (negative support for speakers, negative engagement, negative accountability), and hindering exchanges between speakers and JIIs (negative speaker-JII exchange). Finally, two additional group-level processes were measured based on prior research on this IPV surrogate impact panel (Sackett, 2017) that that may relate to restorative justice encounters and/or individual-level behavior change, but about which no hypotheses were made: JIIs sharing internal conflict (Rossner, 2013) and JIIs appearing uncomfortable (Sackett, 2017). The observational codebook, with examples of each code, is presented in Appendix D.

Two trained researchers used the codebook as a tool to document and code in vivo the frequency of observed interactional processes at each panel. All raters were trained on the observational codebook and coding was calibrated by comparing the raters' coding of a video recording of a related IPV restorative justice process (i.e., a surrogate dialogue). Raters discussed their interpretations of codes and examples of how and when codes were applied. Consensus was reached on the definitions and examples of the codes to increase their reliability and validity. Coders were trained to document discrete instances of 
observed processes. For example, a single instance of positive support by JIIs toward the speakers could be observed in a statement by one audience member expressing respect or affirmation toward one or more speakers. Although it is more common to complete observational coding using video- or audio-recordings (e.g., in research on classroom observations, Bell et al., 2012), these methods are less feasible in the context of community-based interventions and paper and pencil documentation was used in the field instead, as this method is better suited to the context of naturalistic field research (Roberts et al., 1991).

Although training efforts increased the reliability of observer ratings in terms of shared agreement on code definitions and practice applying codes to example interactions, constraints of the field setting related to the physical set up of the space in which panels were held impacted what the two raters were able to observe in the field. A diagram of the panel setting is provided in Figure 4.1 to illustrate the position of panel speakers, audience members, and researchers (raters 1 and 2). Researchers were positioned in these spaces to be as close to audience members as possible without intruding into their field of vision to minimize researchers' impact on naturally occurring processes during panels. While this was intended to increase ecological validity of observations, their positions physically limited the raters' views of opposite sides of the room. Thus, while raters likely observed nearly completely overlapping sets of speaker behaviors from their different vantage points, it is likely that they only observed somewhat overlapping sets of audience behaviors and it is currently impossible to estimate the degree of this overlap. Therefore, inter-rater reliability was not computed to describe the observational ratings 
across coders (e.g., Cohen, 1960), as this score would not distinguish whether disagreement between raters was due to a low level of agreement in their interpretation of a given behavior or whether a behavior was not possible to observe by both raters in the field.

Analysis. Data were first examined for outliers, multicollinearity, missingness, and skewness and kurtosis of variables (Tabachnick \& Fidell, 2007). Although descriptive analyses indicated there were some outliers in some variables, data was examined for correct data entry and the pattern of outliers to determine if any participants' responses were suspiciously uniform (e.g., suggesting a lack of attention to the questions by answering all with the same value) and none indicated such a response pattern. Surveys were screened for an attention check question that asked participants whether they had read and understood all questions in the final survey. Participant responses were removed from the study if they responded to this question in the negative $(n=3)$. No variables had extreme outliers of more than three times the interquartile range, so all remaining responses were retained in the sample. Missing data were excluded pairwise from inferential analyses to increase power in the analyses. Time constraints appeared to be the primary influence on which participants were able to complete both surveys (e.g., some had to leave immediately after panels concluded to travel to homes in other counties), so all completed responses were retained, regardless of the extent of missing data on any given survey. Little's (1988) missing completely at random (MCAR) test suggested that the pattern of missingness in this sample met the assumptions for MCAR $\left(\chi^{2}(843)=859.94, p=.34\right)$. All variables were mean-centered to improve interpretation 
of effects for multivariate analyses of scores with different rating scales. As the current study is informed by only three previously published papers on surrogate impact panels for IPV, with little detailed information to inform study hypotheses, the research questions and hypotheses are more exploratory than confirmatory (i.e., they are not reproducing previously tested hypotheses). No correction was therefore made to the significance levels when reporting study effects (Feise, 2002; Perneger, 1998).

Although the individual responses of participants are not independent from the panels in which they participated (Raudenbush \& Bryk, 2002), previous analysis of archival surveys completed by JIIs in the first study of the panels indicated no significant differences in responses based on which the panel they attended or the referring BIP in which they were enrolled (Sackett, 2017). Although the most theoretically appropriate analysis of group-level effects on individuals would include multilevel modeling (Snijders \& Bosker, 2012), an insufficient number of groups were able to be collected for such models to converge. To explore potential pre-existing differences between participants in different panel groups $(n=6)$, central demographic characteristics expected to be most relevant to the content of the panel were evaluated to test the similarity of groups across panels using a one-way analysis of variance or chi square test. Specifically, these comparisons tested whether participants' age, race, number of children, current enrollment in a BIP, BIP enrollment reason, and weeks of BIP completion were significantly different across panel groups. All of the tests were not significant, suggesting that there were no pre-existing differences between audience groups across panels with respect to participants' age, $F(5,63)=1.17, p>.05$, race, $\chi^{2}(30)=32.41$, 
$p>.05$, number of children, $\chi^{2}(20)=15.00, p>.05$, current enrollment in a BIP, $\chi^{2}(5)=$ $7.27, p>.05$, BIP enrollment reason, $\chi^{2}(20)=21.16, p>.05$, or weeks of BIP program completion, $F(5,45)=1.86, p>.05$. Together, these results suggest panel groups may not create meaningful variation in outcomes that would necessitate the use of multilevel models. Therefore, data were analyzed at the individual level across participants from all panels to detect panel effects.

\section{JII participant analysis: Individual states and individual-level change (RQ1 and}

$\boldsymbol{R Q 2 ) . ~ T o ~ a n a l y z e ~ h o w ~ J I I ~ f e e l i n g s ~ a n d ~ b e l i e f s ~ a r e ~ a s s o c i a t e d ~ w i t h ~ o n e ~ a n o t h e r ~ b e f o r e ~ a n d ~}$ after the panel (RQ1), correlation matrices were produced for measure summary scores pre-panel, post-panel, and across time points. Wilcoxon rank sum tests examined whether JIIs' state empathy, state reintegrative shame and stigmatizing shame, minimization, and motivation to change were significantly different pre- to post-panel (RQ2).

Nonparametric tests were selected for pairwise comparison tests that included at least one mean score distribution that violated the assumption of normality. Simultaneous multiple regression models were conducted for any outcomes that significantly changed pre- to post-panel to determine how additional control variables accounted for changes in these domains. Each multiple regression examined pre-test scores of the outcome domain and JIIs' emotional engagement, identification with the panel content, rating of its factuality, resistance to the panel process, and two demographic variables (age, length of time in a BIP) as independent variables and post-test scores of the outcome domain as the dependent variable. These variables were selected as control variables based on prior research that suggests that dimensions of the restorative justice encounter (e.g., emotional 
engagement, resistance; Rossner, 2013), participants' age (e.g., Bowen \& Gilchrist, 2006), and their tenure in a BIP (e.g., Cuevas \& Bui, 2016) would likely be associated with postintervention outcomes.

Restorative justice process analysis (RQ3, RQ4, and RQ5). To analyze what processes and interactions occurred during IPV impact panels and their consistency with group-level restorative justice processes (RQ3), frequency counts of coded observational processes were averaged across the two coders for each restorative justice process at each step of the panel. Descriptive statistics summarized the average frequency and variation of restorative justice processes implemented during panels. To analyze the extent to which group-level restorative justice processes are associated with one another during panels (RQ4), a correlation matrix was produced of the associations between scores of each domain of observed restorative justice process components. To analyze how grouplevel restorative justice processes are associated with post-panel JII participant attributes, a correlation matrix was produced of the associations between scores of each domain of observed restorative justice process components and all post-panel individual-level outcomes.

\section{Findings}

JII participant demographics. Demographic information was completed by only a sub-set of participants $(n=68)$. The demographic information they provided is presented in Table 4.2. Although the study followed a convenience sampling process, sample demographics suggest that participants were fairly similar to other multi-site study samples of individuals who are required to attend BIPs (Gondolf, 2002), as the 
majority of panel participants were male (97.1\%), heterosexual (88.7\%), and cisgender (100\%). Most participants identified as either White/Caucasian (64.1\%) or Latino, Hispanic, or Spanish origin (20.3\%), which is consistent with common demographics of participants in BIPs in this Northwestern state (e.g., Silvergleid \& Mankowski, 2006). Participants were roughly 37 years old on average, but ages ranged from 20 to 59 years. Nearly one third of participants were either married (20.9\%) or living with a partner (9\%), while most of the remaining participants were single (46.3\%). More than two thirds of participants had at least one child. More than half of participants indicated their highest level of completed education was either some high school or receiving their high school diploma/GED. Most participants were currently employed (89.2\%) with an average annual salary just over $\$ 46,000$, although salaries ranged from $\$ 0$ to $\$ 300,000$ and half the sample earned less than $\$ 36,001$ per year.

Notably, there were no African American participants in the study sample. While this is consistent with the demographics of local BIP participants (e.g., Silvergleid \& Mankowski, 2006), it may be further explained by findings in a previous study of this local surrogate impact panel (Sackett, 2017). One culturally-specific BIP for African American participants operates in this area, and the facilitator of this BIP previously indicated that they do not refer their program members to the panels due to concerns about any alterations from their specific approach to IPV intervention.

Surprisingly, not all participants were enrolled in a BIP when they attended the panel. Most participants were currently enrolled in a BIP (80\%). Of those who were not currently enrolled $(n=13)$, nearly one third named a BIP they had been previously 
enrolled in for times ranging from 12 to 104 weeks. The remaining nine participants were most likely required to attend the panel by PO mandate. The vast majority of participants (90\%) had completed at least 24 weeks of their current or previous BIP before attending the panel. Most participants enrolled in a BIP as a result of a court mandate $(64.9 \%)$ or probation/parole $(22.8 \%)$.

In addition, the vast majority of participants were involved with the criminal justice system, as expected. Nearly all participants had been previously arrested (93.7\%), ranging from 1 to 25 previous arrests. Of those who had been arrested, most participants had one or two IPV-related arrests $(M=1.78, S D=2.63)$. Only $1.7 \%$ of those who had ever been arrested reported zero IPV-related arrests. For the majority of participants who were arrested, an arrest led to their BIP enrollment (86.2\%), which occurred when they were 32.48 years old on average.

\section{JII participant analysis: Individual states and individual-level change (RQ1}

and RQ2). To understand the feelings and beliefs that JII participants endorsed pre-panel (RQ1), descriptive statistics were first calculated for summary scores of the measured domains. Pre- and post-panel mean scores, standard deviations, sample size, and range for the score's items are presented in Table 4.3.

Pre-panel audience state. Average self-report scores suggest that before the panels began, audience members had little to no feelings of reintegrative shame and stigmatizing shame, low empathic distress, and moderate empathic concern and perspective-taking of their own partner. They also endorsed low to moderate levels of minimization of responsibility for their abusive behavior, lack of violence recognition, 
and victim blaming. The motivation that was rated most important for changing their abusive behavior across all participants was thinking it is not right to be abusive, while the least important motivation was not wanting to look bad to others.

Post-panel audience state. At the end of the panel, participants on average felt moderate levels of reintegrative shame, low levels of stigmatizing shame, and moderate to high levels of empathic distress, empathic concern, and perspective-taking toward their own partner. Similar to the start of the panel, audience members endorsed low to moderate levels of minimization, victim blaming, and lack of violence recognition. The most and least important motivations for their behavior change also remained the same.

Overall, audience members indicated high levels of agreement with retrospective statements about how their understanding of abuse increased in various ways after the panel. Self-report ratings suggest that participants were mostly emotionally engaged with the panel, somewhat identified with the panel content, and rated the panel content as mostly factual. Finally, audience members generally indicated little to no resistance to the panel in terms of having problems with the alliance with the speakers, feeling hopeless about changing, and being passively reactive. However, average self-report ratings suggest that audience members had moderate psychological reactance to the panel.

Associations between audience states. To further understand how JII participants' feelings and beliefs are associated with one another before and after the panel (RQ1), Spearman's rho correlation coefficients were computed between mean total domain scores from the pre- and post-panel surveys and reported in Tables 4.4, 4.5, and 4.6. There were many significant correlations within pre-test and post-test scores. All 
significant correlations were generally medium to large in magnitude. The pattern of associations supports a majority of the hypothesized relationships between participant state attributes before and after the panel, although the predictions were not always supported at both pre- and post-test.

Many of the expected positive associations among facilitating states, positive associations among hindering states, and negative associations between facilitating and hindering states were found, but some surprising positive associations were also found between facilitating and hindering states. As hypothesized, JII state empathy (empathic concern, personal distress, perspective-taking), reintegrative shame, motivation to change, and understanding of the impact of abuse tended to be positively associated with one another (hypothesis 1a). Similarly, feelings of stigmatizing shame, minimization of abuse (minimization, lack of violence recognition, and victim blaming), and resistance (problem with alliance, hopelessness, passive reactance, and psychological reactance) were also often positively associated with one another as expected (hypothesis 1b). However, only some of these positive and negative states were strongly negatively associated with one another as anticipated (hypothesis 1c). Unexpectedly, some of the positive and negative states were actually positively associated with one another. As a large volume of correlations were statistically significant, only prototypical and atypical exemplars of the results are presented in tables and described in the narrative below. Tables with all additional correlations are included in Appendix E.

\section{Hypothesized facilitating participant states (hypothesis 1a): Empathy,} reintegrative shame, motivations to change, and understanding of abuse. Empathy and 
reintegrative shame tended to be positively associated with one another, although there were different patterns of association before and after the panel between the three dimensions of empathy (feelings of distress, feelings of concern, and perspective-taking) and reintegrative shame. These associations are presented in Table 4.4. Before the panel, participants' feelings of empathic distress (e.g., anxious, upset, disturbed), empathic concern (e.g., sympathetic, concerned, compassionate), and reintegrative shame (e.g., feeling remorse or regret, feeling bad about something they had done) were all strongly related to one another, but none were correlated with perspective-taking of their own partner (e.g., feeling what their partner felt during their abusive incidents). After the panel, the pattern of relationships between aspects of empathy and reintegrative shame was different. Empathic distress was no longer significantly related to empathic concern, but remained associated with feelings of reintegrative shame. Importantly, post-panel perspective-taking of their own partner was related to both empathic concern $(\rho=.41, p$ $<.001)$ and feelings of reintegrative shame $(\rho=.36, p=.002)$. This suggests that participants' empathic concern and reintegrative shame are more related to their thoughts and feelings about their own partners after the panel than they are when they enter the panel.

There were also several notable positive associations between participants' empathy, reintegrative shame, and several other-focused motivations for behavior change (e.g., the effects of abuse on children) before and after the panel. Associations between empathy and motivations are presented in Table 4.5. There were moderate significant correlations between participants' pre-panel perspective-taking and two such motivations 
for behavior change: the effects of abuse on their partners $(\rho=.31, p=.006)$ and the effects of abuse on their children $(\rho=.28, p=.016)$. However, these associations did not persist after the panel. Pre-panel ratings of the effects of abuse on partners was also positively correlated with both pre-panel empathic concern $(\rho=.20, p=.084)$ and reintegrative shame $(\rho=.20, p=.080)$, although these associations only approached statistical significance. This other-focused motivation was also significantly related to post-panel reintegrative shame $(\rho=.26, p=.036)$, meaning those who rated this factor as more important before the panel tended to have higher levels of reintegrative shame afterward. Pre-panel perspective-taking was also significantly associated with the motivation of improving the quality of relationship with their partner before $(\rho=.32, p$ $=.006)$ and after the panel $(\rho=.39, p=.003)$. Unexpectedly, post-panel perspectivetaking was negatively related to some motivating factors for behavior change, although these were more self-focused in nature: not wanting to lose their job $(\rho=-.35, p=.006)$, the financial impact being too great $(\rho=-.27, p=.036)$, and not getting arrested $(\rho=-.26$, $p=.043)$. This suggests that participants with greater perspective-taking of their own partner before the panel tended to rate other-focused motivations for behavior change as more important (e.g., the effects of abuse on their children, improving the quality of relationship with their partner). After the panel, participants with more perspective-taking also tended to rate self-focused motivations as less important reasons for changing their behavior (e.g., not getting arrested).

Some dimensions of empathy, though, also related positively to more self-focused rather than other-focused motivations. Empathic distress was positively related to the 
motivation of not wanting to feel bad about themselves, both marginally before the panel $(\rho=.21, p=.063)$ and significantly after the panel $(\rho=.28, p=.037)$. Post-panel empathic distress was also positively related to other self-focused motivations before the panel, such as not wanting to feel bad about themselves $(\rho=.33, p=.010)$, the financial impact being too great $(\rho=.31, p=.016)$, and not getting arrested $(\rho=.32, p=.011)$. Pre-panel empathic concern was also positively associated with two self-focused motivations: not wanting to look bad to others $(\rho=.21, p=.074)$, though this was only marginally significant, and not wanting to feel bad about themselves $(\rho=.23, p=.047)$. Dimensions of empathy therefore appeared related to both self- and other-focused motivations for behavior change at different time points.

The vast majority of motivations for behavior change also had strong positive associations among themselves before and after the panel. The highest associations before the panel being between not wanting to lose their job and the financial impact being too great $(\rho=.52, p<.001)$ and between the effects of abuse on their partner and the effects of abuse on their children $(\rho=.46, p<.001)$. The former association remained the strongest correlation after the panel as well, while the latter remained significant but decreased slightly in magnitude $(\rho=.39, p=.002)$. This suggests multiple motivating factors were important to participants in their behavior change and that some factors appeared to be closely tied to one another. Before the panel, there tended to be stronger correlations among self-focused motivations $(.30<\rho<.53)$ and among other-focused motivations $(.32<\rho<.47)$. For example, two self-focused motivations, the financial consequences of abuse and not wanting to lose their jobs, and two other-focused 
motivations, the effects of abuse on their partner and the effects of abuse on their children, were both stronger than the correlations between the self- and other-focused motivations $(-.12<\rho<.38)$. After the panel, there magnitude of the correlations fluctuated somewhat between and among self- and other-focused motivations, although the pattern described earlier remained fairly consistent.

As expected, some of these facilitating individual-level states were also positively associated with participants' retrospective ratings of increasing their understanding of abuse after the panel. These associations are presented in Tables 4.4 and 4.5. Participants who began the panel with higher levels of perspective-taking of their own partner had higher retrospective ratings of their understanding of the impact of abuse after the panel $(\rho=.47, p<.001)$. However, the other two state empathy scores before the panel were not associated with this post-panel outcome. Retrospective understanding of abuse was also positively associated with empathic concern $(\rho=.49, p<.001)$, perspective-taking $(\rho=.53, p<.001)$, and reintegrative shame $(\rho=.29, p=.012)$ after the panel, but were not significantly related to empathic distress or any motivations for behavior change. That is, participants with higher levels of empathic concern, perspective-taking of their own partner, and reintegrative shame after the panel tended to perceive themselves as having more of an increased understanding of the impact of abuse. Their retrospective understanding of abuse did not relate to their level of empathic distress or ratings of which motivations for behavior change were more important to them at the end of the panel. Finally, retrospective understanding of abuse was also marginally associated with a general motivation for behavior change before the panel, not thinking it is right to be 
abusive $(\rho=.25, p=.054)$. This suggests that those who viewed this general motivation as more important before the panel may have seen themselves as increasing more in their understanding of abuse after the panel.

Hypothesized hindering participant states (hypothesis 1b): Stigmatizing shame, minimization of abuse, and resistance. Many hindering states were also positively associated with one another before and after the panel. These associations are presented in Table 4.7. Dimensions of minimization were all strongly correlated with one another at pre- and post-test, such as minimization of abuse (believing there was nothing wrong with their abusive behavior) and lack of violence recognition (not recognizing their behavior was harmful to their partner) after the panel $(\rho=.42, p<.001)$. Several dimensions of resistance were also positively related to one another after the panel, such as problem with alliance with the speakers (e.g., not trusting the panelists, feeling like the panelists were blaming them) and hopelessness (e.g., feeling that life will never get better even if trying to change) after the panel $(\rho=.42, p=.001)$. Unsurprisingly, participants who endorsed one aspect of minimization or resistance seem to also endorse other dimensions of the same hindering states.

However, associations between negative states were not static over the course of the panel, suggesting that some participants may develop stronger relationships among negative states during or after the panel. Although stigmatizing shame was not significantly associated with any dimensions of minimization before or after the panel, both stigmatizing shame and all dimensions of minimization were positively correlated with resistance after the panel. Post-panel stigmatizing shame was related to hopelessness 
$(\rho=.39, p=.002)$ and problem with alliance $(\rho=.28, p=.027)$, while post-panel minimization and victim blaming were positively associated with all dimensions of minimization except psychological reactance. This suggests that participants with greater feelings of stigmatizing shame and minimization at the end of a panel are also more resistant to the panel in multiple ways.

\section{Hypothesized associations between facilitating and hindering participant states}

(hypothesis 1c). Many of the expected patterns of association between positive and negative states were supported by the data. These associations are presented in Table 4.8. For example, perspective-taking was negatively and significantly correlated with all aspects of minimization, as anticipated, both before (e.g., minimization, $\rho=-.58, p<.001$ ) and after (e.g., victim blaming, $\rho=-.51, \mathrm{p}<.001$ ) the panel. Empathic concern and reintegrative shame were also negatively correlated with these minimization aspects, although only some associations were statistically significant. This suggests that participants with greater perspective-taking of their own partners and higher levels of empathic concern tended not to endorse statements minimizing the responsibility for their abuse. Most dimensions of resistance were also negatively associated with dimensions of state empathy, particularly perspective-taking (e.g., with passive reactance, $\rho=-.33, p$ $=.008)$, after the panel. In addition, most dimensions of pre-panel minimization were negatively associated with post-panel empathic concern (e.g., victim blaming, $\rho=-.34, p$ $=.006$ ), perspective-taking (e.g., minimization, $\rho=-.50, p<.001$ ), reintegrative shame (e.g., lack of violence recognition, $\rho=-.32, p=.008$ ), and retrospective ratings of their increased understanding of abuse (e.g., victim blaming, $\rho=-.46, p<.001$ ). Pre-panel 
stigmatizing shame was also negatively related to retrospective understanding of abuse after the panel, although this finding was only marginally significant $(\rho=-.23, p=.073)$. In addition, post-panel stigmatizing shame, all dimensions of minimization, and all dimensions of resistance were also negatively correlated with retrospective understanding of abuse after the panel (e.g., passive reactance, $\rho=-.35, p=.004$ ), although some of these associations were also only marginally significant. This suggests there may be an inverse relationship between hindering individual-level states and participant perceptions of whether the panel increases their understanding of abuse.

Although many expected negative associations between facilitating and hindering states were found, there were also some surprising positive associations between these two types of states. Unexpectedly, pre-panel stigmatizing shame was positively correlated with empathic distress $(\rho=.54, p<.001)$, empathic concern $(\rho=.40, p<.001)$, and reintegrative shame $(\rho=.55, p<.001)$. These associations persisted after the panel with positive associations between stigmatizing shame and empathic distress $(\rho=.49, p<.001)$ and stigmatizing shame and reintegrative shame $(\rho=.51, p<.001)$. However, not all positive associations between facilitating and hindering states before the panel persisted after the panel. For example, pre-panel stigmatizing shame and pre-panel empathic concern were positively correlated $(\rho=.40, p<.001)$, but post-panel stigmatizing shame and post-panel empathic concern were not significantly correlated $(\rho=-.15, p>.10)$. Those with higher levels of state empathy before the panel tended to have less minimization of responsibility or resistance after the panel, while those with greater minimization before the panel tended to have less state empathy, reintegrative shame, and 
increased understanding of the impact of abuse after the panel. However, pre-panel empathic distress was positively associated with most dimensions of resistance (e.g., psychological reactance, $\rho=.31, \mathrm{p}=.026)$, although some were only marginally significant. That is, those in greater distress before the panel tended to have more resistance to the panel process afterward. A dimension of resistance, hopelessness, was also positively associated with post-panel empathic distress $(\rho=.31, p=.017)$. Although those with greater resistance to the panel process tended to have lower levels of state empathy, those with higher levels of hopelessness also tended to have high levels of distress. The unanticipated positive associations between positive and negative states suggests that the experience of impact panels is complex and not unidimensional (either positive or negative). Rather, some seemingly opposing states may exist in participants at the same time.

Similarly, although negative states were expected to negatively relate to all motivations for behavior change, results indicated that some negative states and motivations were actually positively correlated with one another. These associations are presented in Table 4.9. As expected, minimization was negatively correlated an otherfocused motivation before the panel: the effects of abuse on their partner $(\rho=-.23, p$ $=.041)$. The pre-panel motivation of the effects of abuse on their partner was also negatively associated with post-panel victim blaming $(\rho=-.25, \mathrm{p}=.061)$, though marginally, and lack of violence recognition $(\rho=-.28, p=.034)$, meaning participants who rated this factor as more important before the panel tended to have lower levels of minimization after the panel. After the panel, victim blaming $(\rho=-.30, p=.022)$ and 
several dimensions of resistance were also negatively associated with wanting to improve the quality of relationship with their partners (e.g., problem with alliance, $\rho=-.30$, p $=.023)$. However, pre-panel minimization and victim blaming were positively associated with several self-focused motivations, not getting arrested $(\rho=.32, p=.004)$ and not wanting to lose their job $(\rho=.23, p=.044)$. Post-panel minimization and resistance were also positively associated with self-focused motivations, (e.g., not wanting to look bad to others). This suggests that the motivations for behavior change for participants with greater minimization, victim blaming, and resistance may be more related to self-focused factors (e.g., not getting arrested) than other-focused factors (e.g., the impact of abuse on partners).

Changes in participant states. To understand how JII participants changed pre- to post-panel in the feelings and beliefs targeted by restorative justice processes, Wilcoxon rank sum tests examined differences between pre- and post-panel outcomes of state empathy, stigmatizing shame, reintegrative shame, minimization, and motivation to change (RQ2). The pre- and post-panel mean scores and effect size of the mean difference for each score are presented in Table 4.3. Overall, results suggest that JIIs experienced large increases in most of the facilitating states and small decreases in some hindering states after the panel.

The hypothesis that state empathy, reintegrative shame, and motivation to change would increase after the panel (hypothesis 2a) was strongly supported. After the panel, participants significantly increased in empathic distress $(z=-4.61, p<.001)$, empathic concern $(z=-6.35, p<.001)$, reintegrative shame $(z=-4.34, p<.001)$, and a general 
motivation for behavior change: thinking it is not right to be abusive $(z=-2.22, p=.026)$. In addition, perspective-taking also increased after the panel $(z=-1.89, p=.059)$, although only marginally significantly. Most other motivating factors for behavior change did not differ significantly between time points, but the self-focused motivation of not getting arrested decreased and was marginally significant $(z=-1.76, p=.078)$. The increase in these feelings and beliefs were small to large in magnitude, with effect sizes (d) ranging from .15 to 1.50 . The smallest increases were in motivation factors, while the largest were in dimensions of state empathy.

The hypothesis that stigmatizing shame and minimization of abuse would decrease after the panel (hypothesis 2 b) was partially supported. Participants decreased in minimization $(z=-2.51, p=.012)$ and victim blaming $(z=-2.59, p=.01)$, although there were no significant changes in participants' stigmatizing shame or lack of violence recognition. The decreases in these beliefs were small for both victim blaming $(d=.17)$ and minimization $(d=.28)$.

Together, these results suggest that participants have higher levels of state empathy and reintegrative shame and lower levels of minimization and victim blaming at the end of these impact panels. The importance of some motivations for behavior change may also change after panels, such as the general motivation of thinking it is not right to be abusive increasing and not getting arrested decreasing in importance. There may be more sizeable increases in certain dimensions of empathy (e.g., empathic concern) and only small decreases in minimization and victim blaming. 
Conditions of change. Simultaneous multiple regressions were conducted to further determine whether control variables (emotional engagement, identification, factuality, resistance dimensions, age, and length of time in BIPs) contributed incrementally to the prediction of these post-panel changes above and beyond that accounted for by the pre-panel score for each changed domain. Inspection of P-P plots and a graph of the standardized residual values indicated that the assumptions of linear regression were met. As several of the regression models indicated that the control variables were not statistically significant predictors for some post-panel changes, only those with significant control predictors are presented in Tables 4.10 to 4.13 and described in the narrative below. The remaining tables are included in Appendix E.

Many of the changes in participant states were not dependent on these additional factors. Empathic concern, reintegrative shame, and the importance of the two motivations for behavior change that significantly increased or decreased after the panel did not depend on participants' age, length of time in BIPs, emotional engagement (e.g., feeling that the panel had an effect on their emotions), identification with the panel content (e.g., relating to what was described on the panel), rating of the panel's factuality (e.g., that what was described on the panel actually happened), or level of resistance to the panel process. The only significant relationships in these models were between the pre- and post-panel score for each domain: pre- and post-panel empathic concern $(\mathrm{B}=$ $0.40, t(27)=3.12, p=.004)$, pre- and post-panel reintegrative shame $(\mathrm{B}=0.93, t(28)=$ $4.88, p<.001)$, pre- and post-panel ratings of the importance of not getting arrested $(\mathrm{B}=$ 
$0.52, t(30)=3.06, p=.005)$, and pre- and post-panel ratings of the importance of thinking it is not right to be abusive $(\mathrm{B}=0.79, t(29)=3.33, p=.002)$.

However, some of the control variables incrementally predicted participant postpanel scores, above and beyond its pre-panel score, in several domains: empathic distress, perspective-taking, minimization, and victim blaming. Significant control variables in these analyses included multiple dimensions of resistance, participants' age, and their length of time in BIPs, though in some cases they only approached statistical significance. Multiple dimensions of resistance tended to negatively predict empathic distress and perspective-taking and positively predict minimization and victim blaming. Participants’ age negatively predicted empathic distress and positively predicted victim blaming, although the magnitude of the prediction was very slight in both cases. Length of time in BIPs negatively predicted both minimization and victim blaming, although their magnitudes were very slight as well. While the pre-panel scores for each domain tended to be the largest predictor of post-panel scores, such as in perspective-taking $(B=0.76$, $t(29)=6.18, p<.001)$, these additional factors appeared to further influence changes in participant scores after the panel.

Restorative justice process analysis (RQ3 and RQ4). To understand what restorative justice processes occur during surrogate impact panels (RQ3), descriptive statistics were calculated for average total scores of the observed processes. Observed process scores were averaged across the two raters and then averaged across each of the observed panels. The vast majority of the expected restorative justice processes were observed by multiple raters across each panel, with the exception of two processes. 
Negative displays of support towards the speakers by audience members and displays of internal conflict by audience members were not observed to occur during any panels. Means and standard deviations of the frequencies of each panel process observed at each step of the panel are presented in Table 4.14.

Implemented restorative justice processes (RQ3). Panel observation scores indicate that the most frequent actions that occurred across all steps of the panel were several facilitating group-level processes: panel speakers sharing their stories in nonstigmatizing ways, audience members showing positive support for speakers, and speakers showing positive support towards the audience. In addition, the most frequently observed speaker-audience member exchange across all steps of the panels was syncing or attunement.

Examination of the panel processes over time provides further insight into how the interactions occur in the panel setting. During the speaker stories, speakers shared their story in non-stigmatizing ways much more frequently than in stigmatizing ways. Speaker non-stigmatizing sharing increased in frequency from the first to the third speaker and became most frequent in the question and answer session. There were more frequent displays of speaker vulnerability when each speaker shared their story than during the question and answer session. Speakers showed positive support to the audience fairly equally during each of their stories, and showed more than twice as many displays of support during the question and answer session. Negative displays of support by the speakers toward the audience and sharing stories in stigmatizing ways were the two least frequent speaker actions, occurring less than once or twice per panel step on 
average. Audience member positive engagement peaked during the question and answer session, while negative audience engagement, though rare, increased slightly across each step of the panel. Audience member discomfort occurred fairly equally across the three speakers' stories and declined slightly during the question and answer session. Positive displays of support from the audience toward the speakers were the most frequently observed type of audience behavior, which increased across each step of the panel. Audience displays of positive or negative accountability were the least frequently observed audience behaviors and occurred only during the question and answer session, with slightly more displays of positive than negative accountability. Finally, although speaker-audience exchanges were generally less frequently observed than speaker or audience displays toward one another, the most frequently observed type of exchange across all panel steps was syncing/attunement, which peaked during the question and answer sessions. Positive and negative speaker-audience exchanges were most commonly observed during the question and answer session. Positive exchanges were observed twice as frequently as negative exchanges, though both types of interactions were not as common as most other speaker or audience behaviors.

\section{Associations between observed restorative justice processes (RQ4). To}

understand how restorative justice processes were associated with one another during panels (RQ4), Spearman's rho correlation coefficients were computed between each process mean score for each step of the observed panels. These correlations are presented in Table 4.15. Many significant correlations were detected and all significant correlations were large in magnitude. Similar to the associations between individual-level participant 
states, the associations between observed interactional processes seemed to follow a pattern of positive associations among facilitating group-level processes, as expected, as well as some unexpected positive associations between facilitating and hindering grouplevel processes. The hypothesis that facilitating speaker actions (positive support for JIIs, sharing their story in a non-threatening way, and showing vulnerability) would be positively associated with both facilitating JII actions (positive support for speakers, positive engagement, positive accountability) and facilitating speaker-JII exchange and attunement/syncing (hypothesis 4a) was strongly supported. The hypothesis that hindering speaker actions (negative support for JIIs, sharing story in a threatening way), hindering JII actions (negative support for speakers, negative engagement, negative accountability), and negative speaker-JII exchange would be positively associated (hypothesis 4b) was only weakly supported. Unexpectedly, some hindering panel processes were positively associated with facilitating group-level processes.

\section{Hypothesized associations between facilitating group-level processes (hypothesis} 4a). There were many positive associations between facilitating panel group-level processes. Some of the most notable positive associations involved JII displays of positive support to speakers (e.g., expressions of respect for the speakers). JII positive displays of support to speakers was associated with positive engagement from JIIs ( $\rho$ $=.65, p=.001)$, positive exchanges between speakers and JIIs $(\rho=.74, p<.001)$, speaker displays of positive support to JIIs $(\rho=.61, p=.002)$, and syncing/attunement between speakers and the audience (e.g., mirroring behavior; $\rho=.48, p=.019$ ). There were many additional significant associations between positive processes, such as 
between JII positive engagement and JII positive accountability $(\rho=.41, p=.049)$ and between positive speaker-JII exchange and speaker displays of positive support to JIIs ( $\rho$ $=.55, p=.005)$. Panel observations suggest that panels with some facilitating group-level processes (e.g., facilitating JII actions) tend to have others as well (e.g., facilitating speaker actions).

Hypothesized associations between hindering panel processes (hypothesis 4b). In contrast, only two of the expected positive associations between hindering group-level processes were found. Speakers providing negative support for JIIs was positively associated with negative speaker-JII exchange $(\rho=.38, p=.068)$, meaning panels with more negative support for the audience by the speakers (e.g., using stigmatizing names and labels for abusive people) tended to have more observations of negative exchange between speakers and the audience (e.g., interruptions of one another). Negative JII engagement was also positively associated with JII negative accountability $(\rho=.36, p$ $=.084$ ), meaning panels with more negative audience engagement (e.g., appearing uninterested or sullen) tended to have more instances of negative JII accountability (e.g., claiming their actions were unintentional). However, both of these correlations were only marginally significant. This suggests that panels with observations of one type of hindering process (e.g., JII negative engagement) do not necessarily manifest additional types of hindering processes.

Unexpected associations between facilitating and hindering panel processes. Finally, some associations were found between facilitating and hindering panel processes that were significant and unexpected. For example, JII negative accountability was 
positively associated with JII positive accountability $(\rho=.66, p<.001)$, suggesting that panels in which some JIIs demonstrated positive accountability also tended to have JIIs demonstrate negative accountability. Negative speaker-JII exchange was also positively associated with positive speaker-JII exchange $(\rho=.50, p=.013)$, speaker displays of positive support to JIIs ( $\rho=.45, p=.026$ ), and negatively associated with JII discomfort ( $\rho=-.65, p=.001)$. This suggests that similar to the individual-level experience of JIIs, the group-level processes that occur during panels are not unidimensional, as a single panel can manifest both facilitating and hindering restorative justice processes.

\section{Group-level restorative justice process and individual-level participant state}

analysis (RQ5). To further examine the relationships between observed panel processes and participant attributes, Spearman's rho correlation coefficients were computed between each total mean score for processes observed during each panel and post-panel participant feelings and beliefs. The correlations are presented in Tables 4.16 and 4.17. Several significant correlations were detected and all significant correlations were small to moderate in magnitude. The hypothesis that facilitating group-level restorative justice processes (positive support for JIIs, positive support for speakers, and attunement/syncing) would be positively associated with facilitating individual-level states (empathy, reintegrative shame, motivation to change, and understanding of the impact of abuse) after the panel was partially supported (hypothesis 5a). However, the hypothesis that hindering group-level restorative justice processes (negative support for JIIs, negative accountability, and negative speaker-JII exchange) would be positively associated with 
hindering individual-level states (stigmatizing shame, minimization of abuse, and resistance) after the panel was only weakly supported (hypothesis $\mathbf{5 b}$ ).

\section{Hypothesized associations between facilitating restorative justice processes and}

JII participant states (hypothesis 5a). Several positive associations were found between facilitating group-level processes and individual-level states, particularly in domains of empathy and other-focused motivations for behavior change. As expected, speaker displays of positive support to JIIs were positively related to post-panel empathic concern $(\rho=.24, p=.037)$. In addition, JII displays of positive support to speakers were positively associated with two other-focused motivations of behavior change reported after the panel: the effects of abuse on their partner $(\rho=.27, p=.031)$ and the effects of abuse on their children $(\rho=.29, p=.022)$. Positive speaker-JII exchange was also positively associated with post-panel reports of one of these motivations: the effects of abuse on their children $(\rho=.29, p=.022)$. No significant associations were found between any of the hypothesized processes and additional dimensions of state empathy, reintegrative shame, retrospective understanding of abuse, or other motivations for behavior change. While these associations cannot support any causal inferences, the results suggest that several facilitating panel processes (e.g., positive speaker support toward JIIs) may relate to some facilitating individual-level states (e.g., empathy).

Unexpectedly, several facilitating group-level processes were negatively associated with an individual-level state, reintegrative shame, after the panel. Post-panel reintegrative shame was negatively associated with JII positive engagement $(\rho=-.19, p$ $=.091)$ and with JII positive accountability $(\rho=-.19, p=.092)$, although these 
associations were only marginally significant. This suggests that panels with more observations of positive JII engagement and positive JII accountability tended to have lower levels of self-reported reintegrative shame after the panel.

\section{Hypothesized associations between hindering restorative justice processes and}

JII participant states (hypothesis 5b). The vast majority of expected associations between hindering panel processes and hindering JII post-panel states were not found in this sample. JII negative engagement was positively associated with two domains of postpanel resistance, passive reactance $(\rho=.29, p=.02)$ and hopelessness $(\rho=.25, p=.051)$, though the latter association was only marginally significant. JII negative accountability was also positively related to another dimension of resistance, psychological reactance, but this only approached the threshold for statistical significance $(\rho=.22, p=.089)$. Similarly, negative speaker-JII exchange was positively related to a dimension of resistance, problem with alliance, but also only approached statistical significance ( $\rho$ $=.22, p=.08)$. None of the negative panel processes were significantly associated as hypothesized with post-panel stigmatizing shame or any of the three dimensions of minimization. Again, although these associations cannot support any causal inferences, the results suggest that relatively few hindering group-level processes (e.g., JII negative engagement) appear to be related to hindering individual-level states (e.g., resistance).

\section{Discussion}

This study was intended to address gaps in the few previous studies of IPV surrogate impact panels by empirically testing changes in JII participants' feelings and beliefs, observed group-level processes of panels, and how group-level processes relate to 
individual-level feelings and beliefs in the panel setting. Findings significantly expand what is known about how IPV surrogate impact panels function and JIIs' experiences immediately before and after panels. This knowledge can inform future decisions about the use of this potentially beneficial restorative justice program addition to BIPs.

Summary of findings. Key findings indicate that after surrogate impact panels, JIIs experience moderate to large increases in state empathy, reintegrative shame, and a general motivation for behavior change after panels. They also experience small decreases in minimization, victim blaming, and a self-focused motivation for behavior change. Although several of these changes did not appear to be conditional upon JII characteristics (e.g., age, personal identification with the panel content), some changes were related to these additional factors. For example, the increase in JII perspectivetaking of their own partner was higher for JIIs who reported being more emotionally engaged in the panel.

In addition, differentiating the associations between participants' feelings and beliefs at each time point further illuminated how JIIs may be affected by panels. For example, JIIs' empathic concern and reintegrative shame were more strongly associated with perspective-taking of their own partners after the panel than they were before the panel. The closer links between perspective-taking of their own partners, empathic concern, and reintegrative shame after the panel are especially promising findings, given previous research that individuals who perpetrate IPV can particularly fail in having empathy toward their own partner (e.g., Stith, Smith, Penn, Ward, \& Tritt, 2004). These findings suggest that the panel may be an emotionally charged setting for participants, in 
which they feel a variety of emotions related to distress, concern, and reintegrative shame, and that these feelings are more strongly associated with their thoughts and feelings about their own partner after the panel than they are before the panel. These promising results encourage further exploration of IPV surrogate impact panels to understand how they may generate empathic responses from participants and specifically greater perspectivetaking toward their own partner(s).

Most of the expected group-level restorative justice processes were observed in the panel setting, except two: negative JII displays of support towards the speakers and JII displays of internal conflict. The most frequently observed actions during panels were speakers sharing their stories in non-stigmatizing ways and JIIs and speakers showing positive support for one another. The most frequently observed type of exchange between speakers and JIIs was syncing or attunement, a critical component of the Interaction Ritual Model (Rossner, 2013).

Some group-level restorative justice processes appear to be related to individuallevel states in meaningful ways. Several expected positive associations were found between facilitating group-level processes (e.g., JII positive support for speakers) and facilitating individual-level states (e.g., other-focused JII motivations to change their abusive behavior). On the other hand, relatively few of the expected associations was found between hindering group-level processes (e.g., JII negative engagement) and hindering individual-level states (e.g., resistance). Although these findings cannot support any causal inferences about the effects of IPV impact panels, they suggest that panels 
may be capable of promoting desired behavior changes in abusive individuals and future research in this area is warranted.

Contributions. The current study makes several important and unique contributions to the small existing body of research on IPV surrogate impact panels. This study is the first pre- and post-test analysis of immediate changes in JII individual-level feelings and beliefs before and after IPV surrogate impact panels. It is also the first to document specific types of group-level restorative justice processes that occur during panels through field observations, increasing the trustworthiness of the small body of research on IPV surrogate impact panels with the first set of multi-rater other-report data. Finally, it is the first in-depth examination of the relationships among individual-level states and group-level dynamics in this setting. In total, this study adds both depth and breadth to the current understanding of how IPV surrogate impact panels function as a component of BIPs.

Potential influences on individual-level behavior change. Several findings in the current study are relevant to consider as potential processes of change that may begin or increase during IPV surrogate impact panels (Prochaska et al., 1992). The panel could be considered a corrective emotional experience, an activity involved in the process of selfreevaluation that consists of assessing how thoughts and feelings about the self relate to the problem. The increases in JIIs' feelings of empathic concern, empathic distress, reintegrative shame could be possible turning points for JIIs as they continue to progress through their broader behavior change, together with their shifts in motivations for behavior change and perspective-taking of their own partner. 
In addition, some changes in individual-level outcomes were consistent with the Interaction Ritual Model (Rossner, 2013), although the current study did not attempt to differentiate successful and unsuccessful panels through a sequential modeling of panel steps. Findings suggest that some JIIs decrease in their minimization and victim blaming after surrogate impact panels, similar to the shifts Rossner found in restorative justice conference participants who decrease in defiance over the course of the conference (which involves two individuals directly from the same crime). JIIs also tend to increase in emotions of reintegrative shame and those associated with empathic distress and empathic concern, and some JIIs also experience shifts in their motivation to change specifically in the importance of some factors in motivating their change. These immediate panel outcomes are similar to the short-term outcome of symbolic reparation described in Rossner's model, in which those responsible for wrongdoing express remorse. These short-term changes are linked to longer-term behavior change in the model, as these changes can lead to efforts to engage in more pro-social behavior, longterm emotional change, and reduced reoffending.

Finally, the current study's findings also suggest that the group dynamics and individual-level feelings and beliefs of participants in IPV surrogate impact panels may relate to factors that have been found to promote behavior change in previous studies of IPV interventions. Similar to previous research that acknowledgment of responsibility, increasing orientation to change, and positive support of group processes are important behaviors to study in BIP groups (Semiatin et al., 2013; Silvergleid \& Mankowski, 2006), the current study suggests that more positive JII support for survivors in the panel is 
linked to increases in some JIIs motivations to change, specifically regarding the effects of abuse on their partner and the effects of abuse on their children. Although the current study documents only immediate changes in JII states like motivation, previous research suggests that behavior in interventions can predict positive outcomes in treatment, such as decreased partner-reported psychological and physical violence (Semiatin et al., 2013), and may be a small but important step toward individual-level behavior change. Findings from the current study further suggest that IPV surrogate impact panels may create desired individual-level changes in a way that is consistent with feminist theories of how to address IPV by challenging social norms that encourage male dominance and control over others (e.g., Carden, 1994) and demonstrating that a harmed group (e.g., survivors in IPV surrogate impact panels) can be centered in a restorative justice process while maintaining respect for the group responsible for the harm (e.g., JIIs) rather than dominating them. Finally, IPV surrogate impact panel processes and immediate changes are also consistent with individual theories of promoting IPV behavior change by increasing JIIs' motivation and decreasing their resistance (Scott, 2004).

\section{Group-level processes: Facilitating and hindering factors of restorative justice}

encounters. The current study's findings demonstrate that the Interaction Ritual Model (Collins, 2004; Rossner, 2013) is a relevant deductive framework for understanding the restorative justice processes of IPV surrogate impact panels. A majority of the expected restorative justice processes from this model were observed in the panel setting and many of the structural components of restorative justice conferences identified by Rossner translated to the panel context. Although the current study measured the frequency of 
processes across panels rather than percent agreement with questions about these practices, as Rossner did, the following restorative justice processes appeared to translate to the context of IPV surrogate impact panels: balance (e.g., how much was each group contributing, if one group dominated by the other), stigmatization (e.g., if stigmatizing shaming was expressed by stigmatizing names or disapproval of the person), defiance (e.g., if participants deflected responsibility), reintegration (e.g., if support was given by one group to the other, if approval was expressed of a person or group), and emotional energy (e.g., if participants engaged in the process, if they were uncomfortable). In addition, moments of syncing or attunement in the synchronization of survivors and JIIs (e.g., group laughter, shared silence in response to an expression of pain) were observed in IPV surrogate impact panels that parallel the emotional turning point in the Interaction Ritual Model, an especially important interactional process that differentiates successful from unsuccessful attempts at restorative justice (Rossner, 2013).

However, there was some degree of inconsistency between the Interaction Ritual Model (Rossner, 2013) and the observational data in the current study. Specifically, one structural component of the model, solidarity (e.g., physical contact between participants, apology given, forgiveness), did not appear as relevant to IPV surrogate impact panels as other model components. This is likely due to differences in the nature of the relationship between participants in restorative justice conferences and IPV surrogate impact panels. While restorative conferences involve dyadic interactions between a small number of participants who have been connected by the same direct crime or harm, the panels involve participants from similar crimes or harms but are surrogates to one another (i.e., 
they are not from the same direct relationship). While some aspects of solidarity, such as remorse, may still be relevant in this surrogate context, other aspects, particularly apology and forgiveness, may be less relevant and therefore unlikely to manifest.

The pattern of changes in JII individual-level feelings of reintegrative shame and stigmatizing shame in the current study suggest that the group-level processes in IPV surrogate impact panels invoke emotional responses from participants through reintegrative shaming rather than stigmatizing shaming (Braithwaite, 1989). Survivors sharing their story in non-stigmatizing ways and making positive displays of support towards JIIs were more than five to ten times as frequent processes on average than sharing stories in stigmatizing ways and negative displays of support toward JIIs. Rather than focusing their disapproval on JIIs as a whole, survivors tend to focus on problematic behavior and maintain respect for JIIs and appreciation that they are attempting to change. This non-stigmatizing way of engaging with JIIs could further promote positive behavior change, as reintegrative shaming is linked with lower reoffense rates by such processes as acknowledging reintegrative shame and guilt-related emotions, increasing victim empathy, and decreasing minimization of responsibility (Braithwaite \& Braithwaite, 2001).

The observed restorative justice interactions further suggest that the panel manifests a set of social dynamics between survivors and JIIs that are diametrically opposite to the dynamics of abusive relationships, in which one partner attempts to exert power over the other (Pence \& McMahon, 2008). The group-level dynamics of surrogate impact panels are therefore important not only because of their relation to individual- 
level changes in JII outcomes, but are meaningful achievements in and of themselves. The current study focused on the relational interactions between survivors and JIIs not only in an effort to understand how individual-level outcomes change after panels, but to pay attention to the way in which relationship was created during panels and how participants expressed respect toward one another (Llewellyn et al., 2014). An "equitable, and inclusive, power relationship" (p. 194) is the foundation of restorative justice practice and the observed restorative justice processes that took place are manifestations of this program's paradigmatic assumptions: that IPV is harmful and can be changed by survivor-led sharing and relating to JIIs in their common humanity. Surrogate impact panel success depends just as much on the accomplishment of these restorative justice processes - positive support towards one another, positive exchange between participants, syncing/attunement, and so on - as on the individual-level changes that result from panel attendance. Survivors and JIIs in IPV surrogate impact panels appear to be capable of reflecting mutual respect for one another, mutual concern, and the acknowledgment that even these groups who are commonly held in opposition to one another can be interconnected in their efforts to heal and change. In this way, IPV surrogate impact panels may achieve a sense of restored equity by providing an alternative approach to justice and healing.

Triangulation of individual- and group-level findings. The self-report and observational data are fairly consistent with one another, and their convergence suggests that IPV surrogate impact panels involve sets of facilitating and hindering individuallevel states and group-level processes that relate to one another in meaningful ways. 
Facilitating states (JII state empathy, reintegrative shame, motivations to change, and retrospective understanding the impact of abuse) and processes (e.g., positive support for JIIs, positive support for speakers, syncing/attunement) seem to be consistently positively associated with one another. Hindering individual-level states (e.g., stigmatizing shame, minimization) also seem to be strongly associated among themselves, but relatively few associations were found among hindering group-level processes (e.g., negative support for speakers, negative speaker-JII exchange) or between hindering processes and states. The complementary research methods applied in the current study allowed for an indepth comparison among these states and processes and increase the credibility of findings (Denzin, 1978; Lincoln \& Guba, 1985; Stewart \& Shamdasani, 1990).

Surprisingly, some facilitating and hindering individual-level states and grouplevel processes were also positively related to one another (e.g., dimensions of empathy and stigmatizing shame), suggesting that the experience of impact panels is not unidimensional. For example, JII positive accountability was correlated with JII negative accountability. This could indicate that when JIIs heard another participant in the audience make a comment indicating negative accountability, they felt more comfortable to speak and demonstrate positive accountability (or vice versa). However, it could also be an indicator of overall engagement or activity level during panels, such that panels could be differentiated into "more active" and "less active" panels in which instances of both positive and negative accountability were more or less common. The unexpected positive associations found between dimensions of empathy and stigmatizing shame in particular could also indicate that the measure used in the current study (Marschall et al., 
1994) did not fully differentiate stigmatizing from reintegrative shame, as the measure does not specifically reference these constructs and instead differentiates them only as "guilt" and "shame." Although firm conclusions cannot be drawn based on the current study about causal or explanatory mechanisms of IPV surrogate impact panels, these results raise additional questions regarding whether they are due to panels' overall activity level, combinations of different sets of participants in the same panel with favorable and unfavorable reactions to the panel, or whether the panel elicits seemingly conflicting states within the same individuals.

Consistency with previous research on IPV surrogate impact panels. The current study is largely consistent with previous research on IPV impact panels and builds upon earlier research to form a growing body of evidence that these panels increase JIIs' empathy and understanding of the impact of abuse. The current study increases the confidence of previous findings from the most recent published study (Zosky, 2018) that IPV impact panels increase JIIs' awareness of the impact of IPV on direct survivors and children. Specifically, the pre- and post-panel individual-level feelings and beliefs documented in the current study provide greater specificity in how dimensions of empathy (e.g., perspective-taking) relate to retrospective increases in understanding of abuse and other-focused motivations to change abusive behavior. The increases in JII reintegrative shame, state empathy, and perspective-taking of their own partners after panels are also consistent with previous evidence that these panels evoke remorse in JIIs and empathy for speakers (Zosky, 2018), and the observational data from the current study further triangulates ways in which the panel may involve facilitating speaker 
actions, JII actions, and exchanges between them (e.g., JII support toward speakers) that are related to self-reported states (e.g., empathy). The current study also sharpens findings in previous studies of these panels by increasing the clarity of specific grouplevel processes that manifest during panels using a deductive model of restorative justice (Rossner, 2013) and increasing confidence in the current study's findings with the use of multi-rater observational assessment rather than a single researcher's observations in the previous ethnography (Sackett Kerrigan \& Mankowski, 2020a). Finally, the current study findings are consistent with and extend past research on how IPV surrogate impact panels impacts may affect JIIs, beyond identifying perceptions of the possible impacts on JIIs (Sackett Kerrigan \& Mankowski, 2020b), by documenting measurable changes in JIIs' self-reported feelings and beliefs during the panel (e.g., increases in empathy). They also link individual-level states to group-level restorative justice processes (e.g., JII positive support to speakers and an other-focused motivation for behavior change, the effects of abuse on children) to suggest possible ways in which the panel may influence individual participants.

Limitations. The applied nature of this research introduced many limitations that are important to note when considering the current study's findings. First, the study did not evaluate any panel impacts on survivors, but instead focused on JII outcomes as a first step in empirically assessing how panels function. Although we were unable to provide a similarly in-depth modeling of changes in survivor participants due to the small pool of survivor speakers that constrains the possible sample size for such analysis, the authors completed a previous qualitative study to describe the perceived impacts of 
panels on survivors in more detail (Sackett Kerrigan \& Mankowski, 2020c). In addition, it was not possible to implement a true experimental design in this study using random assignment to a no treatment condition, due to ethical concerns held by local gatekeepers in the field (e.g., judges) of withholding program components to JIIs in BIPs. Rather than testing comparisons of two groups of JIIs randomly assigned to either treatment (attending the panel) or control (not attending the panel), the current study findings were limited to only within-group comparisons in a single sample and thus cannot inform causal inferences about possible panel effects. Similarly, a quasi-experimental design was also not possible to implement in this context, due to natural variation in participants' tenure in BIP groups. As is common in the U.S., BIPs in Oregon generally are run in "open group" formats, meaning they contain JIIs with various lengths of time in the program (from enrollment to completion) within a single group. Comparisons of two convenience samples of participants who either attended a panel or were enrolled in a BIP group but did not attend a panel during the study window would thus mean that the "treatment plus" group would be in BIPs for at least 26 weeks to be eligible for the panel, whereas the "treatment as usual group" would vary in their length of time in BIPs. The natural variation in BIP group tenure would introduce a potential confound between the groups and it would therefore be misleading to attempt to isolate panel effects from other BIP effects in such a design. In addition, pilot interviews with probation personnel indicated that an archival analysis of JII case records would be unlikely to provide information regarding the immediate outcomes of panels, as POs are not uniformly required to track whether or not JIIs attend panels during their enrollment in BIPs. An 
analysis of historical records was therefore assumed to be less informative than the current study, which takes a first step toward understanding immediate changes in JIIs after attending a panel. Finally, the demographics of participants who self-selected into the current study's sample suggest that audience members are not very diverse in their demographics, particularly in their gender, race, and sexuality (i.e., few or no African American participants, nearly all male and heterosexual). This limited variability raises questions regarding the cultural relevance of this type of restorative justice program for other groups of audiences (e.g., from same-sex relationships), which data from the current study cannot address.

There are also a number of methodological limitations to the current study. Although multilevel models would be more theoretically appropriate to model the nesting of individual-level self-report data within the panel in which the individual participated, as even a small level of group clustering can inflate Type I errors (Barcikowski, 1981), data collection was extremely costly in time and only six panels were possible to include during the study timeframe. The evaluation of demographic differences between panel groups suggest that the six panel groups were not significantly different in key factors, which slightly mitigates concerns about group-level variance and interdependency.

Study attrition also limited the sample size and raises questions about potential bias in the responses from participants who elected to complete all survey measures. Participation in the panel was completely voluntary and anecdotal feedback from participants indicated that time constraints sometimes limited JIIs' capacity to remain after panels to complete post-panel surveys. However, it is possible that additional factors 
influenced JIIs' decision either not to participate in the study at all or to leave immediately after panels, only completing a pre- but not post-panel survey. Although average attrition from pre- to post-test was fairly low (15.9\%) across all observed panels, attrition rates were as high as $30.0 \%$ in one panel, and it is possible that some participants chose not to complete additional surveys due to their experience in the panel. For example, participants may have experienced heightened activation during panels and a subsequent desire to leave rather than spend more time in the setting focusing on their own feelings and thoughts immediately after the panel. Some participants may have completely rejected the panel content or process, and all associated activities including the post-panel survey. Study attrition may also indicate that data collection activities were overly burdensome on participants who did not have the resources required (e.g., time, energy) to complete the post-panel survey. These possible sources of selection bias were not possible to control, as this voluntary design was considered less threatening to the integrity of study findings than bias that may have resulted if the data collection was more coercive. Findings are believed to be more trustworthy as they are based on information from JIIs who fully elected to participate, as they were not compelled to do so by probation or other external mandate. However, the data in the current study was collected from individuals who chose and were able to fully participate in all survey measures, and these individuals likely differed from those who either did not participate at all or terminated their participation after the pre-panel survey. Those who fully participated may have been extremely responsive to the panel process or especially motivated to share their thoughts and feelings about their experience, and it is not 
possible to know to what extent this influenced the study's findings and conclusions. Attrition is a common issue in BIP evaluations particularly for court-mandated JIIs, with average program dropout rates ranging from $40 \%$ to $60 \%$ (Eckhardt, Murphy, Black, \& Suhr, 2006), making it very difficult to survey all program attenders.

Finally, the nature of the approach to observational data collection in this study limited the agreement that was possible to reach between raters. Observations were made in-vivo during IPV surrogate impact panels through field-based observation, rather than based on a recording from a single viewpoint that could be watched multiple times by the same rater. In an effort to disturb the natural panel setting as little as possible, raters sat behind JII audience members to adhere to panel seating expectations for community members. The large size of the room in which the panels were held required observers to sit on opposite sides of the room in order that all participants could be seen by at least one observer. This meant that raters sometimes observed entirely different groups of participants and could only observe the same interactions at some points during the panel. Any disagreement between raters in their coding of interactions that took place during panels may be due to this quality of data collection (i.e., if a behavior occurred in one sub-set of participants and did not occur in another sub-set). However, disagreement also be due to other factors if an interaction occurred that both raters could feasibly observe in the field, but was only documented by one rather (e.g., the second rater did not see the interaction, the second rater saw the interaction and did not interpret it similarly or interpreted it as not relevant to the observational codes). Such disagreement may have been due to issues in the training of observers as well as limitations of the nature of field- 
based data collection. It is impossible to determine which if any of these factors influenced such disagreement. The average frequencies of observed processes therefore likely underestimate the actual number of processes that met the definition of coded restorative justice processes. Nevertheless, obtaining these estimates is an important first step toward understanding with greater clarity how the interactional processes unfold during panels and how they relate to individual-level outcomes.

Research, practice, and policy implications. Practitioners across the U.S. have expressed interest in research on restorative justice IPV interventions (e.g., F. Mederos, personal communication, October 22, 2019) and therefore need trustworthy information to make decisions about whether and how to implement programs like IPV surrogate impact panels. First, the specific processes of IPV surrogate impact panels must be clearly identified and defined in any discussion of this approach to IPV intervention, as this term has been applied to a wide range of approaches to panel-type practices. In the current study, IPV surrogate impact panels operate as a component of BIPs, and BIP facilitators are responsible for screening potential panel attendees to make sure they meet panel requirements of having attended a BIP for at least 26 weeks and being suitable for the panel environment. The steps of the panel evaluated in the current study also differ from those of other panels in substantial ways, particularly as none of the previously published studies of other panels described a similar degree of direct interaction between speakers and audience members in a question and answer session or other panel process (Burkemper \& Balsam, 2007; Fulkerson, 2001; Zosky, 2018). In addition, other panel implementations have included a wider range of panel speakers (e.g., family members of 
survivors; Burkemper \& Balsam, 2007) or a group discussion among JII attendees from BIPs led by BIP facilitators (Zosky, 2018), which would involve additional types of possible participant actions not included in the current study. The variability of specific panel practices across various panel implementations raises questions regarding the extent to which the current study's findings would translate to other panel contexts. For example, the majority of group-level processes observed during panels in the current study, especially JII actions, took place during the question and answer session, and findings may not transfer to other panel settings that do not involve any direct interaction between panel participants.

In addition, extensive planning and coordination was undertaken by local BIP and restorative justice practitioners prior to implementing the local IPV surrogate impact panel, and extensive maintenance is required to facilitate the panel, recruit and coordinate panel speakers, and coordinate with BIPs to schedule JIIs to attend panels. The screening conditions for JIIs to be eligible to attend surrogate impact panels is another key practice that has varied across other implementations of panel-type practices. For example, the most recent study of these impact panels found that $20 \%$ of their participants $(n=340)$ had completed a BIP when they attended the panel, while $14 \%$ had not begun a BIP and $63 \%$ were concurrently enrolled in a BIP when they attended the panel (Zosky, 2018). In the current study, the majority of participants $(80 \%)$ were currently enrolled in a BIP and an even greater percentage $(90 \%)$ had completed at least 24 weeks of their current or previous BIP before attending the panel when they attended the panel. However, a small number of participants $(n=9)$ may not have been enrolled in a BIP and instead were 
required to attend the panel by PO mandate alone. Study findings also indicate that JIIs' perspective-taking of their own partner before the panel is positively correlated with two key post-panel ratings: other-focused JII motivations for behavior change (the effects of abuse on their partners and the effects of abuse on their children) and JIIs' retrospective increased understanding of the impact of abuse. On the other hand, JII pre-panel stigmatizing shame and minimization was positively associated with post-panel reports of resistance to the panel process. These findings suggest that it would be beneficial for JIIs to be enrolled in BIPs for some period of time, or otherwise engaged in related work to address these their abusive behavior, prior to attending an IPV surrogate impact panel in order to enter the panel with some initial capacity for perspective-taking and reduced levels of stigmatizing shame and minimization. As the panel eligibility requirements set a 26 week threshold for BIP attendance for panel participants, the current study is limited in its ability to detect influences on results based on length of time enrolled in a BIP (i.e., there is a floor effect for this variable). Further research could evaluate dosage of BIPs or other programs in more detail to explore how to optimize the preparation of JIIs before panel attendance so they can receive the most benefit from the panel experience. Finally, there may also be elements of the program planning and implementation process that are not adequately documented in the current study. Therefore, any effort to implement a similar IPV surrogate impact panel will necessarily require extensive preparation and would likely benefit from consultation with experienced facilitators to discuss any specific factors to attend to when attempting to implement in other contexts. 
Future research is warranted to further substantiate the benefits found in the current study through the achieved restorative justice processes and changes in individual-level immediate outcomes. This analysis could be replicated and deepened by modeling the specific sequential activities of panels and their relationship with self-report outcomes using a larger sample of panel participants in order to understand how grouplevel processes are predictive of individual-level outcomes (e.g., using multilevel modeling). For example, findings from the current study suggest that panels may increase participants' understanding of abuse, but future research could measure change in understanding empirically, rather than only measuring participants' retrospective perception of increased understanding at one time point after the panel. The current study also demonstrated that participants on average increase in state empathy (empathic concern and perspective-taking of their own partner) and reintegrative shame after panels, and that these feelings and beliefs are positively associated with their retrospective ratings of increased understanding of the impact of abuse. Future studies that wish to use measures of individual-level responses to IPV interventions or restorative justice practices could refer to the current study's findings to select measures that were most sensitive to change in the IPV surrogate impact panel setting (e.g., empathy, reintegrative shame, minimization) to minimize the length of self-report surveys and reduce the burden on future study participants. In addition, a more controlled observational method could increase reliability of observational data by video-recording panel interactions from multiple perspectives to more thoroughly and accurately document panel processes. More sophisticated measures other than self-report surveys alone could also further illuminate 
how individuals experience panels, such as psychophysiological measures (e.g., heart rate variability, Quintana \& Heathers, 2014) that could provide further insight into their level of emotional, cognitive, or other functioning during panels. Additionally, qualitative analysis of audience questions and comments during the Question \& Answer section of IPV surrogate impact panels could provide further insight into questions regarding what kind of information participants spend most time discussing during panels and what topics they most engage with (e.g., audience questions and responses from speakers about the effects of abuse on children). Audience questions could serve as a proxy for their interest in or connection to the panel material, as another indicator rather than self-report ratings alone of the relevance of the panel content as a whole. Similarly, observations or other-report of individuals in BIP groups could provide important additional sources of information that could confirm or contradict the self-reported changes documented in this study from pre- and post-test surveys of JIIs. For example, participant behavior could be coded by an observer or group facilitator regarding whether individuals demonstrate increased perspective-taking of their own partners after panels, make new connections between their abusive behavior and additional impacts on their partner/children/others that they had not recognized or disclosed before, or express greater motivation to engage in behavior change due to salient reasons from the panel (e.g., the effects of abuse on their partners or children). Data for such coding could include comments or other behavior during BIP groups or homework assignments. Questions regarding the influence of any social desirability bias in the current study's findings could be further considered in future studies as well, as previous research indicates that individuals tend to under- 
report both IPV perpetration and victimization due to impression management (e.g., Bell \& Naugle, 2007), although further investigation suggests that such bias is not due to selfdeception and the influence of social desirability on IPV reporting may be overestimated (Visschers, Jaspaert, \& Vervaeke, 2017). Nevertheless, it is currently unknown whether JIIs might respond differently on self-report questionnaires about their panel experiences were they not completed in public (i.e., in the panel setting). However, restorative justice programs and IPV interventions also intentionally leverage the influence of peers and implicit social norms to influence individual behavior (e.g., Gondolf, 2002), which at least somewhat mitigates concerns about any social desirability bias in the current study's findings. Finally, a longitudinal study of JIIs in BIPs who do and do not attend a surrogate impact panel could more specifically evaluate panel effectiveness by comparing changes in JIIs who attend an IPV surrogate impanel to changes in JIIs who only attend a BIP group. While the current study is a significant contribution to what is known about IPV surrogate impact panels, future research could more specifically isolate panel effects and how they relate to more distal post-intervention outcomes. A longitudinal evaluation could also further investigate differences between participants who attended panels and either did or did not complete a post-panel survey, such as through interviews with survey non-completers after panels. These interviews could elicit feedback on why they elected to leave immediately after the panel and whether their decision not to complete the final survey related to any specific feedback on the panel process that may be useful to consider in optimizing the panel. For example, there could be a lack of cultural fit with the speakers on the panel based on the race, ethnicity, gender, or sexuality of audience 
members and their partners, and feedback from post-panel interviews could suggest if it would be helpful to further tailor the program to specific cultural groups.

Given the contested evaluations of BIP effectiveness (e.g., Babcock et al., 2004; Gondolf, 2004; Coulter \& VandeWeerd, 2009), this research on IPV surrogate impact panels is a step toward exploring how they may contribute to comprehensive IPV interventions. These panels may be capable of augmenting processes targeted by BIPs that promote JII change, such as having empathy for others (Scott \& Wolfe, 2000), a safe group environment of mutual respect and support (Wangsgaard, 2001), and sharing stories to build community (Silvergleid \& Mankowski, 2006). Positive effects such as these would be a promising step forward in the field, given the relatively low cost of this additional component of BIP as a single additional 2-hour meeting. Although the current study can most closely inform future practice in the use of IPV surrogate impact panels as they are practiced in this context (i.e. as a component of BIPs), this study demonstrated that IPV surrogate impact panels may hold promise in changing JIIs to address abusive behavior through transformative restorative justice processes that manifest a different way of doing justice for IPV survivors. 
Table 4.1

Measures in Pre- and Post-Test Surveys of JIIs

\begin{tabular}{|c|c|c|c|}
\hline Construct & Measure & Pre-Test & $\begin{array}{l}\text { Post- } \\
\text { Test }\end{array}$ \\
\hline $\begin{array}{l}\text { Empathic concern } \\
\text { and distress (state) }\end{array}$ & $\begin{array}{l}\text { Emotion adjective items loaded on empathy \& } \\
\text { personal distress factors (Batson et al., 1987) }\end{array}$ & $X$ & $\mathrm{X}$ \\
\hline $\begin{array}{l}\text { Stigmatizing shame, } \\
\text { reintegrative shame } \\
\text { (state) }\end{array}$ & $\begin{array}{l}\text { State Shame and Guilt Scale (Marschall, } \\
\text { Sanfter, \& Tangney, 1994) }\end{array}$ & $X$ & $\mathrm{X}$ \\
\hline $\begin{array}{l}\text { Perspective-taking } \\
\text { empathy (state) }\end{array}$ & $\begin{array}{l}\text { Defendant Empathy Scale (Haegerich \& } \\
\text { Bottoms, 2000) }\end{array}$ & $X$ & $X$ \\
\hline $\begin{array}{l}\text { Minimization, } \\
\text { violence } \\
\text { recognition, partner } \\
\text { blaming }\end{array}$ & $\begin{array}{l}\text { Intimate Violence Responsibility scale (Yun } \\
\text { \& Vonk, 2011) }\end{array}$ & $X$ & $\mathrm{X}$ \\
\hline $\begin{array}{l}\text { Motivation to } \\
\text { change }\end{array}$ & $\begin{array}{l}\text { Motivating Factor for Behavior Change Scale } \\
\text { (Schmidt et al., 2007) }\end{array}$ & $X$ & $\mathrm{X}$ \\
\hline $\begin{array}{l}\text { Understanding of } \\
\text { abuse }\end{array}$ & Understanding of Abuse Scale (WCCC, 2007) & & $\mathrm{X}$ \\
\hline Resistance (state) & Resistance Scale (Levesque et al., 2008) & & $X$ \\
\hline $\begin{array}{l}\text { Emotional } \\
\text { engagement and } \\
\text { perceived realism }\end{array}$ & $\begin{array}{l}\text { Emotional Involvement, Identification, and } \\
\text { Factuality Subscales (Cho et al., 2014) }\end{array}$ & & $X$ \\
\hline $\begin{array}{l}\text { Demographic } \\
\text { characteristics }\end{array}$ & $\begin{array}{l}\text { Demographic items (Mills et al., 2013; } \\
\text { Sackett, 2017) }\end{array}$ & & $\mathrm{X}$ \\
\hline
\end{tabular}


Table 4.2

JII Participant Demographics

\begin{tabular}{|c|c|c|}
\hline Variable & Levels & Sample $(n=68)$ \\
\hline $\begin{array}{l}\text { Age } \\
n=66\end{array}$ & Mean $(S D)$ & $36.79(10.11)$ \\
\hline $\begin{array}{l}\text { Gender } \\
n=68\end{array}$ & $\begin{array}{l}\text { Male } \\
\text { Female } \\
\text { Not sure }\end{array}$ & $\begin{array}{l}97.1 \% \\
1.5 \% \\
1.5 \%\end{array}$ \\
\hline $\begin{array}{l}\text { Gender identity } \\
n=67\end{array}$ & Cisgender & $100 \%$ \\
\hline $\begin{array}{l}\text { Sexuality } \\
n=65\end{array}$ & $\begin{array}{l}\text { Heterosexual } \\
\text { Homosexual } \\
\text { Asexual/non-sexual } \\
\text { Prefer not to disclose } \\
\text { Other }\end{array}$ & $\begin{array}{l}89.2 \% \\
1.5 \% \\
1.5 \% \\
6.2 \% \\
1.5 \%\end{array}$ \\
\hline $\begin{array}{l}\text { Race } \\
n=64\end{array}$ & $\begin{array}{l}\text { White/Caucasian } \\
\text { Black/African American } \\
\text { Latino, Hispanic, or Spanish origin } \\
\text { Asian } \\
\text { Native American or Alaska Native } \\
\text { Middle Eastern or North African } \\
\text { Other }\end{array}$ & $\begin{array}{l}64.1 \% \\
3.1 \% \\
20.3 \% \\
1.6 \% \\
3.1 \% \\
1.6 \% \\
6.3 \%\end{array}$ \\
\hline $\begin{array}{l}\text { Marital status } \\
n=67\end{array}$ & $\begin{array}{l}\text { Single } \\
\text { Living with a partner } \\
\text { Married } \\
\text { Separated } \\
\text { Divorced } \\
\text { Other }\end{array}$ & $\begin{array}{l}46.3 \% \\
9 \% \\
20.9 \% \\
6 \% \\
9 \% \\
9 \%\end{array}$ \\
\hline $\begin{array}{l}\text { Relationship length in } \\
\text { years } \\
n=37\end{array}$ & Mean $(S D)$ & $5.51(5.12)$ \\
\hline $\begin{array}{l}\text { Number of children } \\
n=63\end{array}$ & $\begin{array}{l}0 \\
1 \\
2 \\
3 \\
4+\end{array}$ & $\begin{array}{l}30.2 \% \\
28.6 \% \\
15.9 \% \\
6.3 \% \\
19 \%\end{array}$ \\
\hline $\begin{array}{l}\text { Highest education } \\
\text { completed } \\
n=65\end{array}$ & $\begin{array}{l}\text { Some high school } \\
\text { GED or high school diploma } \\
\text { Some college or trade school } \\
\text { Associate's degree } \\
\text { Vocational or skills certificate } \\
\text { Bachelor's degree } \\
\text { Some graduate school } \\
\text { Graduate school }\end{array}$ & $\begin{array}{l}12.3 \% \\
41.5 \% \\
18.5 \% \\
6.2 \% \\
1.5 \% \\
12.3 \% \\
3.1 \% \\
4.6 \%\end{array}$ \\
\hline $\begin{array}{l}\text { Currently employed } \\
n=65\end{array}$ & $\begin{array}{l}\text { Yes } \\
\text { No }\end{array}$ & $\begin{array}{l}89.2 \% \\
10.8 \%\end{array}$ \\
\hline
\end{tabular}


Table 4.2 (cont.)

Participant Demographics (cont.)

\begin{tabular}{|c|c|c|}
\hline Variable & Levels & Sample $(n=68)$ \\
\hline $\begin{array}{l}\text { Yearly income } \\
n=52\end{array}$ & Mean $(S D)$ & $\$ 46,267.64(\$ 47,604.95)$ \\
\hline $\begin{array}{l}\text { Currently enrolled in a } \\
\text { BIP } \\
n=65\end{array}$ & $\begin{array}{l}\text { Yes } \\
\text { No }\end{array}$ & $\begin{array}{l}80 \% \\
20 \%\end{array}$ \\
\hline $\begin{array}{l}\text { BIP weeks program } \\
\text { completion } \\
n=50\end{array}$ & Mean $(S D)$ & $38.22(20.91)$ \\
\hline $\begin{array}{l}\text { BIP enrollment reason } \\
n=57\end{array}$ & $\begin{array}{l}\text { Volunteered } \\
\text { DHS/Child Welfare (or SCF/CSD) } \\
\text { referral } \\
\text { Court mandate } \\
\text { Probation } \\
\text { Parole }\end{array}$ & $\begin{array}{l}8.8 \% \\
3.5 \% \\
64.9 \% \\
19.3 \% \\
3.5 \%\end{array}$ \\
\hline $\begin{array}{l}\text { Previously arrested } \\
n=63\end{array}$ & $\begin{array}{l}\text { Yes } \\
\text { No }\end{array}$ & $\begin{array}{l}93.7 \% \\
6.3 \%\end{array}$ \\
\hline $\begin{array}{l}\text { If arrested, total number } \\
\text { of arrests } \\
n=45\end{array}$ & $\begin{array}{l}\text { Mean }(S D) \\
1 \\
2 \\
3 \\
4 \\
5 \\
6 \\
7 \\
10 \\
12 \\
25\end{array}$ & $\begin{array}{l}3.16(4.15) \\
44.4 \% \\
22.2 \% \\
8.9 \% \\
4.4 \% \\
4.4 \% \\
6.7 \% \\
2.2 \% \\
2.2 \% \\
2.2 \% \\
2.2 \%\end{array}$ \\
\hline $\begin{array}{l}\text { If arrested, how many } \\
\text { arrests related to DV } \\
n=60\end{array}$ & $\begin{array}{l}\text { Mean }(S D) \\
0 \\
1 \\
2 \\
3 \\
4 \\
21\end{array}$ & $\begin{array}{l}1.78(2.69) \\
1.7 \% \\
70 \% \\
15 \% \\
3.3 \% \\
8.3 \% \\
1.7 \%\end{array}$ \\
\hline $\begin{array}{l}\text { If arrest led to BIP } \\
\text { enrollment, age at arrest } \\
n=27\end{array}$ & Mean $(S D)$ & $32.48(9.45)$ \\
\hline
\end{tabular}


Table 4.3

Pre- and Post-Panel JII Self-Report Facilitating and Hindering State Scores

\begin{tabular}{|c|c|c|c|c|c|c|}
\hline \multirow{2}{*}{ Domain } & \multirow{2}{*}{ Range } & \multicolumn{2}{|c|}{ Pre-Panel } & \multicolumn{2}{|c|}{ Post-Panel } & \multirow{2}{*}{$\begin{array}{l}\text { Effect } \\
\text { size }(d)\end{array}$} \\
\hline & & Mean (SD) & $n$ & Mean (SD) & $n$ & \\
\hline Reintegrative shame*** & $1-5$ & $2.16(0.98)$ & 90 & $2.56(1.16)$ & 77 & .38 \\
\hline Stigmatizing shame & $1-5$ & $1.68(0.82)$ & 90 & $1.67(0.81)$ & 77 & .01 \\
\hline $\begin{array}{l}\text { Empathy dimensions } \\
\text { Empathic distress } * * * \\
\text { Empathic concern*** } \\
\text { Perspective-taking }{ }^{\dagger}\end{array}$ & $\begin{array}{l}1-5 \\
1-5 \\
1-7\end{array}$ & $\begin{array}{l}1.81(0.82) \\
2.33(0.86) \\
4.28(1.67)\end{array}$ & $\begin{array}{l}90 \\
89 \\
87\end{array}$ & $\begin{array}{l}2.39(0.90) \\
3.62(0.81) \\
4.73(1.76)\end{array}$ & $\begin{array}{l}73 \\
74 \\
73\end{array}$ & $\begin{array}{l}.70 \\
1.50 \\
.26\end{array}$ \\
\hline $\begin{array}{l}\text { Minimizing dimensions } \\
\text { Minimization* } \\
\text { Lack of violence recognition } \\
\text { Victim blaming* }\end{array}$ & $\begin{array}{l}1-5 \\
1-5 \\
1-5\end{array}$ & $\begin{array}{l}1.91(0.86) \\
2.10(1.01) \\
1.81(0.86)\end{array}$ & $\begin{array}{l}90 \\
89 \\
87\end{array}$ & $\begin{array}{l}1.68(0.81) \\
2.41(1.34) \\
1.67(0.94)\end{array}$ & $\begin{array}{l}67 \\
66 \\
65\end{array}$ & $\begin{array}{l}.28 \\
.26 \\
.17\end{array}$ \\
\hline $\begin{array}{l}\text { Self-focused motivations } \\
\text { Not to feel bad about self } \\
\text { Not to lose my job } \\
\text { Financial impact too great } \\
\text { Not getting arrested } \\
\text { Not to look bad to others }\end{array}$ & $\begin{array}{l}1-9 \\
1-9 \\
1-9 \\
1-9 \\
1-9\end{array}$ & $\begin{array}{l}5.13(2.67) \\
4.80(3.02) \\
4.83(2.75) \\
5.63(2.90) \\
3.77(2.79)\end{array}$ & $\begin{array}{l}82 \\
80 \\
81 \\
82 \\
81\end{array}$ & $\begin{array}{l}4.81(2.82) \\
4.42(2.83) \\
4.98(2.67) \\
4.77(2.71) \\
3.77(2.86)\end{array}$ & $\begin{array}{l}62 \\
62 \\
62 \\
62 \\
62\end{array}$ & $\begin{array}{l}.12 \\
.13 \\
.06 \\
.29 \\
0\end{array}$ \\
\hline $\begin{array}{l}\text { Other-focused motivations } \\
\text { Effects of abuse on their partner } \\
\text { Effects of abuse on children } \\
\text { Improve rel. quality w/ partner }\end{array}$ & $\begin{array}{l}1-9 \\
1-9 \\
1-9\end{array}$ & $\begin{array}{l}6.89(2.43) \\
6.49(3.02) \\
6.68(2.54)\end{array}$ & $\begin{array}{l}82 \\
77 \\
79\end{array}$ & $\begin{array}{l}7.44(2.21) \\
7.23(2.49) \\
6.44(2.66)\end{array}$ & $\begin{array}{l}62 \\
61 \\
62\end{array}$ & $\begin{array}{l}.24 \\
.27 \\
.09\end{array}$ \\
\hline $\begin{array}{l}\text { General motivation } \\
\text { It's not right to be abusive* }\end{array}$ & $1-9$ & $7.14(2.59)$ & 80 & $7.52(2.10)$ & 60 & .15 \\
\hline $\begin{array}{l}\text { Retrospective increase in } \\
\text { understanding of abuse }\end{array}$ & $1-6$ & - & - & $5.13(1.01)$ & 74 & - \\
\hline Emotional engagement & $1-7$ & - & - & $5.41(1.59)$ & 70 & - \\
\hline Identification & $1-7$ & - & - & $5.00(1.59)$ & 70 & - \\
\hline Factuality & $1-7$ & - & - & $6.04(1.30)$ & 70 & - \\
\hline $\begin{array}{l}\text { Resistance } \\
\text { Problems with alliance } \\
\text { Hopelessness } \\
\text { Psychological reactance } \\
\text { Passive reactance }\end{array}$ & $\begin{array}{l}1-5 \\
1-5 \\
1-5 \\
1-5\end{array}$ & $\begin{array}{l}- \\
- \\
-\end{array}$ & $\begin{array}{l}- \\
- \\
-\end{array}$ & $\begin{array}{l}1.83(0.72) \\
1.77(0.93) \\
2.13(1.17) \\
1.45(0.78)\end{array}$ & $\begin{array}{l}64 \\
64 \\
61 \\
64\end{array}$ & $\begin{array}{l}- \\
- \\
-\end{array}$ \\
\hline
\end{tabular}

Note. ${ }^{\dagger} p<.10 .{ }^{*} p<.05 .{ }^{*} p<.01 .{ }^{* * *} p<.001$ (two-tailed). 


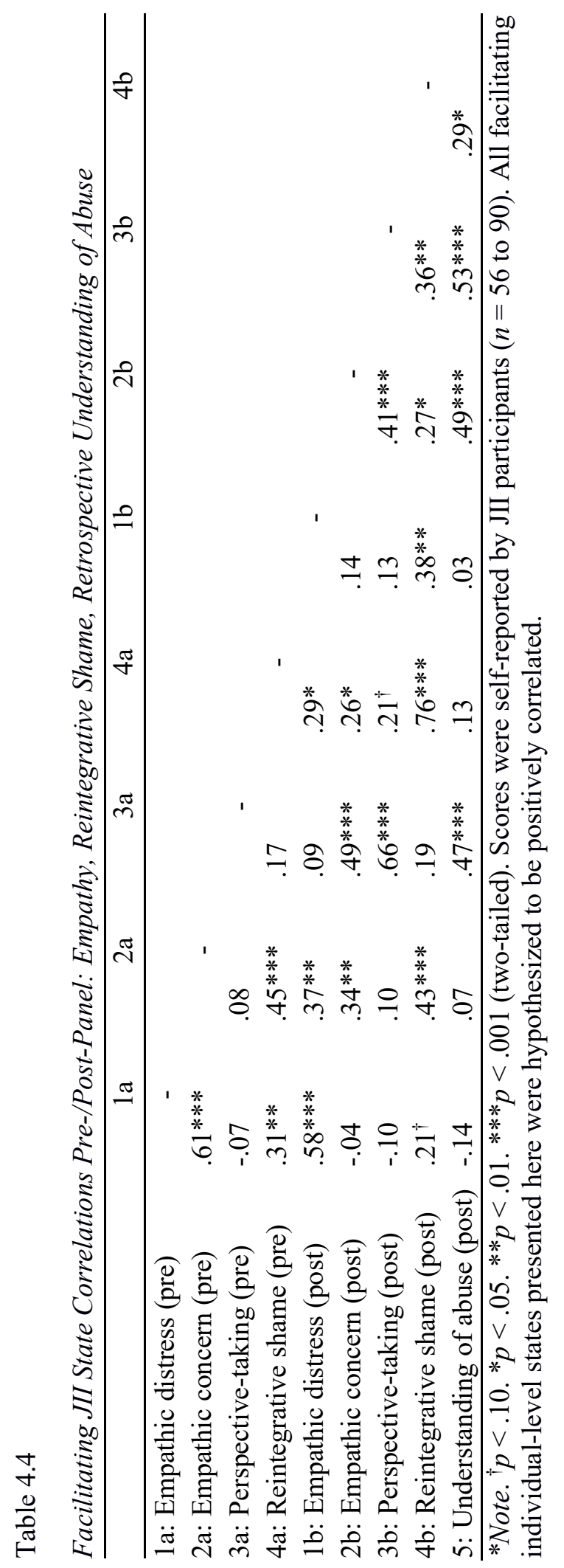




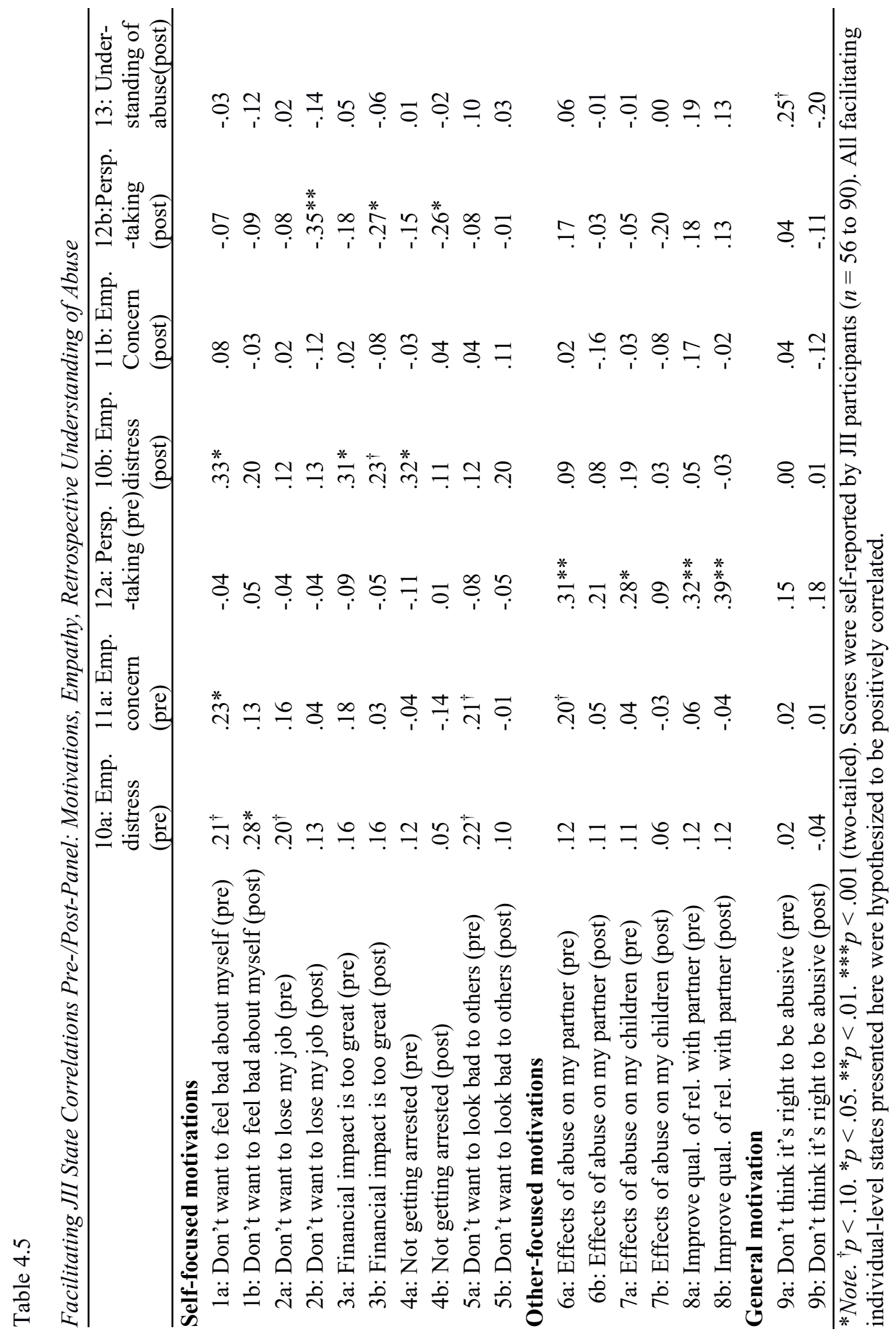




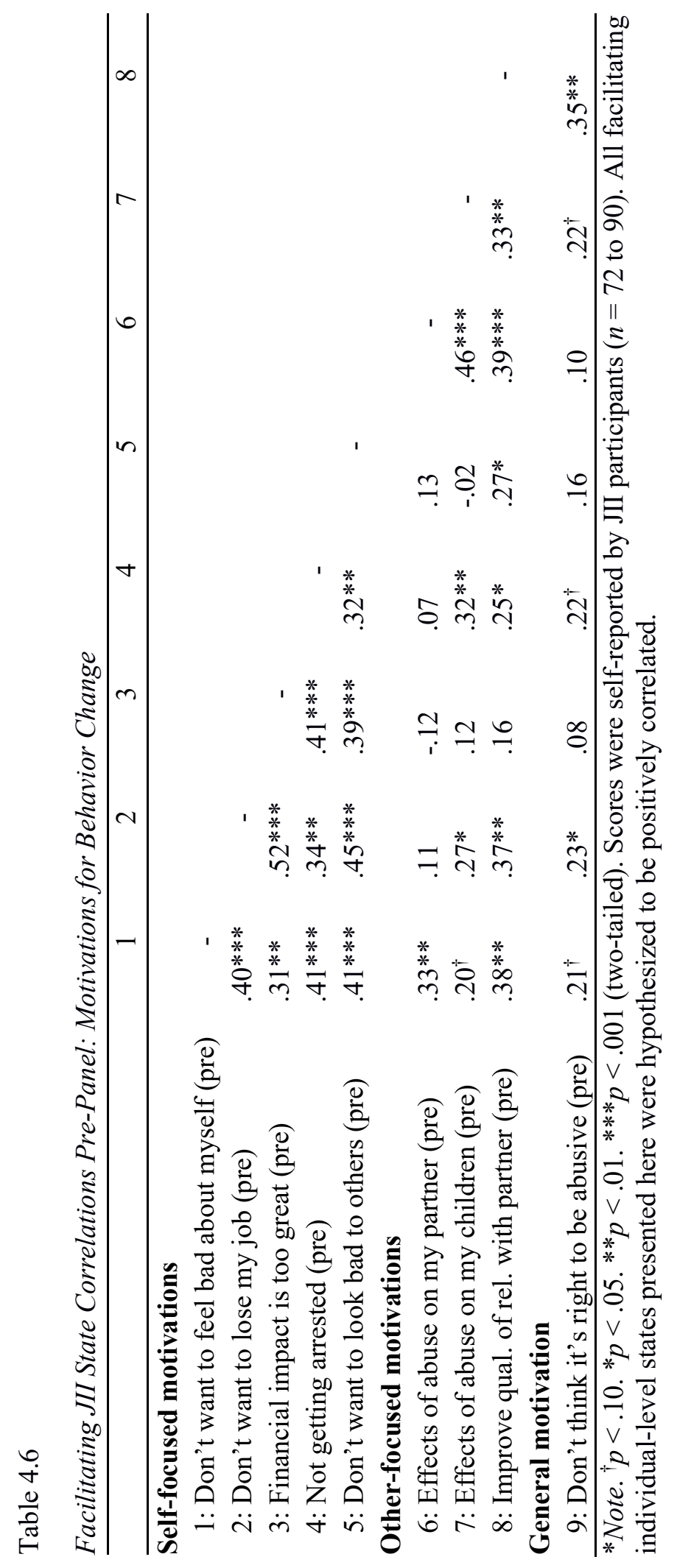




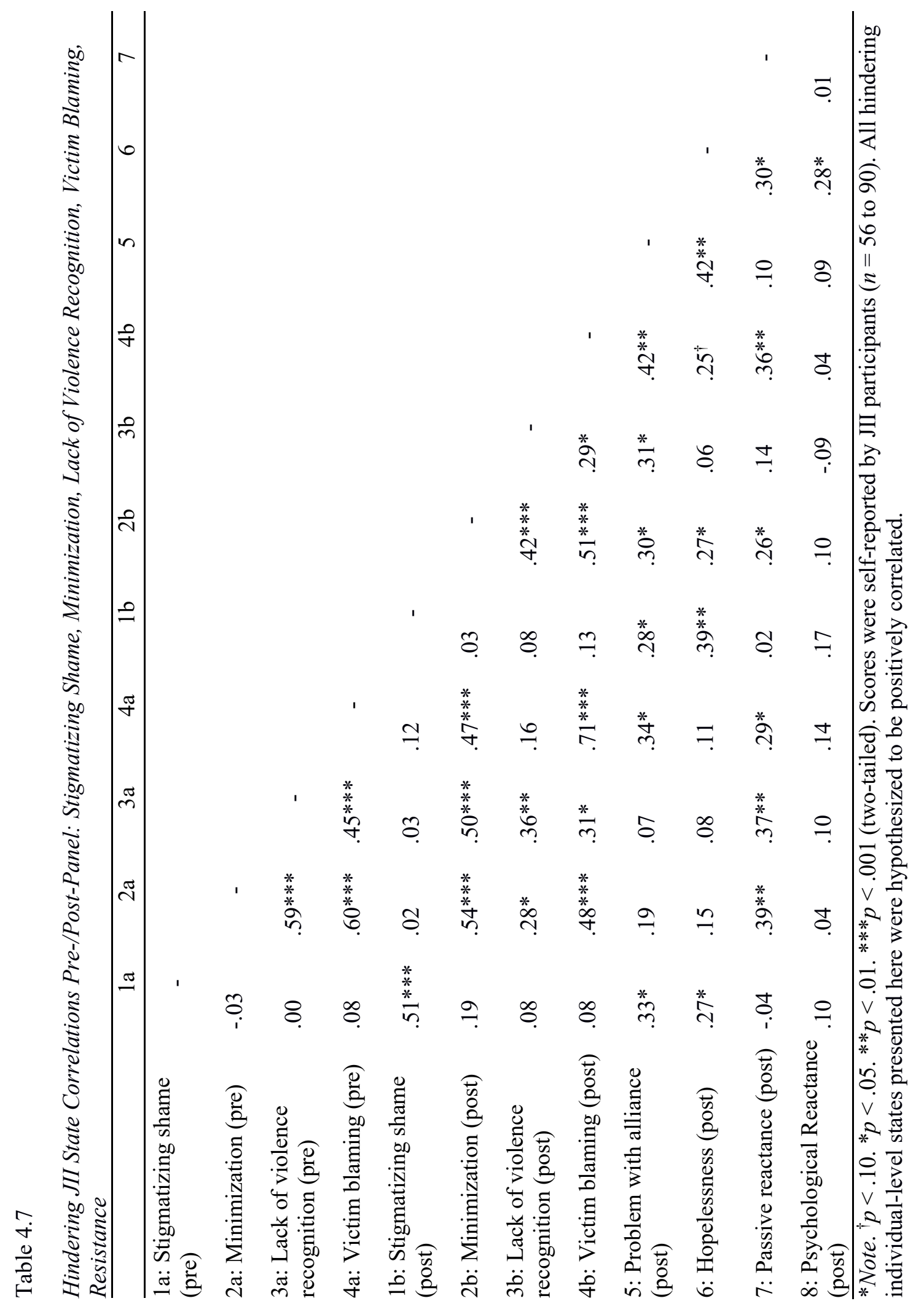




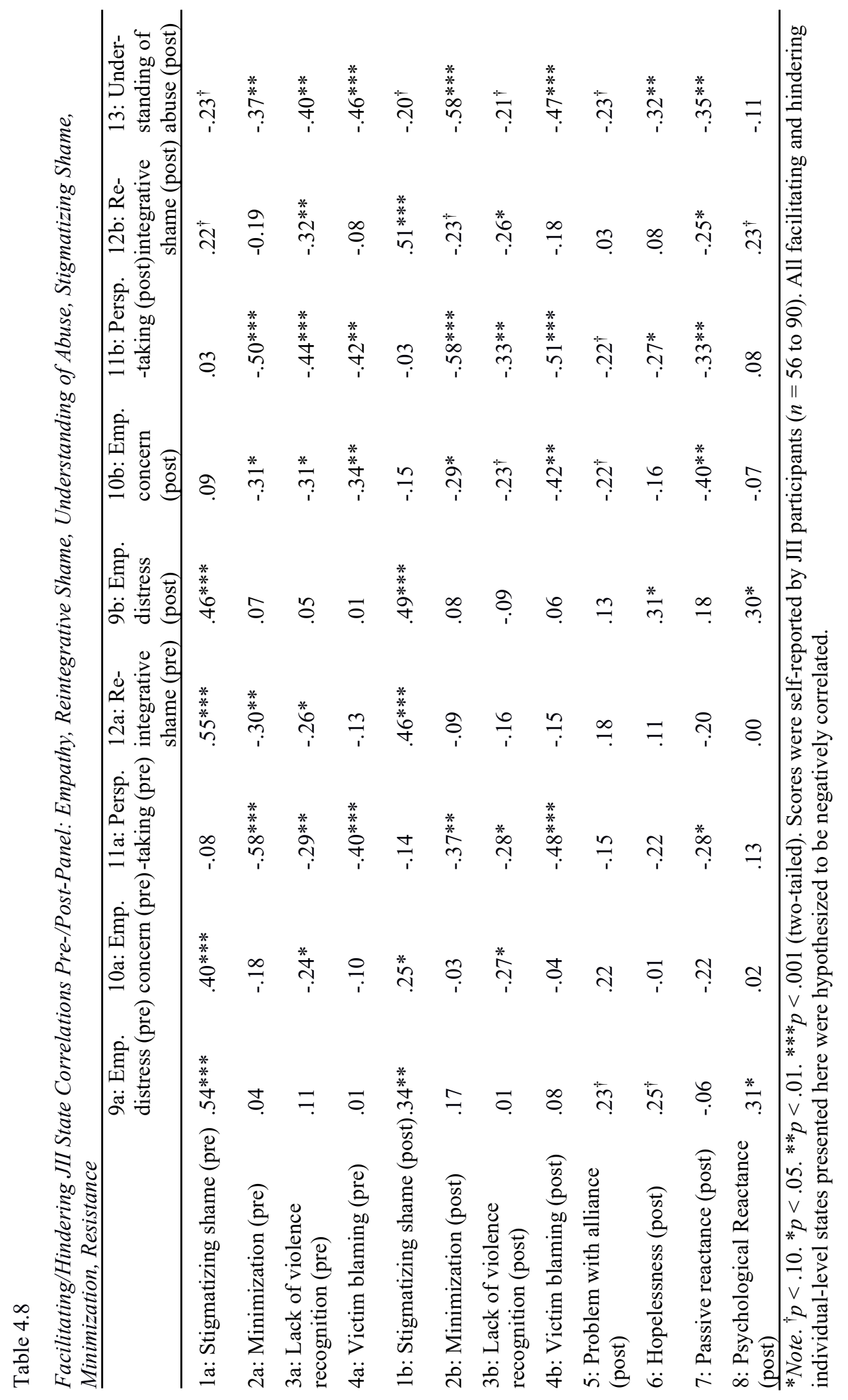




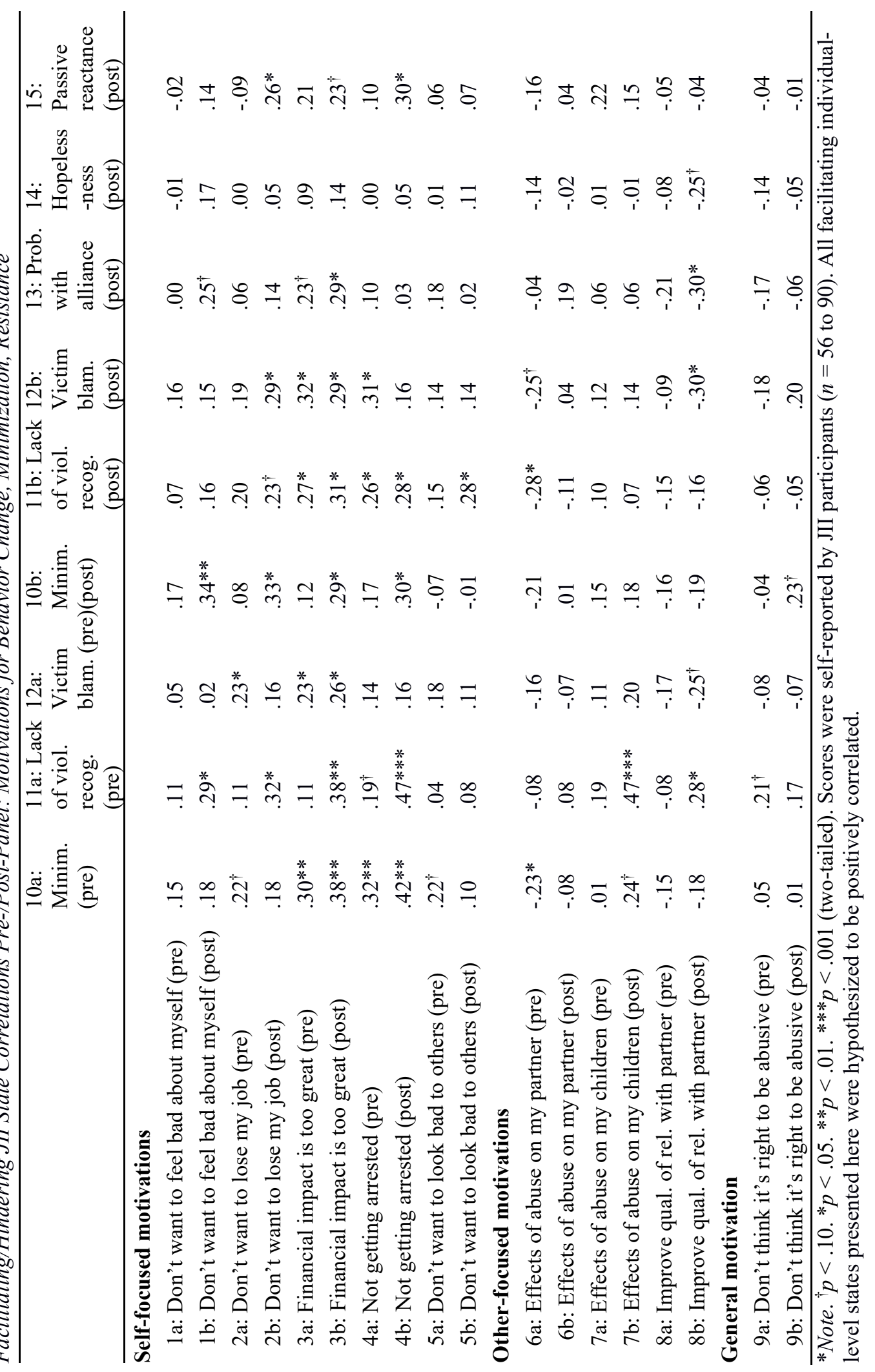


Table 4.10

Multiple Linear Regression of Control Variables on Post-Panel JII Empathic Distress

\begin{tabular}{|c|c|c|c|c|}
\hline Variable & B & SE & $\beta$ & $t$ \\
\hline Constant & .01 & .08 & & .15 \\
\hline Empathic distress (pre) & .73 & .11 & .71 & $6.70 * * *$ \\
\hline Emotional engagement (post) & .13 & .09 & .22 & 1.41 \\
\hline Identification (post) & .01 & .07 & .01 & .01 \\
\hline Factuality (post) & .03 & .10 & .05 & .33 \\
\hline Problem with alliance (post) & -.26 & .14 & -.21 & $-1.89^{\dagger}$ \\
\hline Hopelessness (post) & .48 & .14 & .40 & $3.39 * *$ \\
\hline Passive reactance (post) & .34 & .13 & .26 & $2.51 *$ \\
\hline Psychological reactance (post) & .00 & .07 & -.01 & -.05 \\
\hline Age & -.02 & .01 & -.25 & $-2.67 *$ \\
\hline Weeks in BIP & .00 & .00 & .04 & .47 \\
\hline
\end{tabular}

Note. ${ }^{\dagger} p<.10 .{ }^{*} p<.05 .{ }^{* *} p<.01 .{ }^{* * *} p<.001 . R^{2}=.80$. 
"IT PUTS A FACE TO ALL THE KNOWLEDGE"

Table 4.11

Multiple Linear Regression of Control Variables on Post-Panel JII Perspective-Taking

\begin{tabular}{|c|c|c|c|c|}
\hline Variable & b & $\mathrm{SE}$ & $\beta$ & $t$ \\
\hline Constant & .01 & .16 & & .04 \\
\hline Perspective-taking (pre) & .76 & .12 & 67 & $6.18 * * *$ \\
\hline Emotional engagement (post) & .32 & .18 & .30 & $1.79^{\dagger}$ \\
\hline Identification (post) & -.08 & .12 & -.08 & -.71 \\
\hline Factuality (post) & -.04 & .19 & -.04 & -.23 \\
\hline Problem with alliance (post) & -.06 & .25 & -.02 & -.22 \\
\hline Hopelessness (post) & .47 & .27 & .19 & $1.75^{\dagger}$ \\
\hline Passive reactance (post) & -.57 & .23 & -.24 & $-.246^{*}$ \\
\hline Psychological reactance (post) & .11 & .16 & .07 & .68 \\
\hline Age & -.01 & .02 & -.07 & -.72 \\
\hline Weeks in BIP & .01 & .01 & .09 & 1.01 \\
\hline
\end{tabular}

Note. ${ }^{\dagger} p<.10 .{ }^{*} p<.05 .{ }^{* *} p<.01 .{ }^{* * *} p<.001 . R^{2}=.80$. 
Table 4.12

Multiple Linear Regression of Control Variables on Post-Panel JII Minimization

\begin{tabular}{|c|c|c|c|c|}
\hline Variable & $B$ & SE & $\beta$ & $t$ \\
\hline Constant & .09 & .09 & & .99 \\
\hline Minimization (pre) & .56 & .11 & .57 & $4.96 * * *$ \\
\hline Emotional engagement (post) & -.13 & .10 & -.25 & -1.33 \\
\hline Identification (post) & -.02 & .07 & -.03 & -.23 \\
\hline Factuality (post) & .00 & .10 & .00 & .00 \\
\hline Problem with alliance (post) & .02 & .14 & .02 & .15 \\
\hline Hopelessness (post) & .34 & .14 & .28 & $2.47 *$ \\
\hline Passive reactance (post) & -.04 & .13 & -.04 & -.33 \\
\hline Psychological reactance (post) & -.07 & .07 & -.09 & -.93 \\
\hline Age & -.01 & .01 & -.11 & -1.16 \\
\hline Weeks in BIP & -.01 & .00 & -.32 & $-3.53 * *$ \\
\hline
\end{tabular}

Note. ${ }^{\dagger} p<.10 .{ }^{*} p<.05 .{ }^{* *} p<.01 .{ }^{* * *} p<.001 . R^{2}=.76$. 
Table 4.13

Multiple Linear Regression of Control Variables on Post-Panel JII Victim Blaming

\begin{tabular}{|c|c|c|c|c|}
\hline Variable & $B$ & SE & $\beta$ & $t$ \\
\hline Constant & .02 & .10 & & .18 \\
\hline Victim blaming (pre) & .39 & .11 & .41 & $3.46^{* *}$ \\
\hline Emotional engagement (post) & -.08 & .11 & -.14 & -.73 \\
\hline Identification (post) & -.06 & .08 & -.10 & -.76 \\
\hline Factuality (post) & .01 & .12 & .02 & .09 \\
\hline Problem with alliance (post) & .41 & .16 & .33 & $2.63 *$ \\
\hline Hopelessness (post) & .15 & .16 & .12 & .92 \\
\hline Passive reactance (post) & -.03 & .14 & -.03 & -.22 \\
\hline Psychological reactance (post) & -.04 & .08 & -.05 & -.44 \\
\hline Age & .02 & .01 & .22 & $2.05^{\dagger}$ \\
\hline Weeks in BIP & -.01 & .00 & -.19 & $-1.79^{\dagger}$ \\
\hline
\end{tabular}

Note. ${ }^{\dagger} p<.10 .{ }^{*} p<.05 .{ }^{* *} p<.01 .{ }^{* * *} p<.001 . R^{2}=.70$. 


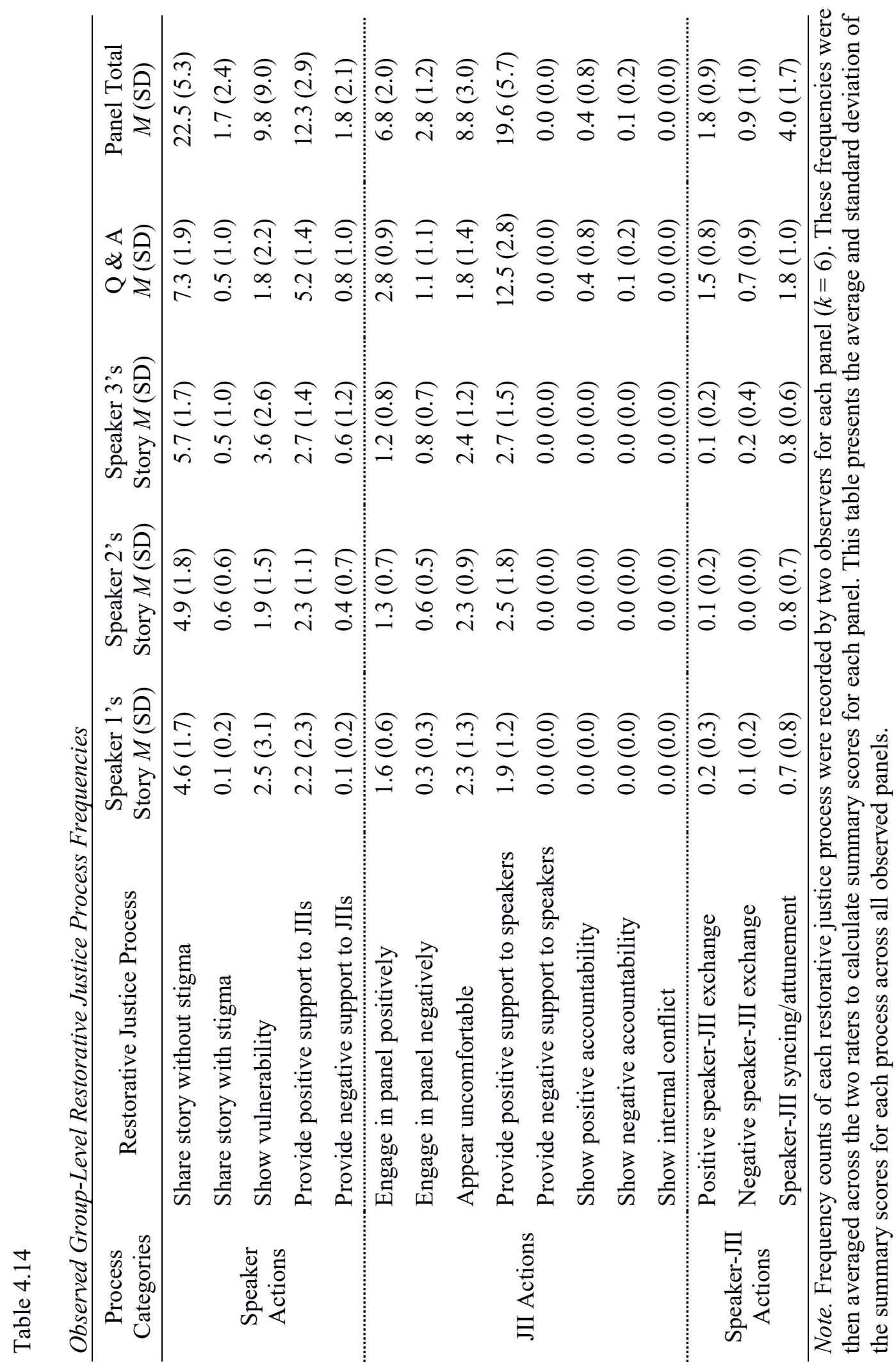




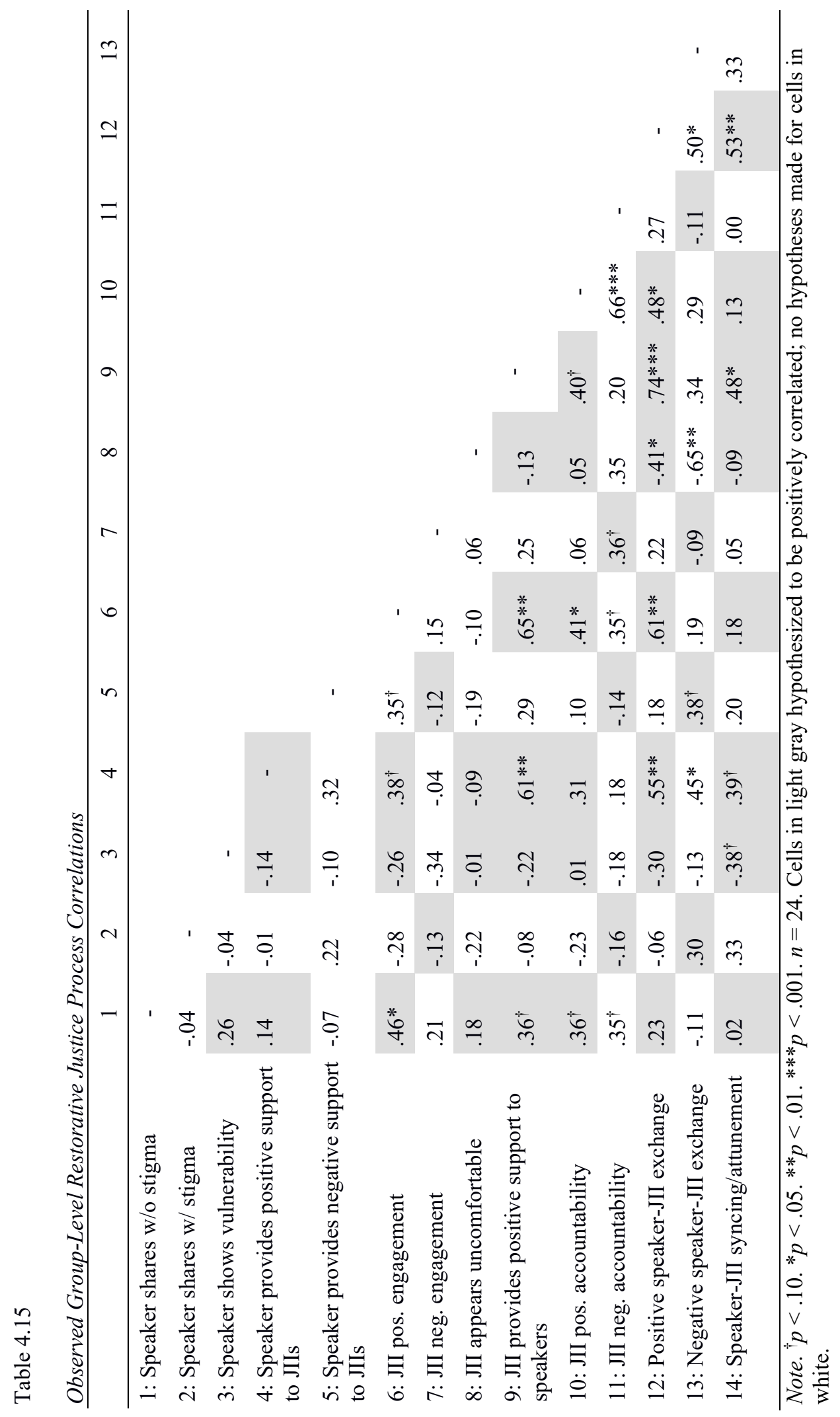




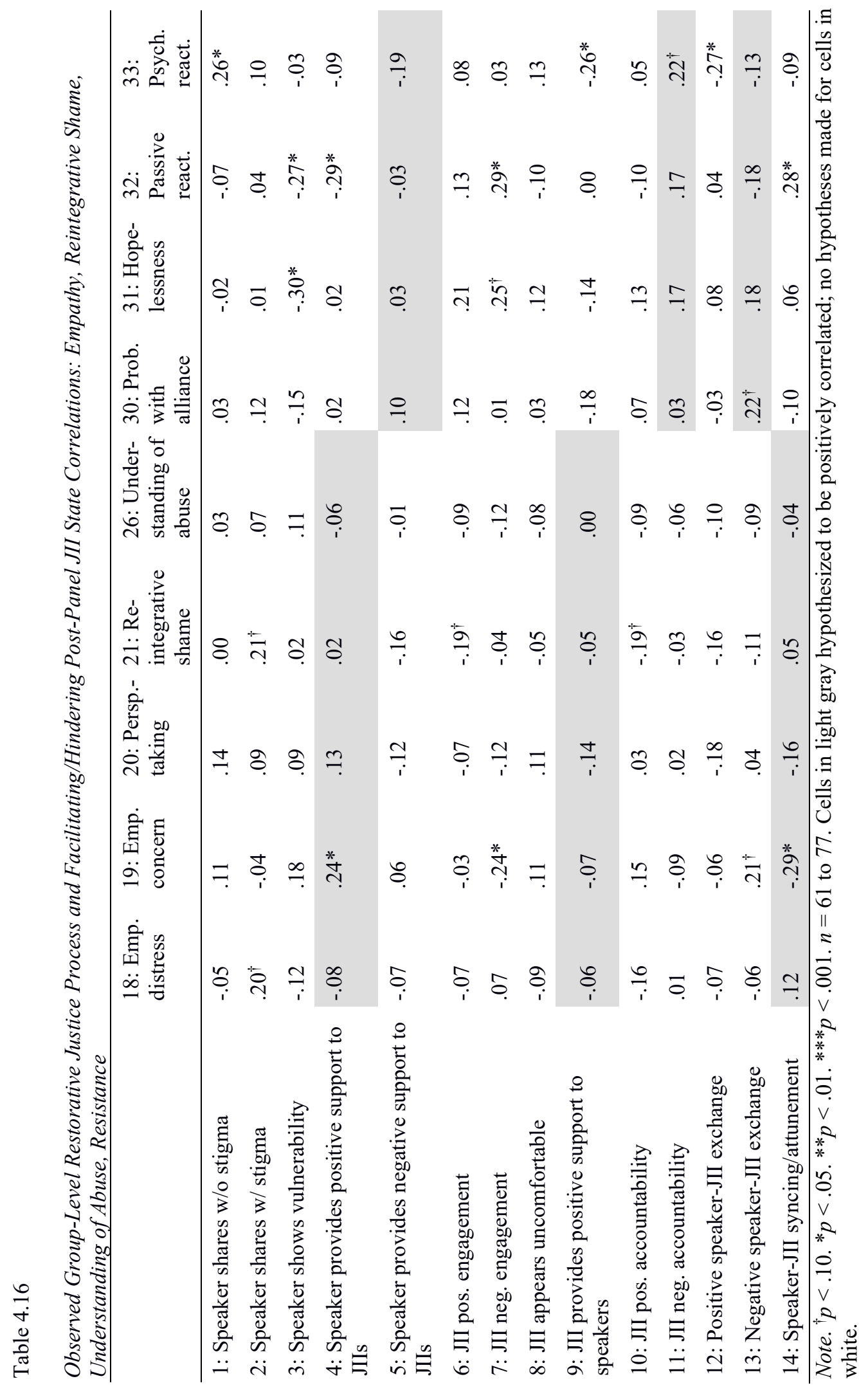




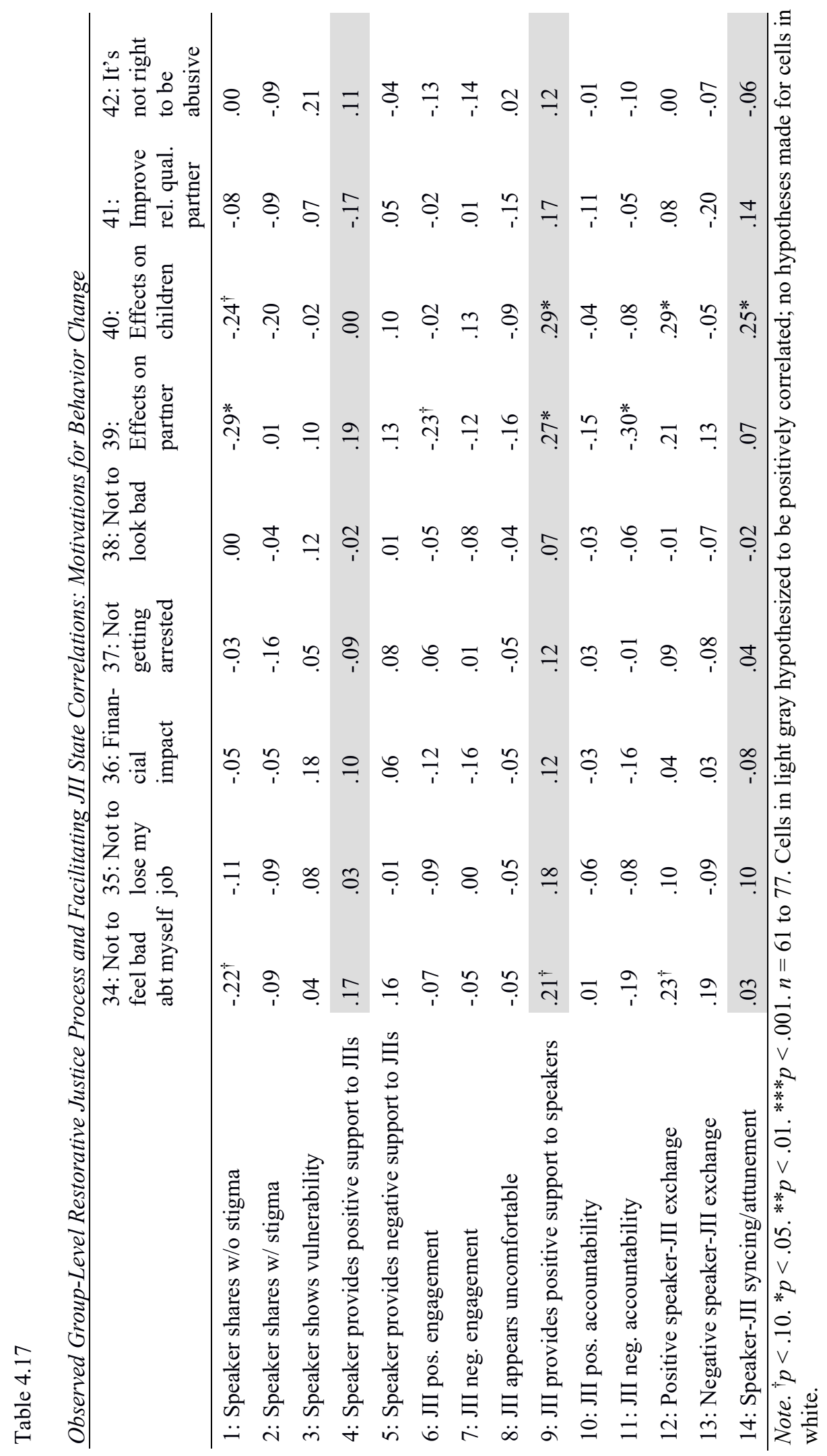




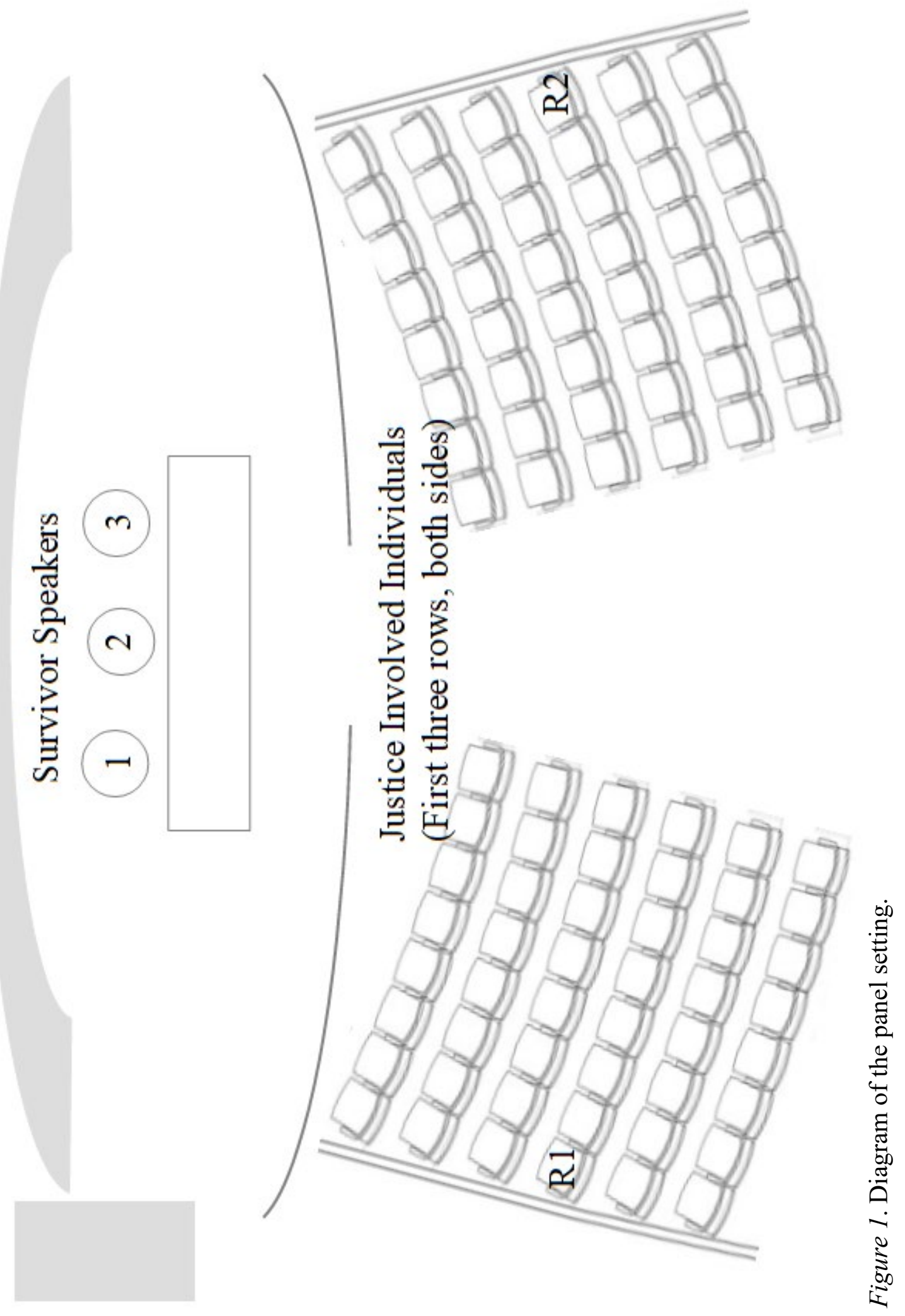




\section{References}

Ahmed, E. (2001). Shame management: Regulating bullying. In Ahmed, E., Harris, N., Braithwaite, J., \& Braithwaite, V. (Eds.) Shame management through reintegration (pp. 209-311). Cambridge: Cambridge University Press.

Armour, M. P., Windsor, L. C., Aguilar, J., \& Taub, C. (2008). A pilot study of a faithbased restorative justice intervention for Christian and non-Christian offenders. Journal of Psychology and Christianity, 27(2), 159-167.

Babcock, J. C., Green, C. E., \& Robie, C. (2004). Does batterers' treatment work? A meta-analytic review of domestic violence treatment. Clinical Psychology Review, 23, 1023-1053.

Baker, N. L., Buick, J. D., Kim, S. R., Moniz, S., \& Nava, K. L. (2013). Lessons from examining same-sex intimate partner violence. Sex Roles, 69, 182-192.

Bandura, A. (1971). Social learning theory. New York, NY: General Learning Press.

Barcikowski, R. S. (1981). Statistical power with group mean as the unit of analysis. Journal of Educational and Behavioral Statistics, 6(3), 267-285.

Batson, C. D., Fultz, J., \& Schoenrade, P. A. (1987). Distress and empathy: Two qualitatively distinct vicarious emotions with different motivational consequences. Journal of Personality, 55(1), 19-39.

Begun, A. L., Shelley, G., Strodthoff, T., \& Short, L. (2001). Nonconventional approaches for intervention in cases of spouse/partner abuse. Journal of Aggression, Maltreatment \& Trauma, 2(10), 105-127. 
Bell, C. A., Gitomer, D. H., McCaffrey, D. F., Hamre, B. K., Pianta, R. C., Qi, Y. (2012). An argument approach to observation protocol validity. Educational Assessment, $17,62-87$.

Bell, K. M. \& Naugle, A. E. (2007). Effects of social desirability on students' selfreporting of partner abuse perpetration and victimization. Violence and Victims, $22(2), 243-256$.

Black, M. C., Basile, K. C., Breiding, M. J., Smith, S. G., Walters, M. L., Merrick, M. T.,...Stevens, M. R. (2011). The national intimate partner and sexual violence survey (NISVS): 2010 summary report. Atlanta, GA: National Center for Injury Prevention and Control, Centers for Disease Control and Prevention.

Bowen, E. \& Gilchrist, E. (2004). Comprehensive evaluation: A holistic approach to evaluating domestic violence offender programmes. International Journal of Offender Therapy and Comparative Criminology, 48(2), 215-234.

Bowen, E. \& Gilchrist, E. (2006). Predicting dropout of court-mandated treatment in a British sample of domestic violence offenders. Psychology, Crime \& Law, 12(5), $573-587$.

Braithwaite, J. (1989). Crime, shame and reintegration. Cambridge: Cambridge University Press.

Braithwaite, J. \& Braithwaite, V. (2001). Shame, shame management and regulation. In Ahmed, E., Harris, N., Braithwaite, J., \& Braithwaite, V. (Eds.) Shame management through reintegration (pp. 3-69). Cambridge: Cambridge University Press. 
Bronfenbrenner, U. (1979). The ecology of human development. Cambridge, MA: Harvard University Press.

Bronfenbrenner, U., \& Morris, P. A. (2006). The bioecological model of human development. In R. M. Lerner \& W. Damon (Eds.), Handbook of Child Psychology: Theoretical Models of Human Development (pp. 793-828). Hoboken, NJ: John Wiley.

Browne, W.J. (1998). Applying MCMC methods to multilevel models. Bath, UK: University of Bath.

Burkemper, B. \& Balsam, N. (2007). Examining the use of restorative justice practices in domestic violence cases. Saint Louis University Public Law Review, 27, 121-133.

Campbell, R., Patterson, D., \& Fehler-Cabral, G. (2010). Using ecological theory to evaluate the effectiveness of an indigenous community intervention: A study of Sexual Assault Nurse Examiner (SANE) programs. American Journal of Community Psychology, 46, 263-276.

Carden, A. D. (1994). Wife abuse and the wife abuser: Review and recommendations. The Counseling Psychologist, 22(4), 539-582.

Cheng, S. Y., Davis, M., Jonson-Reid, M., \& Yaeger, L. (2019). Compared to what? A meta-analysis of batterer intervention studies using nontreated controls or comparisons. Trauma, Violence, \& Abuse. Advanced online publication. https://doi.org/10.1177/1524838019865927

Cho, H., Shen, L., \& Wilson, K. (2013). Perceived realism: Dimensions and roles in narrative persuasion. Communication Research, 41(6), 828-851. 
Clark, A. H., \& Foy, D. W. (2000). Trauma exposure and alcohol use in battered women. Violence Against Women, 6, 37-48.

Cohen, J. (1960). A coefficient of agreement for nominal scales. Educational and Psychological Measurement, 20(1), 37-46.

Collins, R. (2004). Interaction ritual chains. Princeton, NJ: Princeton University Press. Coulter, M. \& VandeWeerd, C. (2009). Reducing domestic violence and other criminal recidivism: Effectiveness of a multi-level batterers intervention program. Violence and Victims, 24(2), 139-153.

Covell, C. N., Huss, M. T., \& Langhinrichsen-Rohling, J. (2007). Empathic deficits among male batterers: A multidimensional approach. Journal of Family Violence, $22(3), 165-174$.

Cuevas, D. A. \& Bui, N. H. (2016). Social factors affecting the completion of a batterer intervention program. Journal of Family Violence, 31(1), 95-107.

Daniels, J. W. \& Murphy, C. M. (1997). Stages and processes of change in batterers' treatment. Cognitive and Behavioral Practice, 4, 123-145.

Denzin, N. K. (1978). Sociological methods. New York, NY: McGraw-Hill.

DiClemente, C. C. \& Prochaska, J. O. (1985). Processes and stages of change: Coping and competence in smoking behavior change. In S. Shiffman \& T. A. Wills (Eds.), Coping and substance abuse (pp. 319-343). San Diego, CA: Academic Press.

Drewery, W. (2016). Restorative practice in New Zealand schools: Social development through relational justice. Educational Philosophy and Theory, 48(2), 191-203. 
Dutton, M. A. \& Goodman, L. A. (2005). Coercion in intimate partner violence: Toward a new conceptualization. Sex Roles, 52(11/12), 743-756.

Eckhardt, C. I., Murphy, C., Black, D., \& Suhr, L. (2006). Intervention programs for perpetrators of intimate partner violence: Considerations from a clinical research perspective. Public Health Reports, 121(4), 369-381.

Edleson, J. L., \& Tolman, R. M. (1992). Intervention for men who batter: An ecological approach. London, England: Sage Publications.

Erdfelder, E., Faul, F., \& Buchner, A. (1996). GPOWER: A general power analysis program. Behavior Research Methods, Instruments, \& Computers, 28, 1-11.

Feise, R. J. (2002). Do multiple outcome measures require p-value adjustment? BMC Medical Research Methodology, 2(8), 1-4.

Fiske, D. W. (1979). Two worlds of psychological phenomena. American Psychologist, $34,733-739$.

Fulkerson, A. (2001). The use of victim impact panels in domestic violence cases: A restorative justice approach. Contemporary Justice Review, 4(34), 355-368.

Gondolf, E.W. (2002). Batterer intervention systems: Issues, outcomes and recommendations. London, England: Sage Publications.

Gondolf, E. W. (2004). Evaluating batterer counseling programs: A difficult task showing some effects and implications. Aggression and Violence Behavior, 9, $605-631$.

Gondolf, E. W. (2012). The future of batterer programs: Reassessing evidence-based practice. Boston, MA: Northeastern University Press. 
Gordon, J. A. \& Moriarty, L. J. (2003). The effects of domestic batterer treatment on domestic violence recidivism: The Chesterfield County experience. Criminal Justice and Behavior, 30, 118-134.

Haaken, J., \& Yragui, N. (2003). Going underground: Conflicting perspectives on domestic violence shelter practices. Feminism \& Psychology, 13, 49-71.

Haegerich, T. M. \& Bottoms, B. L. (2000). Empathy and jurors' decisions in patricide trials involving child sexual assault allegations. Law and Human Behavior, 24(4), 421-448.

Hampton, R. L., LaTaillade, J. J., Dacey, A., \& Marghi, J. R. (2008). Evaluating domestic violence interventions for black women. Journal of Aggression, Maltreatment \& Trauma, 16(3), 330-353.

Harris, N. (2003). Reassessing the dimensionality of the moral emotions. British Journal of Psychology, 94, 457-473.

Hotaling, G. T. \& Buzawa, E. S. (2003). Victim satisfaction with criminal justice case processing in a model court setting. (NCJ 195668). Washington, DC: National Institute of Justice.

Karakurt, G., Koc, E., Cetinsaya, E. E., Ayluctarhan, Z., \& Bolen, S. (2019). Metaanalysis and systematic review for the treatment of perpetrators of intimate partner violence. Neuroscience Biobehavioral Reviews, 105, 220-230.

Kelly, J.G., Ryan, M. Altman, E.B., \& Stelzner, S.P. (2000). Understanding and changing social systems: An ecological view. In J. Rappaport and E. Seidman (Eds.), Handbook of Community Psychology (pp. 133-159). New York, NY: Kluwer. 
Levesque, D. A., Velicer, W. F., Castle, P. H., \& Greene, R. N. (2008). Resistance among domestic violence offenders: Measurement development and initial validation. Violence Against Women, 14(2), 158-184.

Lincoln, Y. S. \& Guba, E. G. (1985). Naturalistic inquiry. London, England: Sage Publications.

Little, R. J. A. (1988). A test of missing completely at random for multivariate data with missing values. Journal of the American Statistical Association, 83(404), 11981202.

Llewellyn, J. J., Archibald, B. P., Clairmont, D., \& Crocker, D. (2014). Imagining success for a restorative approach to justice: Implications for measurement and evaluation. The Dalhousie Law Journal, 36(2), 281-316.

Marschall, D., Sanftner, J., \& Tangney, J. P. (1994). The state shame and guilt scale. Fairfax, VA: George Mason University.

Mills, L. G., Barocas, B., \& Ariel, B. (2013). The next generation of court-mandated domestic violence treatment: A comprehensive study of batterer intervention and restorative justice programs. Journal of Experimental Criminology, 9, 65-90.

Pence, E. \& McMahon, M. (2008). Power and control wheel. In C. M. Renzetti \& J. L. Edleson (Eds.), Encyclopedia of interpersonal violence. Thousand Oaks, CA: Sage Publications.

Pennell, J. \& Burford, G. (2002). Feminist praxis: Making family group conferencing work. In H. Strang \& J. Braithwaite (Eds.), Restorative Justice and Family Violence (pp. 108-127). Cambridge, UK: Cambridge University Press. 
Perneger, T. V. (1998). What's wrong with Bonferroni adjustments. British Journal of Medicine, 316(7139), 1236-1238.

Petrosky, E., Blair, J. M., Betz, C.J., Fowler, K.A., Jack, S.P., Lyons, B.H. (2017). Racial and ethnic differences in homicides of adult women and the role of intimate partner violence - United States, 2003-2014. Morbidity and Mortality Weekly Report, 66(28), 741-746.

Presser, L. \& Van Voorhis, P. (2002). Values and evaluation: Assessing processes and outcomes of restorative justice programs. Crime \& Delinquency, 48(1), 162-188.

Prochaska, J. O. \& DiClemente, C. C. (1984). The transtheoretical approach: Crossing traditional boundaries of change. Homewood, IL: Dorsey Press.

Prochaska, J. O. \& DiClemente, C. C. (1986). Toward a comprehensive model of change. In W. R. Miller \& N. Heather (Eds.), Treating addictive behaviors: Processes of change (pp. 3-27). New York: Plenum Press.

Prochaska, J. O., DiClemente, C. C., \& Norcross, J. C. (1992). In search of how people change: Applications to addictive behaviors. American Psychologist, 47(9), 11021114.

Quintana, D. S. \& Heathers, J. A. J. (2014). Considerations in the assessment of heart rate variability in biobehavioral research. Frontiers in Psychology, 5, 1-10.

Raudenbush, S. W. \& Bryk, A. S. (2002). Hierarchical linear models: Applications and data analysis methods (2nd ed.). Thousand Oaks, CA: Sage Publications.

Riger, S., Raja, S., \& Camacho, J. (2002). The radiating impact of intimate partner violence. Journal of Interpersonal Violence, 17, 184-205. 
Roberts, L. J., Luke, D. A., Rappaport, J., Seidman, E., Toro, P. A., \& Reischl, T. M. (1991). Charting uncharted terrain: A behavioral observation system for mutual help groups. American Journal of Community Psychology, 19(5), 715-737.

Rossner, M. (2013). Just emotions: Rituals of restorative justice. Oxford, UK: Oxford University Press.

Sackett, K. L. (2017). Intimate partner violence impact panels for batterer intervention: A mixed-methods evaluation of a restorative justice process (Master's thesis). Retrieved from ProQuest. (doi:10.15760/etd.5964)

Sackett Kerrigan, K. \& Mankowski, E. S. (2020a). How surrogate impact panels function in the context of intimate partner violence: A mixed-methods study. Manuscript in preparation.

Sackett Kerrigan, K. \& Mankowski, E. S. (2020b). Planting seeds for change: Multiple perspectives on how intimate partner violence surrogate impact panels affect abusive partners. Manuscript in preparation.

Sackett Kerrigan, K. \& Mankowski, E. S. (2020c). Two sides of the same coin: How surrogate impact panels affect intimate partner violence survivors. Manuscript in preparation.

Salazar, L. F., Baker, C. K., Price, A. W., \& Carlin, K. (2003). Moving beyond the individual: Examining the effects of domestic violence policies on social norms. American Journal of Community Psychology, 32(3-4), 253-264.

Schmidt, M. C., Kolodinsky, J. M., Carsten, G., Schmidt, F. E., Larson, M., \& MacLachlan, C. (2007). Short term change in attitude and motivating factors to 
change abusive behavior of male batterers after participating in a group intervention program based on the pro-feminist and cognitive-behavioral approach. Journal of Family Violence, 22, 91-100.

Scott, K. L. (2004). Predictors of change among male batterers: Application of theories and review of empirical findings. Trauma, Violence, \& Abuse, 5(3), 260-284.

Scott, K. L. \& Wolfe, D. A. (2000). Change among batterers: Examining men's success stories. Journal of Interpersonal Violence, 15(8), 827-842.

Semiatin, J. N., Murphy, C. M., \& Elliott, J. D. (2013). Observed behavior during group treatment for partner-violent men: Acceptance of responsibility and promotion of change. Psychology of Violence, 3(2), 126-139.

Sherman, L., Strang, H., Barnes, G., Braithwaite, J., \& Inkpen, N. (1998). Experiments in restorative policing: A progress report to the national police research unit on the Canberra reintegrative shaming experiment (RISE). Australian Federal Police, Australian National University. Retrieved from http://www.aic.gov.au/rjustice/rise/index.html

Shrout, P. E. \& Fleiss, J. L. (1979). Intraclass correlations: Uses in assessing rater reliability. Psychological Bulletin, 86(2), 420-428.

Silvergleid, C. S. \& Mankowski, E. S. (2006). How batterer intervention programs work: Participant and facilitator accounts of processes of change. Journal of Interpersonal Violence, 21(1), 139-159.

Snijders, T. A. B. \& Bosker, R. J. (2012). Multilevel analysis: An introduction to basic and advanced multilevel modeling (2nd ed.). London: Sage Publications. 
Sonkin, D. J. \& Durphy, M. (1997). Learning to live without violence: A handbook for men. Volcano, CA: Volcano Press.

Stewart, D. W. \& Shamdasani, P. N. (1990). Focus groups: Theory and practice. Newbury Park, CA: Sage Publications.

Stith, S. M., Smith, D. B., Penn, C. E., Ward, D. B., \& Tritt, D. (2004). Intimate partner physical abuse perpetration and victimization risk factors: A meta-analytic review. Aggression and Violent Behavior, 10(1), 65-98.

Tabachnick, B. G. \& Fidell, L. S. (2007). Using multivariate statistics. Boston, MA: Pearson/ Allyn \& Bacon.

Taylor, B.G., Davis, R.C., \& Maxwell, C.D. (2001). The effects of a group batterer treatment program in Brooklyn. Justice Quarterly, 18, 170-201.

Van Ness, D. \& Strong, K. (1997). Restoring justice. Cincinnati, OH: Anderson Publishing Co.

Visschers, J., Jaspaert, E., \& Vervaeke, G. (2017). Social desirability in intimate partner violence and relationship satisfaction reports: An exploratory analysis. Journal of Interpersonal Violence, 32(9), 1401-1420.

Wangsgaard, S. M. (2001). The participants' perspectives: Factors of batterer group treatment that facilitate change. Dissertation Abstracts International: Section B: Sciences \& Engineering, 61(11-B), 6153. (UMI No. 2001-95010-071) Washington County Community Corrections (WCCC). (2007). Understanding the impact of abuse measure. Portland, OR: Marci Nelson. 
Yun, S. H. \& Vonk, M. E. (2011). Development and initial validation of the Intimate Violence Response Scale (IVRS). Research on Social Work Practice, 21(5), 562571.

Zehr, H. (1990). Changing lenses: A new focus for crime and justice. Harrisonburg, VA: Herald Press.

Zosky, D. (2018). "Walking in her shoes": The impact of victim impact panels on perpetrators of domestic violence. Victims \& Offenders, 13(6), 739-756. 


\section{Chapter V: Summative Review}

While several previous studies have evaluated surrogate impact panels in the context of intimate partner violence (IPV), the restorative justice processes and immediate impacts of these panels on justice involved individuals (JIIs) have been insufficiently understood. To address these gaps, this dissertation includes three studies that closely examine IPV surrogate impact panels through multiple methods and perspectives on how panels function, how participants experience panels, and how JIIs' immediate feelings and beliefs change after attending the panel. The first manuscript (Chapter II) presents a naturalistic mixed-methods study of IPV impact panels that investigates how survivors and JIIs experience and evaluate IPV impact panels and identifies interactional processes in panels that are consistent with restorative justice principles of stakeholder involvement, repairing harm, and re-envisioning roles (Bazemore, Elis, \& Green, 2007). The second manuscript (Chapter III) reports the perceived impacts of surrogate impact panels on JII participants, including experiencing connection with survivor speakers, reaching new understandings of IPV, and expressing emotional impact and intent to change. Finally, the third manuscript (Chapter IV) presents a study that applied the Interaction Ritual Model of restorative justice (Rossner, 2013) to empirically measure pre- and post-panel changes in JII participant feelings and beliefs and their association with observed group-level processes. This study examines these transformational processes not only because of their potential to explain any changes for individual JIIs, but because they are manifestations of an alternative approach to IPV intervention. This study builds directly upon the previous two and finds strong support for a majority of the hypotheses, particularly that JIIs' state 
empathy and reintegrative shame increases, minimization of responsibility decreases, and the importance of several motivations for addressing their abusive behavior changes after IPV surrogate impact panels.

\section{Contributions and Implications}

In its entirety, one of the primary strengths of this program of research is the prolonged period of time spent examining this local restorative justice practice. This fiveyear investigation, in partnership with IPV impact panel facilitators and participants, uses a variety of qualitative, quantitative, and observational methods to closely study the panel and the dynamic processes occurring within this social setting. The three manuscripts presented in this dissertation describe a deep understanding of how the panel functions, what restorative justice interactive processes take place during IPV impact panels, the perceived impacts of the panel on participants from multiple perspectives, and measurable post-panel changes for JIIs. Although the manuscripts primarily focus on the impacts of panels on JII participants, it is also informed by an understanding of the perceived panel impacts on survivor speakers (Sackett Kerrigan \& Mankowski, 2020). Finally, the comparison and application of inductive findings (Sackett, 2017) and deductive theoretical models and frameworks (Bazemore et al., 2007; Rossner, 2013) in this program of research increase the credibility, transferability, dependability, and confirmability (Lincoln \& Guba, 1985) of study results across the three manuscripts and their ecological validity (Brewer, 2000).

The methods used across the three manuscripts are highly complementary, with each bringing strengths in areas where others have limitations. Gathering data from 
multiple situated sources further increases confidence in study findings (Denzin, 1978; Lincoln \& Guba, 1985), such as the qualitative findings in the second manuscript where BIP providers and survivor speakers provided other-report perspectives on the potential impacts of panels on JII participants. The close attention to the dynamic processes of panels and examination of immediate changes in JII participants as state- rather than trait-level changes are also more likely to identify participant domains sensitive to change due to panel attendance, rather than attempting to detect change from panel effects in distal outcomes like recidivism. This is particularly important in the context of restorative justice evaluation, as recidivism rates are believed to not meaningfully or accurately reflect the functioning of restorative justice programs (Bergseth \& Bouffard, 2012; Zehr, 2002). Finally, the consistency across inductive and deductive previous research strongly supports the study design of pre- and post-panel tests of change in JII participant feelings and beliefs and how IRM restorative justice processes are associated with such change. Within and across the three manuscripts, triangulation of sources (i.e., survivor speakers, JII participants, BIP providers, and research observers), methods (i.e., ethnographic, quantitative surveys, and qualitative interviews and focus groups), and theories (Maximalist model of restorative justice, Bazemore et al., 2007; Interaction Ritual Model, Rossner, 2013; and the social ecological model, Kelly, Ryan, Altman, \& Stelzner, 2000;) greatly increase the credibility of study findings (Denzin, 1978).

Findings across all three manuscripts are largely consistent, with the third study clarifying those of the second by identifying empathy as a key domain of change for JIIs after IPV impact panels. Empathy was previously interpreted as a secondary factor that 
contributed to the overarching primary theme of "reaching new understandings" in the second study, as the emphasis on taking their partner's perspective was perceived as primarily a mechanism toward increased understanding of the impact of abuse. In contrast, findings from the third study suggest that an increase in empathy is a meaningful primary outcome itself. While the dimensions of state empathy measured in the most recent study (i.e., distress, concern, and perspective-taking) are associated with JIIs' increased understanding of the impact of abuse, the pattern of associations between the three empathy variables with this additional outcome and with other variables suggests that different dimensions of empathy relate to JII feelings and beliefs and to restorative justice processes in distinctly important ways. Together, these three papers provide a foundation for developing and clarifying an empirically-grounded program theory of surrogate impact panels. The proposed IPV surrogate impact panel program theory is further informed by an additional qualitative study on the perceived impact of IPV impact panels on survivor participants (Sackett Kerrigan \& Mankowski, 2020).

A model of IPV surrogate impact panel program theory. A program theory emerging from the three studies of this dissertation and a qualitative study within this program of research on the perceived impacts of panels on survivor speakers (Sackett Kerrigan \& Mankowski, 2020) is described in this section and modeled in Figure 5.1. The model specifies hypothesized links between primary program inputs, program processes, expected program outcomes, and resulting long-term impacts (Rossi, Lipsey, \& Freeman, 2004). Each section of the model is described in greater detail below. The model is intended to provide a framework for future hypothesis testing with ecologically valid 
outcomes grounded in restorative justice theory (e.g., the Maximalist model, Bazemore et al., 2007; the Interaction Ritual Model, Rossner, 2013). However, the model does not portray larger structural factors that are involved in IPV perpetration, such as social norms that encourage dominance and control over others within the social and political context of patriarchal societies (Carden, 1994). Although the figure draws upon a social ecological framework to identify key individual- and group-level factors of the program, the broader social ecological model within which this program theory is nested is not displayed in the figure. Future theory-driven research on IPV surrogate impact panels could define goals and tailor outcome measurement to the hypothesized outcomes and impacts of the program model, rather than transplanting outcomes from the criminal justice system (e.g., recidivism, compliance with supervision; Llewellyn, Archibald, Clairmont, \& Crocker, 2014).

Program inputs: Panel participants. The primary panel participants are survivors and JIIs. Panel facilitator(s) also assist with the panel process, as needed. Survivors are centered in the panel process and begin the panel by telling their stories. They enter the panel setting with their current understanding of their own experience and an openness to connect with other participants, including other survivor speakers and JIIs who attend the panel. JIIs sit in the audience and engage by listening to the panel content to varying degrees. JIIs enter the panel setting with their current level of minimization of responsibility for their abusive behavior, state empathy (including feelings of concern, distress, and perspective-taking of their own partners), feelings of reintegrative shame and stigmatizing shame, and expectations about what they will experience in the panel (e.g., that the speakers will be confrontational towards them, that the panel content will be 
irrelevant to them individually).

\section{Program processes: Transformative restorative justice group-level interactions. A} series of transformative restorative justice processes can unfold during IPV impact panels to various extents. The central mechanism of IPV panel impacts is hypothesized to be shared moments of common experience, which can be experienced in common by multiple survivor speakers among themselves, by multiple JIIs among themselves, and, importantly, by both survivor speakers and JIIs together. Creating a common experience shared by both survivor speakers and JIIs is especially important in this model, as it is one way in which IPV impact panels are consistent with a Maximalist definition of restorative justice (Bazemore, 2000) by involving individuals from different sides of a similar (though surrogate, not directly shared) harm in the process. The panel is believed to remove shame from speaking about abuse for both survivors and JIIs, which facilitates these shared moments of connection between participants over their common experiences. Support for one another's change can also be demonstrated by survivors for one another, by JIIs for one another, and mutually between survivors and JIIs for each other. These displays of support validate others' worth and common humanity. These interactions model alternative ways of being with one another and is believed to alter JIIs' learned behavior through direct reinforcement of an alternative power dynamic (Bandura, 1971). The panel disrupts norms of male dominance and control by encouraging survivors to share their stores and break the silence around the harm experienced, surfacing disagreement with the status quo that IPV is a shameful experience to be overcome in private and not in public places.

Attempts to repair relationships, a central goal of restorative justice practices (Zehr, 
2002), is a particularly fraught issue in the context of IPV. While many advocates, professionals, and community members express concern about potential harm to survivors that can come from focusing on such repair (e.g., Stubbs, 2007), IPV relationships are defined by severe harm to relationships that must be healed in some way. This dissertation's body of research suggests that one way to resolve these tensions is by expanding the boundaries of relationships to practice repair among surrogate partners. While the panel participants were not previously involved in direct relationships among themselves, many of which may not be possible to repair without causing further harm, survivors and JIIs can find common ground in their similar histories on either side of IPV and work on healing themselves together in this shared space. Furthermore, in providing a public space in which survivors and JIIs can meet to talk publicly about the nature of IPV and its impact on those who are harmed by it, including abusive partners themselves, the surrogate impact panel could provide a step towards repairing the broader relationship of self to community as the panel reintegrates survivors and JIIs in newly defined roles in public. Rather than hiding in private spaces to heal from shameful experiences, survivors are able to claim public space and validate their experiences as real and important sources of information to one another and to JIIs working to change abusive behavior in IPV intervention programs. Similarly, JIIs are able to sit in public and admit they are struggling with harmful behaviors that are rarely admitted to by those responsible for causing harm and are met with affirmations of their efforts to change.

The group-level dynamics of surrogate impact panels are important to attend to as they may drive individual-level changes in JII outcomes and are meaningful 
demonstrations of how IPV intervention can be characterized by equitable, inclusive power relationships (Llewellyn et al., 2014). The proposed model of the IPV surrogate impact panel program theory (Figure 5.1) specifies ways in which the panel creates equitable relationships to correct the harmful power dynamics of abusive relationships (Pence \& McMahon, 2008). Specifically, the program centers survivors, affirms participants' common humanity, and facilitates moments of shared understanding. Panel processes are hypothesized to lead to increased understanding of abuse, subsequent motivation to change, and progression through stages of change for JIIs and increased empowerment and healing for survivors. While the criminal justice system is particularly focused on individual-level outcomes and decreased recidivism, this restorative justice practice for IPV intervention demonstrates an alternative way of promoting positive relationship to restore equity.

\section{Expected program outputs and long-term impacts: Reintegrative changes for}

individual participants. The model of surrogate impact panel program theory in Figure 5.1 further specifies ways in which the panel is hypothesized to lead to short-term changes in individual-level immediate outcomes and long-term impacts for both survivors and JIIs. Proximal immediate outcomes for survivor speakers include validating and honoring their experiences as real and worth taking the space and time to center for other survivors, JIIs, and broader community members who attend the panel. This is expected to be integrated into survivors' long-term processes of growth, with distal impacts including increased empowerment and increased healing. In the short term, JIIs are believed to be humbled and challenged by the panel, which can manifest in outcomes including increased understanding of the impact of abuse, increased state empathy (including increased 
empathic concern, distress, and perspective-taking), increased reintegrative shame, and decreased minimization of responsibility for their abusive behavior. These short-term proximal changes are expected to be integrated into JIIs long-term processes of growth in their efforts to change, with long-term impacts including increased motivation to change and shift in their stages of change as they move toward action and maintenance of changing their abusive behavior (Prochaska \& DiClemente, 1984).

The distinction between short- and long-term changes for JIIs is informed by cautions about the long-term nature of behavior change in the context of IPV (Begun, Shelley, Strodthoff, \& Short, 2001) and attempts to be realistic about the expectations of the time required for change in this model. True change in the context of IPV abusive behavior in particular is expected to require extensive synthesis and integration on the part

of JIIs. This is particularly true for those who participate in IPV surrogate impact panels, as many of them are likely still in earlier stages of change as their participation is compelled by external mandates and not completely voluntary on their part. The screening process for panel attendance eligibility for JIIs is partly intended to prevent JIIs from attending if they are firmly in the precontemplation phase alone, but even for those in the contemplation stage the process of change is believed to take years to move through preparation and action stages and maintenance is likely ongoing in some way for the rest of their lives (Begun et al., 2001).

\section{Methodological recommendations for restorative justice and IPV research.} This program of research adopted temporal and dynamic perspectives to measure and evaluate patterns of interactional processes over time from multiple standpoints and setting 
characteristics in addition to individual self-report scores. This resulted in a more complete understanding of the panel setting and its participants in context (Seidman, 2012). Data in these studies are the first to empirically describe how IPV surrogate impact panels function and how their processes relate to changes in individual-level immediate outcomes.

Research on additional restorative justice programs and IPV interventions could similarly be oriented toward evaluation of setting processes, rather than toward individual change alone.

Restorative justice evaluation would be further strengthened by increased specificity in the operationalization of the processes that comprise program practices (e.g., a participant acknowledging that they have done wrong and expressing remorse for their actions as concrete demonstrations of positive accountability) and theorized immediate outcomes and long-term changes (e.g., increased motivation to change abusive behavior as a concrete impact rather than "healing"). Although restorative justice values and principles (e.g., Bazemore et al., 2007) are vital to attend to and infuse throughout the evaluation process (Llewellyn et al., 2014), values that are not linked to specific processes and outcomes are extremely difficult to study. Values-driven restorative justice research can recognize that the manifestation of principle-based processes are important program accomplishments in and of themselves, but concrete operationalizations of values increases the likelihood that such evaluations will create a strong body of evidence regarding program functioning. Outcomes that are consistent with program theory and underlying restorative justice theory (i.e., not recidivism) are most likely to be sensitive to change. Similarly, research on IPV intervention programs would benefit from closer focus 
on changes in immediate outcomes that are driven by program theory, rather than the typical distal impact of recidivism alone. Previous research suggests that group dynamics and individual behavior within BIP groups may further illuminate the way in which participants change their abusive behavior through the intervention process (e.g., Semiatin, Murphy, \& Elliott, 2013; Silvergleid \& Mankowski, 2006). Clarifying the links between immediate program outcomes and distal impacts would increase depth of understanding of abusive partners' processes of change and ways in which interventions can be optimized. For example, while research on BIP participants' stage of change commonly focuses on whether participants increase in their stage of change (e.g., Scott \& Wolfe, 2003), they less commonly consider the specific processes involved in such change (Prochaska, DiClemente, \& Norcross, 1992). This creates a gap in understanding regarding the nature and degree of the steps between the intervention as a whole and the outcomes that supposedly describe the intervention, limiting researchers' and practitioners' ability to improve program practices to facilitate desired change in participants. Closer attention to the processes of change could provide more specific direction for future improvement.

\section{Limitations}

One of the most significant limitations of this dissertation is its primary focus on JII audience members and lack of focus on survivor speakers in evaluating how IPV surrogate impact panels potentially affect participants. Although this program of research includes a qualitative study of the perceived impacts of panels on survivors who speak on the panel (Sackett Kerrigan \& Mankowski, 2020), this dissertation focused solely on how the panel may operate as a component of BIPs and does not adequately represent all potential merits 
of the panel and especially its possible benefit to survivor participants. Like all restorative justice programs, the merit of the panel must be grounded in the values and priorities of those who are harmed in abusive relationships first and foremost. Although this dissertation conceptualizes IPV surrogate impact panels as fundamentally a survivor-driven and survivor-centered process, the three manuscripts of this dissertation alone are limited in their capacity to speak to foundational aspects of the program.

As is common in both restorative justice and BIP evaluation research, all three manuscripts are influenced by selection effects both in who choose to attend panel and who additionally participates in voluntary research. Therefore, the data obtained in the studies capture only certain perspectives of IPV survivors, JII participants, and BIP providers. Given that typical rates of BIP drop out tend to range between $40 \%$ and $60 \%$ of JIIs mandated to attend these programs (Eckhardt, Murphy, Black, \& Suhr, 2006), the screening period for JIIs of completing at least 26 weeks of BIP groups before attending the panel means that only those who have not dropped out by that point in the program are actually referred to attend the panel. JIIs who are willing to participate in an interview or complete surveys and feedback forms thus represent an even smaller group of JIIs who experienced the IPV impact panel. Their perspectives therefore likely differ from others who have either chosen not to attend the panel or not to participate in research when attending. For example, JIIs willing to complete interviews or participate in surveys may be more engaged in the panel process and motivated to complete additional activities associated with the panel than those who do not elect to participate in study activities. JIIs who attend the panel may have progressed farther in their process of abusive behavior change and more responsive to 
possible panel effects than those who do not show up for the panel or who drop out of a BIP. The studies in this dissertation therefore reflect the experiences, perceptions, and selfreported post-panel changes of a unique sub-set of the larger population of individuals who perpetrate IPV.

A related theoretical limitation of these studies is the ambiguity in the extent to which JII attendance at panels is "voluntary." Restorative justice theory emphasizes the importance that all participants enter a restorative justice practice completely voluntarily, with genuine openness and willingness to engage with one another (Cheon \& Regehr, 2006). Currently, JIIs are required by participating BIPs to attend a panel in order to meet requirements set by their POs. However, there is a degree of self-selection in who not only receives the referral from the BIP (and their PO) but actually chooses to show up for the panel, as the requirement does not appear to be a strictly enforced mandate by POs. While the involuntary nature of JII participation would compromise the theoretical comparability of panel evaluation to other restorative justice practices, the self-selection effects also compromise comparability, as it is likely that those who actually show up for the panel are different in meaningful ways than those who ignore the direction to attend (e.g., possibly with higher motivation for personal change or greater adherence to rules and supervision requirements). Both of these influences on JII participation limit the extent to which findings from the current studies may transfer (Lincoln \& Guba, 1985) to other restorative justice programs.

It is particularly important to recognize the difference between the phenomenon of “intentional change" versus "societal, developmental, or imposed change" when 
considering individual-level changes in JIIs in IPV intervention programs and particularly in restorative justice IPV interventions. The Transtheoretical Model of change, often applied to evaluations of IPV interventions (Begun et al., 2001), was developed in the context of programs attempting to change addictive behaviors (Prochaska et al., 1992) and focused on the former (intentional change), which therefore may be limited in explaining the latter (imposed change). While the IPV impact panel is not housed completely within the criminal justice system, the PO requirement that JIIs attend the panel raises the question of the extent to which JIIs are engaged in intentional change, externally-imposed change, or both. As restorative justice programs are believed to be most effective when participants are truly voluntary (Cheon \& Regehr, 2006), evaluations of a restorative justice program that include participants who are coerced into enrolling (i.e., JIIs who are court-mandated to enroll in a BIP and required by POs to attend the panel) may not necessarily capture the full potential benefits of the program, were it only to include completely voluntary participants. The eligibility requirement that JIIs typically be enrolled in BIPs for at least 26 weeks and the soft enforcement of the mandate to attend a panel suggest that at least some participants may be engaged in more self-driven, intentional change rather than externally-imposed change alone. Thus, the current studies' findings may reflect at least some degree of change that can manifest from a restorative justice process with voluntary participants, but the detection of program effects is likely still limited by the somewhat involuntary nature of program participation.

\section{Future Directions in Research and Action}

This program of research attempted to deeply understand a local IPV surrogate 
impact panel and findings across the three studies suggest that the panel can provide meaningful benefits to participants. This research could be extended in a number of ways, particularly in future studies using generalizable designs that are more capable of making comparisons between different groups of participants. Program effectiveness could be evaluated by comparing the changes that occur after panel attendance to changes after a control group practice (e.g., participants in other two-hour group sessions, such as a BIP group or other educational session), as the studies in this dissertation were able to document changes in post-panel outcomes but not isolate program effects. Long-term change for both survivors and JIIs could be further evaluated regarding how the panel experience is integrated over time and whether the program results in the anticipated longterm impacts. Further implementation evaluation could also be conducted to identify active ingredients of panel processes using validated observational tools, guided by the theory of program impact modeled in Figure 5.1. For example, future studies could focus on the nature of the attachment between panel speakers and audience members in IPV surrogate impact panels to better understand how panel participation could be optimized. Findings from the mixed methods' study of the perceived panel impacts on JIIs suggest that some audience members may disconnect from the panel process or find reasons to reject the panel based on the content of the material being discussed (e.g., mentally distancing themselves from the perpetrator of severe physical violence described by a survivor speaker). A deeper understanding of how and when audience members disconnect or shut down during panels could identify targets for greater preparation and support for JIIs by BIP facilitators prior to entering the panel setting (e.g., emotion regulation interventions; 
Cameron, Carroll, \& Hamilton, 2018) to increase their capacity to stay engaged during panels, even when they become personally distressed. Finally, additional evaluation could test whether the panel functions differently for different groups of participants (e.g., whether JIIs vary in panel engagement or changes in immediate outcomes based on their stage of change at the start of the panel). While this dissertation demonstrates the potential value of IPV surrogate impact panels, much more remains to be understood regarding their effectiveness and integration in the coordinated community response.

The current institutional response to IPV remains limited, and the logic of using the criminal justice system as the sole mainstream agent for responding to IPV must continue to be questioned. Current responses to IPV within the criminal justice system leave much to be desired, from a lack of utilization of reporting mechanisms (Tjaden \& Thoennes, 2000) possibly due to concerns about the potential additional damage survivors may face if they seek formal support (e.g., Haaken \& Yragui, 2003; Hampton, LaTaillade, Dacey, \& Marghi, 2008; Rap \& Silverman, 2002) to its limited capacity to eradicate violence (e.g., Stover, Meadows, \& Kaufman, 2009; Babcock, Green, \& Robie, 2004). The contradiction in attempting to promote long-term behavioral change in abusive individuals through an institution that uses coercion, threat of punishment, and retribution to maintain order and control over others is particularly concerning. Although much remains to be explored regarding the effectiveness of surrogate impact panels as a component of IPV intervention, the studies presented in this dissertation take several steps forward in understanding how IPV surrogate impact panels may offer additional avenues for survivors and JIIs toward justice and healing. 


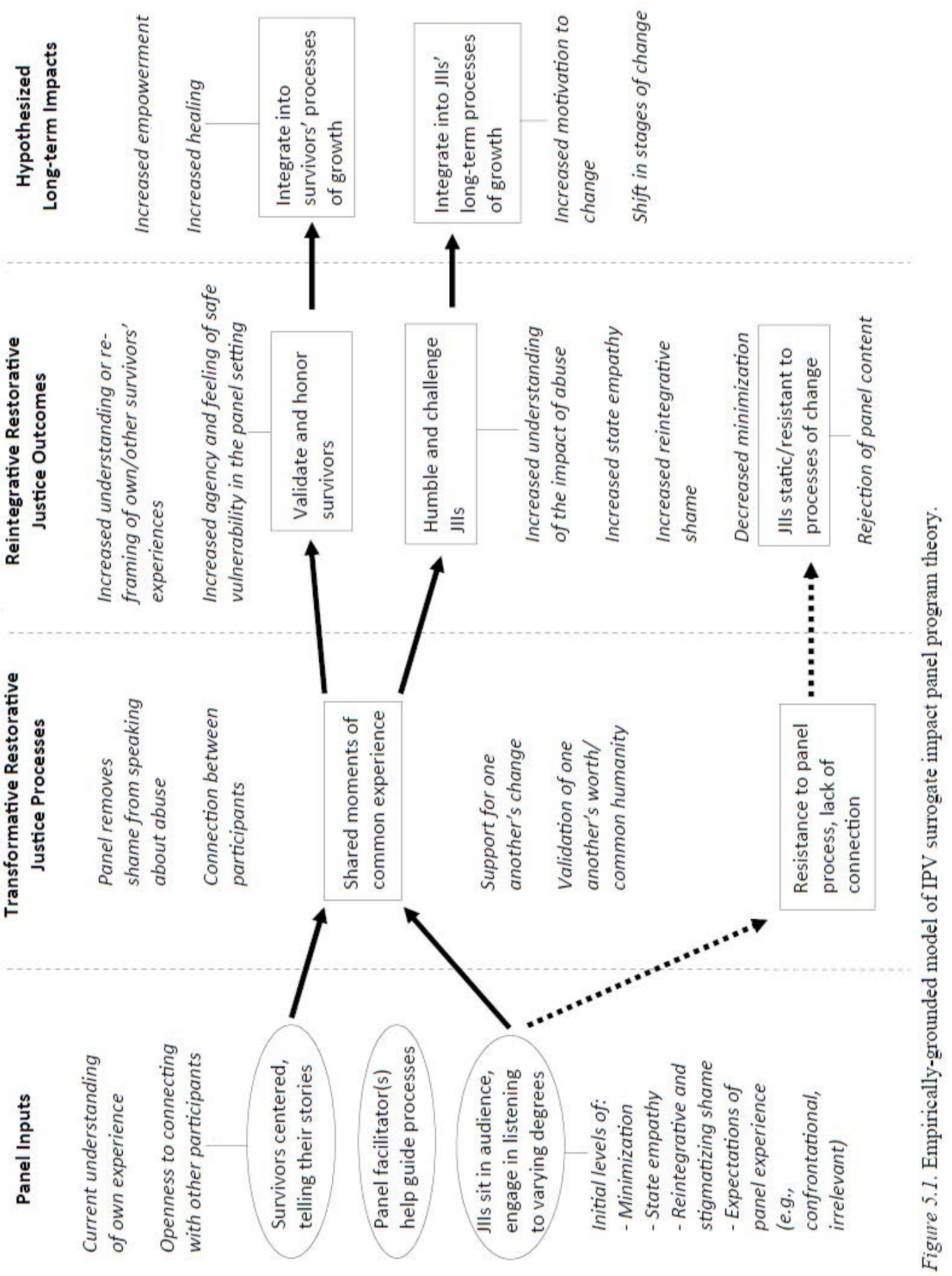




\section{References}

Babcock, J. C., Green, C. E., \& Robie, C. (2004). Does batterers' treatment work? A meta-analytic review of domestic violence treatment. Clinical Psychology Review, 23, 1023-1053.

Bandura, A. (1971). Social learning theory. New York, NY: General Learning Press.

Bazemore, G. (2000). Rock and roll, restorative justice, and the continuum of the real world: A response to "Purism" in operationalizing restorative justice. Contemporary Justice Review, 3(4), 459-477.

Bazemore, G., Elis, L., \& Green, D. L. (2007). The "independent variable” in restorative justice: Theory-based standards for evaluating the impact and integrity of victim sensitive process (part II). Victims \& Offenders, 2(4), 351-373.

Begun, A. L., Shelley, G., Strodthoff, T., \& Short, L. (2001). Nonconventional approaches for intervention in cases of spouse/partner abuse. Journal of Aggression, Maltreatment \& Trauma, 2(10), 105-127.

Bergseth, K. J. \& Bouffard, J. A. (2012). Examining the effectiveness of a restorative justice program for various types of juvenile offenders. International Journal of Offender Therapy and Comparative Criminology, 57(9), 1054-1075.

Brewer, M. B. (2000). Research design and issues of validity. In H. T. Reis \& C. M. Judd (Eds.), Handbook of Research Methods in Social and Personality Psychology (pp. 3-16). Cambridge, UK: Cambridge University Press.

Cameron, L. D., Carroll, P., \& Hamilton, W. K. (2018). Evaluation of an intervention promoting emotion regulation skills for adults with persisting distress due to 
adverse childhood experiences. Child Abuse \& Neglect, 79, 423-433.

Carden, A. D. (1994). Wife abuse and the wife abuser: Review and recommendations. The Counselling Psychologist, 22(4), 539-582.

Cheon, A. \& Regehr, C. (2006). Restorative justice models in cases of intimate partner violence: Reviewing the evidence. Victims and Offenders, 1(4), 369-394.

Denzin, N. K. (1978). Sociological methods. New York, NY: McGraw-Hill.

Eckhardt, C. I., Murphy, C., Black, D., \& Suhr, L. (2006). Intervention programs for perpetrators of intimate partner violence: Considerations from a clinical research perspective. Public Health Reports, 121(4), 369-381.

Haaken, J., \& Yragui, N. (2003). Going underground: Conflicting perspectives on domestic violence shelter practices. Feminism \& Psychology, 13, 49-71.

Hampton, R. L., LaTaillade, J. J., Dacey, A., \& Marghi, J. R. (2008). Evaluating domestic violence interventions for black women. Journal of Aggression, Maltreatment \& Trauma, 16(3), 330-353.

Kelly, J.G., Ryan, M. Altman, E.B., \& Stelzner, S.P. (2000). Understanding and changing social systems: An ecological view. In J. Rappaport and E. Seidman (Eds.), Handbook of Community Psychology (pp. 133-159). New York, NY: Kluwer.

Lincoln, Y. S. \& Guba, E. G. (1985). Naturalistic inquiry. London, England: Sage Publications.

Llewellyn, J. J., Archibald, B. P., Clairmont, D., \& Crocker, D. (2014). Imagining success for a restorative approach to justice: Implications for measurement and evaluation. The Dalhousie Law Journal, 36(2), 281-316. 
Pence, E. \& McMahon, M. (2008). Power and control wheel. In C. M. Renzetti \& J. L. Edleson (Eds.), Encyclopedia of interpersonal violence. Thousand Oaks, CA: Sage Publications.

Prochaska, J. O. \& DiClemente, C. C. (1984). The transtheoretical approach: Crossing traditional boundaries of change. Homewood, IL: Dorsey Press.

Prochaska, J. O., DiClemente, C. C., \& Norcross, J. C. (1992). In search of how people change: Applications to addictive behaviors. American Psychologist, 47(9), 11021114.

Rap, A. \& Silverman, J. (2002). Violence against immigrant women: The roles of culture, context, and legal immigrant status on intimate partner violence. Violence Against Women, 8, 367-398.

Rossi, P. H., Lipsey, M. W., \& Freeman, H. E. (2004). Evaluation: A systematic approach (7th ed.). Thousand Oaks, CA: Sage Publications.

Rossner, M. (2013). Just emotions: Rituals of restorative justice. Oxford, UK: Oxford University Press.

Sackett, K. L. (2017). Intimate partner violence impact panels for batterer intervention: A mixed-methods evaluation of a restorative justice process (Master's thesis). Retrieved from ProQuest. (doi:10.15760/etd.5964)

Sackett Kerrigan, K. \& Mankowski, E. S. (2020). Two sides of the same coin: How surrogate impact panels affect intimate partner violence survivors. Manuscript in preparation.

Scott, K. L. \& Wolfe, D. A. (2000). Change among batterers: Examining men's success 
stories. Journal of Interpersonal Violence, 15(8), 827-842.

Seidman, E. (2012). An emerging action science of social settings. American Journal of Community Psychology, 50(1-2), 1-16.

Semiatin, J. N., Murphy, C. M., \& Elliott, J. D. (2013). Observed behavior during group treatment for partner-violent men: Acceptance of responsibility and promotion of change. Psychology of Violence, 3(2), 126-139.

Silvergleid, C. S. \& Mankowski, E. S. (2006). How batterer intervention programs work: Participant and facilitator accounts of processes of change. Journal of Interpersonal Violence, 21(1), 139-159.

Stewart, D. W. \& Shamdasani, P. N. (1990). Focus groups: Theory and practice. Newbury Park, CA: Sage Publications.

Stover, C. S., Meadows, A. L., \& Kaufman, J. (2009). Interventions for intimate partner violence: Review and implications for evidence-based practice. Professional Psychology: Research and Practice, 40, 223-233.

Stubbs, J. (2007). Beyond apology? Domestic violence and critical questions for restorative justice. Criminology \& Criminal Justice, 7(2), 169-187.

Tjaden, P. \& Thoennes, N. (2000). Extent, nature, and consequences of intimate partner violence: Findings from the National Violence Against Women Survey. Washington, DC: U.S. Department of Justice, Office of Justice Programs, National Institute of Justice.

Zehr, H. (2002). The little book of restorative justice. Intercourse, PA: Good Books. 


\section{Appendix A: Reflexive Stance}

Reflecting on the many notes that I took about my experience researching panel, the nature of how my understanding evolved is most apparent to me in the many questions that I tracked about the panel process between September 2014 and April 2017. I am inherently tied to the means of data collection and knowledge production in this ethnography and so I have attempted to describe here how the research questions, data collection, analysis decisions, and final interpretations were filtered through my perceptions to establish credibility in the findings (Schensul \& LeCompte, 2013). I followed the recommendations of Schensul and LeCompte to minimize threats to internal validity by allowing sufficient time and resources to observe a wide enough range of experiences, participants, opinions, and activities to achieve a deep understanding of the setting.

\section{Prior Experience and Early Assumptions}

Before I ever attended an impact panel, I had initial questions and assumptions about how the panel might operate and what influence the panel would have on survivors and JIIs. I had not worked directly with men enrolled in BIP groups before, but I had previously worked with IPV survivors as a sexual assault advocate and crisis counselor. Although I had received some training on the dynamics of IPV and the overlap with sexual assault and other forms of gender-based violence, I did not consider myself an expert on the subject and felt I had a lot to learn about their experiences. My advocacy background provided a filter for my initial impressions of the panel that I became increasingly aware of, as the training I received to be an advocate gave me an initial 
framework for understanding the nature of sexual assault and IPV. Even in my own initial notes on possible plans, such as one of looking at the historical context of how the response to sexual assaults and/or IPV in this local area developed and considering newer programs that used any type of restorative justice model, I was extremely careful in how I framed my research ideas and the reasons why I was interested in the use of restorative justice for IPV cases.

My first questions about the panel were primarily focused on JII change, as I wondered whether the change that I assumed took place after they attended an impact panel could be in their thoughts about their own behavior or their partner's experience of their abuse. I was curious why JIIs were attending the panels, whether the program mandated their attendance and if so whether they had any other personal motivation to attend. I had similar questions about the survivor participants, how they felt after speaking on the panels, what their impression of the impact was on JIIs, their motivation to participate, and whether they themselves changed as a result of participating.

One of my biggest concerns was that focusing on restorative justice responses to IPV would discount or ignore the effort spent building existing advocacy and abuse intervention programs and establishing IPV and related violence as recognized a crime by state and federal governments. My previous work as an advocate had led me to believe that sexual assault (and I assumed IPV) survivors' needs were not being met by the existing criminal justice system responses, but I was still thinking of their role in this response as primarily program recipients in the system. Although I critiqued what was being offered in the current system, I thought that what primarily needed to change was 
the 'menu' of options offered (e.g., increasing access to restorative justice programs).

I was also very concerned with not "stepping on anyone's toes" of those who had worked in IPV prevention and intervention when I first began researching this subject. I did not want to insult or disparage the work that it took to get these acts recognized as crimes, or somehow "set the clock back" by having any research on this subject be used to argue that such cases should not be handled by the criminal justice system at all or always managed privately between couples or within families. I was especially focused on the question of "safety" and sought out literature on theory or previous studies that could inform whether restorative justice programs were "safe" to use in this context.

I also wondered whether such programs could address or change the power differential between IPV survivors and JIIs, possibly to a unique extent compared to other interventions through BIP or other criminal justice processes. I began to wonder how the local community perceived these responses to IPV and their attitudes toward using criminal justice and restorative justice for these cases here. My concern over the safety of restorative justice practices with IPV cases for survivors shifted slightly to wondering whether these practices and restorative justice principles could adequately address the power dynamic of IPV cases and whether it could truly be a survivor-centered practice.

\section{Entering the Setting and Initial Study Design Considerations}

Attending my first panel drew my attention to a point of tension in the panel process: whose needs come first, the panelists (survivors) or the audience members (JIIs)? I talked with the facilitator about how speakers are recruited for the panels and wondered in those conversations how much emphasis was placed on the panel's impact on speakers 
and how much on the panel's impact on JIIs. Implicitly, I was setting this up as an either/or question: either the panel primarily serves the needs of the survivors or those of the JIIs. In conversations with other stakeholders who interact with the panel, such as BIP providers, I heard this same either/or logic and different decisions around whose needs should first be prioritized.

I came away from the first panel with many more logistical questions: when do men attend, do they come from all programs, what is the PO's role, who are the speakers and how long have they been in the pool, how many speakers are in the pool, how often are new referrals made for new speakers, and how does this compare to other activities that the men are doing in BIP groups to increase empathy? I also wondered how the panels were described to the men in BIPs before they arrived at the panel and how the men understood the purpose of the panel. Across my time observing the panels, I would find answers to questions that would lead to new clarifying or expanding questions. It was a continual process of discovery.

My reading led me to recognize very early on that definitions of restorative justice and related concepts can be very difficult to pin down. I had started to consider many possible points of data for understanding these panels, but given the sometimes slippery nature of what restorative justice is and what it looks like, I decided a process and impact evaluation was the most necessary first step to understanding what was happening in the panels and how it was potentially impacting participants. This seemed particularly relevant for a restorative justice program assessment, given the difficulty in defining the concept and the questions surrounding how restorative justice could be used for IPV 
intervention with this specific panel process.

As I was designing this study, many different potential outcomes came to mind that could be relevant for the participants. I struggled with how to concretely define and measure different components of restorative justice, such as recognition of wrongdoing, healing conflict, rebuilding trust, promoting safety, and committing no further crimes (Von Hirsch, Ashworth, \& Shearing, 2003). I continued to wonder how the panel impacts JIIs, and was especially excited about the possibility that it shifted them from an external to internal motivation not to re-offend.

I had many gaps in my understanding of how these processes and impacts might happen for participants. I thought the panel might be an opportunity to empower the disempowered group (i.e., the survivors), but if this was the case I did not know what mechanisms drove this impact. Would the presence or the magnitude of this impact depend on the number of people attending the panels? Would it instead or additionally depend on the "quality" or "intensity" of the listeners and their interactions?

Looking back on this now, I can see assumptions that I held about why people were motivated to participate, who could benefit and how from these panels, and whose position it was to make decisions about all of this. I brought binary assumptions that the panel operated in either/or benefits supported by external authority, entering with an attitude of humility from not knowing anything about this work at all but implicitly believing that it was the place of professionals to optimize and deliver this program. Ultimately I assumed that eventually I might amass enough knowledge or experience to help guide those external decisions. I thought that one of the most pressing concerns for 
people (read: professionals) who were wondering whether restorative justice was appropriate to use for IPV was how to tell when program participants would be ready to engage in the process in a safe and effective way. I wanted to know how to optimize these decisions about participant readiness for program effectiveness, and implicitly I assumed that this optimization would be done by an outside force, some kind of external judge (i.e., professional) who would know best when and how to offer and administer these programs.

When I was attempting to understand whether the panel could repair harm in any way for the panel participants, I assumed that this act of repair was usually unidirectional. I assumed that JIIs could repair the harm to victims and/or to communities. I assumed that this act of repair would only truly be impactful if it was happening in the direct pairs of people who had been harmed and who had done the harm, and in cases of IPV this did not seem possible. I did not have an understanding of how surrogate interactions could bring real healing or repair harm, and I assumed that this act of repair could only be done from one group to another group. I did not know whether speaking in public as a survivor could be an act of self-repair. I assumed that their healing happened more in counselling settings, support groups, or other related settings where professionals worked with survivors to help them process their past harms. I did not know whether listening alone on the part of JIIs would be enough of an action to repair any of that harm.

I also assumed that these impacts would be possible to differentiate from other intervention program impacts or other work/changes that participants were doing in other ways. I was used to thinking about cause and effect in positivist terms: an action would 
have a clearly observable reaction, which would persist over time if it was truly effective. For example, I imagined that if the panel affected JIIs' defensive thinking, it might do so in a way that this thinking decreased over time after the panel and remained so in a noticeable way.

\section{My Position and Relationship with Research Partners and Participants}

As I continued to attend and observe the panels, my position within the research setting shifted from a welcome but unfamiliar observer, careful not to interject in debriefing conversations for fear of influencing the naturally occurring process, to recognized researcher and a regular presence at panels for speakers and panel facilitators. I remember how receiving funding from the National Science Foundation for a graduate student fellowship to study the process and outcomes of this restorative justice process for IPV increased my confidence in the value of the time I had been spending observing panels. This external support also seemed to solidify my identity for others in the setting as a legitimate researcher. Over time, many of the speakers became familiar with me and seemed to increase their trust in sharing information about their panel experiences with me. Other aspects of my identity as a white, female student in her late twenties from a local university were likely salient to JII audience members, who would meet me for the first time at panels and who formed first impressions of me based on those characteristics, not being regular members of the panel setting and so unavailable to build rapport or trust with me over an extended period of time in the setting. My contact with providers through local BIP provider network meetings slowly turned me into a regular face there as well, recognized as affiliated with the university and further established through my 
service taking meeting minutes.

\section{My Evolving Understanding of the Panel Setting and Processes}

A major breakthrough in my understanding came when I realized that the hyperconcern with participant safety implicitly assumed that the speakers were not capable of taking care of themselves and required some sort of external approval of the panel as "safe for survivors." Much of what I could find in the literature on the subject of whether restorative justice was safe to use for IPV cases drew on secondary sources such as advocates who spoke for survivors (e.g., Curtis-Fawley \& Daly, 2005), implying that they knew best because they were professionals and they had survivors' bests interests in mind. From listening to speakers describe their frustrating experiences with other types of IPV services, I realized this desire to "protect" survivors could be (and often was) extremely paternalistic and condescending, communicating that they could not be trusted to know whether a process was safe for them to engage in or not. This realization helped me begin to focus on the unique quality of speaker control over the panel process and what that process was capable of creating for survivor and JII participants.

Another breakthrough in my perspective as a panel observer resulted when I attended a training on transformative justice and wondered afterward what it means to be afraid of seeing JIIs as people, or as fully human. This deepened the layers of complexity contained in the panel process from my perspective and helped me think about the process more completely. I began to see seemingly contradictory processes and impacts taking place simultaneously within the panel, such as the tension between treating JIIs with respect and non-judgment while not excusing or condoning their abusive behavior. 
These men in the panel audiences did severe damage to those around them; on one hand, this meant that the panel could not function truly as a restorative justice process if it minimized that damage, corrupting the intended focus of increasing JIIs' understanding the impact of abuse. On the other hand, the men themselves are hurting and that hurt is inextricably tied up in their actions; they need to be met with compassion and seen as fully human, not only as "offenders," or they will keep their defenses up and not engage in the process. I continue to wrestle with these tensions today.

Although my understanding has changed over time, becoming more refined as I have heard from stakeholders with multiple perspectives on the panel and gathered data through multiple types of observations, I have also circled back to center on earlier points in my understanding that I believe are most crucial to emphasize in my interpretation of the data in this study. Questions that I first asked over two years ago are still relevant to me today, most especially whether and how the IPV impact panels address the power dynamics of IPV. 


\section{Appendix B: Informed Consent Form}

\section{S Portland State}

You are invited to participate in a study conducted by Kate Sackett, a graduate student from Portland State University (PSU). Ms. Sackett hopes to learn about the process and impacts of different intimate partner violence programs. You were selected as a possible participant because you are attending an impact panel.

If you decide to participate, you will fill out a survey before the panel starts and another survey after it ends. Afterwards, you will be asked to take part in a brief group conversation about your experience here tonight. Other group members will include other audience members from the panel tonight, with whom you may or may not regularly attend groups in a batterer intervention program. Either Ms. Sackett or her research assistant will facilitate the conversation. They will pose several questions to the group and you will be asked to share your experiences and opinions about them.

Both the surveys and the small group conversation will ask you questions about what your experience is like in the panel. You have the right to refuse to answer any questions that you do not want to or find uncomfortable, for any reason and at any point, without penalty.

The group conversation will be recorded with an audio recorder so that the researcher can concentrate on what is being said and guide the conversation. The recording will only be heard by Ms. Sackett or her research assistant and it will be kept in a locked laboratory on the Portland State University campus.

Your identity as a participant will not be revealed to anyone who is not present at the time of the impact panel. Your identity will not be associated with any information in or about the study. However, the researcher cannot guarantee that other group members will keep information that you share during the conversation confidential. Additionally, if you report any behavior that suggests that you are at an immediate risk of harming yourself or another person, this information will be reported to the necessary authority.

The discussion will be held in a private room of the Hillsboro Civic Center (150 E Main St., Hillsboro, OR 97123). The first survey is expected to take about ten minutes and the second survey about fifteen minutes to complete. The small group discussion is expected to last for about twenty minutes. It is possible that participating in the study will make you remember events that were upsetting, or realize new things about the people in your life that may be uncomfortable. Participating in this study may be beneficial to you by having an opportunity to talk about and reflect on your experience attending the impact panel and the potential impact it has had on you or others who attend the panel. 
It is also possible that you may not receive any direct benefit from taking part in this study, but the information that you share will be used to evaluate possible benefits of different intimate partner violence programs. The results of this study may also contribute to a better understanding among local survivors, offenders, and intimate partner violence programs about the impact and improvement of programs for future participants. A written summary report of the findings from this study will be made available upon its completion and published on the research team's website at https://ipvinterventionspdx.wordpress.com/research-page/IPV-programs-study.

Your participation is voluntary. You do not have to take part in this research, and whether or not you choose to participate will not affect your standing or relationship with the panel facilitator, any intimate partner violence programs, probation officers, or anyone else who referred you to the impact panel. You may also withdraw from this study at any time without affecting your status with these groups or individuals.

If you have concerns or problems with your participation in this study or your rights as a research participant, please contact the Portland State University Human Subjects Research Review Committee at The Office of Research Integrity, $1600 \mathrm{SW} 4^{\text {th }}$ Ave., Market Center Building, Suite 620, Portland, OR 97201; phone (503) 725-2227 or 1 (877) 480-4400. If you have questions about the study itself, contact either the principal investigator, Eric Mankowski, at mankowskie@pdx.edu or 503-725-3901, or Kate Sackett at ksackett@pdx.edu or 503-725-3955.

Your signature below indicates that you have read and understand the above information and agree to take part in this study. Please understand that you may withdraw your consent at any time without penalty, and that, by signing, you are not waiving any legal claims, rights, or remedies. The researcher will provide you with a copy of this form for your own records.

Name (Please print):

Signature:

Date: 


\section{Appendix C: Survey Measures}

State Empathy Scale Items (Batson et al., 1987)

Items are rated on a 5-point scale from 1 (Not at all) to 5 (Completely). Participants are asked to rate how much the panel made them feel each of the following adjectives.

Empathic distress
Distressed
Uneasy
Disturbed
Grieved
Upset
Worried
Anxious
Empathic concern
Sympathetic
Tender
Touched
Sorrowful
Moved
Concerned
Soft-hearted
Compassionate

State Guilt/Shame Scale Items (Marschall, Sanfter, \& Tangney, 1994)

Items are rated on a 5-point scale from 1 (Not feeling this way at all) to 5 (Feeling this way very strongly). Participants are asked to rate each statement based on how they are feeling right at that moment.

Shame

I want to sink into the floor and disappear.

I feel small.

I feel like I am a bad person.

I feel humiliated, disgraced.

I feel worthless, powerless.

Guilt

I feel remorse, regret.

I feel tension about something I have done.

I cannot stop thinking about something bad I have done.

I feel like apologizing, confessing.

I feel bad about something I have done.

\section{Defendant Empathy Scale Items (Haegerich \& Bottoms, 2000)}

Items are rated on a 7-point scale from 1 (Strongly disagree) to 7 (Strongly agree).

Participants are instructed that the following statements may or may not describe some of their thoughts and beliefs about their current or former partners that were victimized in 
their relationship(s) and to please rate how much they agree with each statement using the 7-point scale.

I can really imagine the thoughts running through my victim(s)'s head.

I can really feel what my victim(s) must have been feeling during my abusive incident(s).

I can experience the same feelings that my victim(s) experienced.

I can take the perspective of my victim(s) and understand reasons behind their actions.

I feel like I can easily take the perspective of my victim(s).

Understanding of Abuse Scale (WCCC, 2007)

Items are rated on a 6-point scale from 1 (Slightly disagree) to 6 (Strongly agree).

The panel tonight was helpful to me.

I feel more convinced that I should stop being violent and controlling in my relationships.

I better understand how my physical abuse has harmed my victim(s).

I better understand how my verbal and emotional abuse has harmed my victim(s).

The panel tonight has changed how I think/feel about domestic violence.

I feel more understanding about what survivors of domestic violence experience.

The panel tonight helped me understand the long-term effects of abuse of others.

\section{Emotional Engagement and Perceived Realism Subscales (Cho et al., 2014)}

Items are rated on a 7-point scale from 1 (Strongly disagree) to 7 (Strongly agree).

Participants are instructed that the following statements may or may not describe their experience at the panel and to please rate how much they agree with each statement using the 7-point scale.

\section{Emotional Involvement}

The panel tonight had an effect on my emotions.

The panel made me emotional.

I could feel the emotions of the people on the panel tonight.

I was emotional while listening to the panel.

Identification

I could relate to the situation(s) described in the panel.

I could identify with what was described in the panel.

I could relate to the event(s) covered in the panel.

Factuality

The panel was based on facts.

The panel described something that had really happened.

What was described in the panel had actually happened.

\section{Resistance Scale (Levesque et al., 2008)}

Items are rated on a 5-point scale from 1 (Not at all) to 5 (Very much) with an additional option $(\mathrm{N} \backslash \mathrm{A})$ for starred $(*)$ items. Participants are instructed that listed are thoughts and 
feelings that they may experience and to please rate how much they experienced each of the following during the panel.

Problems with Alliance: Focusing on the speaker's use of confrontation and inability to help the client feel understood, safe, and supported

How much did you not trust the people on the panel tonight?

How much did you feel that people on the panel were criticizing you?

How much did you feel that the people on the panel blame you for everything?

How much did you feel like what the people on the panel talked about tonight has nothing to do with the real world?

Hopelessness: Feeling hopeless, overwhelmed, depressed or anxious about making changes

How afraid did you feel about the thought of changing?

How hopeless did you feel about making changes in your life?

How much did you feel that your life will never get better, even if you try to change?

Passive Reactance: Responding with pressure to change by participating only

superficially, without meeting expectations or responding appropriately

How bored or uninterested did you feel during the panel tonight?

How much attention did you pay to the panel tonight?

Psychological Reactance: Responding to pressure to change with an angry or

negativistic stance

How angry did you get when someone told you what you should and should not do in your relationship?*

How much did you feel like telling people to mind their own business when they told you how to behave in your relationship?*

How mad did you get when people told you that you need to change?*

\section{Intimate Violence Responsibility Scale (Yun \& Vonk, 2011)}

Items are rated on a 5-point scale from 1 (Strongly disagree) to 5 (Strongly agree).

Participants are instructed that the following statements may or may not describe some of their beliefs about the event(s) in their relationship that led them to be enrolled in a program for domestic violence and to please rate how much they agree with each statement using the 5-point scale.

\section{Minimization}

It was not serious.

It was just a small problem.

What I did wasn't that big a deal.

My aggression was really small.

I don't have a problem with being aggressive.

I really didn't do anything.

There was nothing wrong about what I did.

Violence recognition

What I did was aggressive to my partner.

I was aggressive during the event. 
I regret being aggressive to my partner.

What I did was harmful to my partner.

I hurt my partner during the event.

Victim blaming

It was really my partner's fault.

My partner caused me to act that way.

If my partner listened to me, it wouldn't happen.

It happened because my partner pushed my buttons.

\section{Motivating Factor for Behavior Change Scale (Schmidt et al., 2007)}

Participants are instructed that listed are motivations that they may experience and to indicate the order of how important each factor is in motivating them to change their abusive behavior from MOST (1) to LEAST (9) important.

Don't want to feel bad about myself

Don't want to lose my job

Financial impact is too great

Not getting arrested

Don't want to look bad to others

Effects of abuse on my partner

Effect of abuse on my children

Improve the quality of relationship with my partner

Don't think it is right to be abusive

\section{Demographic Items (Mills et al., 2013; Sackett, 2017)}

Age

Gender

Gender identity

Sexuality

Race

Current marital status

Length of time in current relationship (if applicable)

Number of children (if applicable)

Highest level of education completed

Currently employed

Current yearly income

Number of prior arrests

Number of prior arrests related to domestic violence

Age at time of arrest that led to batterer intervention program enrollment

Enrollment status in a batterer intervention program

Name of batterer intervention program enrolled in (current/past)

Length of time in a batterer intervention program group

Reason for enrolling in a batterer intervention program 
"IT PUTS A FACE TO ALL THE KNOWLEDGE"

\section{Appendix D: Panel Observational Codebook}

\begin{tabular}{|c|c|c|}
\hline Code & Code Definition & Example(s) \\
\hline $\mathbf{P S} \rightarrow \mathbf{J}$ & Positive support for JIIs & $\begin{array}{l}\text { Approval of them as a person } \\
\text { Respect for them } \\
\text { Relates to them }\end{array}$ \\
\hline $\mathbf{N S} \rightarrow \mathbf{J}$ & Negative support for JIIs & $\begin{array}{l}\text { Harassing or shouting at them } \\
\text { Disapproval of them as a person } \\
\text { Stigmatizing shaming toward them } \\
\text { Stigmatizing names and labels used (e.g.,"junkie") }\end{array}$ \\
\hline $\mathbf{S S}+$ & $\begin{array}{l}\text { Sharing story in a non- } \\
\text { threatening/positive way }\end{array}$ & $\begin{array}{l}\text { Speaking matter-of-factly } \\
\text { Not blaming audience members } \\
\text { Disapproval of their actions expressed but not of them }\end{array}$ \\
\hline SS - & $\begin{array}{l}\text { Sharing story in a } \\
\text { threatening/negative way }\end{array}$ & $\begin{array}{l}\text { Moral lecturing at them } \\
\text { Disappointment in offenders themselves }\end{array}$ \\
\hline SV & Speaker shows vulnerability & Speaker displays emotion \\
\hline
\end{tabular}

\section{JII Actions}

\begin{tabular}{|l|l|l|}
\hline \multicolumn{1}{|c|}{ Code } & \multicolumn{1}{|c|}{ Code Definition } & \multicolumn{1}{|c|}{ Example(s) } \\
\hline PS $\rightarrow \mathbf{S}$ & Positive support for speakers & $\begin{array}{l}\text { Respect for them } \\
\text { Refer to them by name } \\
\text { Admiration for them } \\
\text { Acknowledgment of them }\end{array}$ \\
\hline NS $\rightarrow \mathbf{S}$ & Negative support for speakers & $\begin{array}{l}\text { Yells or shouts } \\
\text { Asks victim-blaming question } \\
\text { Questions speaker/s account of events }\end{array}$ \\
\hline JE + & JII positive engagement & $\begin{array}{l}\text { Holds eye contact with speaker/s } \\
\text { Emotional engagement such as crying, anger, laughing, } \\
\text { smiling in panel } \\
\text { Cognitive engagement such as realizing they have } \\
\text { something in common with speaker/s }\end{array}$ \\
\hline JE - & JII negative engagement & $\begin{array}{l}\text { Defiance or resistance expressed } \\
\text { Yells or shouts } \\
\text { Speech is affected by irregularities/incoherence } \\
\text { Appears sullen, uninterested, or unresponsive }\end{array}$ \\
\hline JA + & JII negative accountability & $\begin{array}{l}\text { Acknowledges that they have done wrong } \\
\text { Remorse for their actions } \\
\text { Responsibility for their actions } \\
\text { Offers apology }\end{array}$ \\
\hline $\begin{array}{l}\text { Indicates they hold others responsible for their own actions } \\
\text { laims their actions were accidental or unintentional }\end{array}$ \\
\hline
\end{tabular}


JII Actions (cont.)

\begin{tabular}{|l|l|l|}
\hline \multicolumn{1}{|c|}{ Code } & \multicolumn{1}{|c|}{ Code Definition } & \multicolumn{1}{c|}{ Example(s) } \\
\hline JIC & JII shares internal conflict & $\begin{array}{l}\text { Feelings of shame or guilt } \\
\text { Displays severity toward themselves }\end{array}$ \\
\hline JU & JII appears uncomfortable & $\begin{array}{l}\text { Expresses discomfort such as being restless, anxious, } \\
\text { fidgety } \\
\text { Engages in hiding and concealing behavior such as } \\
\text { lowering head, hand covering parts of face, averting gaze } \\
\text { Retreats from or avoids the attention of others }\end{array}$ \\
\hline
\end{tabular}

Speaker-JII Exchange

\begin{tabular}{|l|l|l|}
\hline \multicolumn{1}{|c|}{ Code } & \multicolumn{1}{|c|}{ Code Definition } & \multicolumn{1}{c|}{ Example(s) } \\
\hline SJE + & Positive speaker-JII exchange & $\begin{array}{l}\text { Participants demonstrate conversational turn-taking } \\
\text { Physical contact such as a handshake between JII/s and } \\
\text { speaker/s } \\
\text { JII/s and speaker/s interact informally with each other }\end{array}$ \\
\hline SJE - & Negative speaker-JII exchange & $\begin{array}{l}\text { Speaker interrupts an JII } \\
\text { Speaker interrupts another speaker } \\
\text { JII interrupts a speaker } \\
\text { JII interrupts another JII }\end{array}$ \\
\hline SJA/S & Speaker-JII attunement/syncing & $\begin{array}{l}\text { JII/s share symbolic gestures with speaker/s such as } \\
\text { mirroring behavior } \\
\text { Clear emotional "turning point" observed across } \\
\text { participants }\end{array}$ \\
\hline
\end{tabular}




\section{Appendix E: Additional Results}

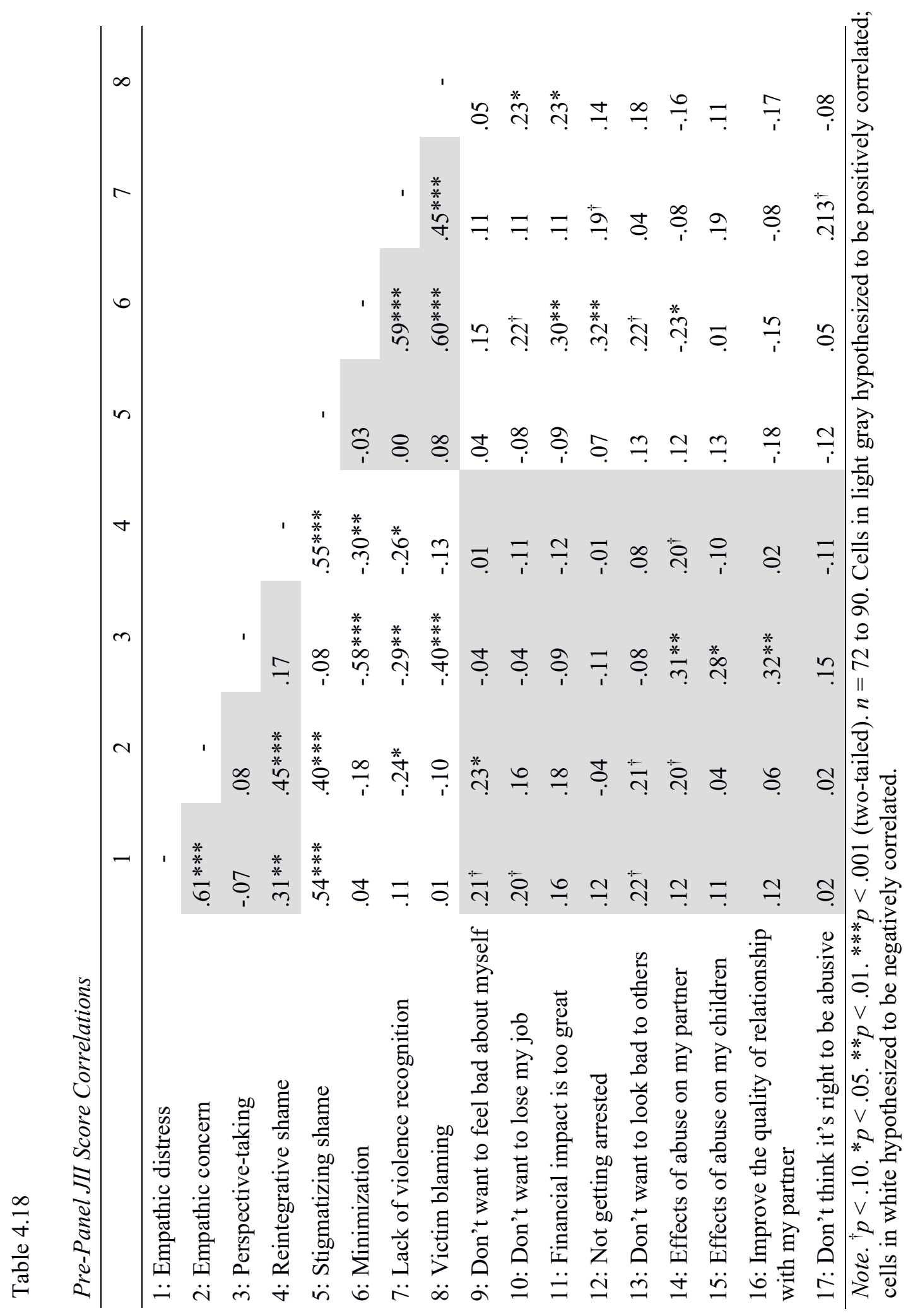




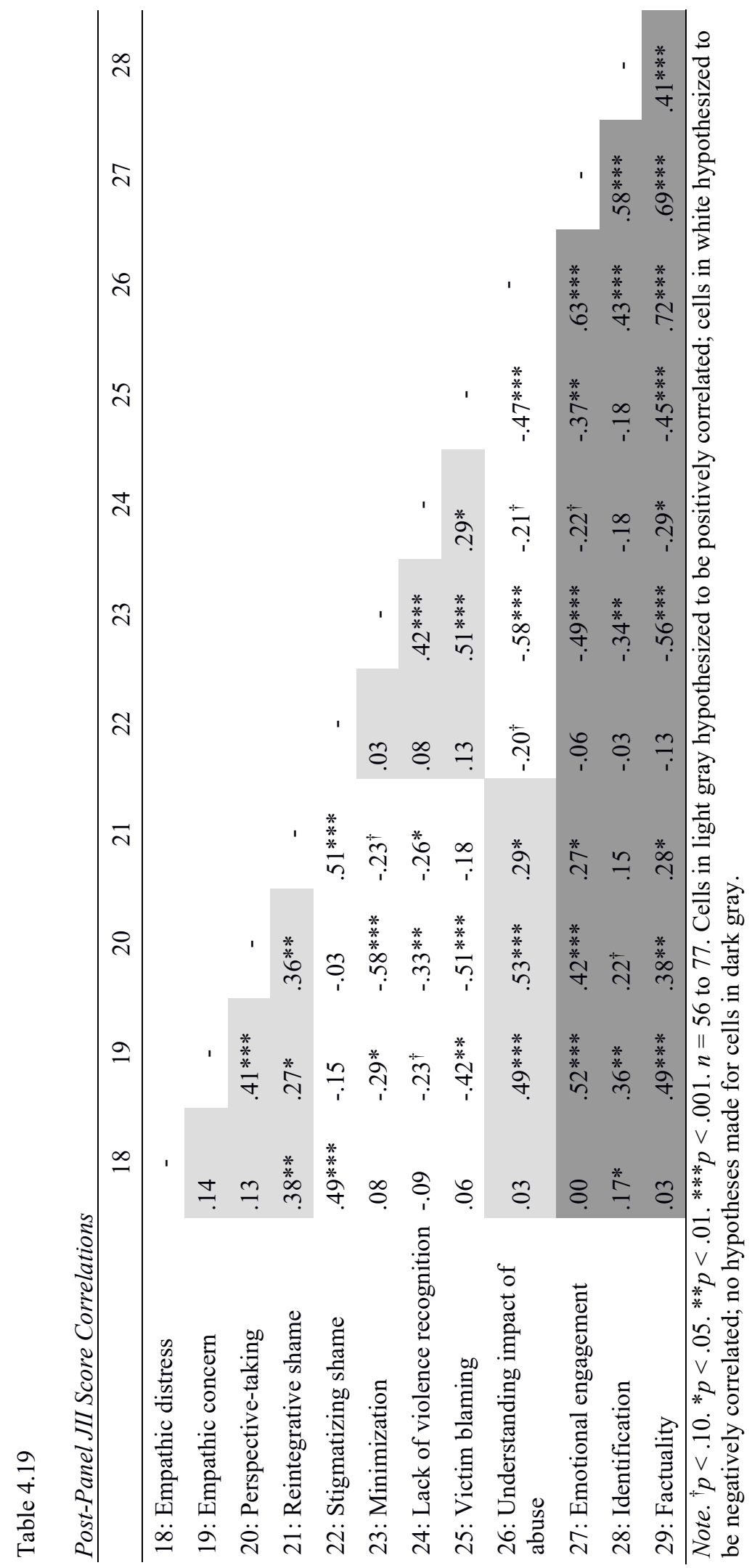




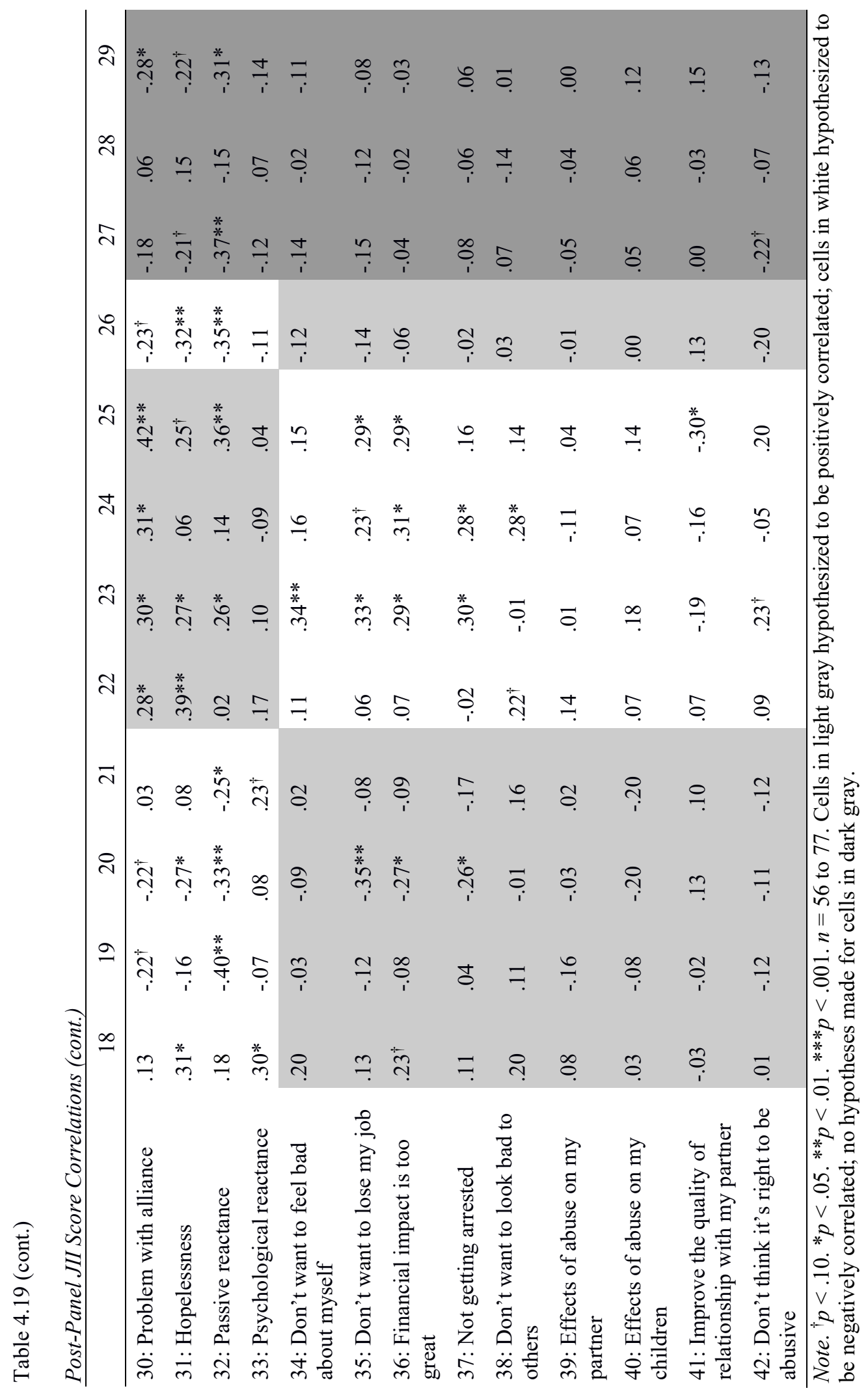




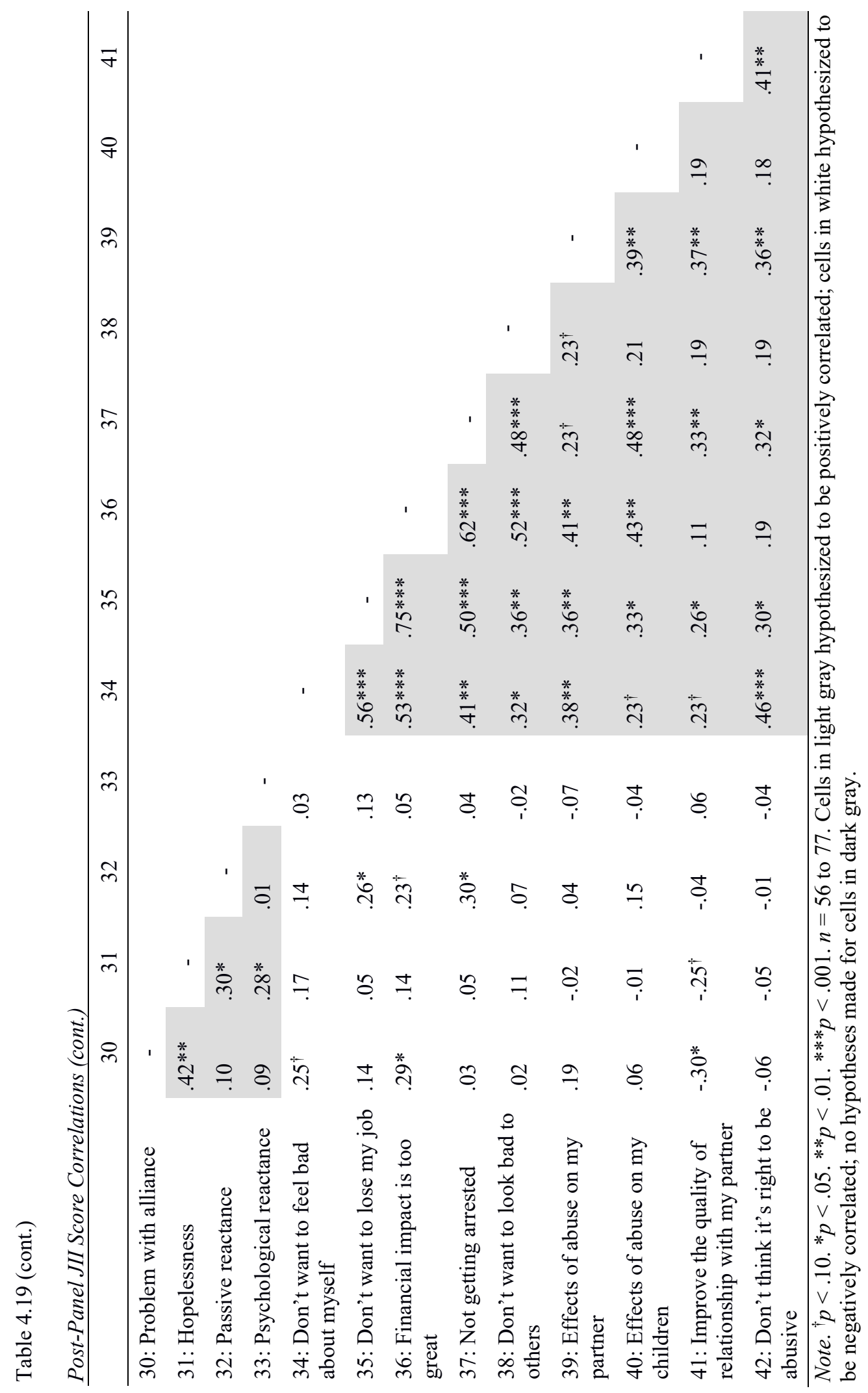




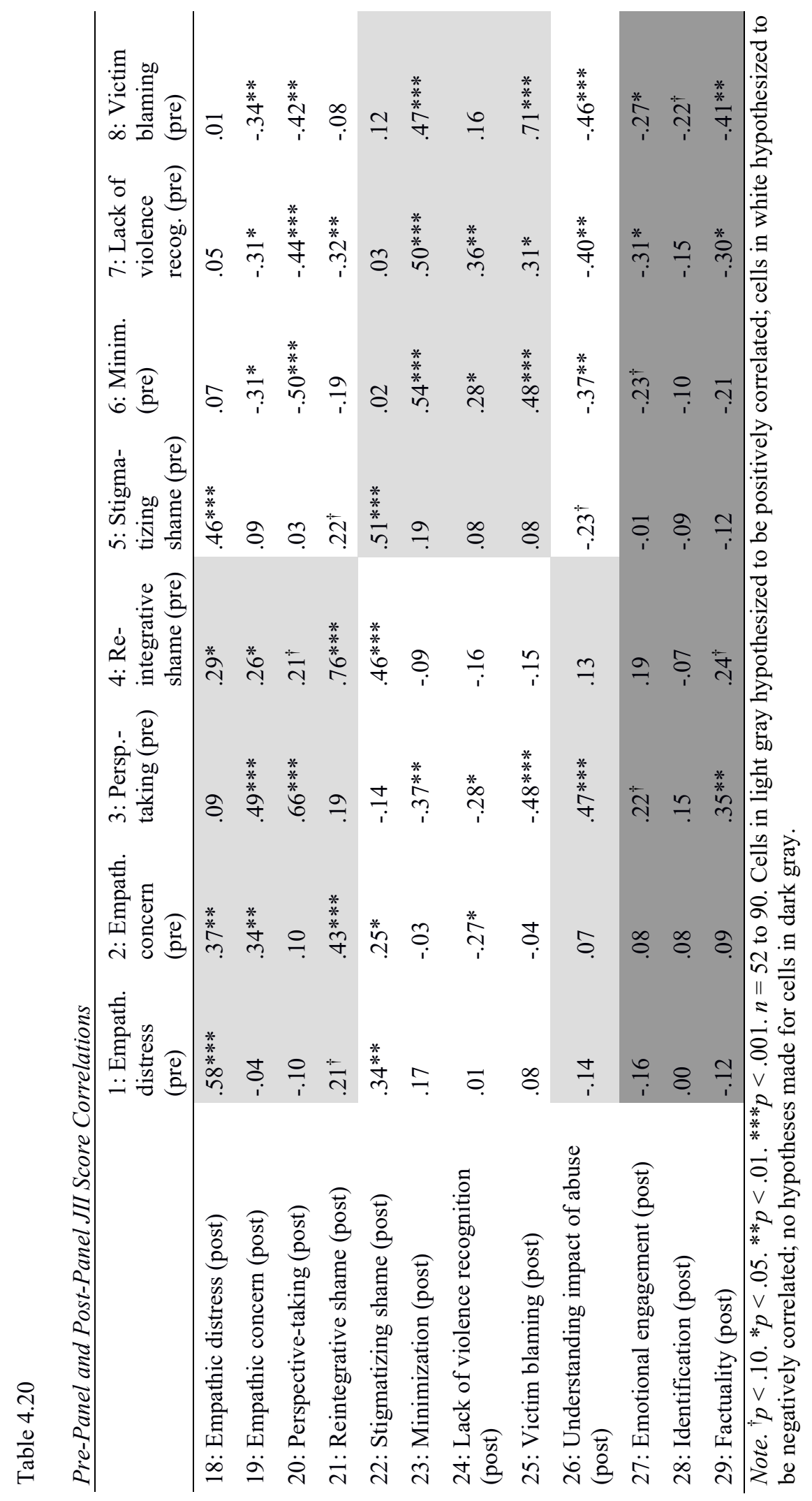




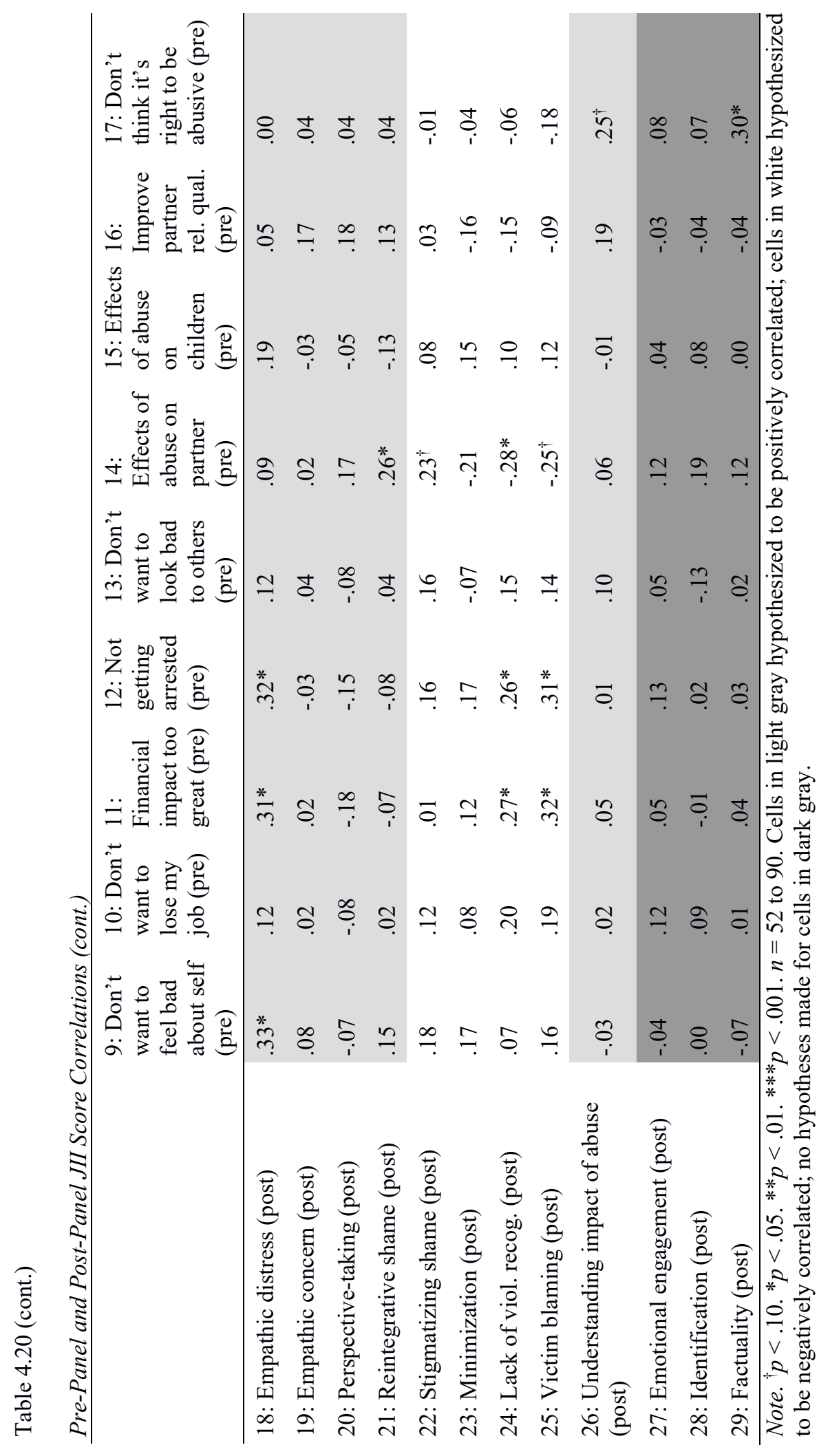




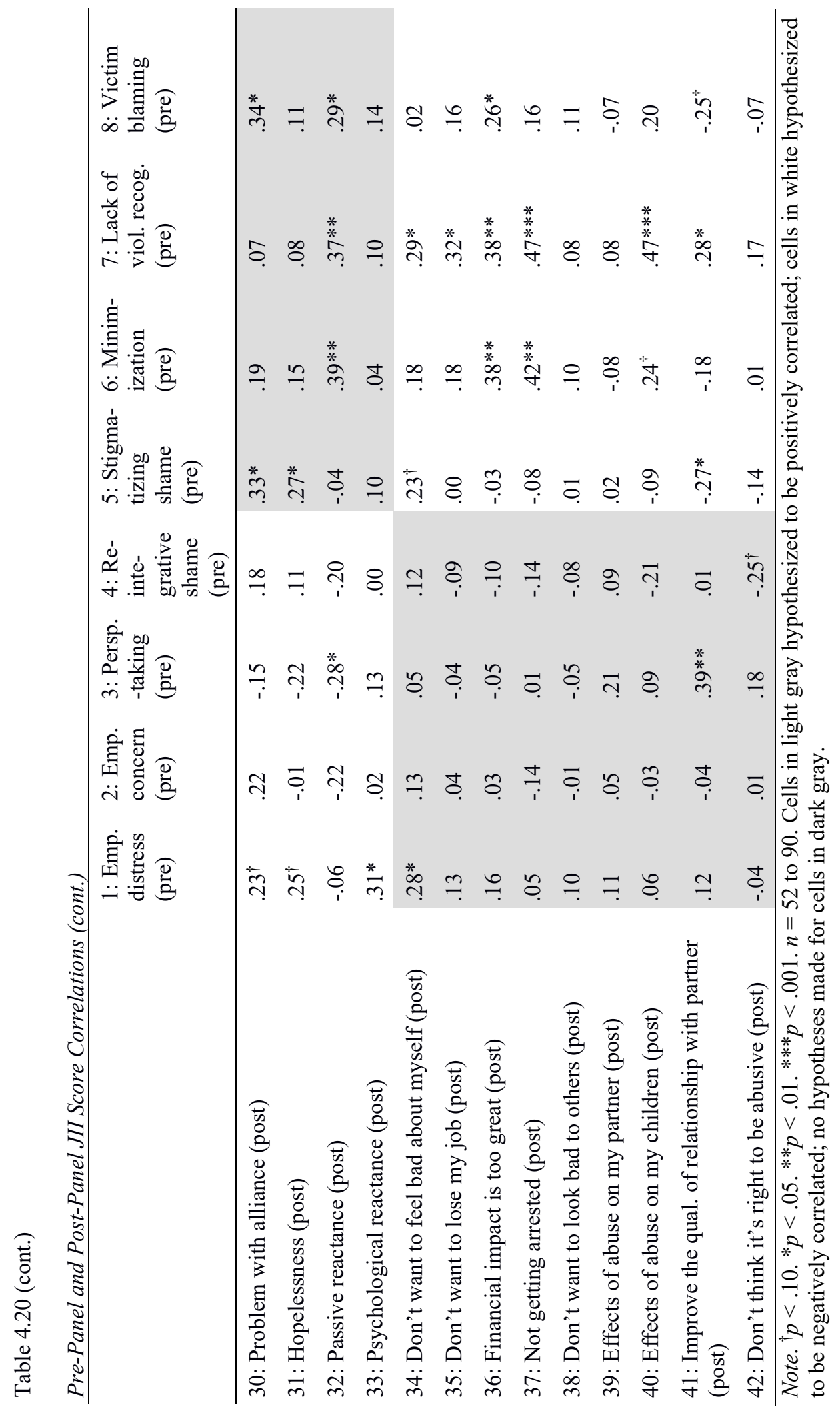




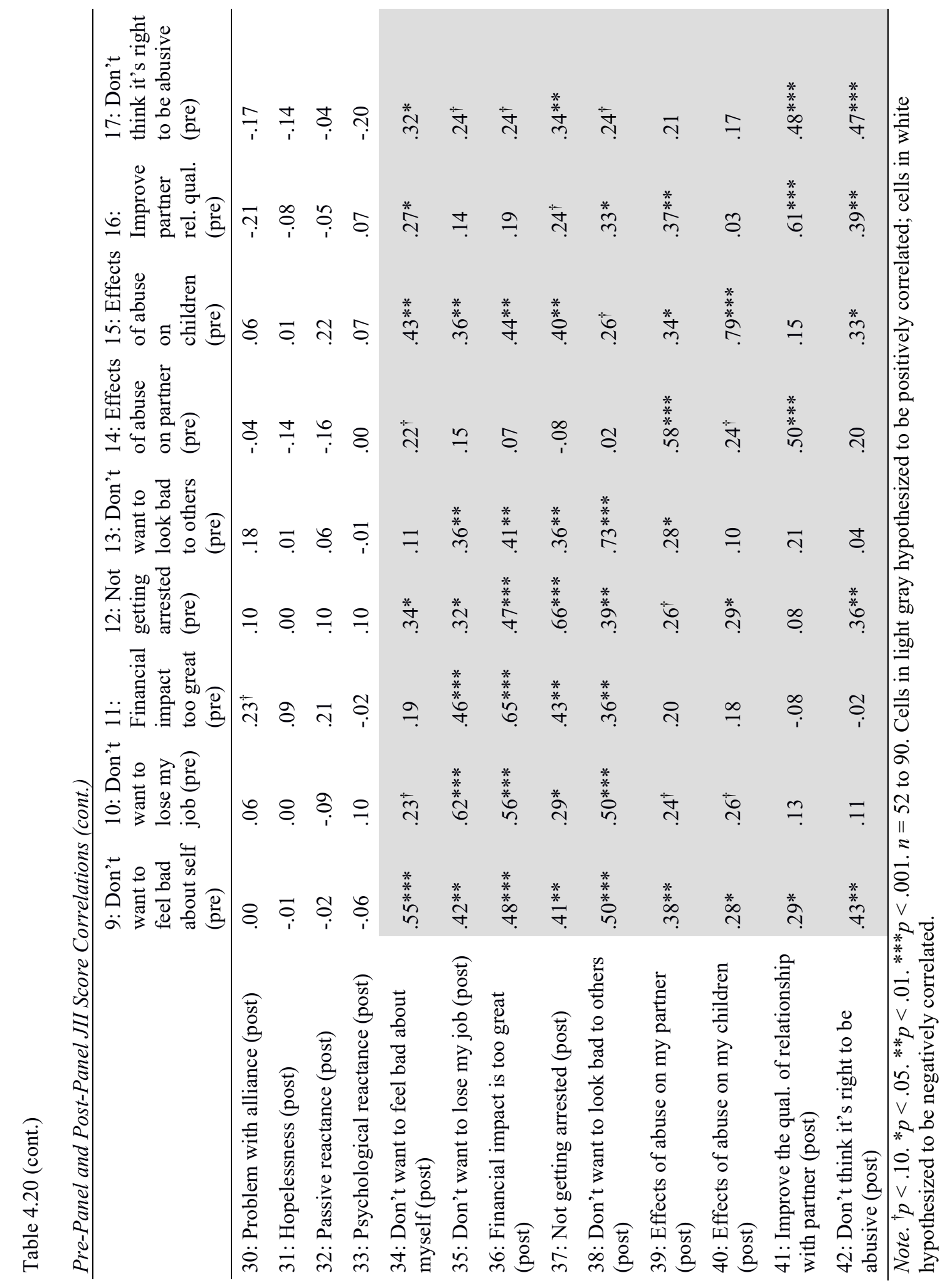


Table 4.21

Multiple Linear Regression of Control Variables on Post-Panel JII Empathic Concern

\begin{tabular}{|c|c|c|c|c|}
\hline Variable & $B$ & $\mathrm{SE}$ & $\beta$ & $t$ \\
\hline Constant & -.07 & .10 & & -.68 \\
\hline Empathic concern (pre) & .40 & .13 & .41 & $3.12 * *$ \\
\hline Emotional engagement (post) & .14 & .11 & .26 & 1.32 \\
\hline Identification (post) & .12 & .08 & .22 & 1.62 \\
\hline Factuality (post) & .12 & .12 & .18 & 1.02 \\
\hline Problem with alliance (post) & -.13 & .16 & -.11 & -.78 \\
\hline Hopelessness (post) & -.11 & .17 & -.10 & -.66 \\
\hline Passive reactance (post) & -.05 & .16 & -.04 & -.31 \\
\hline Psychological reactance (post) & -.09 & .08 & -.13 & -.11 \\
\hline Age & .00 & .01 & -.05 & -.46 \\
\hline Weeks in BIP & .00 & .00 & -.02 & -.18 \\
\hline
\end{tabular}

Note. ${ }^{\dagger} p<.10 .{ }^{*} p<.05 .{ }^{* *} p<.01 .{ }^{* * *} p<.001 . R^{2}=.68$. 
Table 4.22

Multiple Linear Regression of Control Variables on Post-Panel JII Reintegrative Shame

\begin{tabular}{|c|c|c|c|c|}
\hline Variable & b & $\mathrm{SE}$ & $\beta$ & $t$ \\
\hline Constant & .17 & .13 & & 1.31 \\
\hline Reintegrative shame (pre) & .93 & .19 & .70 & $4.88 * * *$ \\
\hline Emotional engagement (post) & .21 & .15 & .31 & 1.44 \\
\hline Identification (post) & .12 & .10 & .17 & 1.23 \\
\hline Factuality (post) & -.10 & .15 & -.13 & -.70 \\
\hline Problem with alliance (post) & -.05 & .22 & -.03 & -.24 \\
\hline Hopelessness (post) & .07 & .20 & .04 & .32 \\
\hline Passive reactance (post) & .05 & .20 & .03 & .26 \\
\hline Psychological reactance (post) & .08 & .12 & .08 & .68 \\
\hline Age & .00 & .01 & .03 & .26 \\
\hline Weeks in BIP & .00 & .01 & .04 & .33 \\
\hline
\end{tabular}

Note. ${ }^{\dagger} p<.10 .{ }^{*} p<.05 .{ }^{* *} p<.01 .{ }^{* * *} p<.001 . R^{2}=.71$. 
Table 4.23

Multiple Linear Regression of Control Variables on Post-Panel JII Motivation of Not Getting Arrested

\begin{tabular}{lcccc}
\hline Variable & \multicolumn{2}{c}{ SE } & & $\beta$ \\
\hline Constant & -.49 & .37 & & -1.32 \\
Not getting arrested (pre) & .52 & .17 & .52 & $3.06^{* *}$ \\
Emotional engagement (post) & .57 & .40 & .34 & 1.43 \\
Identification (post) & -.20 & .27 & -.12 & -.74 \\
Factuality (post) & -.35 & .42 & -.18 & -.83 \\
Problem with alliance (post) & .70 & .56 & .19 & 1.24 \\
Hopelessness (post) & -.29 & .58 & -.08 & -.50 \\
Passive reactance (post) & .50 & .62 & .14 & .81 \\
Psychological reactance (post) & .23 & .32 & .10 & .72 \\
Age & .04 & .04 & .14 & 1.03 \\
Weeks in BIP & -.02 & .02 & -.12 & -.89 \\
\hline
\end{tabular}

Note. ${ }^{\dagger} p<.10 .{ }^{*} p<.05 .{ }^{* *} p<.01 .{ }^{* * *} p<.001 . R^{2}=.52$. 
Table 4.24

Multiple Linear Regression of Control Variables on Post-Panel Motivation of Thinking it is Not Right to Be Abusive

\begin{tabular}{|c|c|c|c|c|}
\hline Variable & $B$ & SE & $\beta$ & $t$ \\
\hline Constant & -.06 & .37 & & -.15 \\
\hline $\begin{array}{l}\text { Don't think it's right to be } \\
\text { abusive (pre) }\end{array}$ & .79 & .24 & .54 & $3.33 * *$ \\
\hline Emotional engagement (post) & -.14 & .42 & -.09 & -.34 \\
\hline Identification (post) & .34 & .28 & .22 & 1.22 \\
\hline Factuality (post) & .56 & .45 & .30 & 1.24 \\
\hline Problem with alliance (post) & .13 & .57 & .04 & .23 \\
\hline Hopelessness (post) & -.16 & .61 & -.05 & -.27 \\
\hline Passive reactance (post) & .68 & .61 & .18 & 1.11 \\
\hline Psychological reactance (post) & -.32 & .32 & -.15 & -1.00 \\
\hline Age & -.05 & .04 & -.22 & -1.34 \\
\hline Weeks in BIP & -.01 & .02 & -.07 & -.47 \\
\hline
\end{tabular}




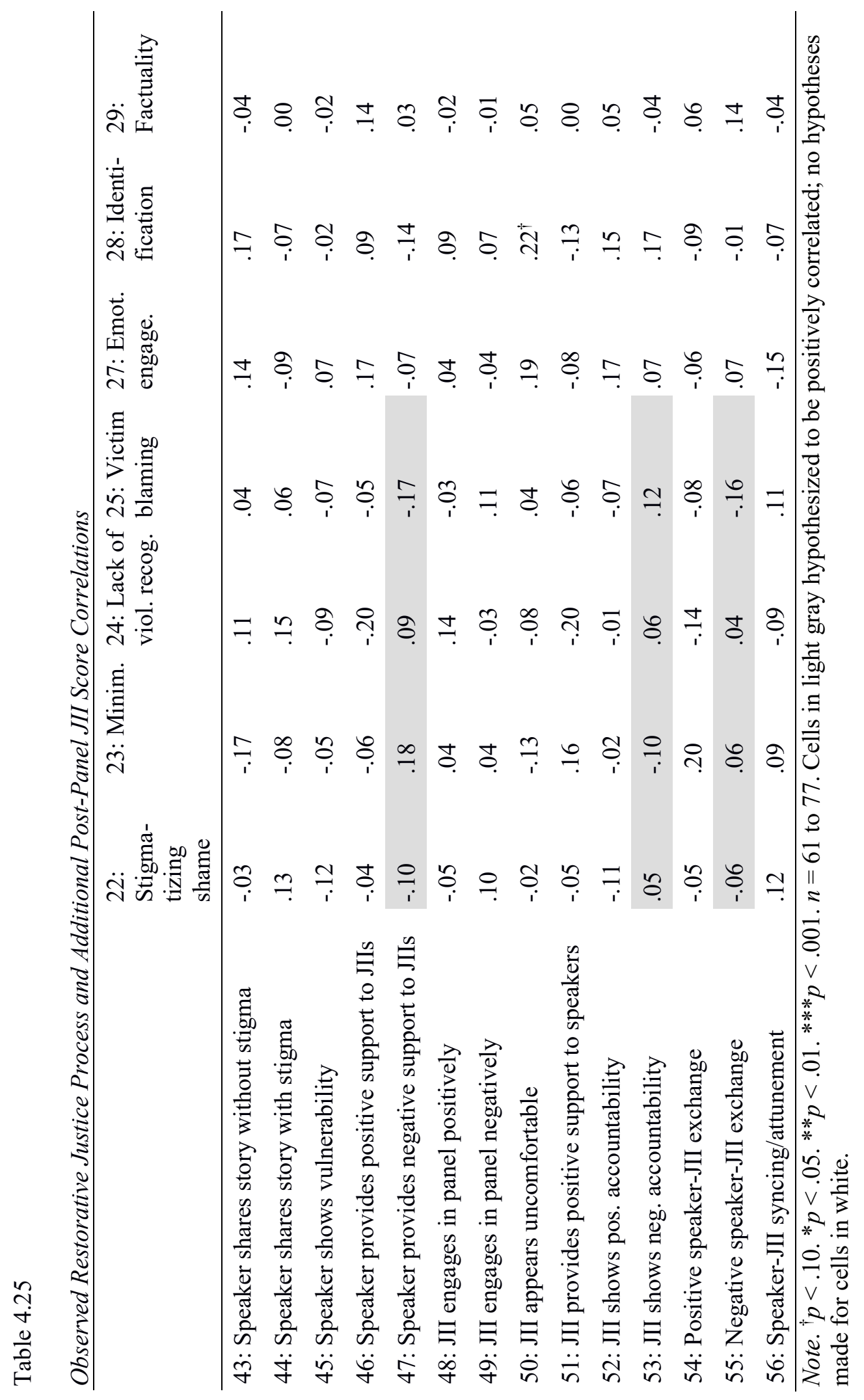

